\title{
Preliminary investigation of energy dissipation at culvert outlets using a riprap step
}

\author{
Belinda M. Weikle \\ West Virginia University
}

Follow this and additional works at: https://researchrepository.wvu.edu/etd

\section{Recommended Citation}

Weikle, Belinda M., "Preliminary investigation of energy dissipation at culvert outlets using a riprap step" (2000). Graduate Theses, Dissertations, and Problem Reports. 1036.

https://researchrepository.wvu.edu/etd/1036

This Thesis is protected by copyright and/or related rights. It has been brought to you by the The Research Repository @ WVU with permission from the rights-holder(s). You are free to use this Thesis in any way that is permitted by the copyright and related rights legislation that applies to your use. For other uses you must obtain permission from the rights-holder(s) directly, unless additional rights are indicated by a Creative Commons license in the record and/ or on the work itself. This Thesis has been accepted for inclusion in WVU Graduate Theses, Dissertations, and Problem Reports collection by an authorized administrator of The Research Repository @ WVU. For more information, please contact researchrepository@mail.wvu.edu. 


\title{
Preliminary Investigation Of Energy Dissipation At Culvert Outlets Using A Riprap Step
}

\author{
Belinda M. Weikle
}

\author{
Thesis submitted to the \\ College of Engineering and Mineral Resources \\ at West Virginia University \\ in partial fulfillment of the requirements \\ for the degree of \\ Masters of Science \\ in \\ Civil Engineering
}

\author{
Robert Eli, Ph.D., Chair \\ Donald Gray, Ph.D \\ Barry Dickson
}

Department of Civil and Environmental Engineering

\author{
Morgantown, West Virginia \\ 2000
}

Keywords: Riprap Step, Energy Dissipation, Hydraulic Jump

Copyright 2000 Belinda M. Weikle 


\section{ABSTRACT \\ Preliminary Investigation Of \\ Energy Dissipation At Culvert Outlets \\ Using A Riprap Step}

\section{Belinda M. Weikle}

One method used to attenuate high-energy flow at culvert outlets is the construction of a riprap energy dissipator. The current riprap design used by the WVDOH experiences problems with excessive sedimentation and is only applicable at culvert outlets where the flow velocity is low. The purpose of this investigation was to construct a testing device to allow for the testing of physical models and produce a preliminary riprap step design that would perform more effectively than the current design. The new design proposed meets the following criteria. It is:

- Easily constructed on site using available materials

- Economically efficient

- Applicable to various culvert sizes and flowrates

- Self cleaning and requires low maintenance

- Able to re-establish natural flow conditions downstream of the outlet

Several model steps were constructed and tested. This thesis reviews the construction of all experimental equipment and the development of a preliminary design. 


\section{ACKNOWLEDGEMENTS}

The author would like to thank Dr. Robert Eli for serving as the Chairman for her graduate committee and Dr. Donald Gray and Mr. Barry Dickson for serving as committee members.

The author would also like to thank her parents, Stephen E. and Sylvia M. Sheppard, and her husband, Samuel R. Weikle, for their emotional support of the author during the months the research for this thesis was conducted.

The West Virginia Department of Highways funded the research and material necessary for the completion of this project. 
TABLE OF CONTENTS

ACKNOWLEDGEMENTS

TABLE OF CONTENTS

LIST OF TABLES

LIST OF FIGURES

Introduction

Problem Statement

Setting

Current Design

Field Experiences With the Current Riprap Energy Dissipator

Background and Literature Review

Riprap

Hydraulic Jump

Hydraulic Jump Forms

Governing Equations

Specific Head and Energy Loss

Jump Length

Shortcomings of the Hydraulic Jump

Initial Investigations

Drainage Pipe

Rock Gradations for West Virginia Quarries

Procedure

Development of Experimental Equipment $\quad 25$

Pump Selection

Tank Selection

Frame Development

Inlet and Outlet Boxes

Piping Assembly

Measuring Devices

Flowmeter

Piezometer Board

31

Three-Point Depth Gage

32

Pitot Tube Device

Slope Adjustment Devices

Model Construction

Cast Acrylic Pallets

Rock Pallets

Analysis

Data Collection

Equivalent or 'Melted' Riprap Step Height

Water Surface Elevation Data Influences

Reverse Flow

Not Fully Expanded Jet

Spurting Flow 


\section{TABLE OF CONTENTS, continued}

Splashing Flow $\quad \frac{\text { PAGE }}{54}$

Hydraulic Jump $\quad 55$

Pooling $\quad 55$

$\begin{array}{ll}\text { Velocity Profile Investigation } & 56\end{array}$

$\begin{array}{lr}\text { Test Culvert Analysis } & 58\end{array}$

Equivalent Rectangular Froude Number $\quad 60$

$\begin{array}{lr}\text { Energy Calculations } & 60\end{array}$

0.5-inch Cast Acrylic Step $\quad 65$

1.0-inch Cast Acrylic Step $\quad 69$

$\begin{array}{ll}\text { 1.5-inch Cast Acrylic Step } & 73\end{array}$

2.0-inch Cast Acrylic Step $\quad 77$

2.5-inch Cast Acrylic Step $r$

0.0-inch Equivalent Riprap Step $\quad 85$

0.5-inch Equivalent Riprap Step $\quad 89$

1.0-inch Equivalent Riprap Step $\quad 93$

1.5-inch Equivalent Riprap Step 97

2.0-inch Equivalent Riprap Step $\quad 101$

2.5-inch Equivalent Riprap Step 105

Comparison to "Natural” Energy Grade Line $\quad 109$

Flow Characteristics $r 112$

Error Analysis $\quad 114$

$\begin{array}{ll}\text { Results } & 116\end{array}$

Non-Dimensional Comparison of Cast Acrylic and Riprap Step 116

Froude Number and Non-Dimensional Energy Difference $\quad 123$

$\begin{array}{lr}\text { Energy Dissipation Performance Parameter } & 130\end{array}$

Cast Acrylic and Riprap Step Comparison - EDPP 139

Conclusions and Recommendations $\quad 146$

$\begin{array}{lr}\text { References } & 148\end{array}$

$\begin{array}{ll}\text { VITA } & 168\end{array}$ 


\section{LIST OF TABLES}

1.1 Design Dimensions as Multiple of Culvert Diameter

3.1 Average Yearly Circular Pipe Diameter Quantities for 1992-1997

3.2 Rock Gradations for Greer Quarry at Morgantown, WV

3.3 Rock Gradations for Cave-In-Rock Quarry at Cave-In-Rock, IL

3.4 Rock Gradations for Three-Rivers Quarry at Smithland, KY

3.5 Rock Gradations for Manheim Mine at Rowlesburg, WV

3.6 Rock Gradations for Snowflake Quarry at Fort Springs, WV

3.7 Averaged Rock Gradations for Martin Marietta Quarries

4.1 Water Surface Elevation Readings

4.2 Zone 2 Pallets Nominal Step Heights

4.3 Stone Sample Characteristics and Dimensions (Greer Quarry) 41

4.4 Rock Step Equivalent, Pallet Number \& Rock Type 42

5.1 Effective Rock Height Affecting Zone 2 Flow in Test Channel 50

5.2 Calculations for Velocity Profile Correction Factor 56

5.3 Alpha Values Obtained by Methods 1 and 2 (50 gpm at 8\% Slope) 57

5.4 Alpha Values Obtained by Methods 1 and 2 (100 gpm at 8\% Slope) 58

$\begin{array}{lll}5.5 & \text { Test Culvert Analysis } & 59\end{array}$

$\begin{array}{lll}5.6 & \text { Test Culvert Data } & 62\end{array}$

5.7 Example of Energy Calculations Performed 63

5.8 Energy Calculations for 0.5-inch Cast Acrylic Step @ 2\% Slope 67

5.9 Energy Calculations for 0.5-inch Cast Acrylic Step @ 4\% Slope 68

5.10 Energy Calculations for 0.5-inch Cast Acrylic Step @ 6\% Slope 68

5.11 Energy Calculations for 0.5-inch Cast Acrylic Step @ 8\% Slope 68

5.12 Energy Calculations for 1.0-inch Cast Acrylic Step @ 2\% Slope 71

5.13 Energy Calculations for 1.0-inch Cast Acrylic Step @ 4\% Slope 72

5.14 Energy Calculations for 1.0-inch Cast Acrylic Step @ 6\% Slope 72 


\section{LIST OF TABLES, continued}

5.15 Energy Calculations for 1.0-inch Cast Acrylic Step @ 8\% Slope

5.16 Energy Calculations for 1.5-inch Cast Acrylic Step @ 2\% Slope

5.16 Energy Calculations for 1.5-inch Cast Acrylic Step @ 2\% Slope

5.17 Energy Calculations for 1.5-inch Cast Acrylic Step @ 4\% Slope 76

5.18 Energy Calculations for 1.5-inch Cast Acrylic Step @ 6\% Slope 76

5.19 Energy Calculations for 1.5-inch Cast Acrylic Step @ 8\% Slope 76

5.20 Energy Calculations for 2.0-inch Cast Acrylic Step @ 2\% Slope 79

5.21 Energy Calculations for 2.0-inch Cast Acrylic Step @ 4\% Slope 80

5.22 Energy Calculations for 2.0-inch Cast Acrylic Step @ 6\% Slope 80

5.23 Energy Calculations for 2.0-inch Cast Acrylic Step @ 8\% Slope 80

5.24 Energy Calculations for 2.5-inch Cast Acrylic Step @ 2\% Slope 83

5.25 Energy Calculations for 2.5-inch Cast Acrylic Step @ 4\% Slope 84

5.26 Energy Calculations for 2.5-inch Cast Acrylic Step @ 6\% Slope 84

5.27 Energy Calculations for 2.5-inch Cast Acrylic Step @ 8\% Slope 84

5.28 Energy Calculations for 0.0-inch Equivalent Riprap Step @ 2\% Slope 87

5.29 Energy Calculations for 0.0-inch Equivalent Riprap Step @ 4\% Slope 88

5.30 Energy Calculations for 0.0-inch Equivalent Riprap Step @ 6\% Slope 88

5.31 Energy Calculations for 0.0-inch Equivalent Riprap Step @ 8\% Slope 88

5.32 Energy Calculations for 0.5-inch Equivalent Riprap Step @ 2\% Slope 91

5.33 Energy Calculations for 0.5-inch Equivalent Riprap Step @ 4\% Slope 92

5.34 Energy Calculations for 0.5-inch Equivalent Riprap Step @ 6\% Slope 92

5.35 Energy Calculations for 0.5-inch Equivalent Riprap Step @ 8\% Slope 92

5.36 Energy Calculations for 1.0-inch Equivalent Riprap Step @ 2\% Slope 95

5.37 Energy Calculations for 1.0-inch Equivalent Riprap Step @ 4\% Slope 96

5.38 Energy Calculations for 1.0-inch Equivalent Riprap Step @ 6\% Slope 96

5.39 Energy Calculations for 1.0-inch Equivalent Riprap Step @ 8\% Slope 96 


\section{LIST OF TABLES, continued}

5.40 Energy Calculations for 1.5-inch Equivalent Riprap Step @ 2\% Slope

5.41 Energy Calculations for 1.5-inch Equivalent Riprap Step @ 4\% Slope 100

5.42 Energy Calculations for 1.5-inch Equivalent Riprap Step @ 6\% Slope 100

5.43 Energy Calculations for 1.5-inch Equivalent Riprap Step @ 8\% Slope 100

5.44 Energy Calculations for 2.0-inch Equivalent Riprap Step @ 2\% Slope 103

5.45 Energy Calculations for 2.0-inch Equivalent Riprap Step @ 4\% Slope 104

5.46 Energy Calculations for 2.0-inch Equivalent Riprap Step @ 6\% Slope 104

5.47 Energy Calculations for 2.0-inch Equivalent Riprap Step @ 8\% Slope 104

5.48 Energy Calculations for 2.5-inch Equivalent Riprap Step @ 2\% Slope 107

5.49 Energy Calculations for 2.5-inch Equivalent Riprap Step @ 4\% Slope 108

5.50 Energy Calculations for 2.5-inch Equivalent Riprap Step @ 6\% Slope 108

5.51 Energy Calculations for 2.5-inch Equivalent Riprap Step @ 8\% Slope 108

5.52 Comparison Between "Natural” and Calculated Energy in Zone 2 for 'Smooth' Steps 110

5.53 Comparison Between “Natural” and Calculated Energy in Zone 2 for 'Rough' Steps 111

5.54 Flow Characteristics for Cast Acrylic Steps 112

5.55 Flow Characteristics for Riprap Steps 113

5.56 Expected Error For Various Calculated Values 115

$\begin{array}{lll}\text { 6.1 Comparison of Values for EDT for Cast Acrylic Steps } & 117\end{array}$

$\begin{array}{lll}\text { 6.2 Comparison of Values for EDT for Riprap Steps } & 118\end{array}$

6.3 Comparison of Values for EDV for Cast Acrylic Steps 119

$\begin{array}{ll}\text { 6.4 Comparison of Values for EDV for Riprap Steps } & 120\end{array}$

6.5 Flow Depth at Culvert Outlet and Testing Channel - Cast Acrylic Steps 121

6.6 Flow Depth at Culvert Outlet and Testing Channel - Riprap Steps 122

$\begin{array}{lll}6.7 & \text { Values for E3 at Given Culvert Slopes } & 130\end{array}$

6.8 Values for the Energy Dissipation Performance Parameter (EDPP) Cast Acrylic Steps 131 


\section{LIST OF TABLES, continued}

PAGE

6.9 Values for the Energy Dissipation Performance Parameter (EDPP) Equivalent Riprap Steps

132 


\section{Chapter 1}

\section{Introduction}

\subsection{Problem Statement}

Energy dissipation is a prime concern at culvert outlets. The methods of attenuating the energy depend on the flow parameters at the culvert outlet, such as velocity, etc. The West Virginia Division of Highways (WVDOH) uses several types of energy dissipators. Their methods of energy dissipation include various baffle block designs and riprap basin designs.

The baffle block designs are generally constructed at culvert outlets with high velocity flows. The baffle blocks consist of reinforced concrete and are expensive and difficult to build. Maintenance costs can be high due to debris and sedimentation occurring on the apron of the dissipator.

Riprap basins, whether grouted or not, are generally placed by the WVDOH at culvert outlets where there is low velocity flow, usually with Froude numbers less than 3 and/or flowrates less than 50 cfs. Riprap is very economical compared to the baffle block designs, but can only be effectively placed at culvert outlets with low velocity flows. It may also require frequent maintenance due to debris and sedimentation on the apron or on the riprap itself. There is a need for an alternative method of energy dissipation at culvert outlets that can withstand higher velocity flows than riprap, yet is more economical than the baffle block design.

The term "riprap", as used here, refers to rock riprap. In 1989, Hydraulic Engineering Circular 11 (HEC-11) defines riprap as a flexible channel or bank lining or facing consisting of a well graded mixture of rock, broken concrete, or other material, usually dumped or hand-placed, which provides protection from erosion. Dumped riprap is graded stone dumped on a prepared slope in such a manner that segregation will not take place. Hand-placed riprap is stone laid carefully by hand or by derrick following a definite pattern, with the voids between the larger stones filled with smaller stones and surface kept relatively even.

This Thesis will examine the effectiveness of the non-grouted rock riprap energy dissipator used by the WVDOH. The current riprap design problems will be investigated and possible solutions discussed. An alternative riprap step design with adequate energy dissipation, low maintenance and economical feasibility will be presented. 


\subsection{Setting}

West Virginia is a densely vegetated, mountainous state, having steep terrain that is drained by channels, streams, and rivers into the low-lying valleys. The natural drainage process involves the balancing of the physical and erosive properties of the drainage channel, stream, or river with the needed energy dissipation of the flow. Whenever a man-made structure is placed in a natural setting, this balance, or equilibrium, is disrupted due to changes in channel roughness, slope, rate of energy dissipation, cross-section and direction of flow. Measures must then be taken to re-establish the balance to avoid damage to the surrounding structures or the downstream channel. When the rate of energy dissipation is changed, whether it is increased or decreased, the degree of erosion and sedimentation also changes, affecting the channel equilibrium. Culvert placement usually decreases energy attenuation, and as a result erosion problems can occur.

The West Virginia Department of Highways (WVDOH) Drainage Manual (1984) specifies the design procedures for the construction of riprap energy dissipators for culvert outlets. Additional guidance for riprap energy dissipators may be found in the Federal Highway Administration (FHWA) HEC-14 (Hydraulic Design of Energy Dissipators for Culverts and Channels, 1983).

\subsection{Current Design}

As previously mentioned, schematics of the current riprap energy dissipator design may be obtained from the WVDOH Drainage Manual or HEC-14. The criteria for design directives of new energy dissipators must provide for sufficient energy dissipation, characterized by simplicity of design, effectiveness of energy dissipation and low construction cost.

The current WVDOH riprap flowchart, schematic, and construction details are shown in Figures 1.1, 1.2, and 1.3 . 


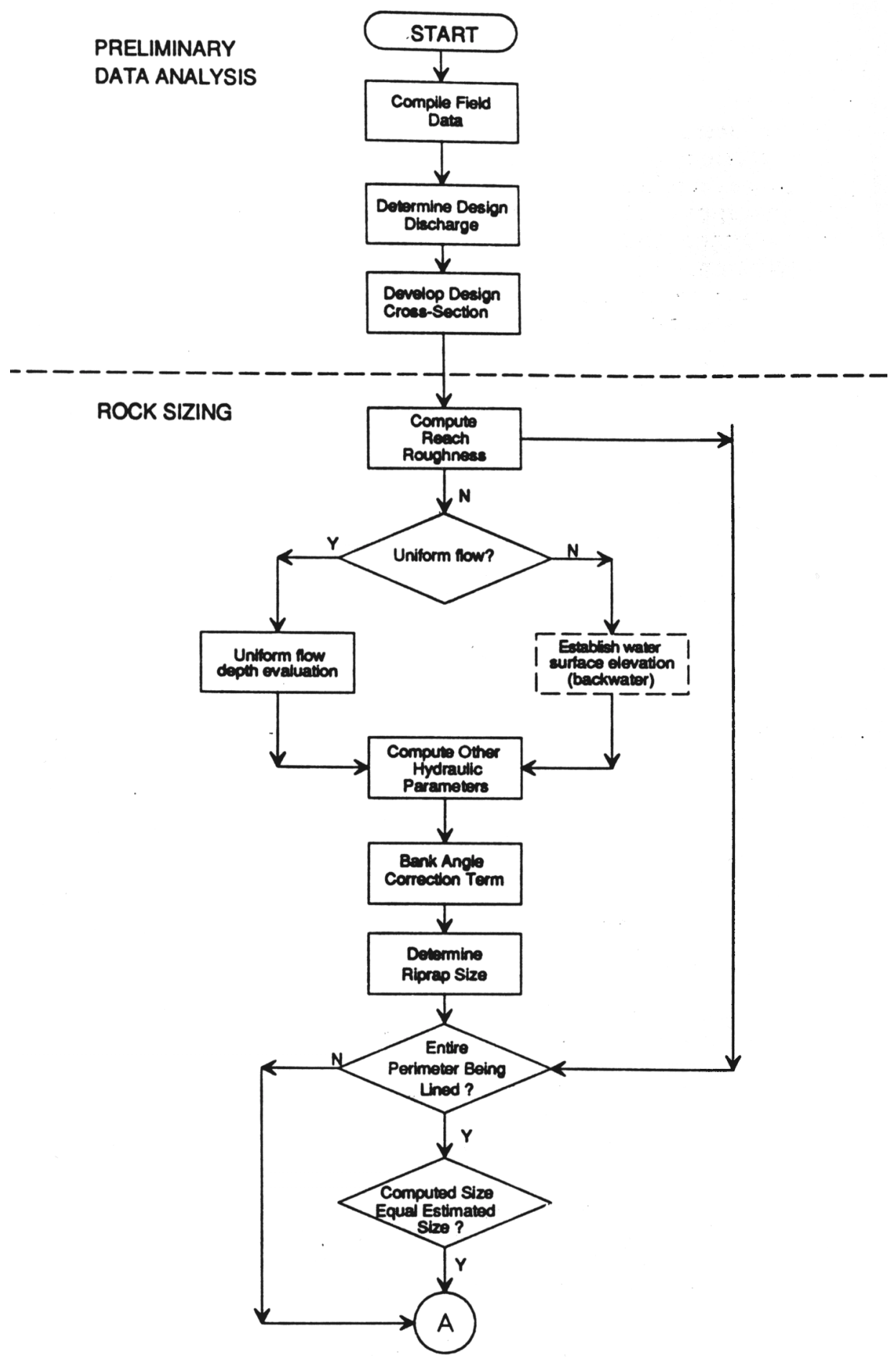

Figure 1.1 Riprap Design Procedure Flow Chart (HEC-11, 1989) 


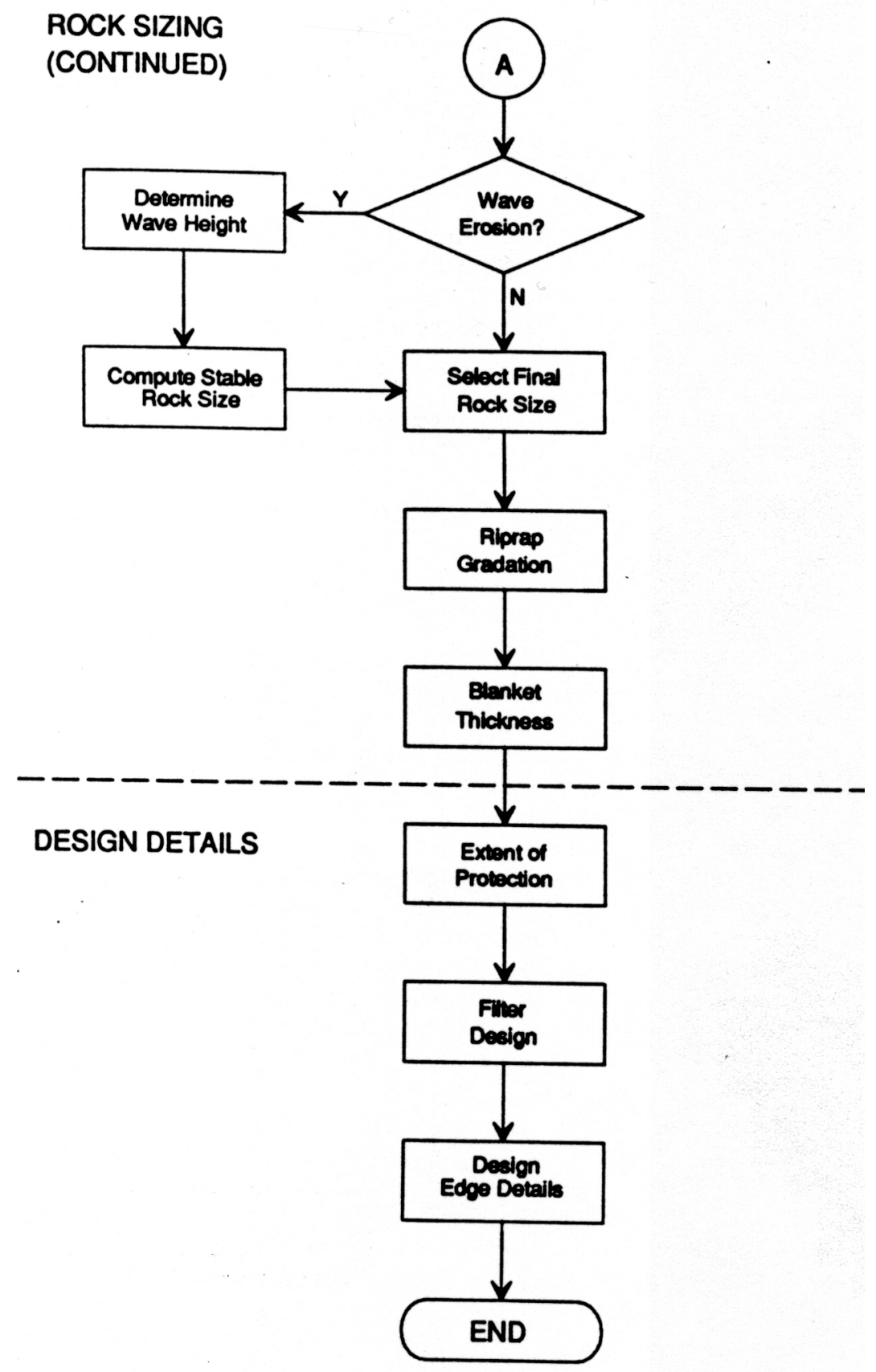

Figure 1.2 (Continued) Riprap Design Procedure Flow Chart (HEC-11, 1989) 
NOTE A - IF EXIT VELOCIY OF BASIN IS SPECIFIED, EXTEND BASIN AS REQUIRED TO OBTAIN IF SECTION AREA AT SEC. A-A) = SPECIFIED EXIT VELOCITY.

NOTE B - WARP BASIN TO 作 CHANNEL BOTTOM AT SEC. A-A

DISSIPATOR POOL APRON
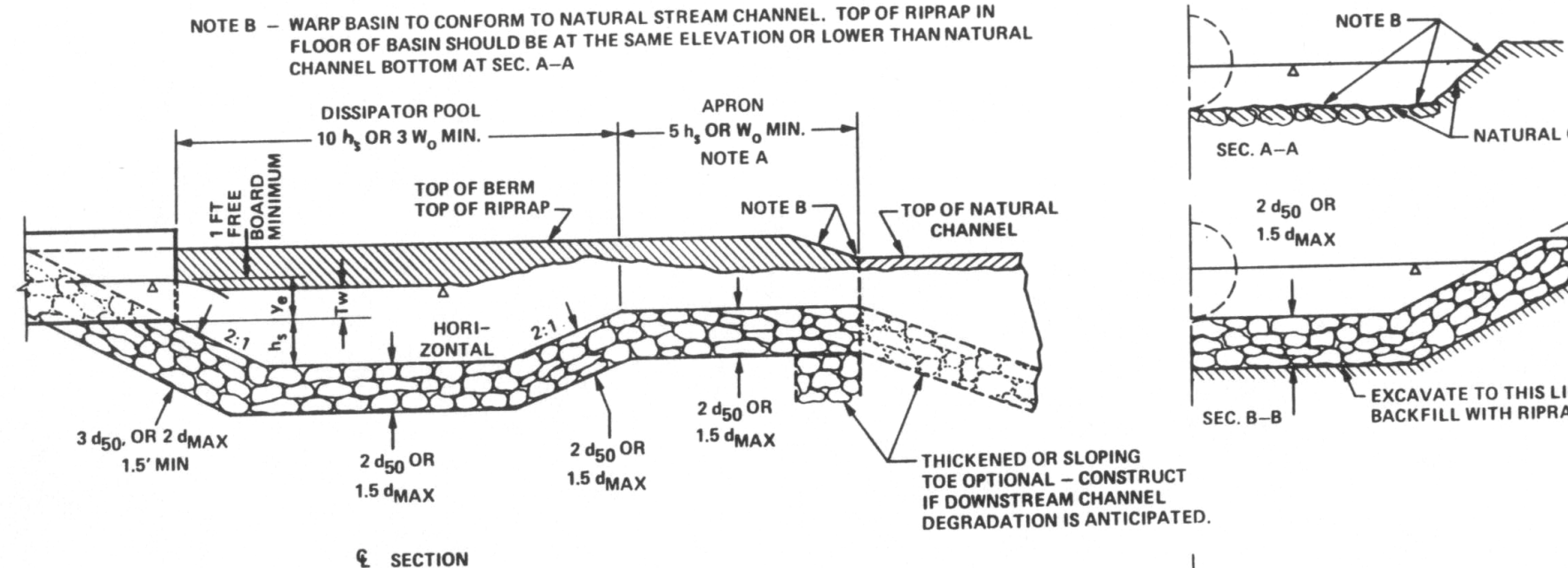
SEC.A-A
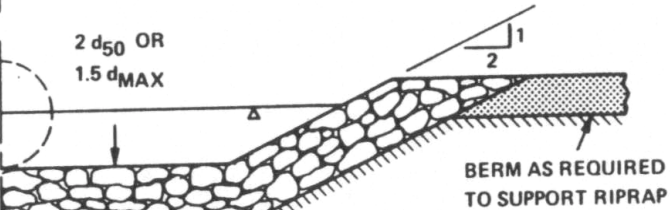

SEC. B-B $\begin{gathered}\text { EXCAVATE TO THIS LINE } \\ \text { BACKFILL WITH RIPRAP }\end{gathered}$

\section{\& SECTION}
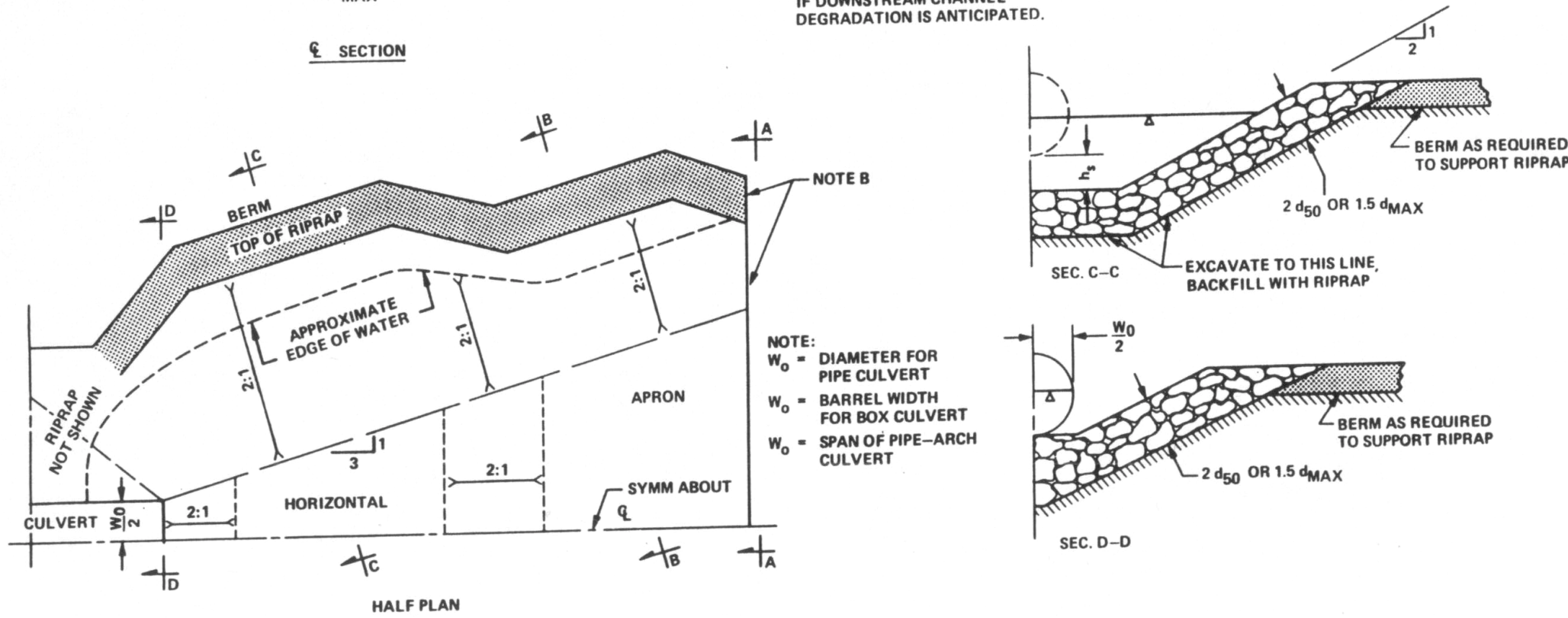

Figure 1.3 Details of Riprapped Culvert Energy Basin (HEC-14, 1983) 
The research project's experimental test runs will be conducted on a scale model. In order to construct a scale model of the wingwall and apron used in conjunction with the current riprap energy dissipator design, the various dimensions were taken from the appropriate WVDOH drawings, and placed in Microstation for ease of interpretation and manipulation. The dimensions of the wingwall and apron are all a function of pipe diameter with the exception of thickness, T, and cutoff wall height, $\mathrm{W}$, which are determined by the standard construction specifications. A schematic of the WVDOH wingwall and apron is shown in Figures 1.4, 1.5, and 1.6. The dimensions are shown as a multiple of culvert diameter in Table 1.1.

Table 1.1 Design Dimensions as Multiple of Culvert Diameter

\begin{tabular}{|c|c|}
\hline Dimension & $\begin{array}{c}\text { Multiple of } \\
\text { Diameter }\end{array}$ \\
\hline $\mathrm{L}$ & 1.2 \\
\hline $\mathrm{M}$ & 0.6 \\
\hline $\mathrm{N}$ & 1.2 \\
\hline $\mathrm{O}$ & 1.3 \\
\hline $\mathrm{P}$ & 3.9 \\
\hline $\mathrm{Q}$ & 1.8 \\
\hline
\end{tabular}

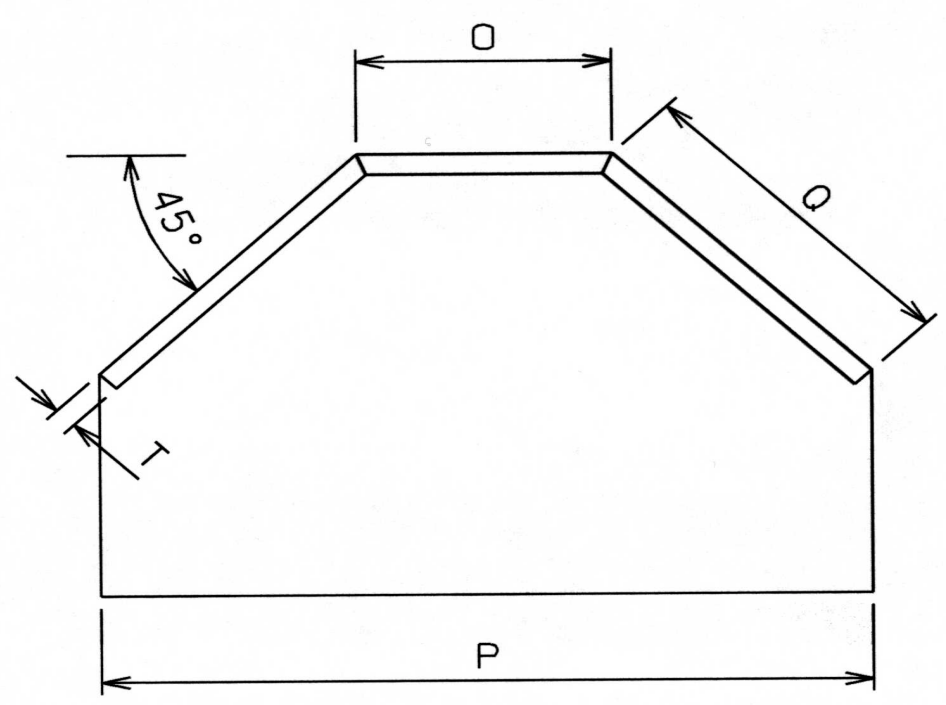

Figure 1.4 Plan of Current WVDOH Headwall, Wingwall and Apron 


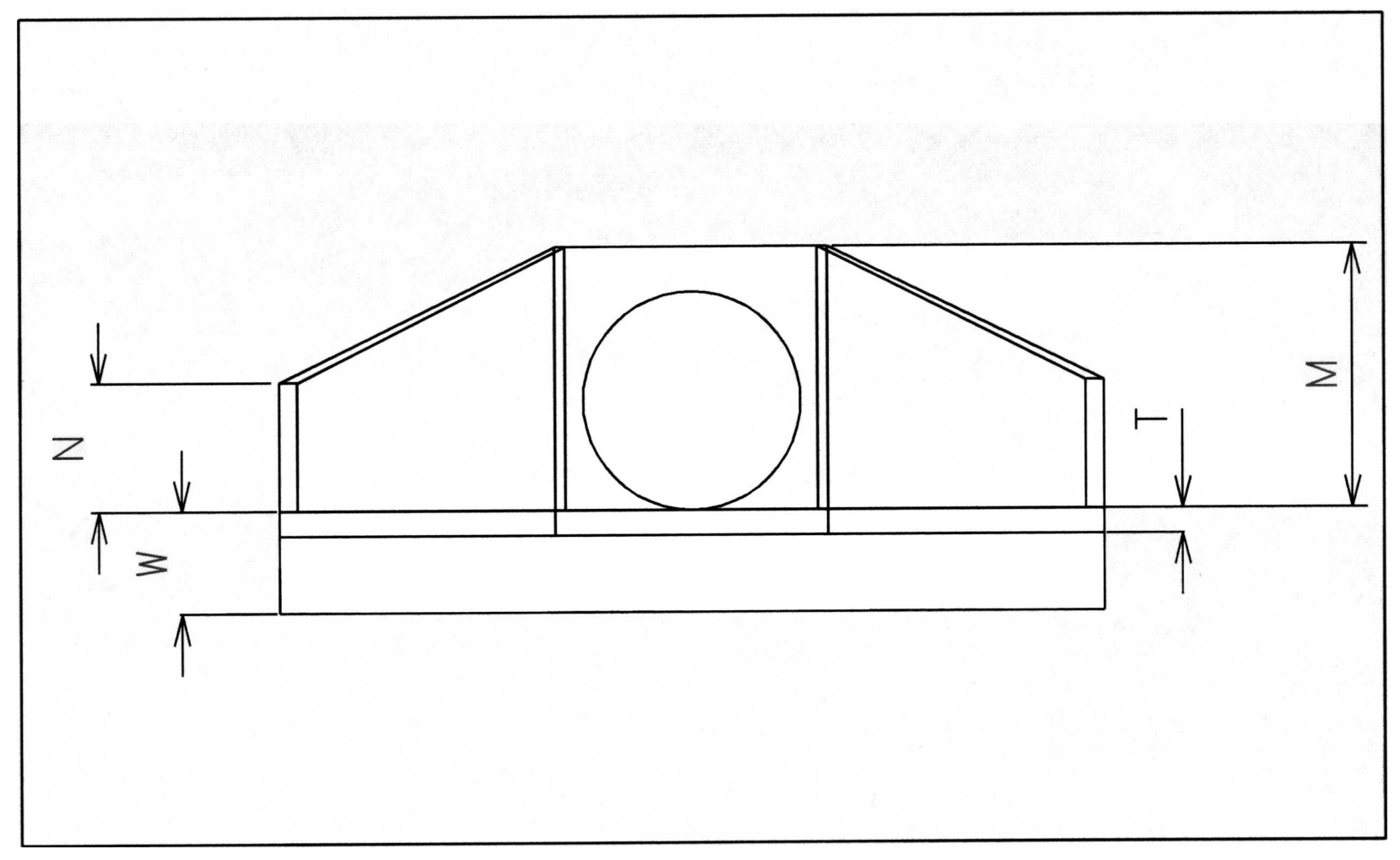

Figure 1.5 Front View of Current WVDOH Headwall, Wingwall and Apron

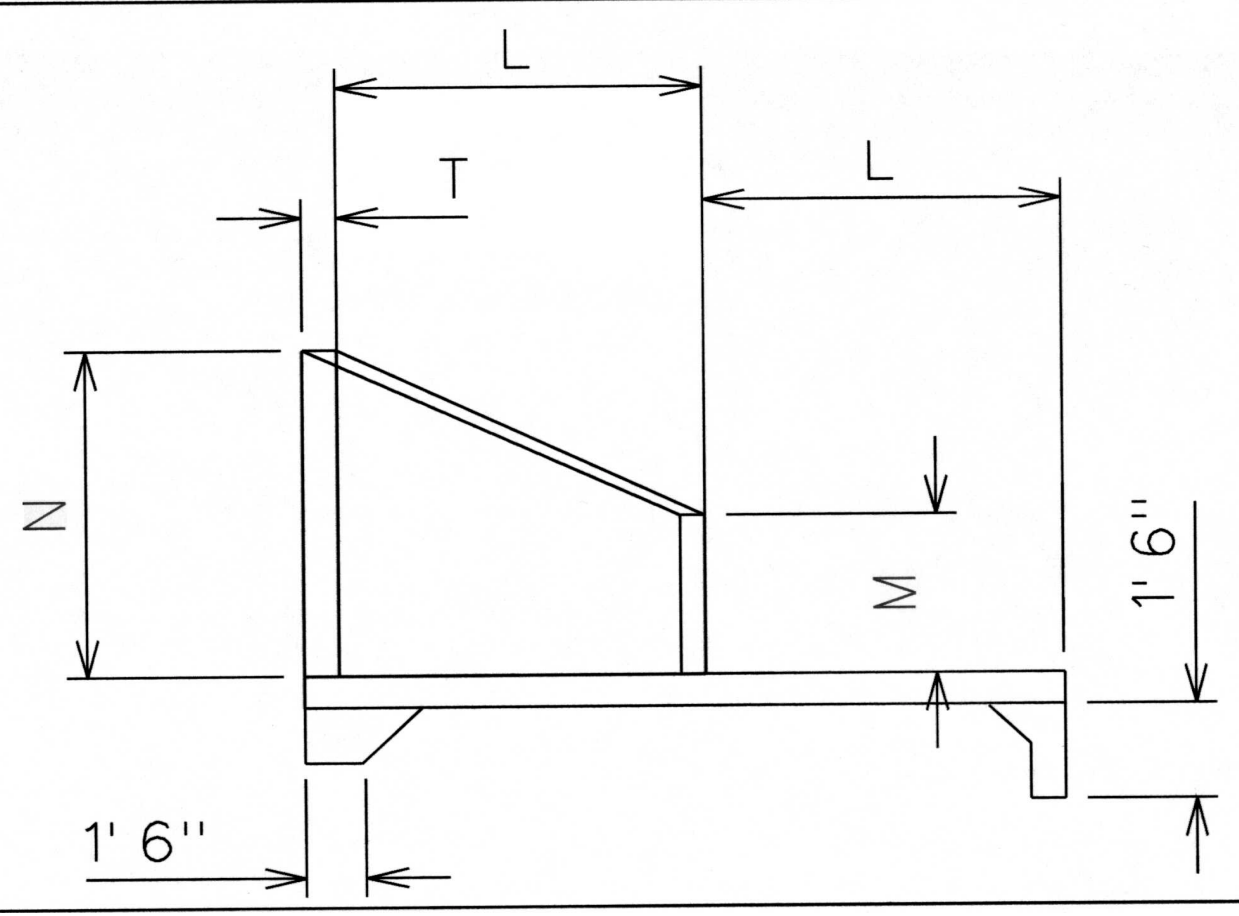

Figure 1.6 Profile of Current WVDOH Headwall, Wingwall and Apron 
As with current WVDOH riprap designs, the proposed alternative riprap step energy dissipator design will be preceded by the same wingwall and apron geometry design as shown in Figures 1.4, 1.5, and 1.6.

\subsection{Field Experiences With the Current Riprap Energy Dissipator}

Current riprap design used by the WVDOH has both advantages and disadvantages. The advantages were ease of placement, whether hand placed or dropped, without a need for skilled laborers, and low cost. The disadvantages of the current design were scouring, either local or gully, ineffective attenuation of energy at high flow velocities, and sediment accumulation resulting in low to no energy dissipation. A new riprap design must be developed and implemented as an alternative design to the current riprap design, that will eliminate or reduce existing problems. 


\section{Chapter 2}

\section{Background and Literature Review}

Considerable effort and time was initially spent in exploring a variety of riprap designs that held promise of providing an acceptable solution to the energy dissipation problem. Once an acceptable design approach was developed, time constraints imposed on the project limited the number of additional alternatives that could be explored. Because no riprap step design could be found in the literature, there was no related research data available that could provide direct support to this investigation.

\subsection{Riprap}

The definition of riprap varies according to the source. The simplest definition of riprap is a natural rock dumped or hand-placed to prevent erosion (Streambank Protection Guidelines, 1983). Generally, riprap is used to minimize erosion at the toe of a soil bank, to prevent erosion by placing a riprap blanket over a slope of a bank, to prevent erosion by piling riprap in windrows at the top or within an eroding bank, or to dissipate energy at culvert outlets. Riprap is one of the most common and economical methods of dealing with the problem of scouring at the end of culverts or pipe outlets (Shafai-Bajestan and Albertson, 1993). Some advantages of using riprap are: it is a speedy method of construction, skilled labor is not required, and usually, local sources of rock may be used (Streambank Protection Guidelines, 1983). Graded riprap is cheaper and more stable while uniform riprap has more voids and is less stable. The use of graded riprap is advantageous due to its healing process; one rock tumbling downstream due to erosion activity may fill a void further downstream, thus promoting stabilization.

\subsection{Hydraulic Jumps}

Hydraulic jumps are usually an inherent part of energy dissipator design. There are two different types of hydraulic jumps, a natural hydraulic jump and a forced hydraulic jump (HEC-14, 1983). The natural hydraulic jump occurs when there is a change from supercritical $(\mathrm{Fr}>1)$ to subcritical $(\mathrm{Fr}<1)$ flow conditions on a uniform bed (no 
local blockage or artificial roughness). The forced hydraulic jump is a tool utilized by energy dissipators, and is forced by blocks, sills, and riprap, or other artificial roughness elements. The roughness elements can be used inside culvert barrels, at culvert exits, or in the open channels downstream of the exit (HEC-14, 1983).

\subsubsection{Hydraulic Jump Forms}

Hydraulic jumps are usually referenced to the approach Froude number in order to categorize them appropriately. The physical characteristics of the hydraulic jump change with increasing Froude number. Energy absorption characteristics vary for each of the hydraulic jump forms, as seen below in Figure 2.1.

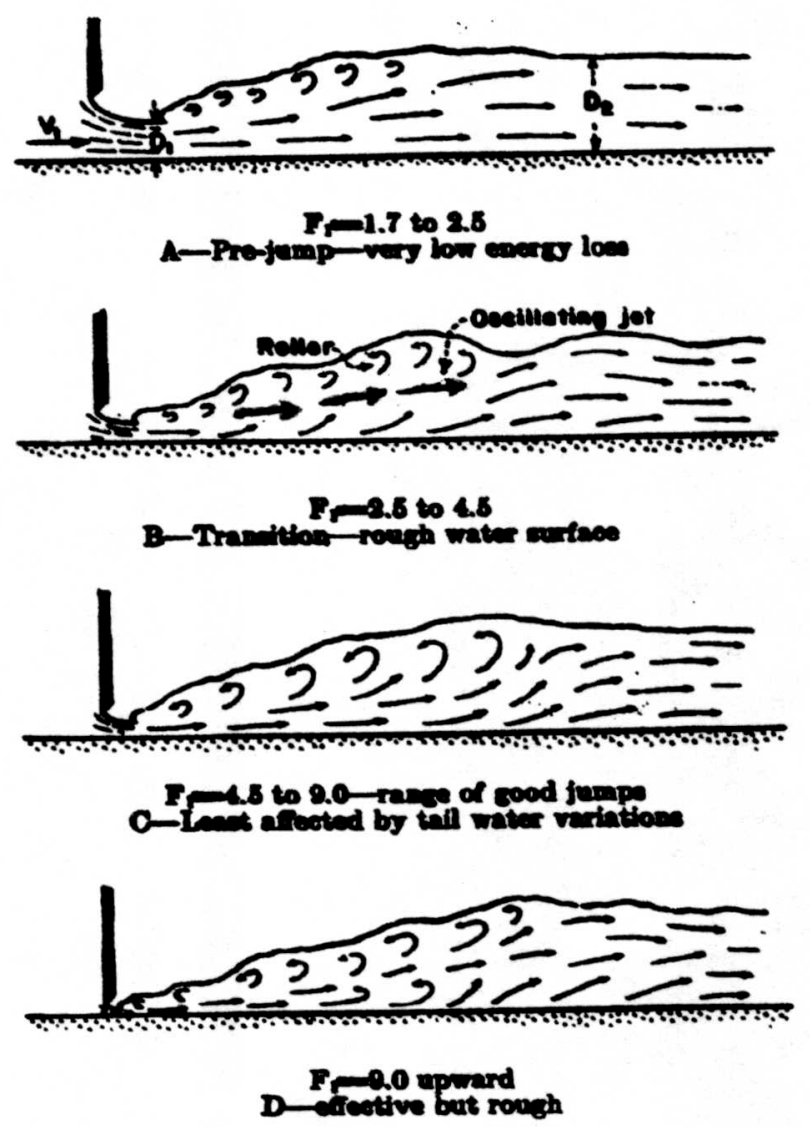

Figure 2.1 Hydraulic Jump Forms (Peterka, 1958) 
Weak Jump $\left(1<\mathrm{Fr}_{1}<2.5\right)$

Oscillating Jump $\left(2.5<\mathrm{Fr}_{1}<4.5\right)$

Steady Jump $\left(4.5<\mathrm{Fr}_{1}<9\right)$

Strong Jump $\left(\mathbf{F r}_{1}>\mathbf{9}\right)$
For $1<\mathrm{Fr}_{1}<1.7, \mathrm{y}_{1}$ and $\mathrm{y}_{2}$ are approximately equal to each other, and only a slight ruffle is formed on the surface. This undulation results in very little energy dissipation. As $\mathrm{Fr}_{1}$ approaches 1.7, a number of small rollers are formed on the water surface, although the downstream water surface remains smooth. The energy loss is low in this jump.

The jet at the entrance to the jump oscillates from the bottom to the top at an irregular period. Turbulence may be near the channel bottom at one instant and at the water surface the next. These oscillations result in the formation of irregular waves, which may persist for long distances downstream of the jump. These waves may cause considerable damage to the channel banks. This range of $\mathrm{Fr}_{1}$ should be avoided when designing an energy dissipator.

The jump forms steadily at the same location, and the position of the jump is least sensitive to the downstream flow conditions. The jump is well balanced and energy dissipation is considerable. The jump is stable with the fluid turbulence confined to the jump. The water surface downstream will usually appear to be smooth and an energy loss ranging from 45 to 70 percent can be expected.

The difference between the conjugate depths is large, slugs of water roll down the front of the jump face into the high velocity jet and generates additional waves. The jump action is very rough and the dissipation rate is high, but the turbulence can cause downstream erosion.

(Chaudhry, 1993, and HEC-14, 1983)

\subsubsection{Governing Equations}

Past studies of similar nature utilize the principles of momentum, energy, and Froude number equations.

The momentum equation is the sum of the forces equal to the change in the momentum flux, or

$\Sigma F=\Delta(Q V \rho)=\Delta\left[Q\left(V_{2}-V_{1}\right) \rho\right]$

Where:

$$
\begin{aligned}
& F=\text { Force } \\
& V=\text { Average flow velocity } \\
& V 1=\text { Upstream average flow velocity } \\
& V 2=\text { Downstream average flow velocity } \\
& Q=\text { Flowrate } \\
& \rho=\text { Density of water }
\end{aligned}
$$


the energy, and head loss for a horizontal, rectangular channel, through the jump equations are listed below,

$$
\begin{aligned}
& \frac{V_{1}^{2}}{2 g}+y_{1}=\frac{V_{2}^{2}}{2 g}+y_{2}+h_{L} \\
& h_{L}=\frac{\left(y_{1}-y_{2}\right)^{3}}{4 y_{1} y_{2}}
\end{aligned}
$$

Where:

$$
\begin{aligned}
& y_{1}=\text { Upstream water depth } \\
& y_{2}=\text { Downstream water depth } \\
& g=\text { Acceleration due to gravity } \\
& V_{1}=\text { Upstream velocity } \\
& V_{2}=\text { Downstream velocity } \\
& F r_{1}=\text { Upstream Froude number }
\end{aligned}
$$

The Froude number, Fr, is a dimensionless parameter and is important in establishing similitude between the model prototype (Roberson et al, 1995). Froude number is given by:

$$
F r=\frac{V}{\sqrt{g y}}
$$

Where:

$$
\begin{aligned}
& F r=\text { Froude number } \\
& V=\text { Flow velocity } \\
& y=\text { hydraulic depth }
\end{aligned}
$$

The Froude number is proportional to the inertial force and the body force (Peterka, 1958).

$$
F r^{2}=\frac{V^{2}}{g y}=\frac{\rho V^{2} y^{2}}{\rho g y^{2}} \cong \frac{\text { InertialForce }}{\text { BodyForce }}
$$


The Federal Highway Administration, in 1987, produced a video, Hydraulics of Energy Dissipators outlining the procedure for analyzing the hydraulic jump in stilling basins. Since density is unchanging in open channels and culverts, the term can be eliminated from the continuity equation, leaving the volume rate of flow, or discharge, equal to the area times the volume or $Q=A_{1} V_{1}=A_{2} V_{2}$. The momentum flux at one end of the hydraulic jump does not equal the momentum flux at the other end of the hydraulic jump. The momentum equation relates change in momentum flux across the control volume to the forces produced by hydrostatic pressure and boundary, or shear forces. The shear forces or boundary forces are small and considered insignificant, therefore neglected. The hydrostatic forces on the control volume are balanced by a change in the momentum across the control volume. The hydraulic jump equation combines the momentum equation with the continuity equation and introduces the Froude number defined above. This yielding,

$$
\frac{y_{2}}{y_{1}}=\frac{1}{2}\left(\sqrt{1+8 F r_{1}^{2}}-1\right)
$$

which can be used to give the tailwater depth that is necessary to produce a hydraulic jump assuming that the depth and velocity of the flow upstream of the jump for a rectangular channel is known (HEC-14, 1983).

\subsubsection{Specific Head and Energy Loss}

Using the governing equations presented above one can calculate the energy lost in the jump on a level bed by taking he difference between the specific head upstream and downstream. This difference is the loss of energy, expressed in units of head, due to the dissipation of energy in the jump. The upstream depth, $\mathrm{y}_{1}$, and the downstream depth, $\mathrm{y}_{2}$, are called conjugate depths and $\mathrm{y}_{2}$ is said to be sequent to $\mathrm{y}_{2}$ (Gray, 2000). Figure 2.2 shows the relationship between specific head and depth of the hydraulic jump It is essential to know the magnitude of energy loss produced by the jump so that efficiencies of the dissipator design can be fully evaluated. 


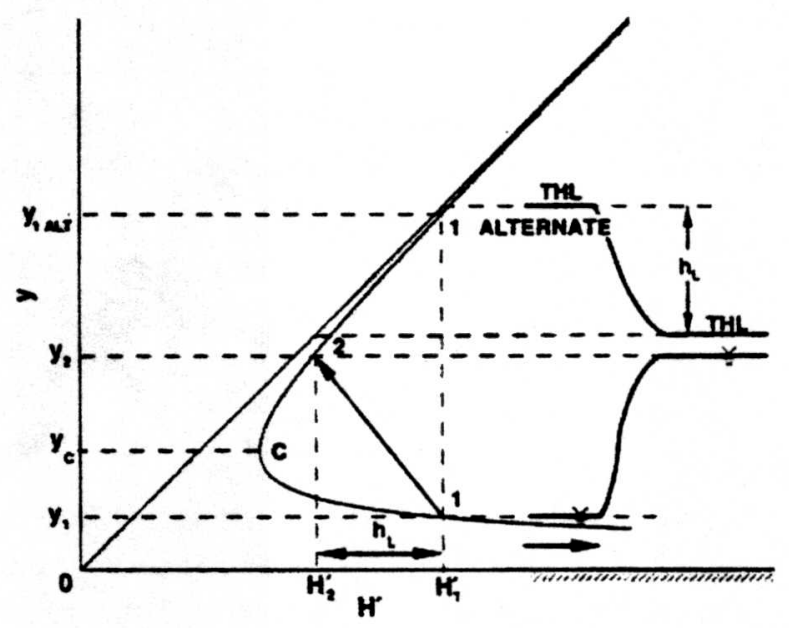

Figure 2.2 Specific Head. NOTE: H' represents specific head and $\mathrm{H}_{1}{ }^{\prime}$ and $\mathrm{H}_{2}{ }^{\prime}$ are specific heads upstream and downstream

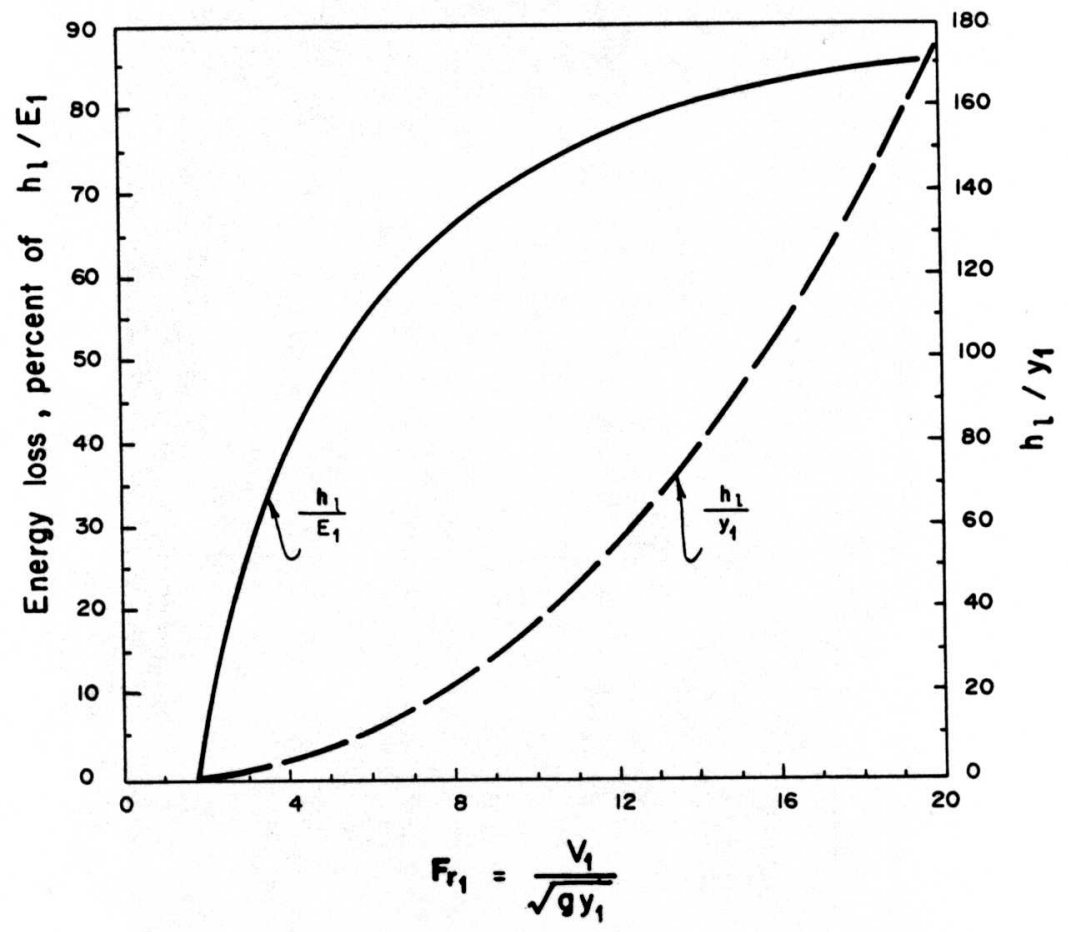

Figure 2.3 Energy Dissipation in Jump (Chaudhry, 1993) 


\subsubsection{Jump Length}

It is difficult to determine the length of the hydraulic jump due to its complex and random flow patterns.

The formation of rollers, eddies, air entrainment, and a highly turbulent flow surface make the beginning and end of the jump more difficult to locate. If the jump is controlled by an abrupt rise, the jump is formed at a distance $\mathrm{x}$ upstream of the rise.

$$
x=5\left(h+y_{3}\right)
$$

Where:

$$
\begin{aligned}
& x=\text { Horizontal distance in channel preceding the abrupt rise } \\
& h=\text { Abrupt rise (step) height } \\
& y_{3}=\text { Downstream water depth }
\end{aligned}
$$

See Figure 2.4 below.

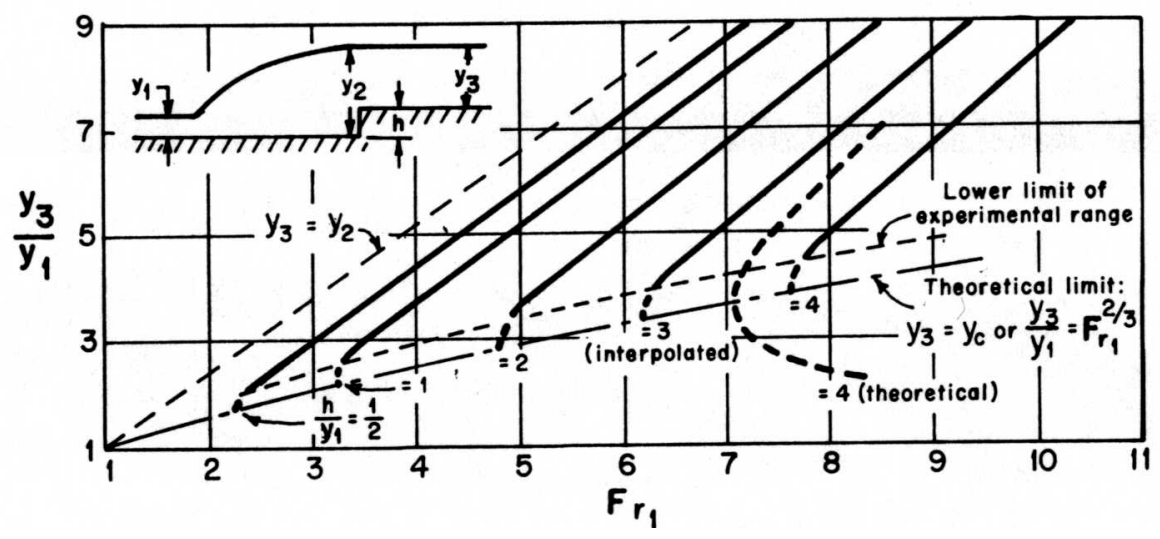

Figure 2.4 Jump Controlled by Abrupt Rise (Chaudhry, 1993) 


\subsubsection{Shortcomings of the Hydraulic Jump}

A free hydraulic jump is a jump without the aid of objects or obstructions in the path of flow. The free hydraulic jump is a desirable means of dissipating energy at high velocity flows. However, the free hydraulic jump is normally considered impractical and economically undesirable where design and economic considerations are concerned. As seen with the oscillating hydraulic jump form discussed in Section 2.2.1, the hydraulic jump was destructive to the downstream channel as well as the hydraulic structure itself. The main drawback of the free hydraulic jump is the length of structure needed to contain the jump to prevent the channel from being degraded and soil being carried downstream (Peterka, 1978). In order to produce the most stable and economical energy dissipator, or stilling basin, it is necessary to alter the hydraulic jump characteristics.

Reinforcement of these ideas was supported by two groups of researchers, Roberson et al. and Peterka. In 1978, Peterka stated that stilling basins are seldom designed to confine the entire length of the hydraulic jump, first, for economic reasons, and second, because there are means for modifying the jump characteristics to obtain comparable or better performance characteristics in shorter lengths. In 1995, Roberson et al. believed that a carefully designed stilling basin not only improved the dissipation characteristics of a hydraulic jump, it would also shorten its length and stabilize the position of the jump so that it was not sensitive to fluctuations in tailwater level. This latter attribute made the design safer.

These ideas can be accomplished by the introduction of the forced hydraulic jump. A forced hydraulic jump is caused by the introduction of additional resistive forces to the flow produced by the placement of objects in the flow path, which increases the conjugate depth. According to Chaudhry, the location of a hydraulic jump may be controlled by adding a variety of structures to the channel bottom, such as baffle blocks, sills, and drops or rises. 


\section{Chapter 3}

\section{Initial Investigations}

Following a literature review to determine the history of riprap steps, it was discovered that there was insufficient information available to initiate the project. Additional information was needed regarding common drainage pipe sizes used by the WVDOH in designs where the new riprap step design was to be used and the gradation of stone that was to be supplied by local quarries.

\subsection{Drainage Pipe}

The investigation focused on circular drainage pipes, disregarding all other non-circular drainage pipe geometries such as square, rectangular, arch and elliptical. Documentation of circular drainage pipe quantities placed for 1992-1997 was obtained from by the WVDOH's main office in Charleston, WV. After an extensive screening and summation of the data, frequency of application based on total length for each diameter, is listed in

Table 3.1. It will be noted that $95 \%$ of all pipe placed into service is 4.25 -feet diameter or less. Equivalent graphic plots are shown in Figures 3.1 and 3.2.

\begin{tabular}{|c|c|c|c|c|c|c|c|}
\hline $\begin{array}{c}\text { Diameter } \\
(\mathrm{ft})\end{array}$ & $\begin{array}{l}\text { Sum Avg. } \\
\text { (Linear ft.) }\end{array}$ & $\%$ & Cumulative \% & $\begin{array}{c}\text { Diameter } \\
(\mathrm{ft})\end{array}$ & $\begin{array}{l}\text { Sum Avg. } \\
\text { (Linear ft.) }\end{array}$ & $\%$ & Cumulative \% \\
\hline 0.25 & 0.0 & 0.00 & 0.00 & 6.25 & 0.0 & 0.00 & 98.35 \\
\hline 0.50 & 13740.1 & 12.17 & 12.17 & 6.50 & 82.9 & 0.07 & 98.43 \\
\hline 0.75 & 3.8 & 0.00 & 12.17 & 6.75 & 0.0 & 0.00 & 98.43 \\
\hline 1.00 & 806.5 & 0.71 & 12.89 & 7.00 & 927.4 & 0.82 & 99.25 \\
\hline 1.25 & 6456.1 & 5.72 & 18.60 & 7.25 & 35.0 & 0.03 & 99.28 \\
\hline 1.50 & 45260.7 & 40.08 & 58.69 & 7.50 & 0.0 & 0.00 & 99.28 \\
\hline 1.75 & 32.2 & 0.03 & 58.72 & 7.75 & 0.0 & 0.00 & 99.28 \\
\hline 2.00 & 21849.2 & 19.35 & 78.07 & 8.00 & 280.4 & 0.25 & 99.53 \\
\hline 2.25 & 0.0 & 0.00 & 78.07 & 8.25 & 0.0 & 0.00 & 99.53 \\
\hline 2.50 & 6380.8 & 5.65 & 83.72 & 8.50 & 0.0 & 0.00 & 99.53 \\
\hline 2.75 & 1230.9 & 1.09 & 84.81 & 8.75 & 155.9 & 0.14 & 99.66 \\
\hline 3.00 & 5212.0 & 4.62 & 89.43 & 9.00 & 52.9 & 0.05 & 99.71 \\
\hline 3.25 & 203.0 & 0.18 & 89.60 & 9.25 & 0.0 & 0.00 & 99.71 \\
\hline 3.50 & 2078.8 & 1.84 & 91.45 & 9.50 & 0.0 & 0.00 & 99.71 \\
\hline 3.75 & 0.0 & 0.00 & 91.45 & 9.75 & 142.6 & 0.13 & 99.84 \\
\hline 4.00 & 3491.4 & 3.09 & 94.54 & 10.00 & 78.5 & 0.07 & 99.91 \\
\hline 4.25 & 0.0 & 0.00 & 94.54 & 10.25 & 0.0 & 0.00 & 99.91 \\
\hline 4.50 & 1175.7 & 1.04 & 95.58 & 10.50 & 0.0 & 0.00 & 99.91 \\
\hline 4.75 & 0.0 & 0.00 & 95.58 & 10.75 & 0.0 & 0.00 & 99.91 \\
\hline 5.00 & 1764.0 & 1.56 & 97.14 & 11.00 & 22.3 & 0.02 & 99.93 \\
\hline 5.25 & 225.2 & 0.20 & 97.34 & 11.25 & 0.0 & 0.00 & 99.93 \\
\hline 5.50 & 219.0 & 0.19 & 97.54 & 11.50 & 0.0 & 0.00 & 99.93 \\
\hline 5.75 & 0.0 & 0.00 & 97.54 & 11.75 & 15.3 & 0.01 & 99.94 \\
\hline 6.00 & 923.0 & 0.82 & 98.35 & 12.00 & 67.0 & 0.06 & 100.00 \\
\hline
\end{tabular}




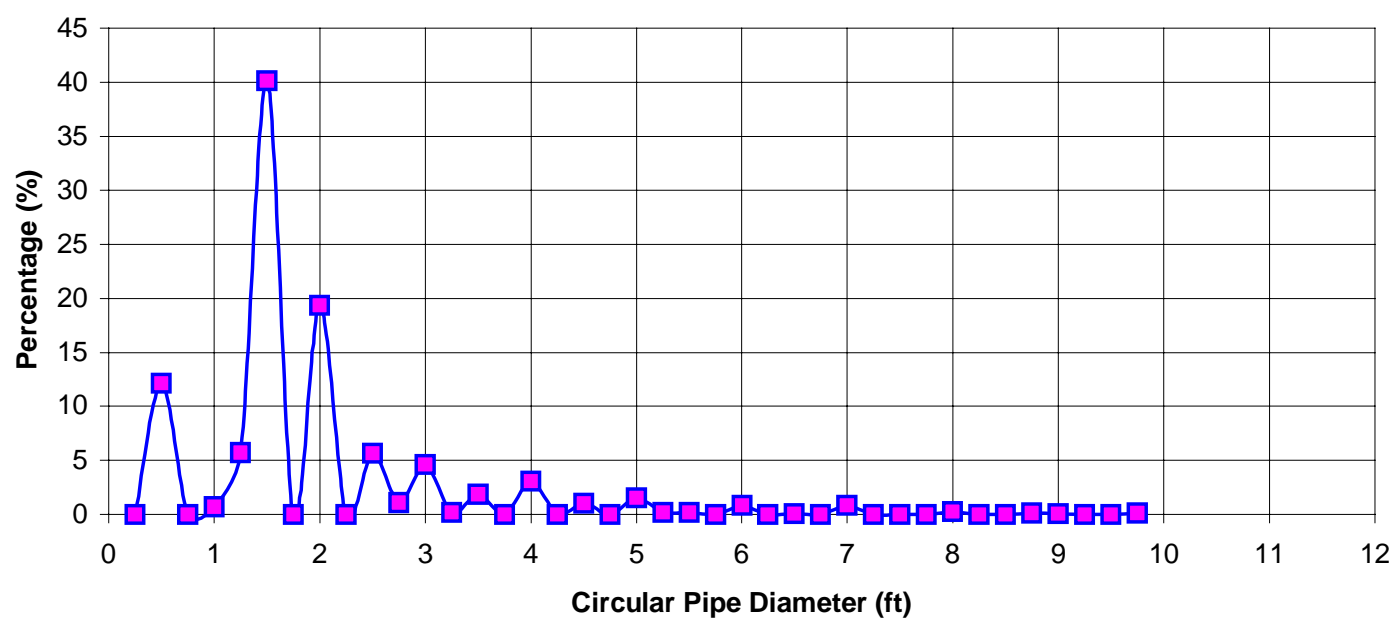

Figure 3.1 Circular Pipe Diameters - WVDOH Placement

Cumulative Percentage Circular Pipe Diameters - WVDOH Placement

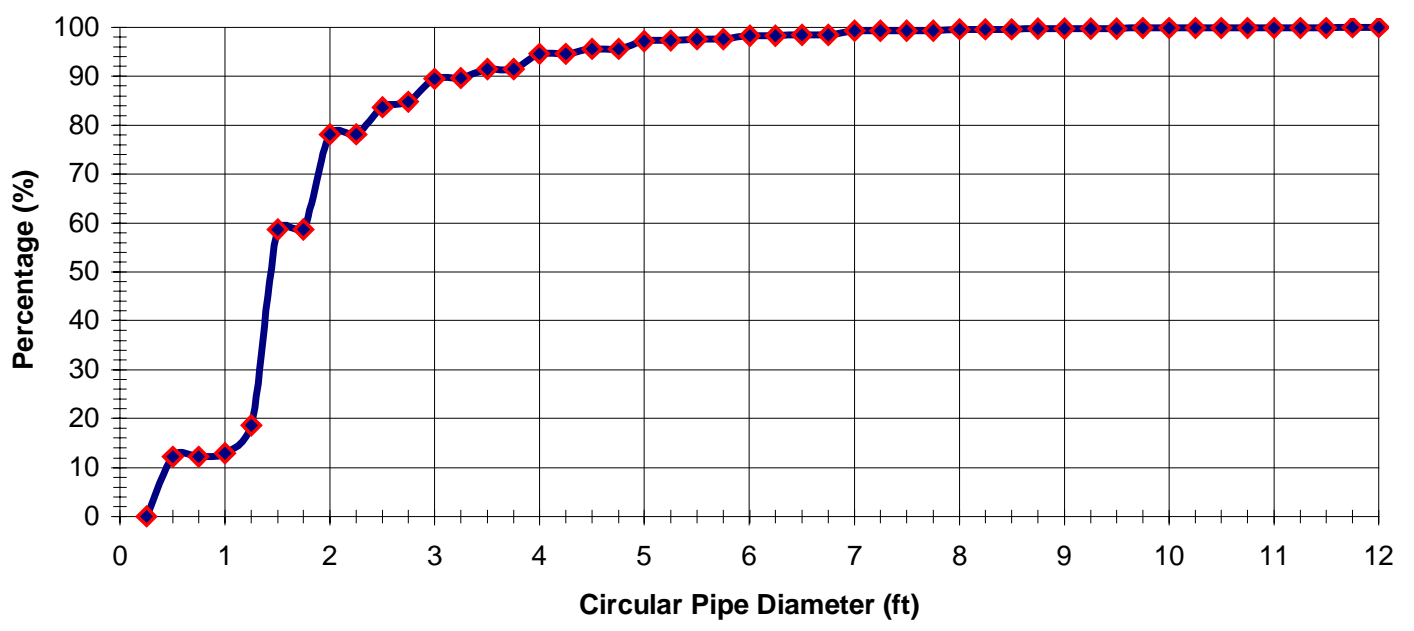

Figure 3.2 Cumulative Circular Pipe Diameters - WVDOH Placement

\subsection{Rock Gradations for West Virginia Quarries}

An important aspect of this project was to determine the rock gradations supplied to the WVDOH. The rock supplied by local quarries would potentially be used in the construction of the riprap step energy dissipator. At this early stage of development, the gradation required for the project was unknown. The necessity for investigating current rock gradations supplied to the WVDOH by rock quarries was evident. All ten district engineers were 
contacted and requested to report a list of information on the quarries within their district that supplied rock for state funded projects. The lists of rock quarries supplying state funded projects with rock were compiled and analyzed. It was discovered that two rock quarries, Greer, and Martin Marietta, supplied in part, 44 of the 55 counties, 75 percent of West Virginia. The quarries were contacted and representative rock gradation samples obtained. Since rock gradation samples from Greer were from one representative mine near Morgantown, the samples were averaged and shown in Table 3.2. Martin Marietta's rock gradation samples were from four mine sites; Cave-In-Rock at Cave-InRock, IL (MM-A); Three Rivers Quarry at Smithland, KY (MM-B); Manheim Mine at Rowlesburg, WV (MM-C); and Snowflake Quarry at Fort Springs, WV (MM-D), and shown in Tables 3.3, 3.4, 3.5, and 3.6, respectively. The four quarries representative samples were averaged and shown in Table 3.2.

\begin{tabular}{|c|c|c|c|c|c|c|c|}
\hline \multirow{3}{*}{$\begin{array}{l}\text { Sieve } \\
\text { (in) }\end{array}$} & \multirow{3}{*}{$\begin{array}{c}\text { Sieve } \\
\text { Dimensions } \\
(\mathrm{mm})\end{array}$} & \multicolumn{6}{|c|}{ Percent Finer By Weight } \\
\hline & & \multicolumn{6}{|c|}{ Aggregate Type } \\
\hline & & $\mathrm{R}-7$ & $\mathrm{R}-6$ & $\mathrm{R}-4$ & $\# 4$ & $\# 57$ & \#8 \\
\hline 30.00 & 762.00 & 100 & & & & & \\
\hline 24.00 & 609.60 & 12 & 100 & & & & \\
\hline 18.00 & 457.20 & 9 & 66 & & & & \\
\hline 12.00 & 304.80 & 6 & 32 & 100 & & & \\
\hline 6.00 & 152.40 & & 2 & 9 & & & \\
\hline 3.00 & 76.20 & & & 25 & 100 & & \\
\hline 2.00 & 50.80 & & & & 100 & 100 & \\
\hline 1.50 & 38.10 & & & & 95 & 100 & \\
\hline 1.00 & 25.40 & & & & 45 & 99 & \\
\hline 0.75 & 19.05 & & & & 8 & 87 & \\
\hline 0.50 & 12.70 & & & & 4 & 38 & 100 \\
\hline 0.38 & 9.53 & & & & 2 & 13 & 96 \\
\hline$\# 4$ & 4.75 & & & & & 3 & 28 \\
\hline$\# 8$ & 2.36 & & & & & 2 & 4 \\
\hline$\# 16$ & 1.18 & & & & & 1 & 3 \\
\hline Pan & 0.00 & 0 & 0 & 0 & 0 & 0 & 0 \\
\hline
\end{tabular}




\begin{tabular}{|c|c|c|c|c|c|c|c|c|c|c|c|c|}
\hline \multirow{3}{*}{$\begin{array}{l}\text { Sieve } \\
\text { (in) }\end{array}$} & \multirow{3}{*}{$\begin{array}{c}\text { Sieve } \\
\text { Dimensions } \\
(\mathrm{mm})\end{array}$} & \multicolumn{11}{|c|}{ Percent Finer By Weight } \\
\hline & & \multicolumn{11}{|c|}{ Aggregate Type } \\
\hline & & $\# 1$ & \#3 & $\# 4$ & \#467 & \#5 & \#57 & $\# 67$ & \#78 & $\# 7$ & \#8 & $\# 9$ \\
\hline 4.00 & 101.60 & 100 & & & & & & & & & & \\
\hline 3.50 & 88.90 & 100 & & & & & & & & & & \\
\hline 3.00 & 76.20 & 88 & & & & & & & & & & \\
\hline 2.50 & 63.50 & 54 & 100 & & & & & & & & & \\
\hline 2.00 & 50.80 & - & 95 & 100 & 100 & & & & & & & \\
\hline 1.50 & 38.10 & 12 & 55 & 100 & 100 & 100 & 100 & & & & & \\
\hline 1.00 & 25.40 & - & 9 & 22 & 75 & 90 & 96 & 100 & & & & \\
\hline 0.75 & 19.05 & 2 & - & 3 & 39 & 29 & 78 & 92 & 100 & 100 & & \\
\hline 0.50 & 12.70 & & 2 & - & 15 & 3 & 38 & 47 & 92 & 92 & 100 & \\
\hline 0.38 & 9.53 & & & 2 & 14 & 1 & 15 & 26 & 58 & 60 & 94 & 100 \\
\hline$\# 4$ & 4.75 & & & & 2 & & 2 & 2 & 11 & 11 & 22 & 86 \\
\hline \#8 & 2.36 & & & & & & 1 & 1 & 3 & 3 & 4 & 26 \\
\hline$\# 16$ & 1.18 & & & & & & & & 2 & 2 & 1 & 2 \\
\hline Pan & 0.00 & 0 & 0 & 0 & 0 & 0 & 0 & 0 & 0 & 0 & 0 & 0 \\
\hline
\end{tabular}

Table 3.4 Rock Gradations for Three Rivers Quarry at Smithland, KY

\begin{tabular}{|c|c|c|c|c|c|c|c|c|c|c|c|}
\hline \multirow{3}{*}{$\begin{array}{c}\text { Sieve } \\
\text { (in) }\end{array}$} & \multirow{3}{*}{$\begin{array}{c}\text { Sieve } \\
\text { Dimensions } \\
(\mathrm{mm})\end{array}$} & \multicolumn{10}{|c|}{ Percent Finer By Weight } \\
\hline & & \multicolumn{10}{|c|}{ Aggregate Type } \\
\hline & & \#1 & \#3 & $\# 357$ & \#4 & \#467 & \#57 & \#67 & \#78 & $\# 7$ & \#8 \\
\hline 4.00 & 101.60 & 100 & & & & & & & & & \\
\hline 3.50 & 88.90 & 95 & & & & & & & & & \\
\hline 3.00 & 76.20 & 91 & & & & & & & & & \\
\hline 2.50 & 63.50 & 40 & 100 & 100 & & & & & & & \\
\hline 2.00 & 50.80 & - & 96 & 98 & 100 & 100 & & & & & \\
\hline 1.50 & 38.10 & 10 & 60 & - & 96 & 96 & 100 & & & & \\
\hline 1.00 & 25.40 & - & 10 & 40 & 24 & 68 & 96 & 100 & & & \\
\hline 0.75 & 19.05 & 1 & - & - & 4 & 46 & 72 & 91 & 100 & 100 & \\
\hline 0.50 & 12.70 & & 1 & 12 & - & 24 & 34 & 39 & 91 & 91 & 100 \\
\hline 0.38 & 9.53 & & & - & 1 & 14 & 14 & 23 & 60 & 60 & 98 \\
\hline$\# 4$ & 4.75 & & & 1 & & 3 & 3 & 6 & 10 & 10 & 18 \\
\hline$\# 8$ & 2.36 & & & & & & 2 & 3 & 3 & 3 & 2 \\
\hline$\# 16$ & 1.18 & & & & & & & & 2 & 2 & 1 \\
\hline Pan & 0.00 & 0 & 0 & 0 & 0 & 0 & 0 & 0 & 0 & 0 & 0 \\
\hline
\end{tabular}




\begin{tabular}{|c|c|c|c|c|c|c|}
\hline \multicolumn{3}{|c|}{ Table 3.5 Rock Gradations for Manheim Mine at Rowlesburg, WV } \\
\hline \multirow{3}{*}{$\begin{array}{c}\text { Sieve } \\
\text { (in) }\end{array}$} & $\begin{array}{c}\text { Sieve } \\
\text { Dimensions } \\
(\mathrm{mm})\end{array}$ & \multicolumn{5}{|c|}{ Percent Finer By Weight } \\
\hline & & $\# 1$ & $\# 4$ & $\# 467$ & $\# 57$ & $\# 8$ \\
\hline 4.00 & 101.60 & 100 & & & & \\
\hline 3.50 & 88.90 & 95 & & & & \\
\hline 3.00 & 76.20 & - & & & & \\
\hline 2.50 & 63.50 & 50 & & & & \\
\hline 2.00 & 50.80 & - & 100 & 100 & & \\
\hline 1.50 & 38.10 & 9 & 100 & 97 & 100 & \\
\hline 1.00 & 25.40 & - & 58 & 86 & 100 & \\
\hline 0.75 & 19.05 & 1 & 9 & 57 & 81 & \\
\hline 0.50 & 12.70 & & - & 36 & 28 & 100 \\
\hline 0.38 & 9.53 & & 1 & 21 & 8 & 88 \\
\hline$\# 4$ & 4.75 & & & 5 & 3 & 19 \\
\hline$\# 8$ & 2.36 & & & & 2 & 5 \\
\hline$\# 16$ & 1.18 & & & & & 3 \\
\hline Pan & 0.00 & 0 & 0 & 0 & 0 & 0 \\
\hline
\end{tabular}

\begin{tabular}{|c|c|c|c|c|c|c|c|}
\hline \multicolumn{2}{|c|}{ Table 3.6 Rock Gradations for Snowflake Quarry at Fort Springs, WV } \\
\hline \multirow{2}{*}{$\begin{array}{c}\text { Sieve } \\
\text { (in) }\end{array}$} & $\begin{array}{c}\text { Sieve } \\
\text { Dimensions } \\
(\mathrm{mm})\end{array}$ & \multicolumn{6}{|c|}{ Percent Finer By Weight } \\
\hline & 101.60 & & & & & & \\
\hline 4.00 & 88.90 & & & & & & \\
\hline 3.50 & 76.20 & & & & & & \\
\hline 3.00 & 63.50 & 100 & & & & & \\
\hline 2.50 & 50.80 & 98 & 100 & & & & \\
\hline 2.00 & 38.10 & 55 & 98 & 100 & & & \\
\hline 1.50 & 25.40 & 7 & 43 & 96 & 100 & & \\
\hline 1.00 & 19.05 & - & 7 & - & 91 & & \\
\hline 0.75 & 12.70 & 1 & - & 40 & - & 100 & \\
\hline 0.50 & 9.53 & & 2 & 15 & 34 & 87 & 100 \\
\hline 0.38 & 4.75 & & & 3 & 6 & 17 & 87 \\
\hline$\# 4$ & 2.36 & & & 1 & 1 & 6 & 19 \\
\hline$\# 8$ & 1.18 & & & & & 3 & 6 \\
\hline$\# 16$ & 0.00 & 0 & 0 & 0 & 0 & 0 & 0 \\
\hline Pan & & & & & & & \\
\hline
\end{tabular}




\begin{tabular}{|c|c|c|c|c|c|c|c|c|c|c|c|c|}
\hline \multirow{3}{*}{$\begin{array}{c}\text { Sieve } \\
\text { (in) }\end{array}$} & \multirow{3}{*}{$\begin{array}{c}\text { Sieve } \\
\text { Dimensions } \\
(\mathrm{mm})\end{array}$} & \multicolumn{11}{|c|}{ Percent Finer By Weight } \\
\hline & & \multicolumn{11}{|c|}{ Aggregate Type } \\
\hline & & $\# 1$ & $\# 3$ & $\# 4$ & \#467 & $\# 5$ & $\# 57$ & $\# 67$ & \#78 & $\# 7$ & $\# 8$ & $\# 9$ \\
\hline 4.00 & 101.60 & 100 & & & & & & & & & & \\
\hline 3.50 & 88.90 & 97 & & & & & & & & & & \\
\hline 3.00 & 76.20 & 90 & & & & & & & & & & \\
\hline 2.50 & 63.50 & 48 & 100 & & & & & & & & & \\
\hline 2.00 & 50.80 & & 96 & 100 & 100 & & & & & & & \\
\hline 1.50 & 38.10 & 10 & 57 & 99 & 98 & 100 & 100 & & & & & \\
\hline 1.00 & 25.40 & & 9 & 37 & 76 & 90 & 97 & 100 & & & & \\
\hline 0.75 & 19.05 & 1 & & 6 & 47 & 29 & 77 & 51 & 100 & 100 & & \\
\hline 0.50 & 12.70 & & 1 & & 25 & 3 & 35 & 14 & 92 & 92 & 100 & \\
\hline 0.38 & 9.53 & & & 2 & 16 & 1 & 13 & 10 & 59 & 60 & 92 & 100 \\
\hline \#4 & 4.75 & & & & 3 & & 3 & 2 & 11 & 11 & 19 & 87 \\
\hline$\# 8$ & 2.36 & & & & & & 2 & 1 & 3 & 3 & 4 & 23 \\
\hline$\# 16$ & 1.18 & & & & & & & & 2 & 2 & 2 & 4 \\
\hline Pan & 0.00 & 0 & 0 & 0 & 0 & 0 & 0 & 0 & 0 & 0 & 0 & 0 \\
\hline
\end{tabular}

Another important aspect of this investigation was determining the similarities and differences between the gradations for supposed equivalent rock types. Sample rock gradations were compared from the five locations for rock/stone sizes \#4, \#57, and \#8 shown in Figures 3.3, 3.4, and 3.5. An averaged aggregate gradation curves plot for West Virginia quarries is shown in Figure 3.6.

\section{Material Gradation Curves For \#4 Stone}

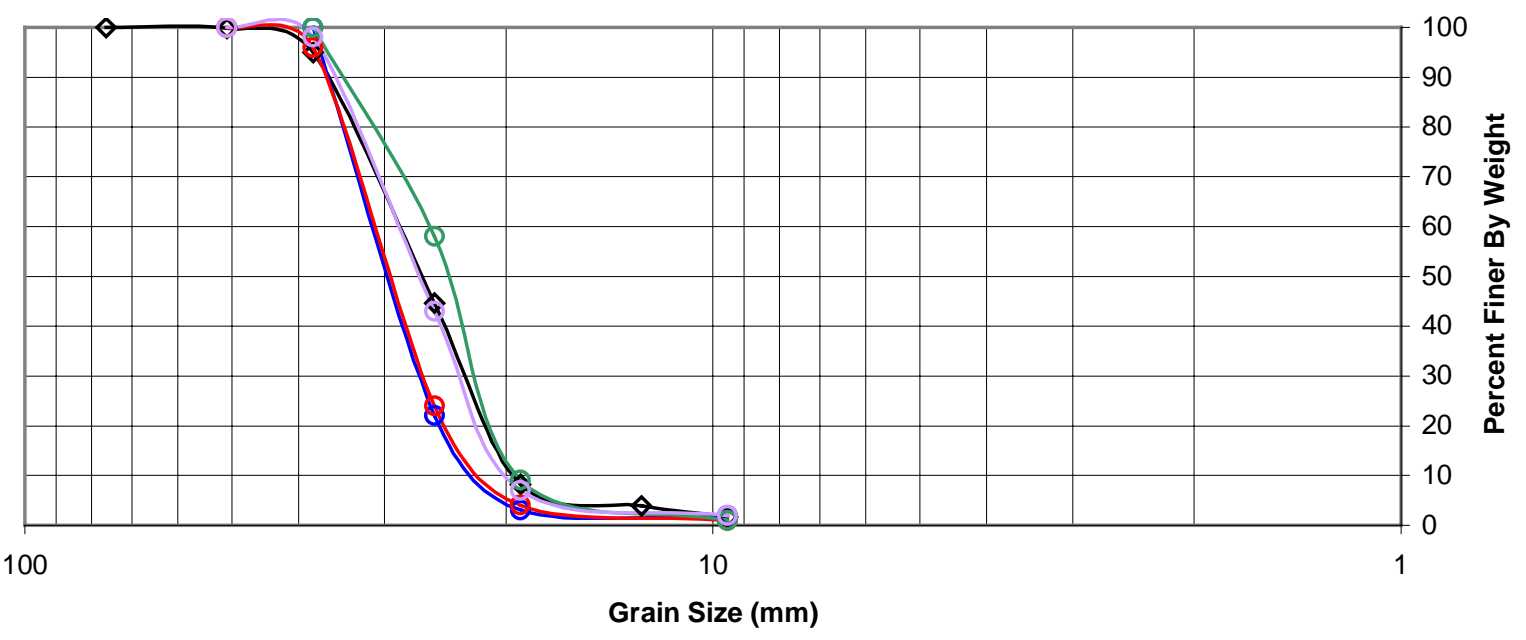

$$
\diamond \text { Greer } \odot \text { MM-A } \odot \text { MM-B } \odot \text { MM-C } \odot-\text { MM-D }
$$

Figure 3.3 Sample Gradation Curves for \#4 Stone 


\section{Material Gradation Curves For \#57 Stone}

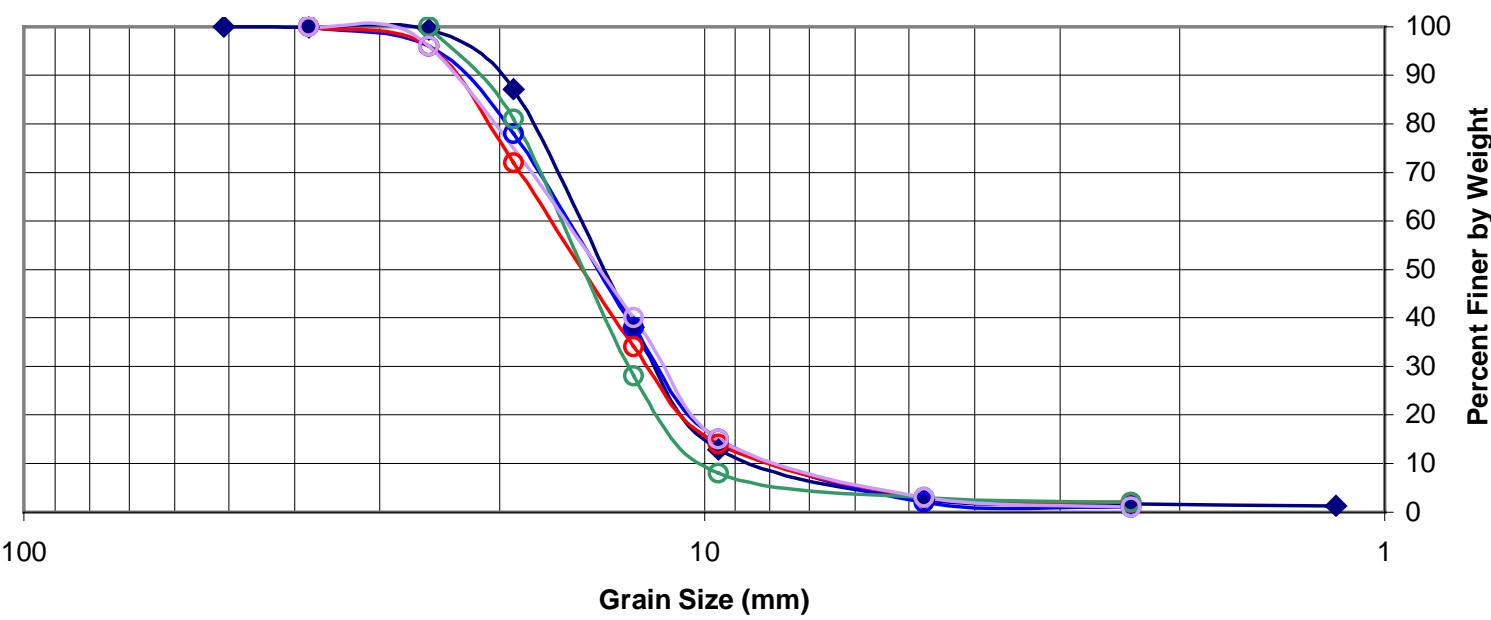

$\neg-$ Greer $\multimap$ MM-A $\odot$ MM-B $-0-$ MM-C $\odot-$ MM-D

Figure 3.4 Sample Gradation Curves for \#57 Stone

Material Gradation Curves For \#8 Stone

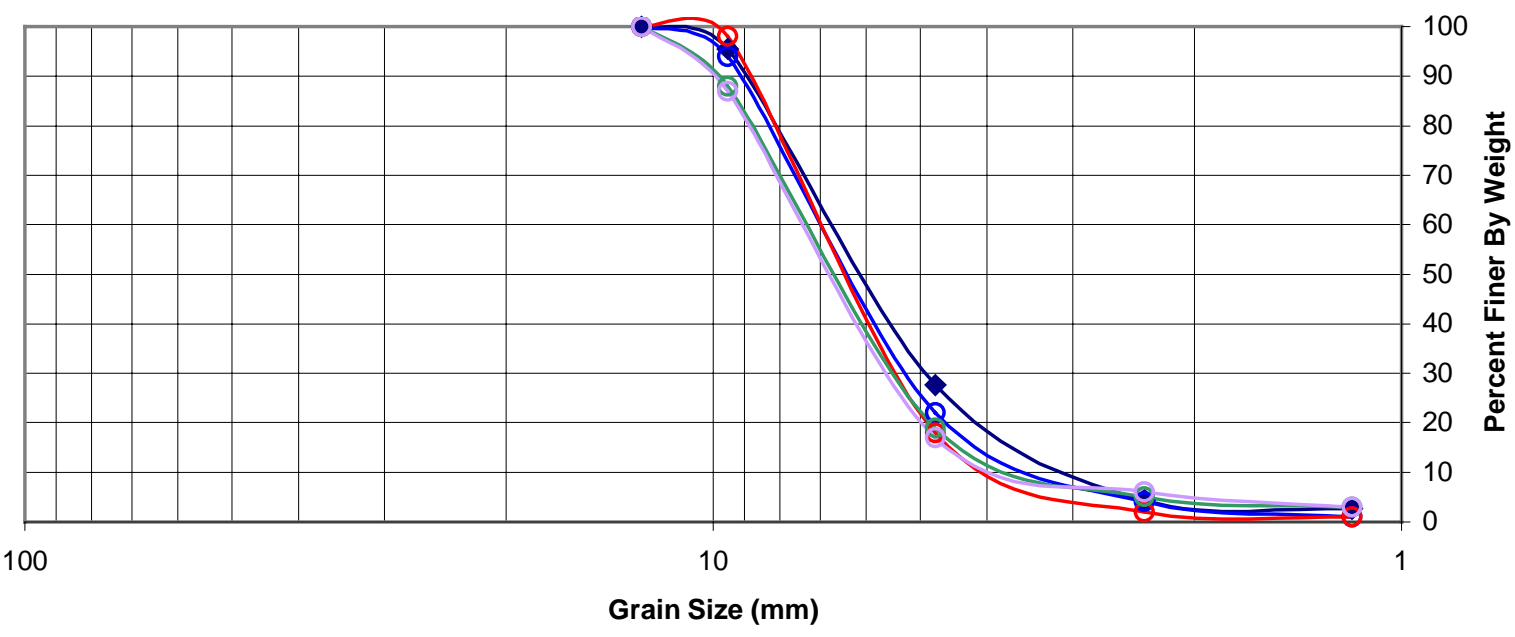

$\rightarrow-$ Greer $\rightarrow$ MM-A - - MM-B $\odot$ - MM-C $\rightleftharpoons$ MM-D

Figure 3.5 Sample Gradation Curves for \#8 Stone 
WV Quarries' Average Aggregate Gradation Curves

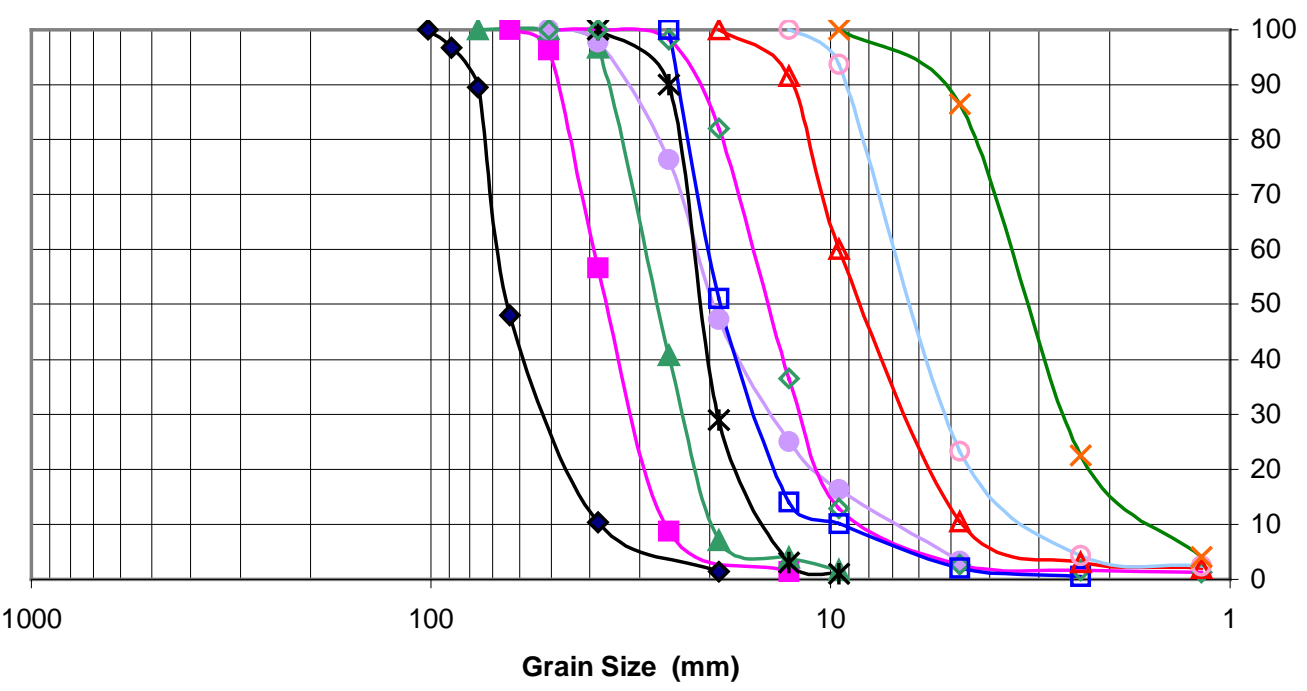

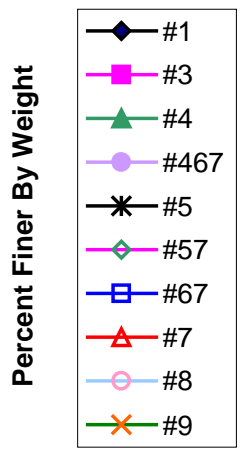

Figure 3.6 Averaged Aggregate Gradation Curves

After the data for the samples was compared, the differences between the five rock samples in Figures 3.3, 3.4, and 3.5 were considered negligible. The sample gradation data was combined in Figure 3.6 that shows ten commonly used rock size gradation curves. Once the range of rock gradations available for state funded projects was obtained, the selection of appropriate rock sizes for the model rock pallets was completed. The results from the quarry investigation provided information that may be used in furthering research of sizing rock for riprap step energy dissipator in the field. Scale model rock pallet (step) construction is discussed in more detail in Chapter 4.

\subsection{Potential Computer Models}

The investigation into the feasibility of an alternative riprap step design delved into the possibility of computer modeling the new design by using HEC-RAS, Version 2.0/2.1 and Riprap Design System, Version 2.0 software packages. After applying the software to several trial runs, it was determined that the software packages could not produce the type of results thought to be pertinent to the project. Therefore, the possibility of utilizing HEC-RAS and Riprap Design System software was dismissed. 


\section{Chapter 4}

\section{Procedure}

\subsection{Development of Experimental Equipment}

At the beginning of the research project the decision was made to construct a flume at WVU to support the testing of physical scale models rather than use an existing facility. The construction of a "custom-built" flume would permit modifications that would likely be necessary over the life of the project. The flume consisted of two tanks to allow for re-circulation of water, necessary piping, and various measuring devices. The flume was designed to accommodate a range of slopes and be within the economic constraints of the project budget, and was to be housed in the Civil Engineering Hydraulics Lab at West Virginia University.

\subsection{Pump Selection}

A centrifugal pump was selected to provide the re-circulation of water necessary for the experiments. The pump was to operate at low head and would need to accommodate a range of flowrates. Preliminary calculations were performed using standard culvert capacity relationships to assure that the flume would properly model flow conditions that are expected in the field. The selection of a 4.25 -inch diameter culvert model required that the maximum flow be approximately 200 gpm under inlet control conditions. This flowrate was used in determining the specifications needed for the pump. For a submerged culvert at the inlet the following equation applies (FHWA

HDS \#5, 1985):

$$
\frac{H W_{i}}{D}=c\left|\frac{Q}{A D^{0.5}}\right|+Y-0.5 S^{2}
$$

Where:

$$
\begin{aligned}
& H W_{i}=\text { Headwater depth above inlet control section invert (ft) } \\
& D=\text { Interior height of culvert Barrel }(\mathrm{ft}) \\
& Q=\text { Discharge (cfs) } \\
& A=\text { Full cross sectional area of culvert barrel }\left(\mathrm{ft}^{2}\right) \\
& S=\text { Culvert Barrel Slope }(\mathrm{ft} / \mathrm{ft}) \\
& Y, c=\text { Constants from inlet control design equations }
\end{aligned}
$$


With the test culvert diameter at 4.25 -inches and assuming 1-foot of headwater and $10 \%$ slope, $\mathrm{Q}$ was found to be approximately $200 \mathrm{gpm}$. The pump selected was purchased from the Interstate Pump Company, and provided slightly over 200 gpm, at 25 feet of head, which provided some excess capacity. The pump setup is shown in Figure 4.1.

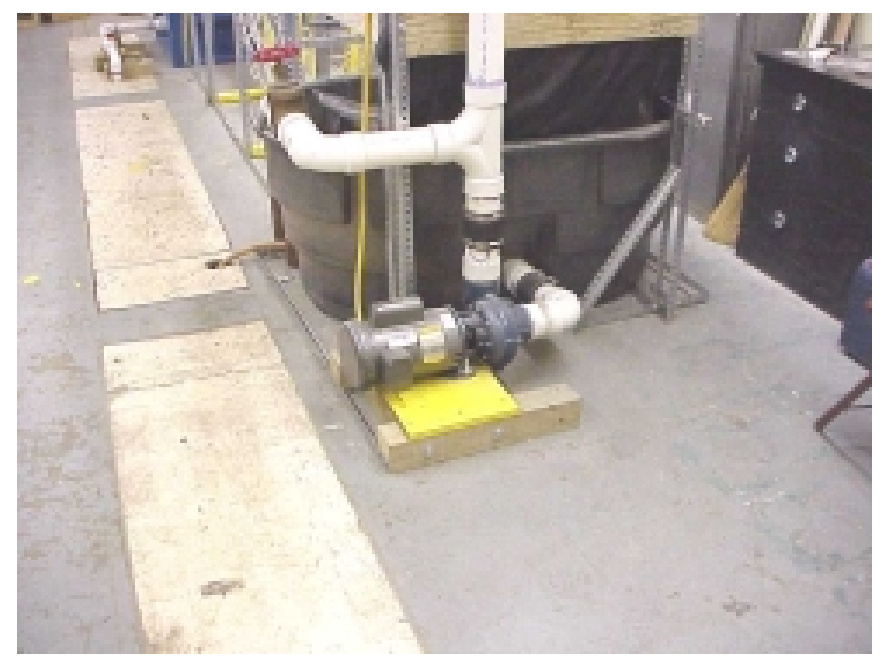

Figure 4.1 Centrifugal Pump Setup

\subsection{Tank Selection}

In order for the flume to properly re-circulate an adequate supply of water, two tanks were needed. The upstream tank needed to be tall, to supply sufficient head, while the downstream tank needed to be short in height so that flow could exit the culvert and be collected by gravity. It also needed to meet the volume requirements on the intake side of the pump. It was determined that the necessary volume for the operation of the flume was approximately 500 gallons. The downstream tank, a 150-gallon oval agricultural tank, was obtained from an agricultural supply store, and is shown in Figure 4.2. Due to the unusual dimensional requirements of the upstream tank, it was impossible to obtain the tank through commercial providers. Therefore, the decision was made to construct a custom designed upstream tank. The upstream tank was constructed from $3 / 4$-inch pressure treated plywood reinforced with $2 \times 4$ framing. The tank dimensions were 3' x 3' x 5' with an approximate volume of 340 gallons. A square opening, $1.5^{\prime} \times 1.5^{\prime}$, was cut in the front of the upstream tank in 


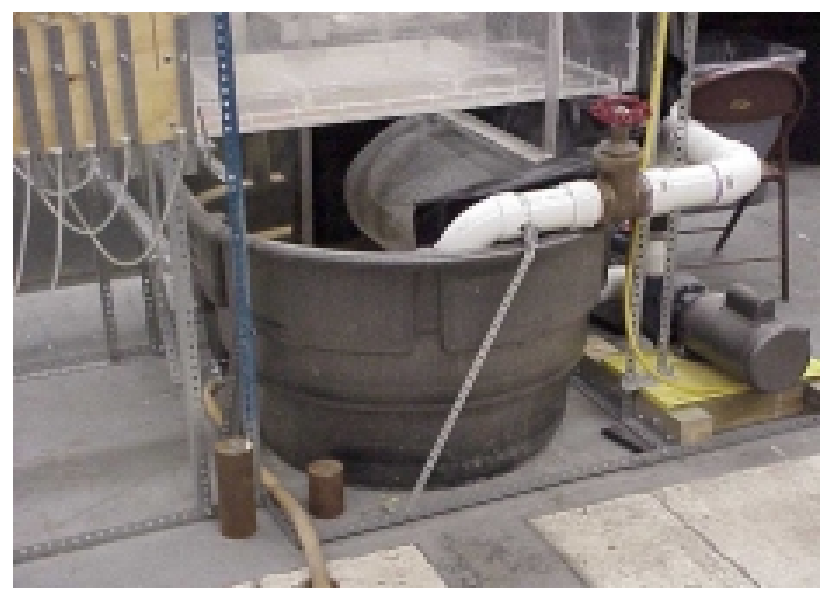

Figure 4.2 Downstream Tank

preparation for the addition of the inlet culvert box. The inlet box will be described in greater detail in another section. The completed blue and yellow upstream tank is shown in Figure 4.3. In the initial design stage of the upstream tank, a pond liner was to be used as a bladder for water containment. This proved difficult to install since the seams could not be easily fused to prevent water leakage. This problem was rectified by the removal of the pond liner and application of a waterproof coating on the inside surface of the plywood. The coating chosen was an elastomeric polymer, originally intended for sealing roofs. After several applications of the polymer, the tank was sufficiently waterproofed. It was found to be necessary to reinforce the outside of the upstream tank with $2 \times 4$ framing due to hydrostatic forces.

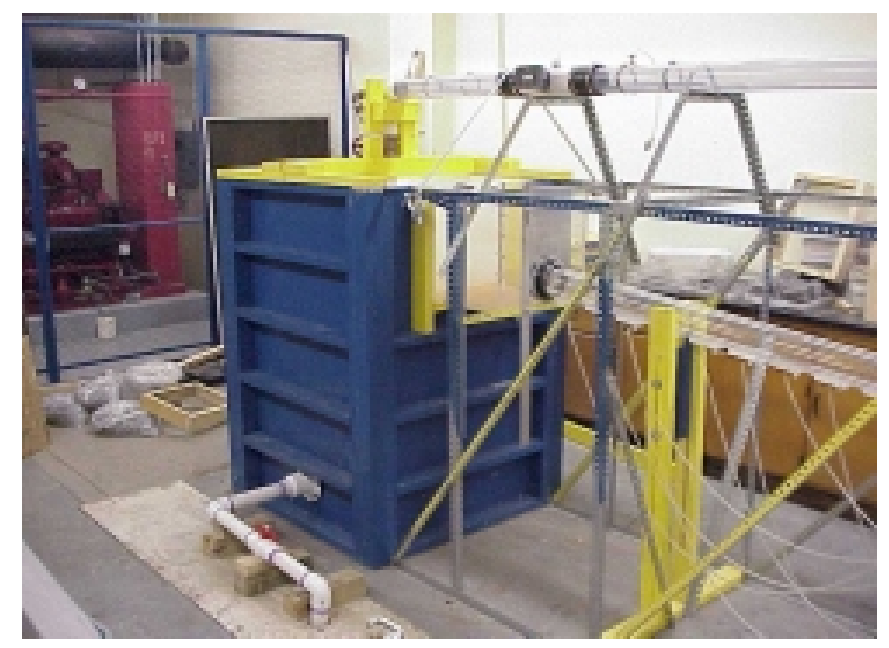

Figure 4.3 Upstream Tank 
The outside of the upstream tank was painted for aesthetic purposes as well as mold prevention due to the constant high humidity in the hydraulics lab.

\subsection{Frame Development}

In order to provide a structure to accommodate piping, piezometer bank, flowmeter, slope adjustment, testing channel, and to keep tanks in a fixed position, a support frame was constructed. The frame consisted of perforated, galvanized 1.25-inch angle iron, which provided an easy means of construction. The framing was simply cut to size and bolted together with 5/16-inch bolts. Trapezoidal braces were constructed on the top of the frame to provide a cradle for the return flow piping. The frame also allows for slope adjustment, which will be discussed in greater detail in a later section.

\subsection{Inlet and Outlet Boxes}

Two cast acrylic boxes were constructed to allow for visual examination of physical flow phenomenon present at this inlet and outlet of the culvert. The inlet box dimensions were $1.5^{\prime}$ x $1.5^{\prime}$ x $1.5^{\prime}$ and it was constructed from 0.5 -inch cast acrylic. The inlet box was constructed to create uniform and steady flow conditions approaching the inlet of the model culvert. The inlet box is shown below in Figure 4.4.

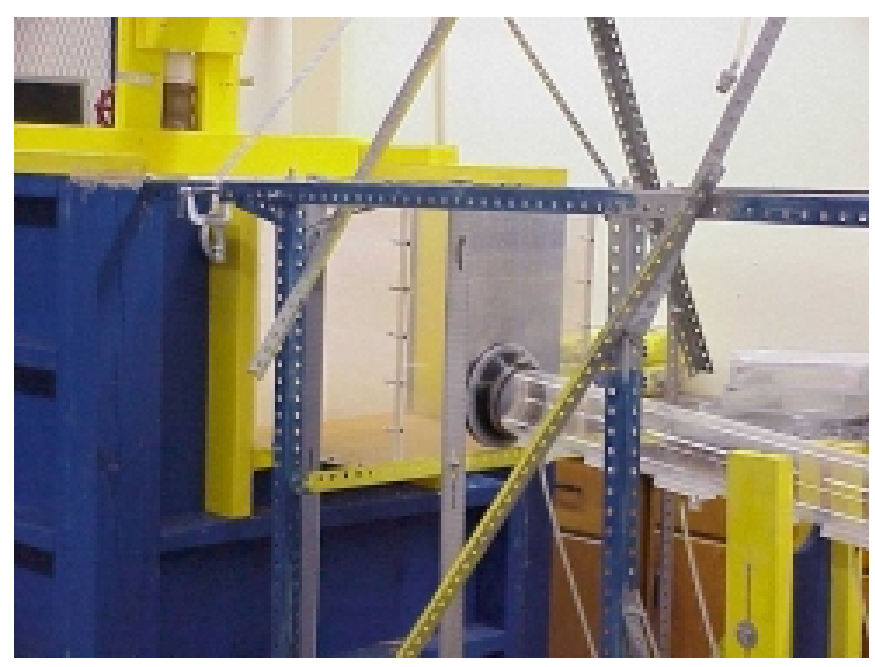

Figure 4.4 Inlet Box 
The outlet box dimensions were 2' x 4' x 1.04' and was also constructed from 0.5 -inch cast acrylic. Twenty, 2-inch holes and eight, 1.5-inch holes were drilled out on the downstream end of the outlet box to provide adequate drainage exiting through the floor of the outlet box. A screen was constructed from 0.25 -inch hardware cloth and placed over the drilled out holes to prevent debris from entering the downstream tank. A coiled section of hardware cloth was suspended from an angle iron brace, directly below the drilled holes in the outlet box, into the

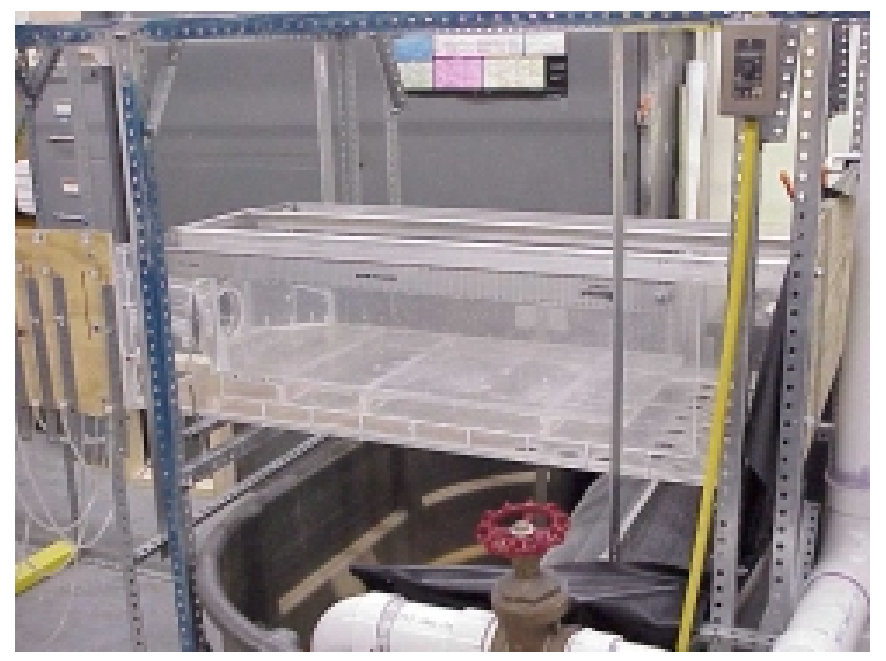

Figure 4.5 Outlet Box

upper portion of the downstream tank. The coiled hardware cloth prevented air bubbles created by descending, splashing flow into the tank from being pumped throughout the system and producing erroneous flowrate readings. The purpose of the outlet box construction was to serve as a container for the hydraulic models. A testing channel constructed from the same 0.5 -inch cast acrylic was placed within the outlet box. This testing channel will be discussed in greater detail in another section. The outlet box is shown in Figure 4.5.

\subsection{Piping Assembly}

The water supply piping network for the testing flume consisted of 3-inch PVC sewer pipe. Clear acrylic pipe was selected for the model culvert. The PVC pipe proved easy to work with as all fittings could be glued together and cutting the pipe to size could be accomplished with simple tools. Two, 3-inch gate valves provided the flow adjustments needed for experimental runs. One gate valve was located at the upstream tank, near the end of the supply line from the pump, and the flow could be reduced or increased by the valve. The second gate valve was placed at the outlet tank and served as a bypass valve. To provide a low flow capability, the bypass valve was opened to allow some of the supply line flow to re-circulate back into the outlet tank. This bypass was necessary in 
order to maintain a minimum required pump flowrate during low discharge testing, about $50 \mathrm{gpm}$. The supply line was extended vertically downward into the upstream tank so that the submerged jet would dissipate excess turbulent energy in the flow prior to reaching the culvert inlet. The test culvert was constructed of 4.25 -inch inside diameter transparent acrylic pipe. One major problem with the test culvert was keeping it sealed at the inlet and outlet boxes, while still allowing for slope adjustment. Sealing was accomplished by the use of two rubber grommets attached to the inlet and outlet boxes with custom washers machined from standard plastic stock. The grommets were attached to the pipe with pipe clamps and proved extremely effective at sealing the test culvert and allowing for slope adjustment. The test culvert is shown in Figure 4.6.

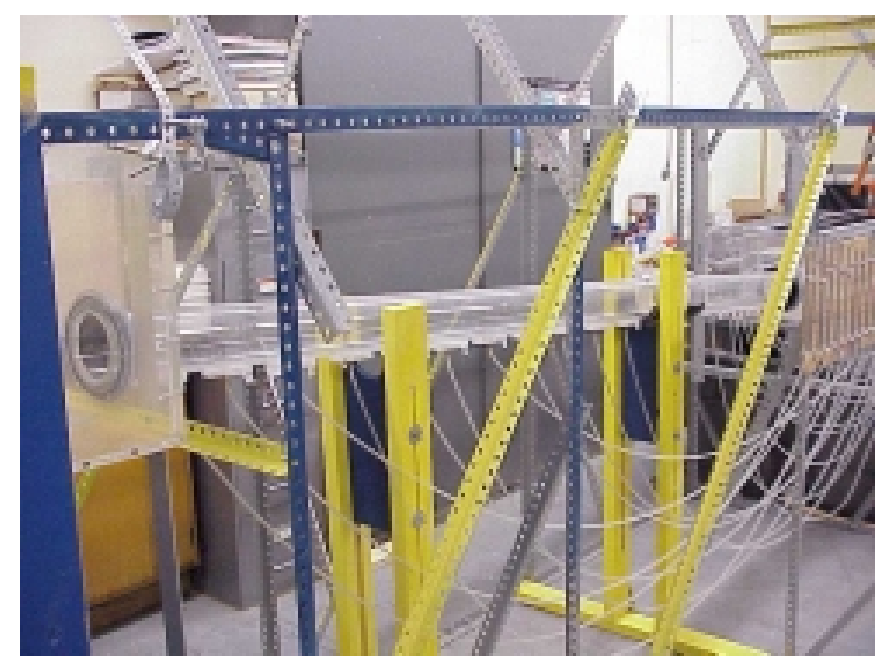

Figure 4.6 Test Culvert

\subsection{Measuring Devices}

To provide data crucial for hydraulic calculations, several measuring devices were used. The devices implemented in the experimental procedures are as follows:
- $\quad$ Flowmeter
- $\quad$ Piezometer Board
- $\quad$ Three-Point Depth Gage
- $\quad$ Pitot Tube Device
- $\quad$ Slope Adjustment Devices

The measuring devices are discussed in further detail in this section, along with associated problems, corrections, and construction considerations where appropriate. 


\subsubsection{Flowmeter}

A flowmeter was purchased that reads flowrate in gallons per minute over a range of $40-450 \mathrm{gpm}$ with \pm $2.0 \%$ full-scale linearity and $\pm 1.0 \%$ full-scale repeatability. The flowmeter is shown in Figure 4.7.

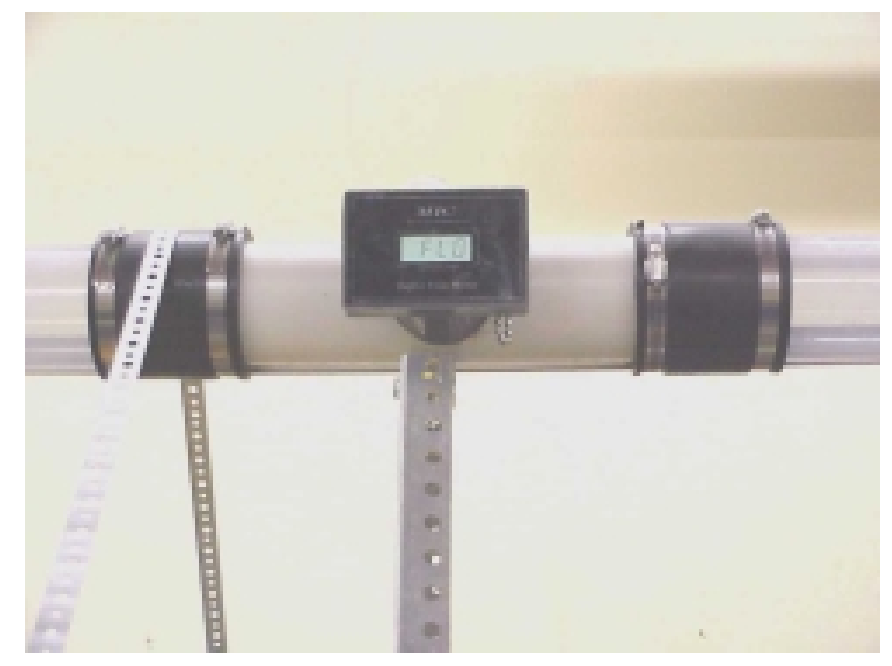

Figure 4.7 Flowmeter

Initially, the supply line, from the downstream to upstream tank, contained a double elbow bend upstream of the flowmeter. This location produced erroneous flowmeter readings with high fluctuations. It was determined that the double bend was producing vortices that were causing the incorrect readings. It was also suspected that air was being trapped at certain locations in the supply line. To correct these problems, three modifications were made. First, the double elbow bend was removed and replaced with a single elbow. Second, the overhead supply line was replaced with translucent 3-inch PVC pipe to allow for visual inspection of the flow entering and exiting the flowmeter. Third, several air bleeds were placed along the overhead supply line to remove any trapped air from the line. These corrections eliminated the problems mentioned, and provided greater assurance of accurate measurements. 


\subsubsection{Piezometer Board}

In order to measure the water surface elevation at various locations in the test culvert, a piezometer board was constructed. The board consisted of nineteen, 1/4-inch Plexiglas tubes attached to a 1/4-inch plywood board. Scales were mounted next to the tubes with bolts and wing nuts that could slide vertically, in a milled slot, to allow for the establishment of a zero reading. The tubes were attached to tygon tubing at the bottom, and connected to the test culvert at various points through brass fittings. First, 1/32-inch diameter holes were drilled in the test culvert invert to serve as the piezometer tap. The brass fittings were threaded into small rectangular blocks of Plexiglas that were glued to the test culvert around the previously drilled holes. This produced a row of piezometer tap measurements along the invert of the test culvert from which uniform flow depth could be established. The piezometer setup is shown in Figure 4.8.

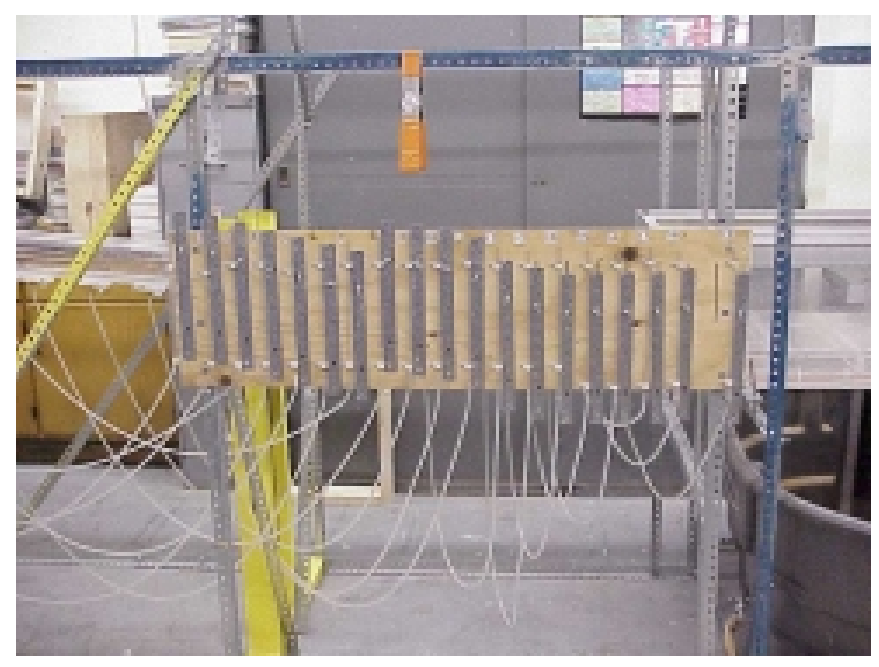

Figure 4.8 Piezometer Board

\subsubsection{Three-point Depth Gage}

To obtain water depths, a point gage was borrowed from an existing flume and modified by adding two lateral points (prongs). The modified three-point depth gage was to provide a more accurate representation of the average flow depth along any cross section in the test channel. The point gage had a verneir scale that was accurate to 0.001-foot. The scale is shown in Figure 4.9. First, the center point was lowered to the water surface and a reading was taken. Next the lateral points were lowered and another reading was taken. The average of the "inside" and "outside" depth reading is the average flow depth for that cross section. A track was constructed of $1 \frac{1}{1 / 2}$-inch 
aluminum angle that allowed the point gage to travel along the testing channel so depth reading could be taken at various points. To provide longitudinal measurement along the testing channel, a scale was bolted on the outside of the outlet box and a pointer was attached to the side of the gage. The three-point depth gage is shown in Figure 4.10 .

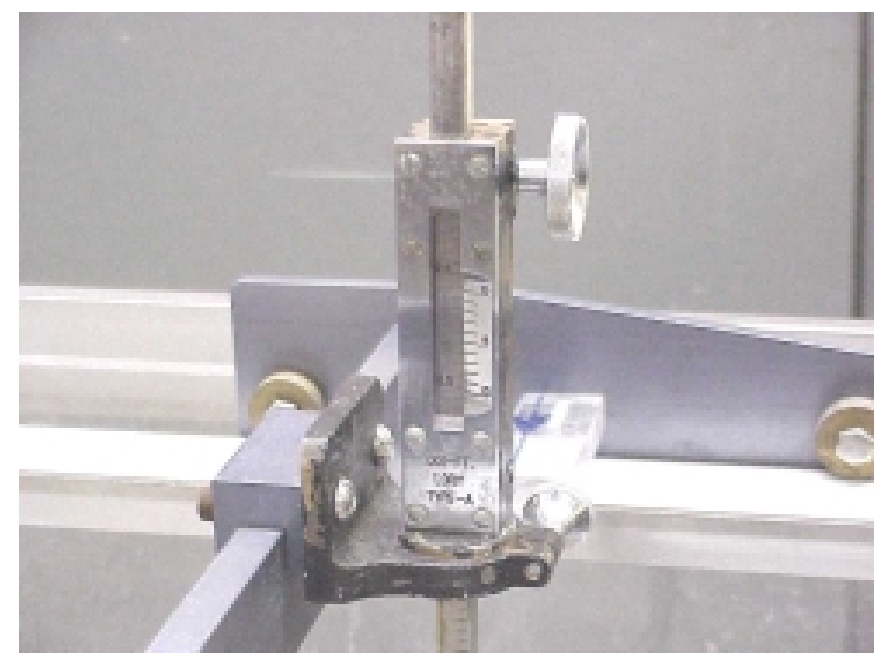

Figure 4.9 Point Gage Scale

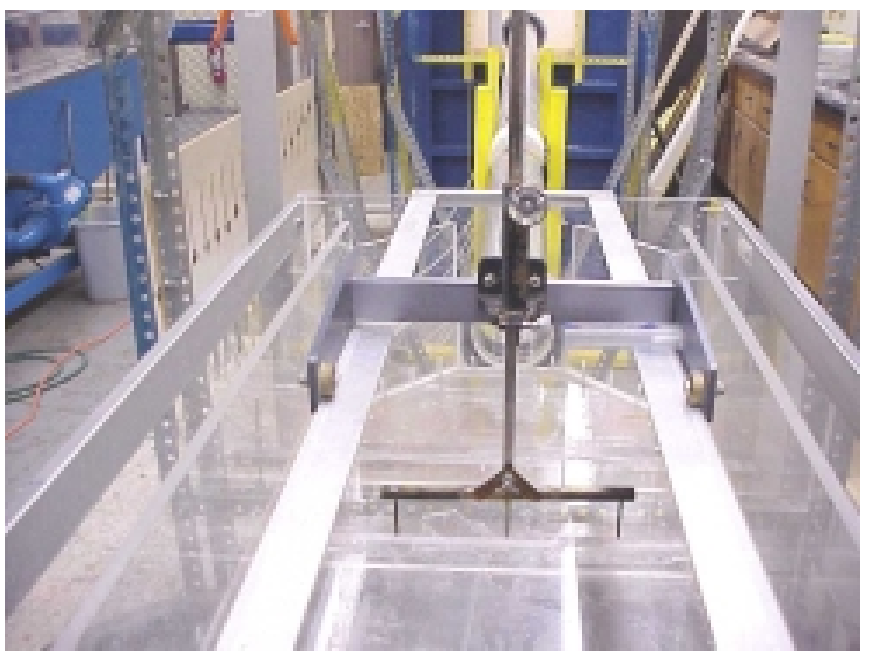

Figure 4.10 Three-Point Depth Gage

Table 4.1 shows the distance from the culvert outlet to the point where each of the water surface elevation readings were taken. Figure 4.11 shows the positions of the cross-section where each of the water surface elevation readings along the horizontal length of the testing channel were obtained. 


\begin{tabular}{|c|c|}
\hline Table 4.1 & $\begin{array}{l}\text { Water Surface Elevation } \\
\text { Readings }\end{array}$ \\
\hline $\begin{array}{c}\text { Test } \\
\text { Channel } \\
\text { Cross- } \\
\text { Section }\end{array}$ & $\begin{array}{c}\text { Horizontal Distance From } \\
\text { Culvert (mm) }\end{array}$ \\
\hline AA & 139.5 \\
\hline A & 269.5 \\
\hline B & 434.5 \\
\hline C & 624.5 \\
\hline D & 779.5 \\
\hline DD & 879.5 \\
\hline E & 931.5 \\
\hline
\end{tabular}

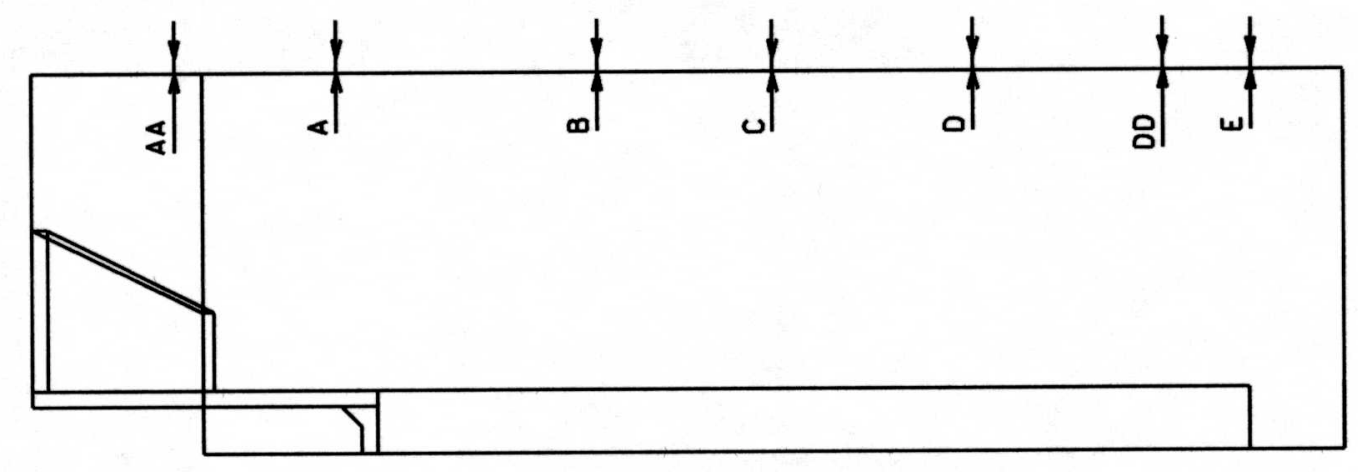

Figure 4.11 Position of Water Surface Elevation Readings

\subsubsection{Pitot Tube Device}

In order to more accurately compute the energy grade line for various model tests, it was decided that the velocity profile for the rectangular test section needed to be established. A Pitot tube was constructed using $5 \mathrm{~mm}-$ glass tubing. When this tube was first tested there were many oscillations present, so a 3-milimeter-glass tube was inserted inside the horizontal section of the existing tube to produce a damping effect. Next the Pitot tube was 
clamped into a Plexiglas cradle and then fitted to a Plexiglas slide and track to allow for vertical and lateral adjustments. A metric scale and pointer were then fixed to the apparatus to allow for depth and total head measurements. The rectangular channel cross section was then divided into 15 evenly spaced subsections and tic marks were placed on the surface of the Plexiglas track. The completed apparatus can be seen in Figures 4.12 and 4.13 .

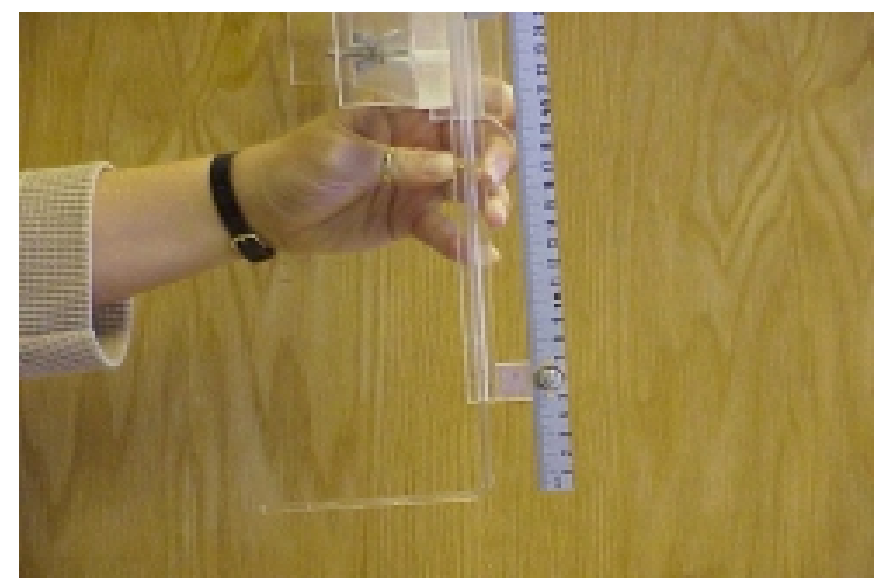

Figure 4.12 Pitot Device (side view)

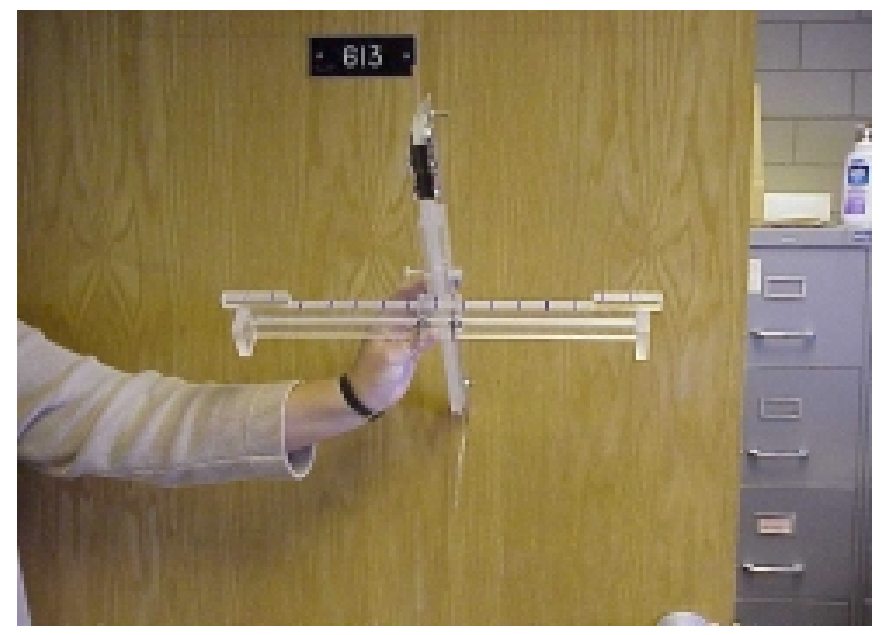

Figure 4.13 Pitot Device (front view) 
In applying the Pitot tube for establishing the velocity profile the Energy equation was used:

$$
\frac{p}{\gamma}+\frac{V^{2}}{2 g}+z=\text { PitotMeasurementAboveDatum }
$$

Where:

$$
\begin{aligned}
& p=\text { Pressure } \\
& \gamma=\text { Specific weight of water } \\
& V=\text { Velocity } \\
& g=\text { Acceleration due to gravity } \\
& z=\text { Height above zero datum }
\end{aligned}
$$

The first term, $\frac{p}{\gamma}$, represents local pressure head, is assumed to be the depth of water above the centerline of the Pitot tube, a hydrostatic assumption. The second term, $\frac{V^{2}}{2 g}$ which represents the velocity head, was computed in $\mathrm{mm} / \mathrm{s}$ with the value for acceleration due to gravity being $9807 \mathrm{~mm} / \mathrm{s}^{2}$. The last term, $z$, represents the datum elevation that was taken as the elevation of the false floor in the rectangular channel. The datum was established by placing the center of the Pitot tube at the surface of the false floor and recording the depth from the scale attached to the Pitot apparatus.

To determine the value for the velocity correction factor, alpha, the following expression was used:

$$
\alpha=\frac{1 u^{3} d A}{V^{3} A}
$$

Where $\alpha$ is the value for the velocity correction factor. The point velocity found from the Pitot tube is represented by $u$. The term $\mathrm{dA}$ is each incremental area in which a corresponding measurement was taken. The values in the numerator are then summed from 1 to 15 , as there were 15 sections of measurement. In the denominator, $\mathrm{V}$ represents the average velocity and $\mathrm{A}$ is the total cross-sectional area of the flow.

\subsubsection{Slope Adjustment Devices}

Slopes of 2, 4, 6 and $8 \%$ were selected for testing in the experimental runs. Therefore it was crucial that the flume could be adjusted accordingly. To allow for slope variation, the outlet box rested on adjustable supports at the front and back of the box. The supports could be bolted at incremental heights on the vertical columns on either 
side of the box. Two pieces of all-thread steel rod were attached to the support on the left and right of the box, along with another piece of steel angle. This piece of steel angle was adjusted by lifting up the box and turning nuts on the threaded rod to achieve the desired setting. Next, a datum was established by attaching five scales to the frame, using surveying equipment, and then all slope adjustments were calculated based on that elevation. One scale was placed at the test culvert inlet and the other four scales around the outlet box so it could easily be leveled. The slope adjustment setup is shown in Figure 4.14. A close-up of the support adjustment is shown in Figure 4.15.

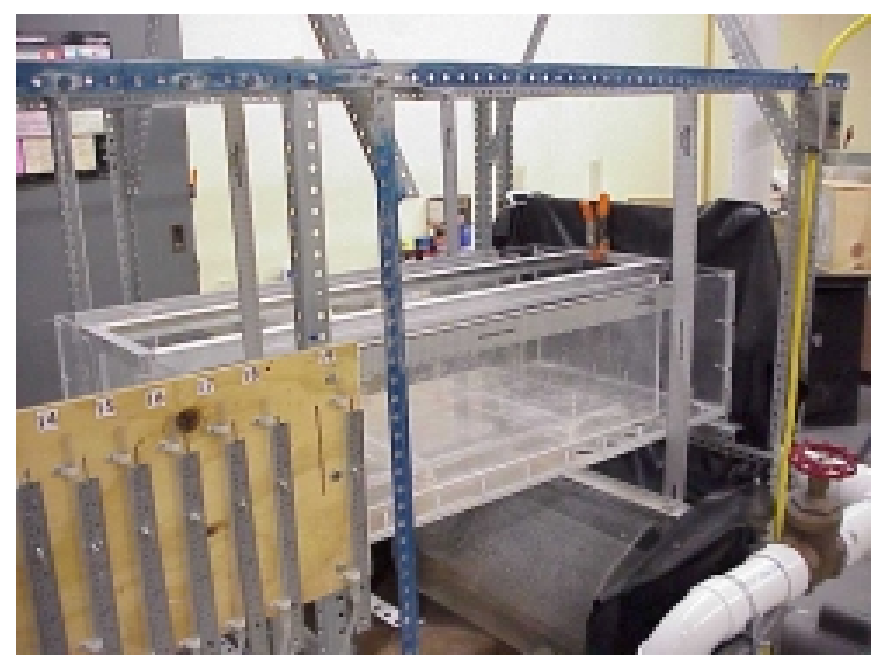

Figure 4.14 Outlet Box Slope Adjustment

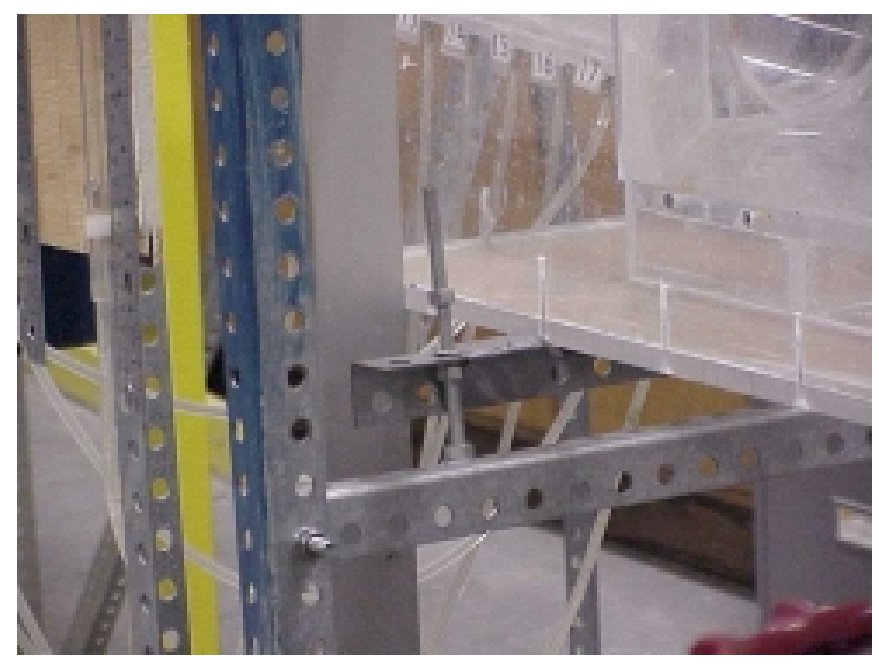

Figure 4.15 Support Adjustment 


\subsection{Model Construction}

Four principal components were required to perform the planned hydraulic model tests of riprap step: 1) a culvert outlet configuration consisting of headwall, wingwall, and apron, 2) a testing channel, 3) the cast acrylic pallets, and 4) the rock pallets to be tested. Since plans were available for the existing culvert apron design, the scale model was easily constructed of 0.5 -inch thick cast acrylic. All dimensions were expressed as a function of culvert diameter and the scale model was constructed based on this non-dimensionality. A rectangular testing channel was used to contain the flow within lateral boundaries. To produce the rectangular channel, two vertical walls were attached to the model apron, and two concrete pallets were built to simulate downstream channel conditions. The pallet, either the smooth cast acrylic or the rock that was closest to the apron was referred to as the Zone 1 pallet, and the farthest downstream pallet as the Zone 2 pallet. The Zone 2 pallet was raised as required to simulate a smooth or riprap step as desired. Two vertical cast acrylic extensions were added to the wingwalls to prevent flows from short-circuiting over the wingwalls due to splashing, etc. The testing channel is shown in Figure 4.16 .

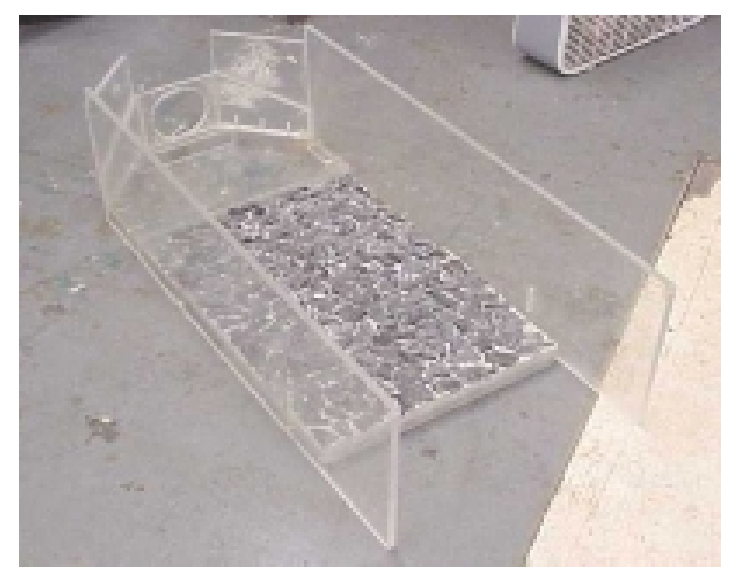

Figure 4.16 Testing Channel

Zone 1 pallets, either smooth cast acrylic or rough rock, were constructed so that an averaged flow depth remained at zero datum. Twelve Zone 2 pallets, shown in Table 4.2, were constructed, six cast acrylic and six rock. 


\begin{tabular}{|c|c|c|}
\hline Table 4.2 & \multicolumn{2}{|c|}{$\begin{array}{l}\text { Zone 2 Pallets } \\
\text { Nominal Step Heights }\end{array}$} \\
\hline $\begin{array}{c}\text { Cast Acrylic } \\
\text { (Actual Height) }\end{array}$ & $\begin{array}{c}\text { Rock Height } \\
\text { (Area Averaged) }\end{array}$ & $\begin{array}{c}\text { SI Units } \\
(\mathrm{mm})\end{array}$ \\
\hline 0.0 & 0.0 & 0.00 \\
\hline 0.5 & 0.5 & 12.7 \\
\hline 1.0 & 1.0 & 25.4 \\
\hline 1.5 & 1.5 & 38.1 \\
\hline 2.0 & 2.0 & 50.8 \\
\hline 2.5 & 2.5 & 63.5 \\
\hline
\end{tabular}

The smooth cast acrylic pallets were to be used as a smooth step reference model for the rough rock pallets (riprap step). The pallets are discussed in the following sections. For simplicity purposes, the steps will be referenced by inches and not SI values.

\subsubsection{Cast Acrylic Pallets}

The 0.5-inch cast acrylic pallets, referred to as smooth pallets, were constructed for both Zones 1 and 2 . A single pallet, $352 \mathrm{~mm} \times 413 \mathrm{~mm} \times 12.7 \mathrm{~mm}$, was constructed for Zone 1 . The Zone 1 pallet was cemented in place at a location where the upper surface would be at zero datum. Six Zone 2 pallets, $300 \mathrm{~mm}$ long and $413 \mathrm{~mm}$ wide. The pallets were precisely cut and constructed to obtain the desired range of step heights as listed in Table 4.2. All construction joints for the smooth pallets in Zone 2 were sealed with Silicon cement. At the base of each step, with exception of the 0.0-inch step, a section of rubber weather door stripping was attached with Silicon cement to the inner portion of the step's flow impact panel as well as the inner portion of the step's back panel. Glue strips prevented an unaccountable loss of flow under the step. Given the very careful construction of the steps, a very tight fit was achieved between the test channel wall and the wall of the step preventing significant bypassing of flow.

Realizing a need for ease of step removal and placement, one hole was drilled through both sides of the test channel into the in-place step. Metal pins were inserted into the holes to hold the steps in place. This process was repeated for each of the six steps. The removal and replacement process involved: 1) removing pins, 2) removing step, 3) placing new step, 4) inserting pins, and 5) taking measurements for the next step height. Photographs of the smooth step assembly are shown in Figures 4.17 and 4.18. 


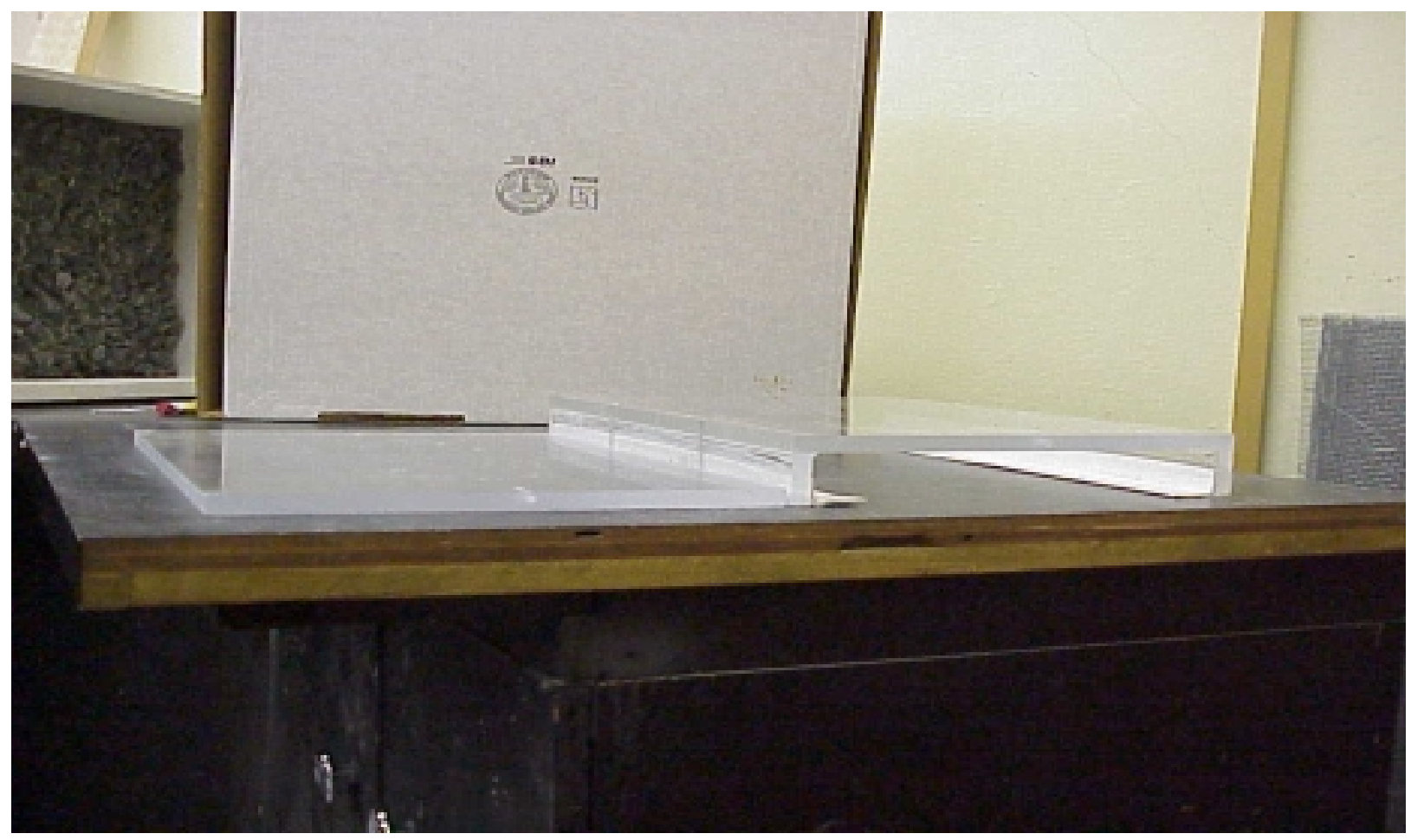

Figure 4.17 Sample Cast Acrylic Assembly Profile

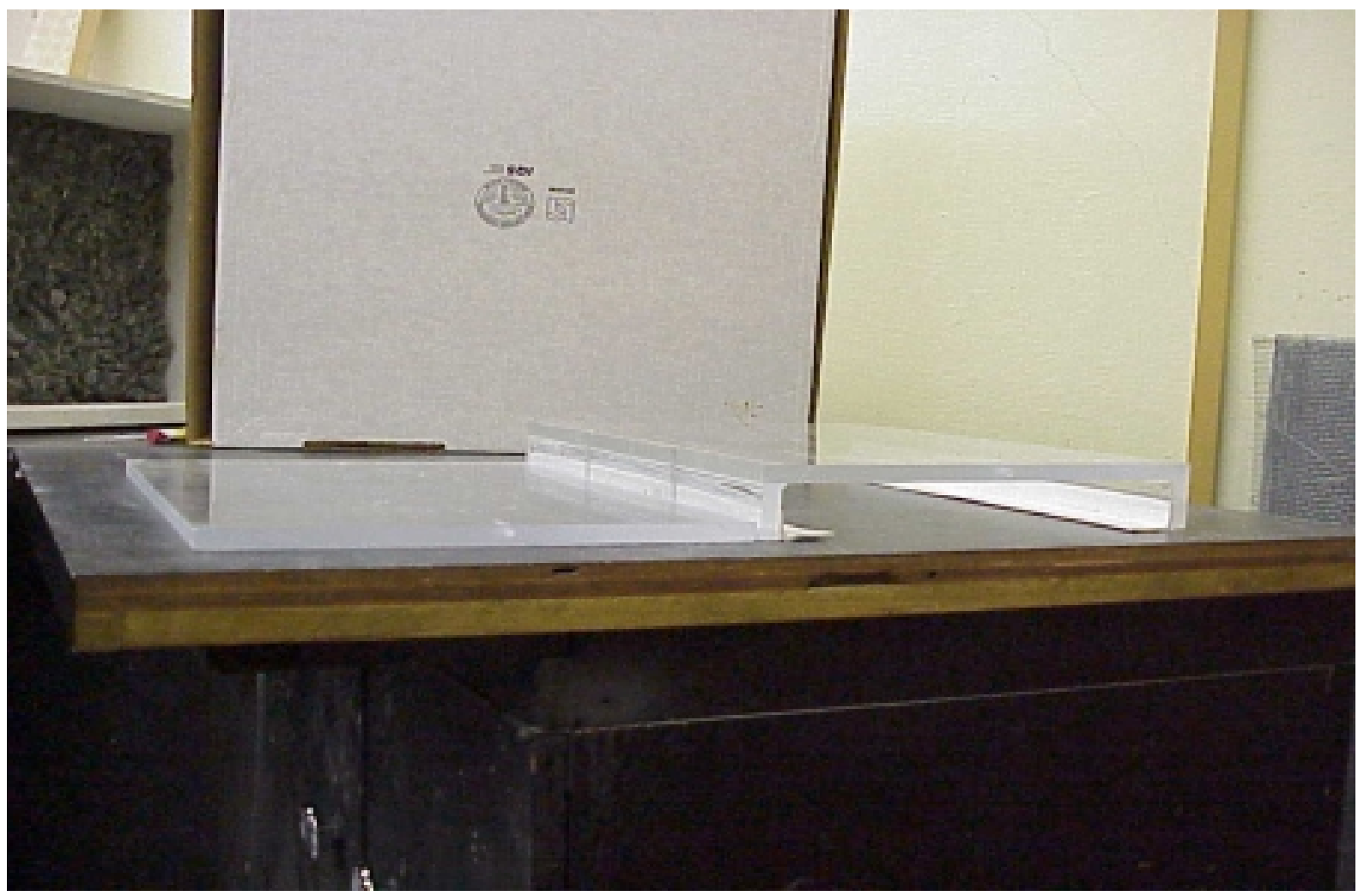

Figure 4.18 Sample Cast Acrylic Assembly 


\subsubsection{Rock Pallets}

Rock samples, ranging from 6-inch stone to \#8 stone, were obtained from Greer quarry. The stone was thoroughly cleaned and dried. After representative stone samples were inspected, dimensions and characteristics were recorded and shown in Table 4.3 below.

\begin{tabular}{|c|c|c|c|c|c|}
\hline Table 4.3 & \multicolumn{5}{|c|}{ Stone Sample Characteristics and Dimensions (Greer Quarry) } \\
\hline $\begin{array}{l}\text { Stone Type } \\
\text { (Size) }\end{array}$ & Number of Sides & $\begin{array}{l}\text { Length } \\
\text { (mm) }\end{array}$ & $\begin{array}{l}\text { Width } \\
\text { (mm) }\end{array}$ & \begin{tabular}{|c|}
$\begin{array}{c}\text { Height } \\
(\mathrm{mm})\end{array}$ \\
\end{tabular} & $\begin{array}{c}\text { Circumference } \\
(\mathrm{mm})\end{array}$ \\
\hline 6" & 6 & 160 & 110 & 90 & 353 \\
\hline 6" & 6 & 140 & 70 & 65 & 310 \\
\hline 6" & 4 & 140 & 103 & 90 & 305 \\
\hline 6" & 6 & 115 & 100 & 86 & 242 \\
\hline $6 "$ & 5 & 120 & 100 & 74 & 338 \\
\hline 6" & 5 & 140 & 90 & 80 & 290 \\
\hline 1 & 7 & 50 & 45 & 38 & 135 \\
\hline 1 & 5 & 60 & 47 & 30 & 138 \\
\hline 1 & 5 & 80 & 47 & 42 & 145 \\
\hline 1 & 4 & 85 & 80 & 72 & 200 \\
\hline 1 & 7 & 57 & 37 & 33 & 150 \\
\hline 1 & 3 & 112 & 60 & 48 & 165 \\
\hline 1 & 5 & 70 & 50 & 43 & 150 \\
\hline 1 & 6 & 55 & 50 & 38 & 155 \\
\hline 1 & 6 & 105 & 65 & 60 & 225 \\
\hline 1 & 5 & 60 & 36 & 29 & 125 \\
\hline 4 & 4 & 70 & 37 & 35 & 140 \\
\hline 4 & 4 & 46 & 35 & 32 & 118 \\
\hline 4 & 4 & 37 & 29 & 31 & 95 \\
\hline 4 & 5 & 55 & 31 & 27 & 120 \\
\hline 4 & 5 & 53 & 45 & 30 & 110 \\
\hline 4 & 5 & 36 & 35 & 22 & 96 \\
\hline 4 & 4 & 75 & 61 & 20 & 130 \\
\hline 4 & 4 & 45 & 36 & 20 & 105 \\
\hline 4 & 6 & 49 & 18 & 12 & 75 \\
\hline 4 & 3 & 41 & 20 & 25 & 72 \\
\hline 4 & 5 & 28 & 22 & 17 & 82 \\
\hline 4 & 5 & 42 & 33 & 25 & 95 \\
\hline 57 & 5 & 32 & 15 & 19 & 85 \\
\hline 57 & 4 & 38 & 22 & 19 & 72 \\
\hline 57 & 5 & 22 & 14 & 13 & 60 \\
\hline 57 & 6 & 28 & 20 & 13 & 63 \\
\hline 57 & 5 & 27 & 25 & 16 & 80 \\
\hline 57 & 4 & 29 & 23 & 14 & 64 \\
\hline 57 & 5 & 28 & 11 & 12 & 43 \\
\hline 57 & 4 & 33 & 17 & 11 & 55 \\
\hline 57 & 4 & 17 & 15 & 10 & 40 \\
\hline 57 & 4 & 19 & 14 & 14 & 52 \\
\hline 57 & 5 & 30 & 28 & 8 & 61 \\
\hline
\end{tabular}




\begin{tabular}{|c|c|c|c|c|c|}
\hline $\begin{array}{c}\text { Table 4.3 } \\
\text { (Cont.) }\end{array}$ & Stone Sample Characteristics and Dimensions (Greer Quarry) \\
\hline $\begin{array}{c}\text { Stone Type } \\
\text { (Size) }\end{array}$ & Number of Sides & $\begin{array}{c}\text { Length } \\
(\mathbf{m m})\end{array}$ & $\begin{array}{c}\text { Width } \\
(\mathbf{m m})\end{array}$ & $\begin{array}{c}\text { Height } \\
(\mathbf{m m})\end{array}$ & $\begin{array}{c}\text { Circumference } \\
(\mathbf{m m})\end{array}$ \\
\hline 67 & 5 & 20 & 13 & 20 & 57 \\
\hline 67 & 6 & 17 & 16 & 13 & 51 \\
\hline 67 & 4 & 19 & 17 & 16 & 55 \\
\hline 67 & 6 & 21 & 19 & 18 & 62 \\
\hline 67 & 4 & 22 & 16 & 17 & 55 \\
\hline 67 & 5 & 23 & 12 & 14 & 50 \\
\hline 67 & 4 & 13 & 10 & 11 & 35 \\
\hline 67 & 4 & 16 & 12 & 8 & 40 \\
\hline 67 & 5 & 15 & 9 & 8 & 31 \\
\hline 67 & 5 & 15 & 12 & 10 & 36 \\
\hline 67 & 4 & 20 & 13 & 10 & 29 \\
\hline 8 & 4 & 16 & 11 & 8 & 27 \\
\hline 8 & 4 & 15 & 10 & 8 & 35 \\
\hline 8 & 4 & 18 & 8 & 12 & 35 \\
\hline 8 & 5 & 20 & 10 & 8 & 30 \\
\hline 8 & 4 & 14 & 10 & 8 & \\
\hline
\end{tabular}

Six rock gradations were randomly selected to construct the Zone 2 rock pallets listed in Section 4.8. Table 4.4 shows the relationship between step equivalent, pallet number and rock type.

\begin{tabular}{|c|c|c|}
\hline Table 4.4 & $\begin{array}{l}\text { Rock Step Equivalent, Palle } \\
\text { Type }\end{array}$ & Rock \\
\hline \begin{tabular}{|c|} 
Step \\
Equivalent \\
(in)
\end{tabular} & $\begin{array}{l}\text { Pallet } \\
\text { Number }\end{array}$ & $\begin{array}{l}\text { Rock } \\
\text { Type }\end{array}$ \\
\hline 0.0 & $\begin{array}{l}\text { Matching Zone } 1 \\
\text { and Zone } 2\end{array}$ & $\begin{array}{l}\# 57 \\
\# 67\end{array}$ \\
\hline 0.5 & 2 & $\begin{array}{c}\# 1 \\
\# 57 \\
\# 67\end{array}$ \\
\hline 1.0 & 5 & $\begin{array}{c}\# 1 \\
\# 57 \\
\end{array}$ \\
\hline 1.5 & 3 & $\begin{array}{c}\text { 6-inch } \\
\# 4 \\
\# 67\end{array}$ \\
\hline 2.0 & 8 & $\begin{array}{c}\text { 6-inch } \\
\# 1 \\
\# 57 \\
\end{array}$ \\
\hline 2.5 & 7 & $\begin{array}{c}\text { 6-inch } \\
\# 1\end{array}$ \\
\hline
\end{tabular}

Forms, constructed from 2x4 lumber, and connected using 2-inch wood screws, served as molds for the rock pallets. Plastic florescent light cover grids, providing support for the vinyl cement used, were cut into $352 \mathrm{~mm}$ 
$\mathrm{x} 413 \mathrm{~mm}$ and 300mm x 413mm sections for Zones 1 and 2, respectively, and placed in the forms. Vinyl cement was mixed and poured into the wooden forms and evenly screeded with a flat edge. The specific equivalent step height rock gradation was lightly inserted into the cement progressing from the largest to the smallest rock type. A single layer of the largest rock type was placed such that every rock contacted with the next. Voids between the rocks occur when uniformly graded rock is clustered together. In order to fill the voids, the second largest rock type was inserted into the cement. This process was repeated until the smallest of the rock types in the specific equivalent step height rock gradation was used. The rock pallets constructed are shown in Figures 4.19, 4.20, 4.21, $4.22,4.23$ and 4.24 .

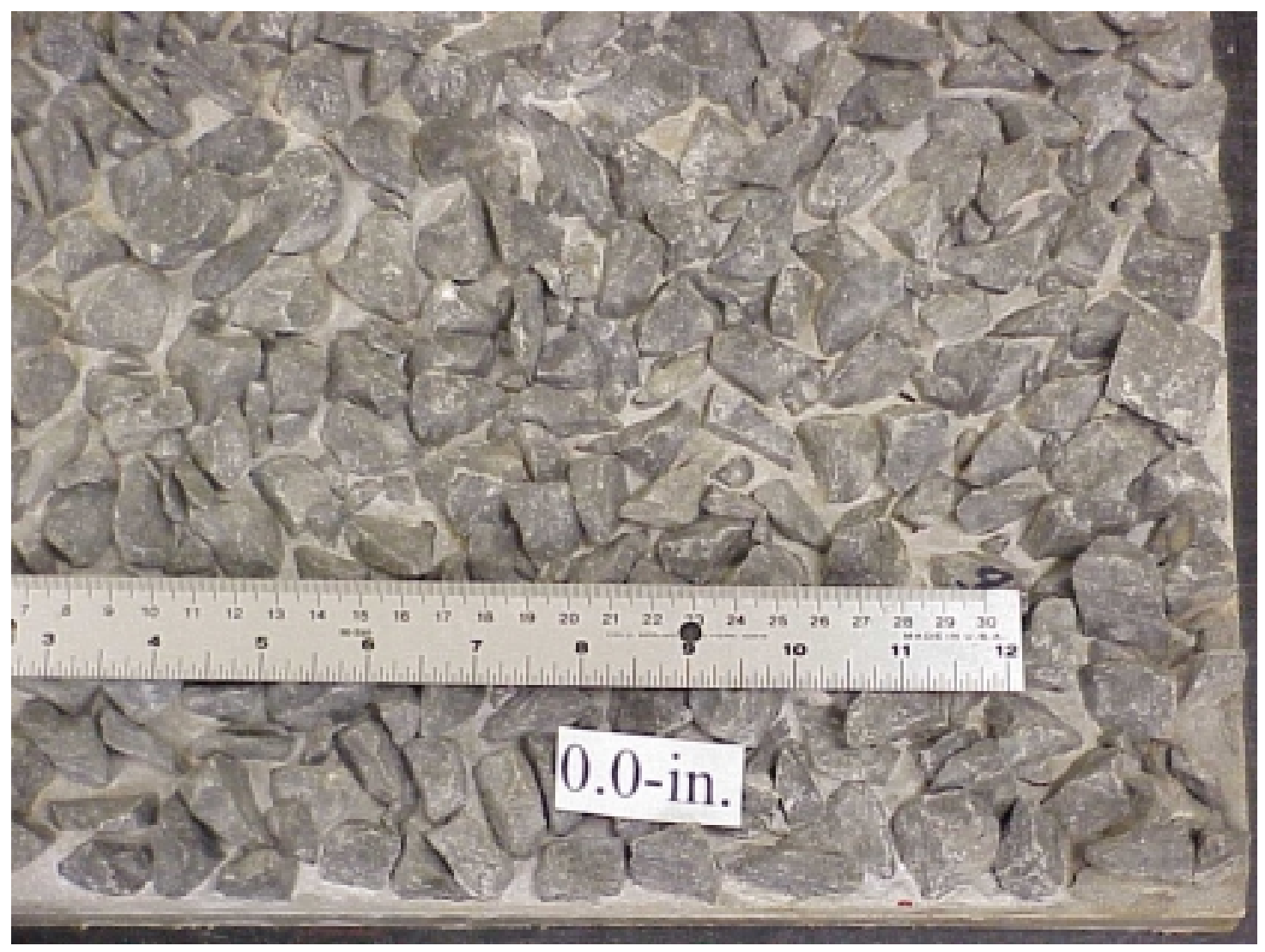

Figure 4.19 0.0-inch Equivalent Step Height 


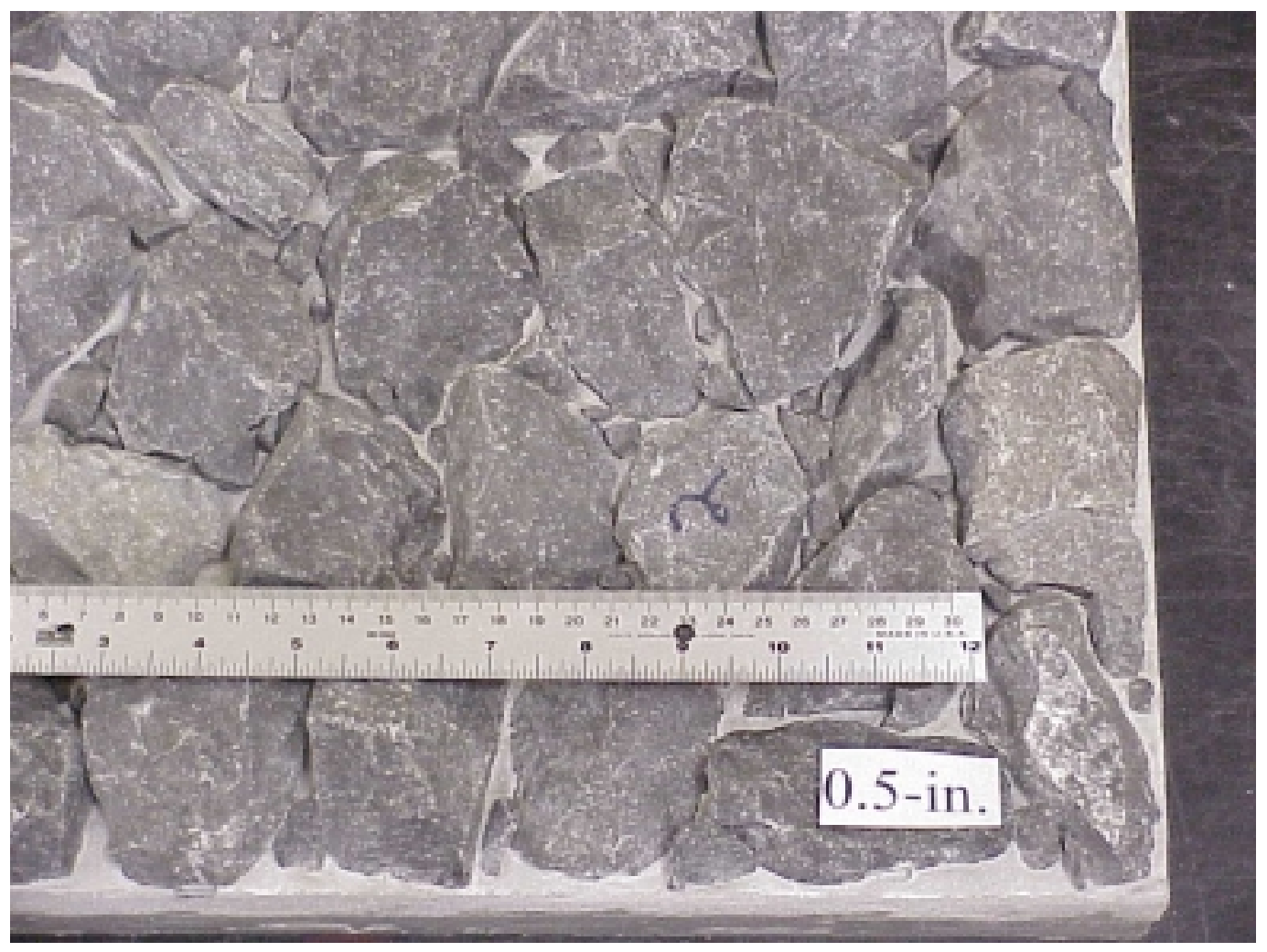

Figure 4.20 0.5-inch Equivalent Step Height

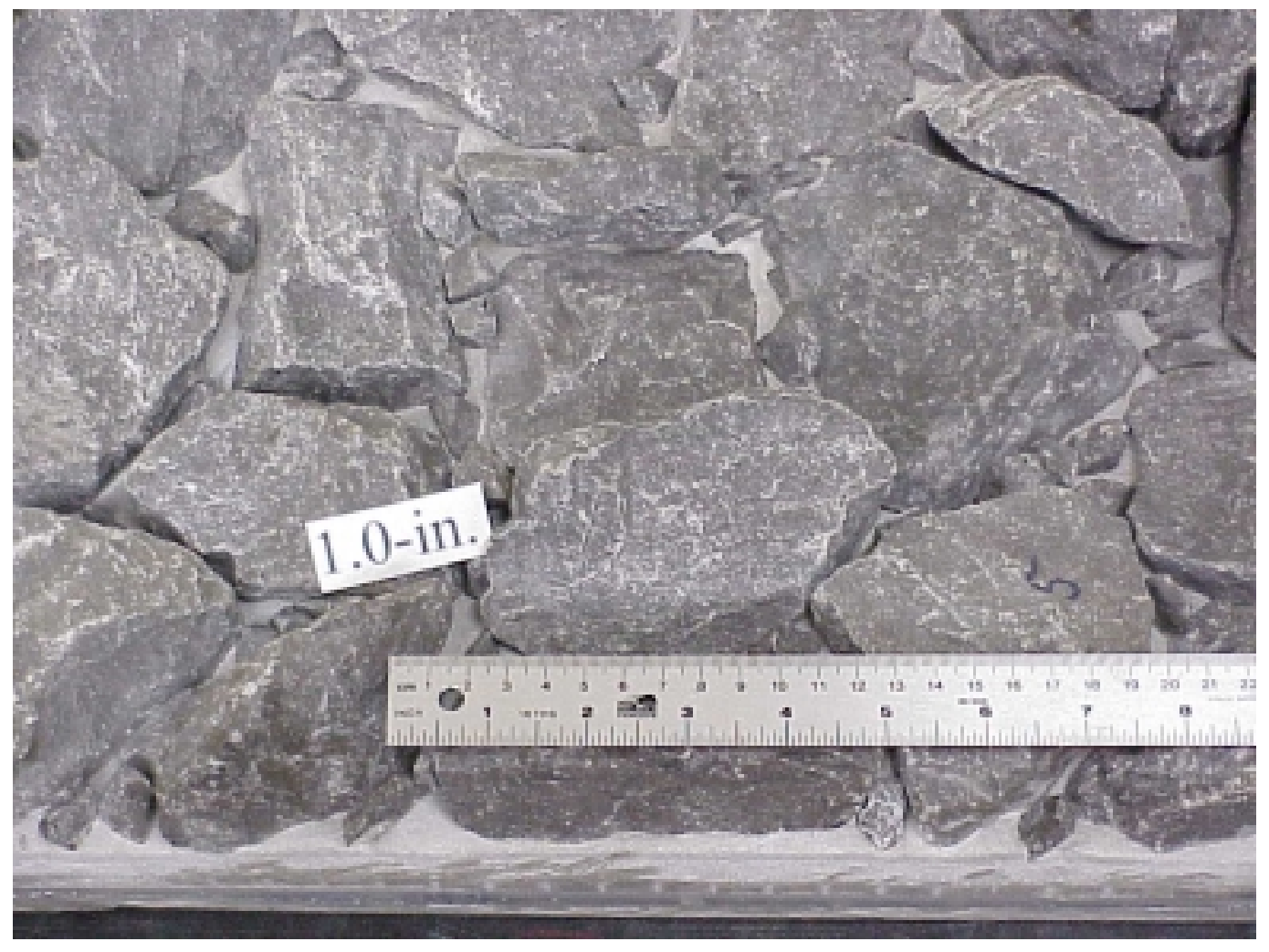

Figure 4.21 1.0-inch Equivalent Step Height 


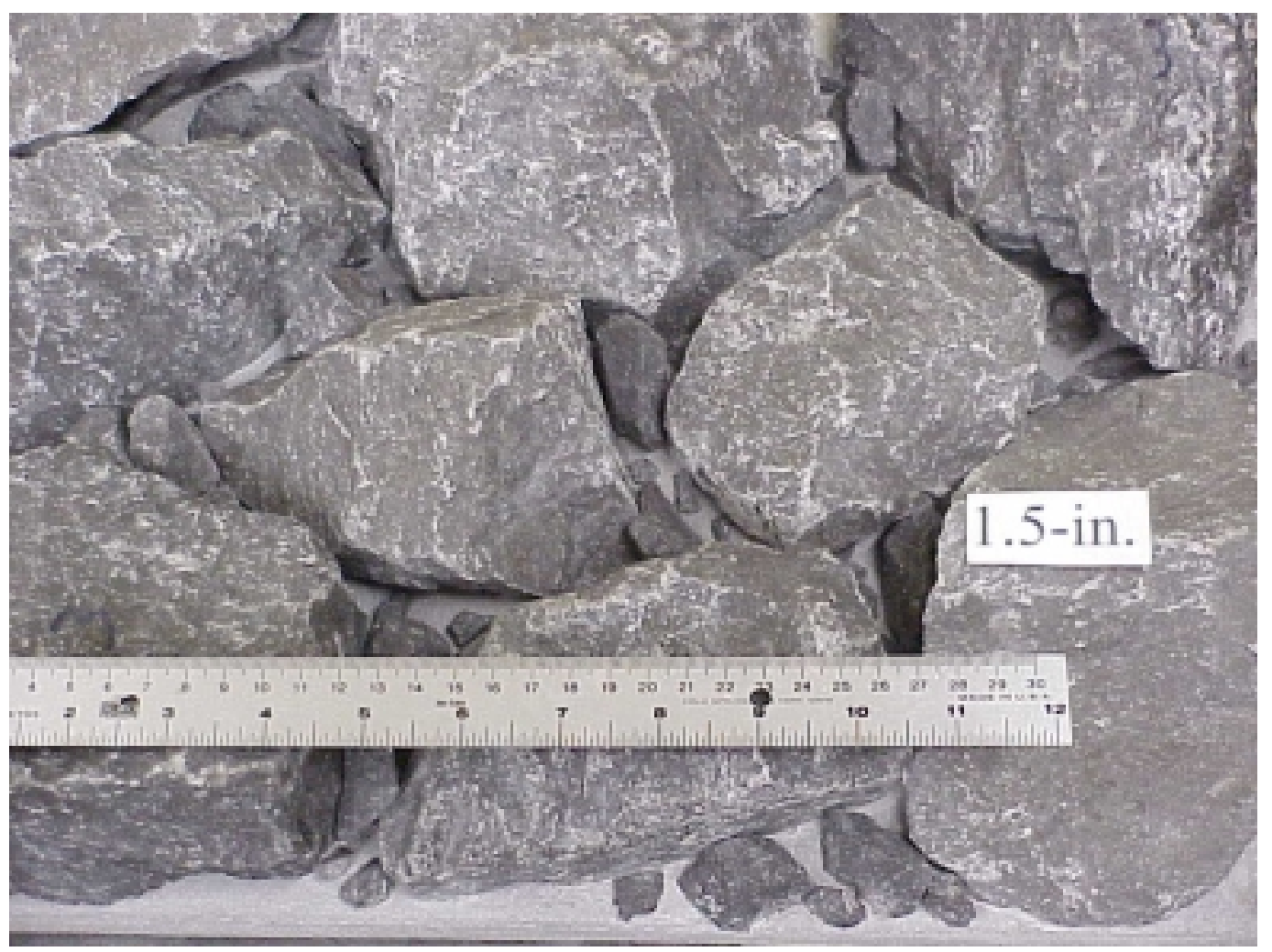

Figure 4.22 1.5-inch Equivalent Step Height

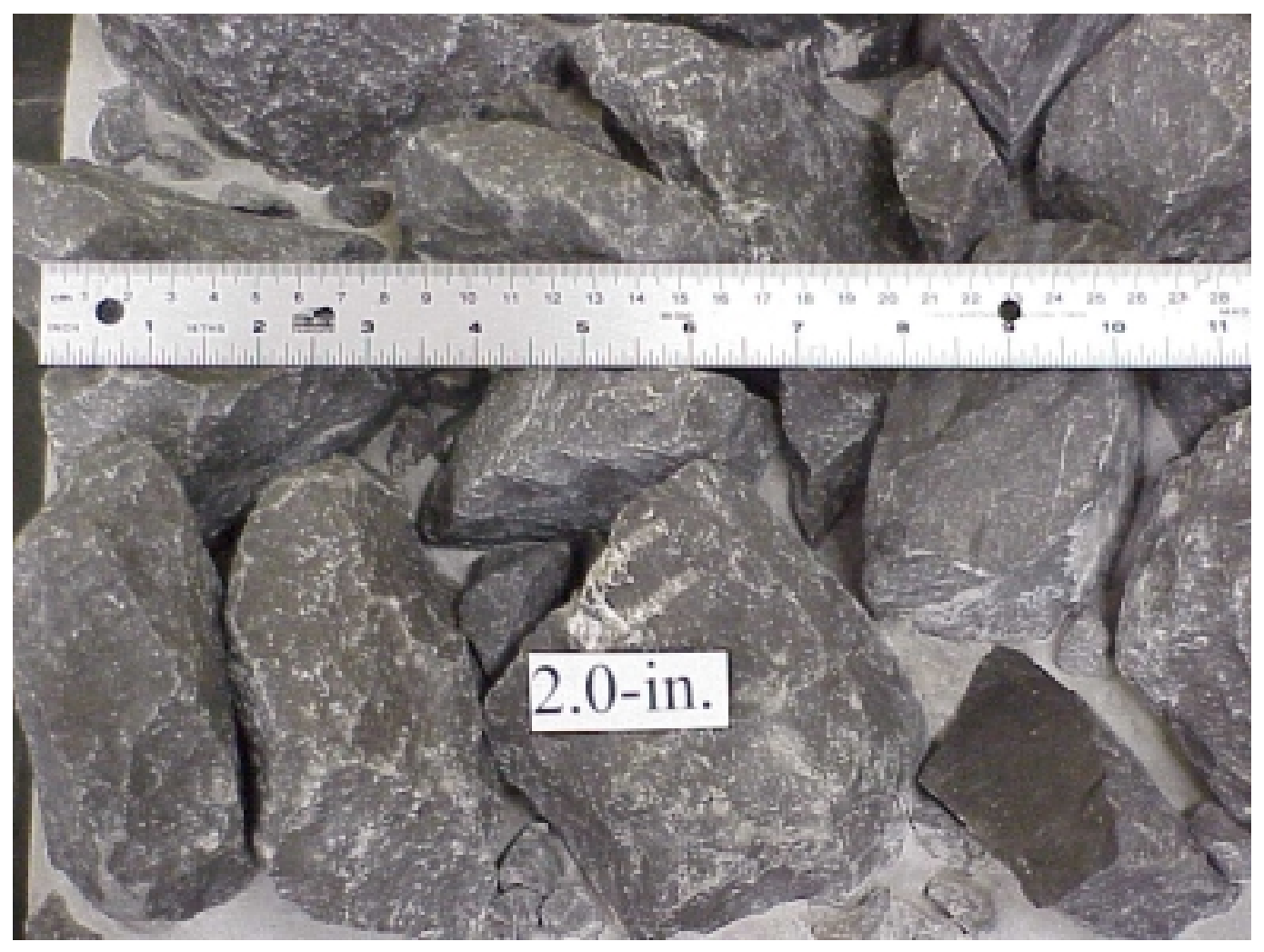

Figure 4.23 2.0-inch Equivalent Step Height 


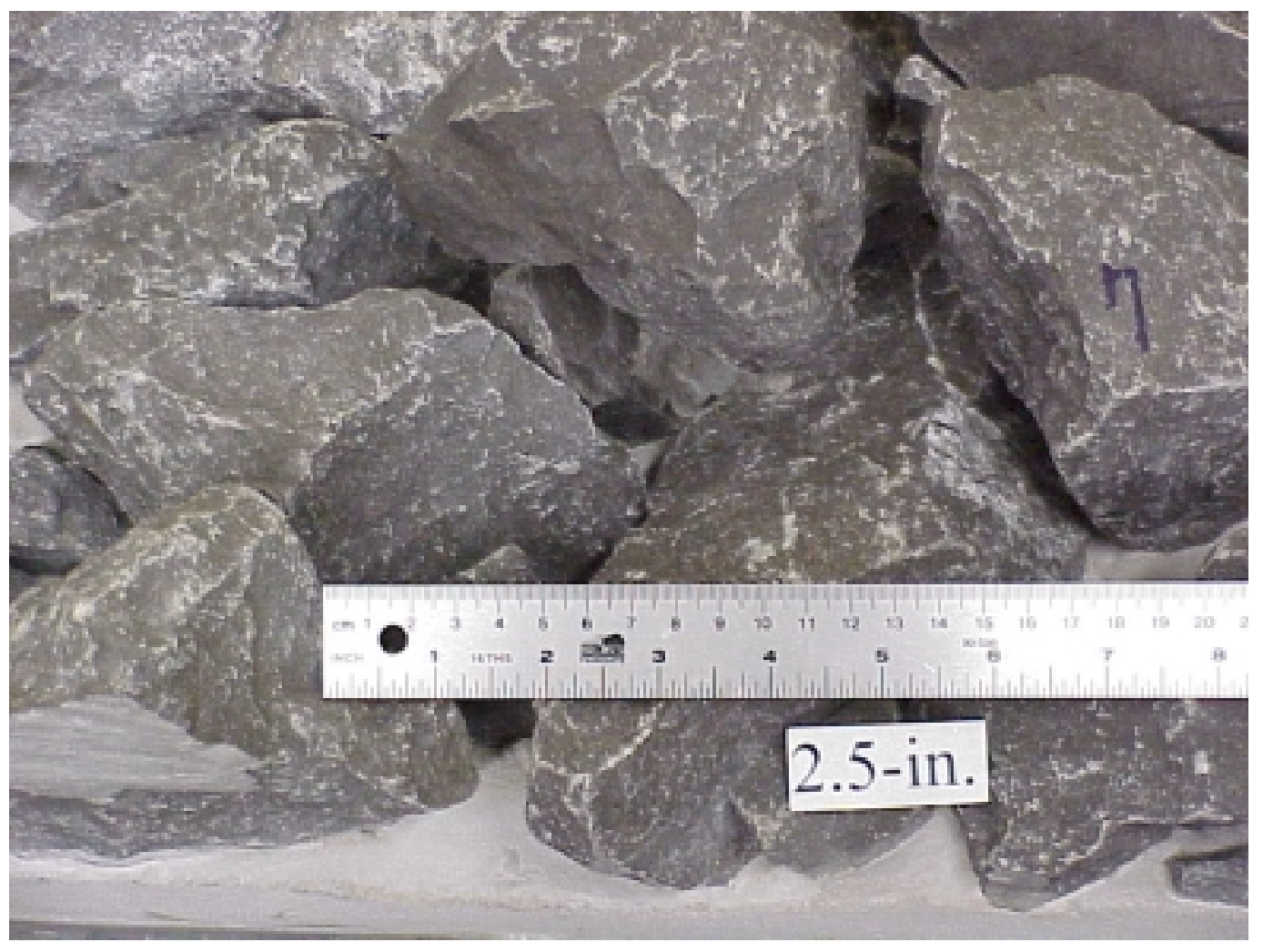

Figure 4.24 2.5-inch Equivalent Step Height

The cement rock pallets were moistened during the 48-hour curing period and then removed form the wooden forms. At various flowrates, the water surface would not flow over the highest rock in the pallet. Since the equivalent step height calculations were based on the assumption that the water height would be greater than the highest rock in the pallet, it was necessary to perform volumetric displacement tests on each of the rock pallets. Incremental water and rock volume data was recorded for future application in the energy calculations in the testing channel. Volumetric displacement testing boxes, $352 \mathrm{~mm} \times 413 \mathrm{~mm} \times 254 \mathrm{~mm}$, and 300mm x $413 \mathrm{~mm} \times 254 \mathrm{~mm}$, were constructed from 3/4-inch plywood, 1"x10" lumber, and 2-inch wood screws. Two, 3-inch holes were drilled into the bottom section of the plywood allowing a space for hand removal of the pallet after the volumetric test was completed. The plastic grids were then removed and the pallet was positioned into the tightly fitting volumetric testing box. In order to reduce surface tension affects, the surface of the rock pallet was moistened and the water level in the box was increased until the water surface was in the same horizontal plane as the cement surface containing the protruding rock. Incremental volumes of water were added and corresponding water surface elevations noted shown in Figure 4.25. 
Water Volume Displacement Tests - All Equivalent Step Heights

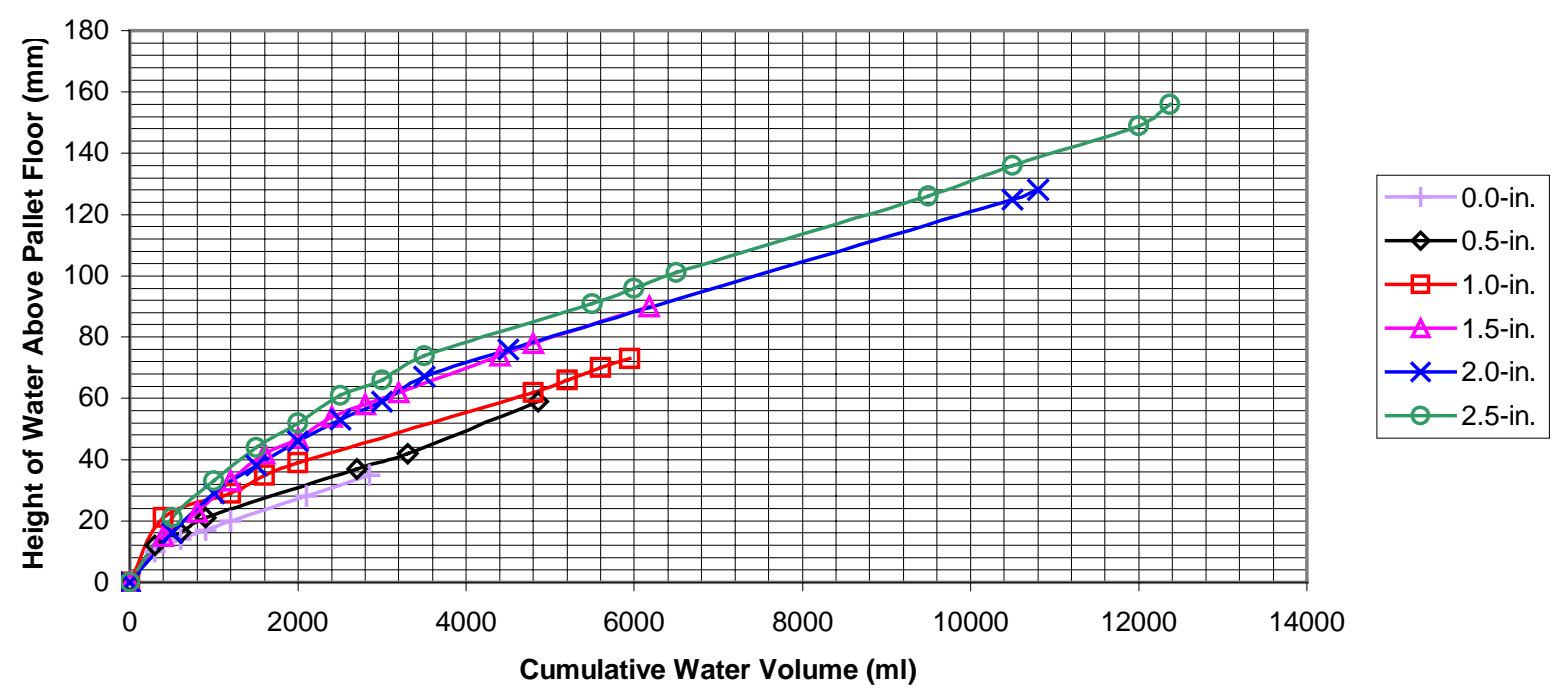

Figure 4.25 Water Volume Displacement Tests

To prevent chipping and disfigurement of the pallets, a 0.5 -inch plexiglas section with pallet dimensions was cemented onto the bottom of each cement pallet base. After the completion of the volumetric displacement tests, calculations were performed to determine the necessary shim heights to achieve the nominal step height desired.

To prevent confusion in later sections, a diagram of a sample riprap step cross-section with flow is shown in Figure 4.26.

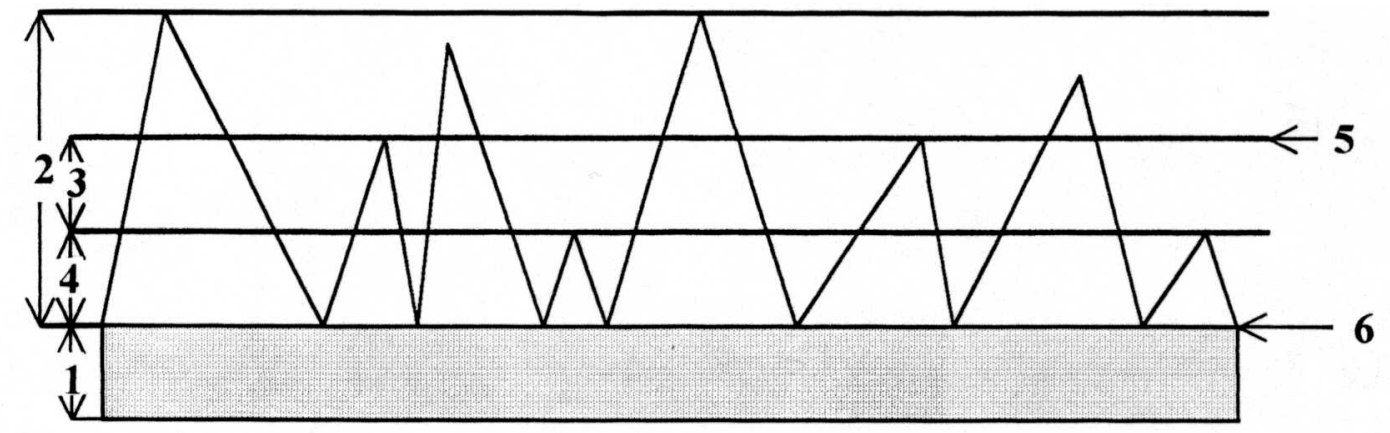

Figure 4.26 Sample Riprap Step Cross-section With Flow 
Where:

$1=$ Cement base thickness

$2=$ Equivalent (nominal) riprap step height

$3=$ Depth of water

4 = Actual (melted) rock height

$5=$ Water surface elevation

$6=$ Zero datum 


\section{Chapter 5}

\section{Analysis}

Following the completion of the testing flume, hypotheses were developed for the investigation of the riprap steps. In order for the riprap steps to meet the goals of the project the following criteria had to be satisfied. The design must be:

- $\quad$ Reasonably easy to construct on site

- $\quad$ Economically feasible

- $\quad$ Applicable to various culvert sizes and flowrates

- $\quad$ Self cleaning and require low maintenance (not directly addressed by experimentation)

- $\quad$ Capable of re-establishing natural flow conditions downstream of the outlet

The riprap steps constructed were intended for culvert diameters equal to or less than 4.25 feet.

\subsection{Data Collection}

Following the completion of the testing flume, several riprap step heights and/or gradations were tested. The purpose was to observe which riprap steps forced a hydraulic jump and provided the best energy attenuation. The twelve riprap steps, each having a unique height and/or configuration were tested. Each experimental run required the measurement of five main parameters:

- Flowrate

- $\quad$ Three point depth data

- Headwater at inlet

- Slope

- Piezometer readings

A data sheet was developed to accommodate the various data taken. Culvert slopes tested were 2, 4, 6, and 8 percent. Headwater was read at the beginning of each test, measured from the invert of the test culvert. Piezometer readings were taken before the pump was turned on to establish a tare reading (zero depth). The depth reading was computed as an average of the middle point and the reading from the two lateral points of the three-point gage. Along with the three-point depth measurements, the flow behavior at the culvert outlet, interactions with the wingwalls, and any adverse effects or flow anomalies were noted based on visual observations. Flowrates of 50, 75, 
100,125 , and $150 \mathrm{gpm}$ were applied to each step height, both smooth cast acrylic and rock riprap, at each of the four slopes.

\subsection{Equivalent or 'Melted' Riprap Step Height}

Further explanation is needed in order to fully understand what is meant by equivalent riprap step height. When using the 'smooth' cast acrylic steps, the flow in the test channel impacted each step at its given height, either $0.5,1.0,1.5,2.0$ or 2.5 -inches. A simple subtraction operation provided the necessary flow depth measurement. A more complicated approach was needed to obtain the equivalent step height with the rock steps. As mentioned earlier, the equivalent step heights were calculated based on the assumption that the flow would completely cover the rock in the step. Rarely was this the case with the riprap steps. With the use of the volumetric displacement test data, the volume and actual effective ('melted') height of the rock impacted by the flow was calculated. The comparison between the equivalent riprap step height and the effective 'melted' riprap step height is presented in

Table 5.1. Note: The riprap step height given is for reference purposes only, and is not the actual step height based on wetted rock volume (referenced to as the 'melted' height). Calculations were performed on the 'melted' height.

\begin{tabular}{|c|c|c|c|c|c|c|}
\hline Table 5.1 & Effective Rock Height Affecting Zone 2 Flow in Test Channel \\
\hline Slope & Flowrate & 0.5 -inch & 1.0 -inch & 1.5 -inch & 2.0 -inch & 2.5 -inch \\
\cline { 3 - 7 }$(\%)$ & (gpm) & \multicolumn{5}{|c|}{ (in) } \\
\hline 2 & 50 & 0.347 & 0.894 & 1.22 & 1.81 & 1.95 \\
\cline { 2 - 7 } 2 & 75 & 0.382 & 0.944 & 1.26 & 1.82 & 1.96 \\
\cline { 2 - 7 } 2 & 100 & 0.414 & 0.931 & 1.27 & 1.81 & 1.97 \\
\cline { 2 - 7 } 2 & 125 & 0.465 & 0.933 & 1.29 & 1.82 & 1.97 \\
\cline { 2 - 7 } 2 & 150 & 0.474 & 0.945 & 1.30 & 1.83 & 1.96 \\
\hline 4 & 50 & 0.360 & 0.917 & 1.26 & 1.81 & 1.95 \\
\cline { 2 - 7 } 4 & 75 & 0.386 & 0.927 & 1.28 & 1.82 & 1.96 \\
\cline { 2 - 7 } 4 & 100 & 0.442 & 0.928 & 1.27 & 1.82 & 1.96 \\
\cline { 2 - 7 } 4 & 125 & 0.478 & 0.933 & 1.37 & 1.82 & 1.97 \\
\cline { 2 - 7 } 4 & 150 & 0.503 & 0.949 & 1.29 & 1.83 & 1.98 \\
\hline 6 & 50 & 0.350 & 0.881 & 1.26 & 1.81 & 1.95 \\
\hline 6 & 75 & 0.375 & 0.903 & 1.27 & 1.81 & 1.96 \\
\hline 6 & 100 & 0.411 & 0.931 & 1.26 & 1.82 & 1.97 \\
\hline 6 & 125 & 0.456 & 0.926 & 1.27 & 1.80 & 1.97 \\
6 & 150 & 0.433 & 0.925 & 1.29 & 1.82 & 2.01 \\
\hline 8 & 50 & 0.353 & 0.921 & 1.23 & 1.81 & 1.95 \\
\hline 8 & 75 & 0.368 & 0.891 & 1.24 & 1.81 & 1.95 \\
\cline { 2 - 7 } 8 & 100 & 0.405 & 0.905 & 1.25 & 1.81 & 1.96 \\
\hline 8 & 125 & 0.400 & 0.929 & 1.28 & 1.82 & 1.96 \\
\hline 8 & 150 & 0.348 & 0.928 & 1.27 & 1.82 & 1.41 \\
\hline
\end{tabular}




\subsection{Water Surface Elevation Data Influences}

Many types of flow influenced the experimenter's ability to obtain accurate water surface elevation readings. Some of the influences are: 1) reverse flow, 2) not fully expanded jet, 3) spurting flow, 4) swirling flow, 5) splashing flow, 6) pooling, and 7) hydraulic jump. Note: The letter or abbreviation in parenthesis by each of the flow influences is a representative symbol referenced in Section 5.20.

\subsubsection{Reverse Flow (R)}

One influence on the water surface elevation readings was the presence of reverse flow of the test channel. Reverse flow is common with expanding jets into open channel flow in channels, especially rectangular channels. Figure 5.1 shows an example of reverse flow experienced in the test channel. A boundary could be seen

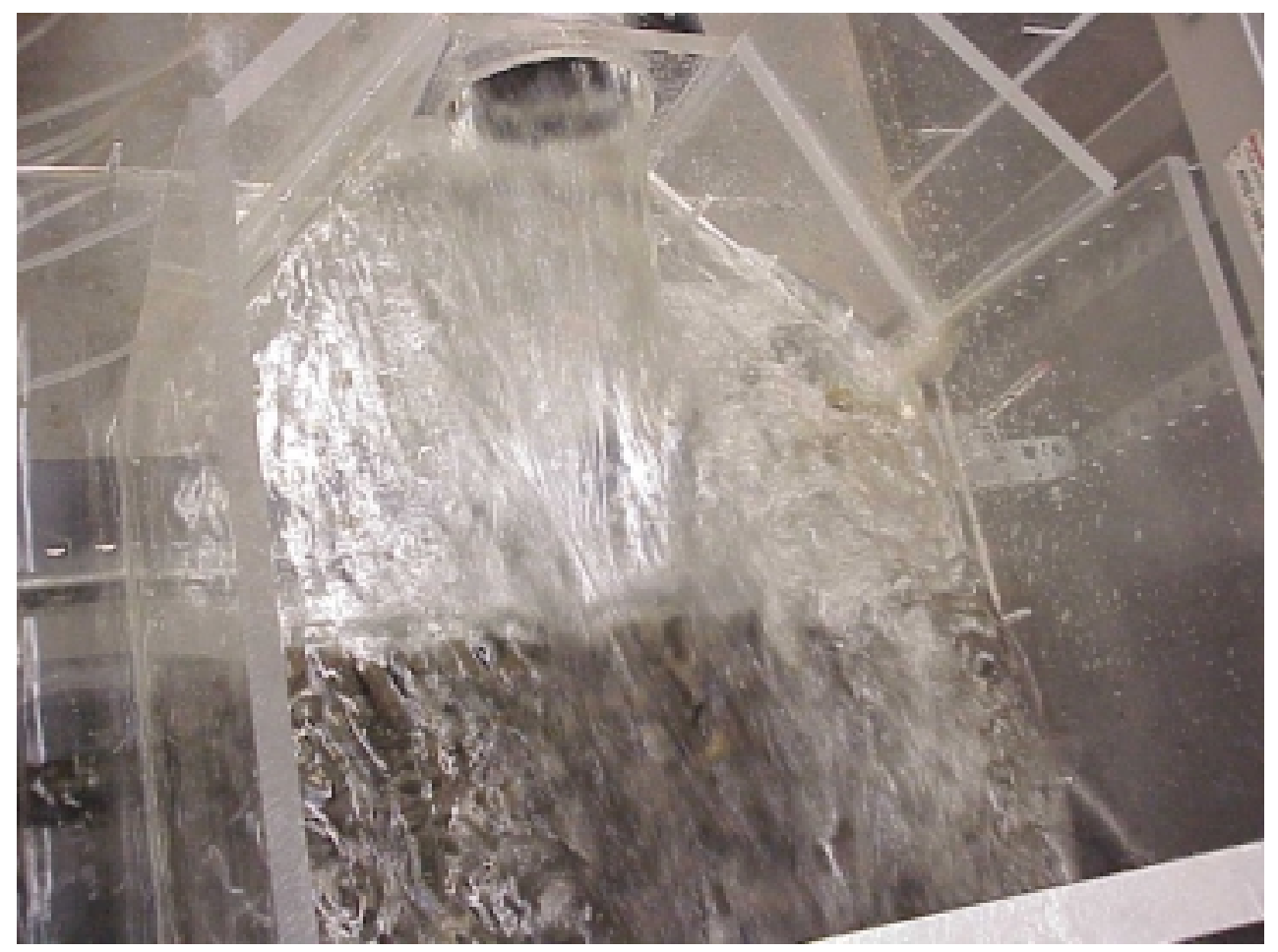

Figure 5.1 Reverse Flow in Test Channel

between the reverse flow, characterized by vortices, and the expanding jet exiting the test culvert and flowing across Zone 1. Two different water surface elevations, inside and outside the boundary between the two types of flow, caused great difficulty in obtaining accurate water surface elevation readings. 


\subsubsection{Not Fully Expanded Jet (X)}

Before initializing the project, based on previous research, it was believed that the dimensions of the test channel would be adequate for all the experimental runs. After initializing the experimental runs, it was discovered that high flowrates produced a jet in the test channel that could not fully expand before impacting against the step in Zone 2. Refer to Figure 5.2. As a result, two different water surface elevations, inside and outside the boundary between the un-expanded jet and the more uniform flow, caused difficulty in obtaining accurate readings.

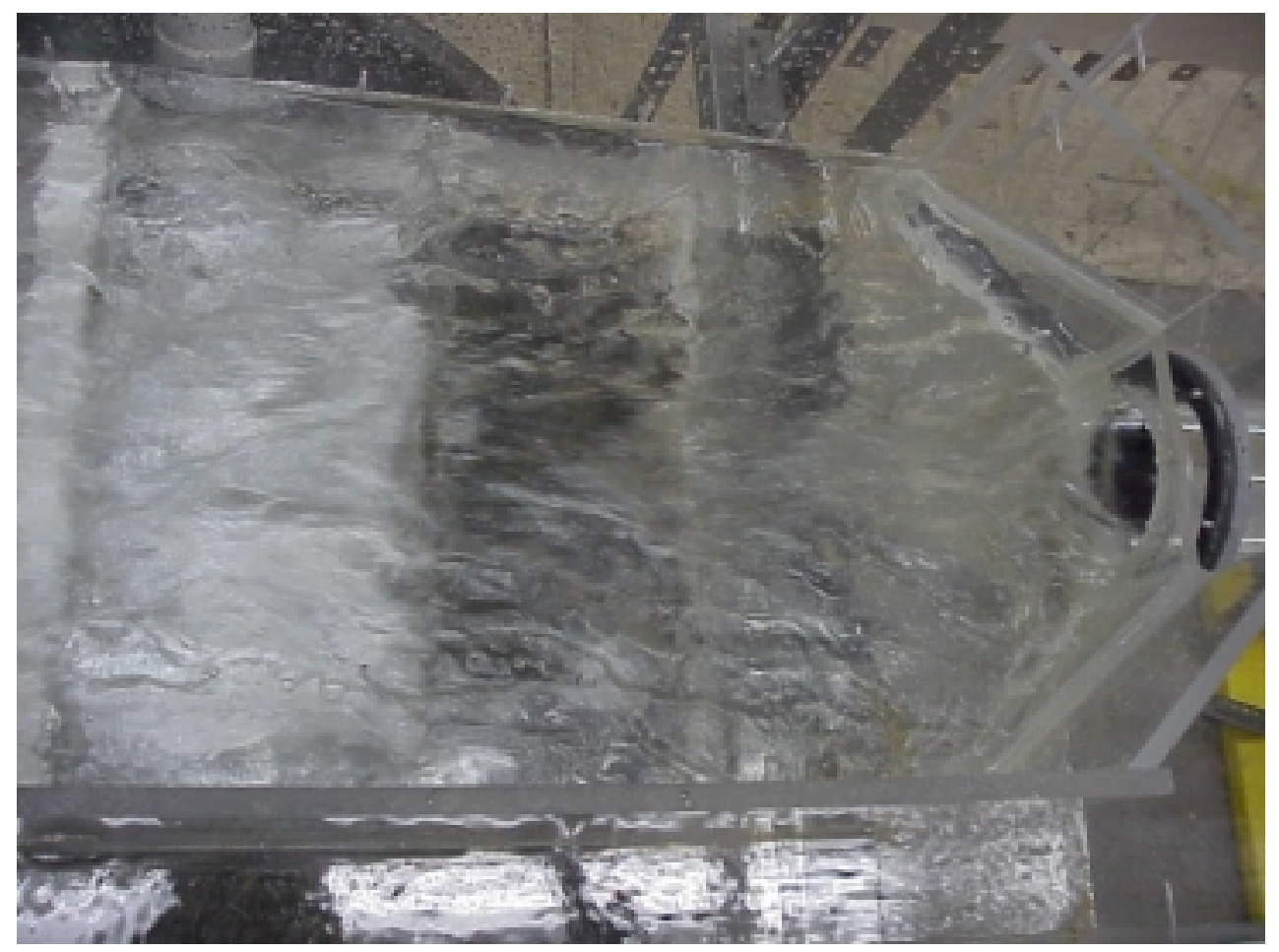

Figure 5.2 Not Fully Expanded Jet

\subsubsection{Spurting Flow $(P)$}

A characteristic of flowing water impacting an object is a spurting flow. As the flow in the test channel impacted against the step in Zone 2, often a spurting flow would occur as seen in Figure 5.3. The spurting flow is sometimes referred to as a "rooster tail". Due to the impossibility of collecting water surface elevation readings at particular areas in Zone 2 caused by the spurting flow, averaging values with the three-point gage was not possible and a single reading had to be applied for the entire cross-section. 


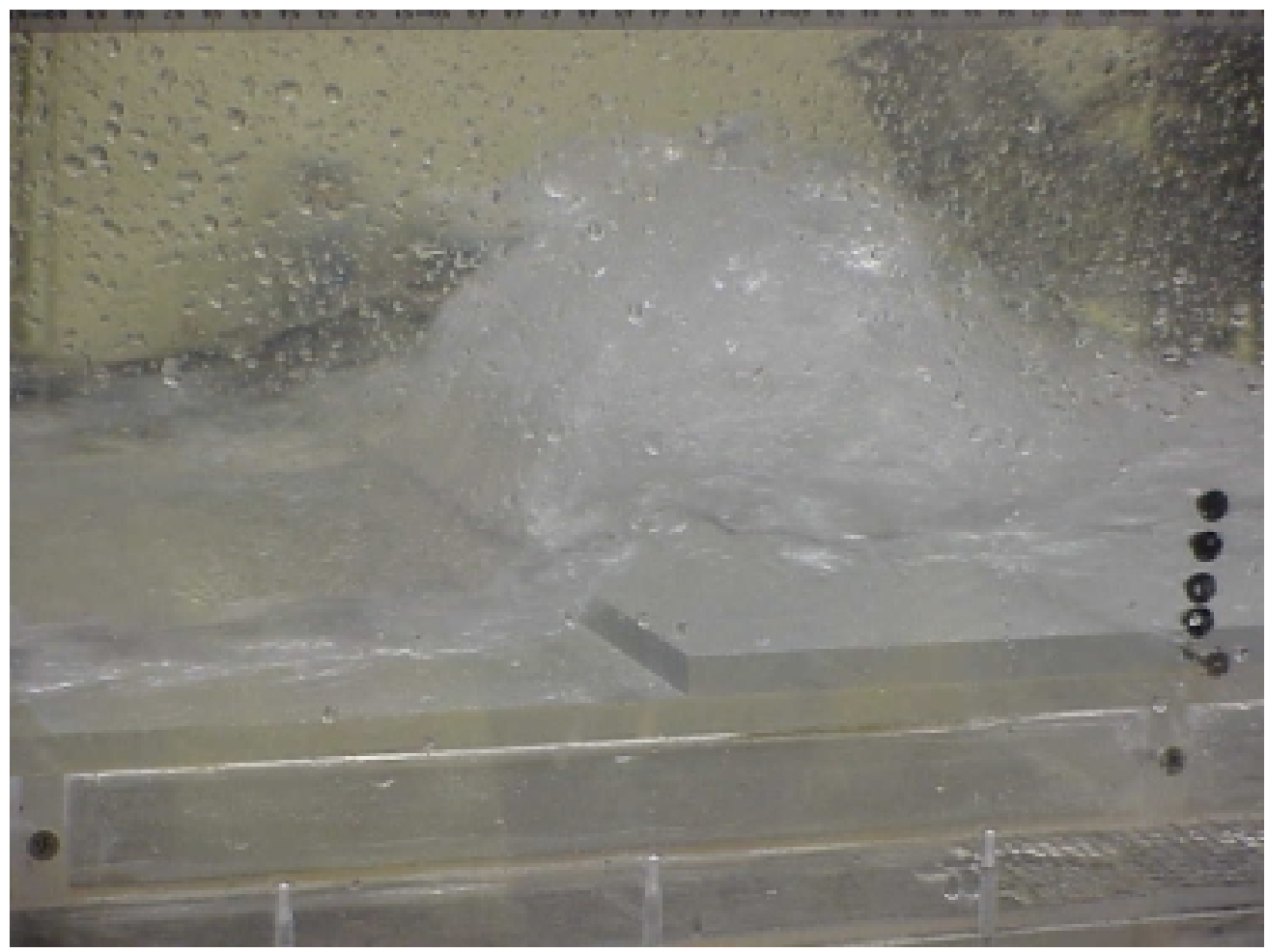

Figure 5.3 Spurting Flow

\subsubsection{Swirling Flow (W)}

A rarely observed phenomenon occurred in a couple experimental runs. A flow instability, or the Coanda effect, was believed to have been present. The Coanda effect is primarily a resulting problem of turbulent flow and turbulent mixing. When the flow proceeds down the center of a channel with vortices on either side, an unstable situation is formed. With circulating water, a momentary pressure change is experienced resulting in a higher pressure on one wall of the testing channel than the other. Since water flows from high pressure to low pressure, the flow goes in the direction of the wall with the lower pressure. The jet is most stable attached to the wall. A balance is reached between the momentum component toward the wall and the pressure. When the balance is reached, the jet moves away from the wall and tries to attach itself to the other wall as a pressure change takes place (Fluid Amplifiers, 1966).

Most often a balance between momentum and pressure is reached with no such effects occurring. Only on rare occasions was this effect seen, as in Figure 5.4. Instead of impacting the step at the center, the impact would occur at one side. The water surface elevation readings were difficult to obtain due to the oscillating flow with varied elevations. 


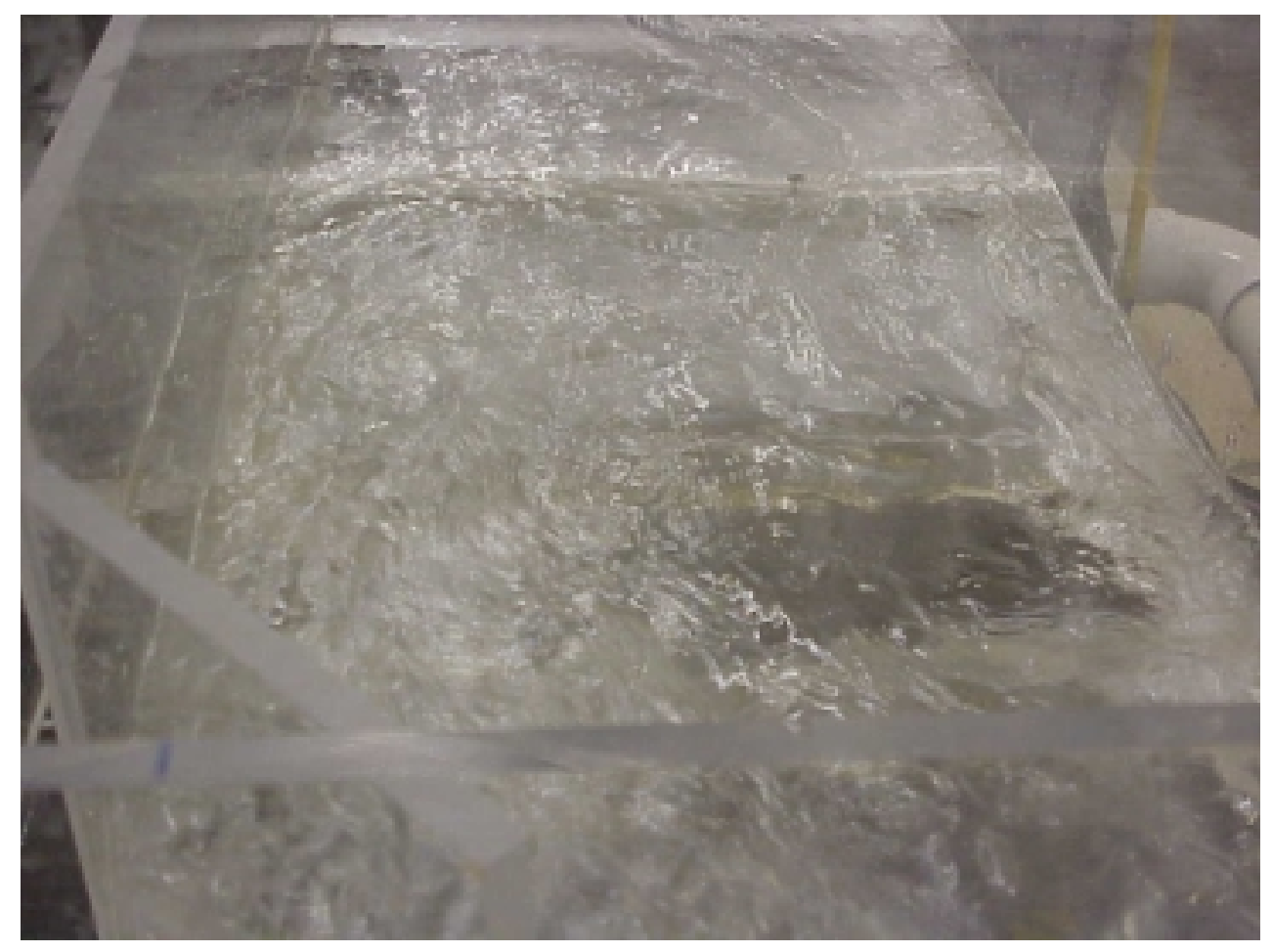

Figure 5.4 Swirling Flow

\subsubsection{Splashing Flow (S)}

Splashing flow occurred primarily with riprap steps. Unlike the smooth cast acrylic steps, riprap steps have a rough, angular surface consisting of many obstacles and voids. As the flow impacts the rock in the step, flow splashes and becomes more turbulent, increasing energy dissipation. As a result of the splashing against the rock, especially larger rock in the 2.0-inch and 2.5-inch equivalent riprap steps, accurate water surface elevations readings were difficult to obtain. See Figure 5.5. 


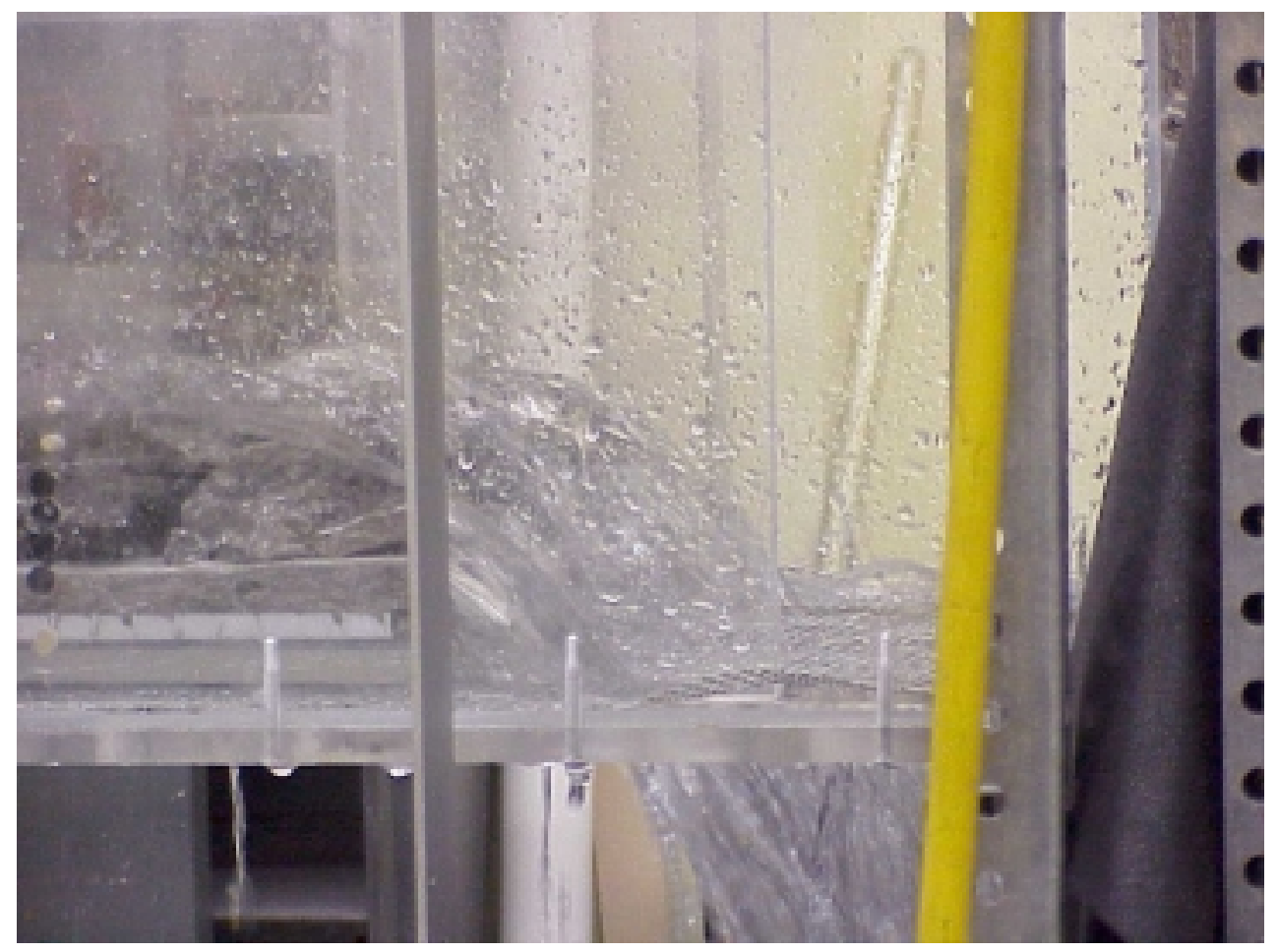

Figure 5.5 Splashing Flow

\subsubsection{Hydraulic Jump}

Hydraulic jumps were discussed in Section 2.2.1. Froude numbers of the jumps in the test channel were less than 4.5. Types of flows will be classified as the following:

- $\quad \mathbf{J 0}=$ No Jump $(\mathrm{Fr}<1)$

- $\quad \mathbf{J 1}=$ Weak Jump $(1<\mathrm{Fr}<2.5)$

- $\quad \mathbf{J 2}=$ Oscillating Jump $(2.5<\mathrm{Fr}<4.5)$

- $\wedge=$ Jump Located in Test Channel

- $\quad *=$ Jump Located in Test Culvert

Example: $\mathbf{J}^{*} *$ Representing Oscillating Jump in Test Culvert

\subsubsection{Pooling (L)}

Pooling, accumulation of water in Zone 1 due to the increase step height in Zone 2, of the flow occurred at higher step heights. Pooling effects raised the energy grade lines, EGL, giving the appearance that the increase in step height was not an effective means of dissipating energy in Zone 2 of the test channel. Pooling and EGLs are discussed further in later sections. 


\subsection{Velocity Profile Investigation}

To determine the value for alpha, the velocity head correction factor, the following expression was used:

$$
\alpha=\frac{1^{15} u^{3} d A}{V^{3} A}
$$

Where:

$$
\begin{aligned}
& \alpha=\text { Velocity correction factor } \\
& u=\text { Point velocity found from the Pitot tube } \\
& d A=\text { Incremental area at which measurements were taken } \\
& V=\text { Average velocity } \\
& A=\text { Total cross-sectional area of flow }
\end{aligned}
$$

\begin{tabular}{|c|c|c|c|c|c|c|c|c|c|}
\hline \begin{tabular}{|c|}
1 \\
Width \\
Increments
\end{tabular} & \begin{tabular}{|c|}
2 \\
Depth \\
From \\
Bottom of \\
Tube \\
\end{tabular} & $\begin{array}{c}3 \\
\text { Pitot } \\
\text { Reading }\end{array}$ & $\begin{array}{c}4 \\
\text { Pitot } \\
\text { Depth }\end{array}$ & $\begin{array}{c}5 \\
\text { Depth From } \\
\text { Center of } \\
\text { Tube }\end{array}$ & $\mathrm{p} /$ gamma & $\begin{array}{c}7 \\
\text { Point Velocity } \\
\text { @ section }\end{array}$ & $\begin{array}{c}8 \\
\text { Area @ } \\
\text { section }\end{array}$ & $\begin{array}{c}9 \\
\left(u^{3}\right) d A\end{array}$ & $\begin{array}{c}10 \\
\text { Incremental } \\
\text { Flowrate }\end{array}$ \\
\hline (Section) & $(\mathrm{mm})$ & $(\mathrm{mm})$ & $(\mathrm{mm})$ & $(\mathrm{mm})$ & $(\mathrm{mm})$ & $(\mathrm{mm} / \mathrm{s})$ & $\left(\mathrm{mm}^{2}\right)$ & & $\left(\mathrm{mm}^{3} / \mathrm{s}\right)$ \\
\hline 1 & 241 & 45.0 & 250 & 244 & 6.50 & 869 & 317 & $2.078 E+11$ & 275150 \\
\hline 2 & 241 & 60.0 & 247 & 244 & 3.50 & 1053 & 317 & $3.694 \mathrm{E}+11$ & 333322 \\
\hline 3 & 241 & 85.0 & 248 & 244 & 4.50 & 1257 & 317 & $6.282 E+11$ & 397867 \\
\hline 4 & 242 & 125 & 249 & 245 & 4.50 & 1537 & 289 & $1.050 \mathrm{E}+12$ & 444452 \\
\hline 5 & 248 & 135 & 253 & 251 & 2.50 & 1612 & 124 & $5.191 \mathrm{E}+11$ & 199739 \\
\hline 6 & 248 & 140 & 253 & 251 & 2.50 & 1642 & 124 & $5.488 \mathrm{E}+11$ & 203473 \\
\hline 7 & 248 & 150 & 253 & 251 & 2.50 & 1701 & 124 & $6.097 E+11$ & 210742 \\
\hline 8 & 248 & 153 & 253 & 251 & 2.50 & 1715 & 124 & $6.253 E+11$ & 212520 \\
\hline 9 & 248 & 160 & 253 & 251 & 2.50 & 1758 & 124 & $6.727 \mathrm{E}+11$ & 217768 \\
\hline 10 & 248 & 155 & 253 & 251 & 2.50 & 1729 & 124 & $6.410 \mathrm{E}+11$ & 214284 \\
\hline 11 & 248 & 145 & 253 & 251 & 2.50 & 1672 & 124 & $5.790 \mathrm{E}+11$ & 207139 \\
\hline 12 & 248 & 140 & 253 & 251 & 2.50 & 1642 & 124 & $5.488 \mathrm{E}+11$ & 203473 \\
\hline 13 & 241 & 140 & 247 & 244 & 3.50 & 1636 & 317 & 1.387E+12 & 518091 \\
\hline 14 & 241 & 90.0 & 246 & 244 & 2.50 & 1310 & 317 & $7.119 \mathrm{E}+11$ & 414805 \\
\hline 15 & 241 & 75.0 & 246 & 244 & 2.50 & 1192 & 317 & $5.369 \mathrm{E}+11$ & 377580 \\
\hline SUMS: & & & & & & 22326 & 3180 & $9.636 \mathrm{E}+12$ & 4430403 \\
\hline
\end{tabular}

The values in the numerator are then summed from 1 to 15 , as there were 15 sections of measurement. Initial calculations were performed at $50 \mathrm{gpm}$ at $8 \%$ slope, since the flow appearance at $8 \%$ slope appeared the most nonuniform. The first method used values obtained solely from the Pitot tube. Table 5.2 lists the data measurements and results of the computations.

The first column, width increments, is the section number assigned to each location of measurement. The second column, depth from bottom of tube, is the location of the water surface found by locating the point at which the Pitot tube first contacts the surface of the flow. The third column, Pitot reading, is the value obtained by recording the 
height of water that appeared in the Pitot tube. Note that due to oscillations, the Pitot reading was an average based on visual inspection. The fourth column, Pitot depth, is the location of the Pitot tube when it was placed into the flow to obtain a Pitot reading. The fifth column, depth from center of tube, is an adjustment of column two. In order to produce more accurate results, the initial water surface measurement was taken from the bottom of the tube and then half diameter adjustment was applied to give the water surface elevation from the center of the tube. Column six, $\rho$ /gamma, is the height of the column of water from the center of the Pitot tube to the surface of the flow, (column 4) minus (column 5). Column seven, point velocity @ section, is the value for u as determined from the energy equation solving for V. Column eight, area @ section, is the value of the incremental cross sectional area at the corresponding width increment. The value for width is found by dividing the total width of the channel, $413 \mathrm{~mm}$, by the number of width increments, 15 . The height for the incremental cross-sectional area is found by subtracting the datum elevation from the depth of water from the center of the tube. Column nine, $\left(\mathrm{u}^{3}\right) \mathrm{dA}$ is the product of the cube of the point velocity and the incremental area, (column 7$)^{3} *($ column 8$)$. Column ten is the incremental flowrate found by the product of columns seven and eight. Note that columns eight, nine, and ten are summed, with the total given for each at the bottom of the table.

For the first method of determining alpha by the Pitot data alone, the value for the numerator is the sum of column nine. The value for the average velocity, $\mathrm{V}$, is found by dividing the total of the incremental flowrates by the total of the incremental areas. The value for $\mathrm{A}$ is the sum of the incremental areas.

A second method of determining alpha was by the use of data obtained by experiments performed using the three-point gage and flowmeter. The average velocity, total area, and alpha values were obtained by the use of the three point data. Alpha was calculated by using the same numerator values as in the first method, however the denominator values were obtained from the three point gage data. The values obtained from the two methods are shown in Table 5.3

\begin{tabular}{|c|c|c|c|}
\hline Table 5.3 & \multicolumn{3}{|c|}{$\begin{array}{c}\text { Alpha Values Obtained by Methods 1 and } 2 \\
(50 \mathrm{gpm} \text { at 8\% Slope) }\end{array}$} \\
\hline Results Based on Pitot Data & Results from Three-Point Data \\
\hline $\begin{array}{c}\text { Average Velocity } \\
(\mathrm{mm} / \mathrm{s})\end{array}$ & 1390 & Average Velocity $(\mathrm{mm} / \mathrm{s})$ & 1150 \\
\hline Area $\left(\mathrm{mm}^{\wedge} 2\right)$ & 3180 & Area $\left(\mathrm{mm}^{\wedge} 2\right)$ & 2760 \\
\hline Alpha & 1.12 & Alpha & 2.32 \\
\hline
\end{tabular}


The same procedure was performed at $100 \mathrm{gpm}$ at $8 \%$ slope and the velocity correction factor obtained by the two methods at this setting is displayed in Table 5.4.

\begin{tabular}{|c|c|c|c|}
\hline Table 5.4 & \multicolumn{3}{|c|}{$\begin{array}{c}\text { Alpha Values Obtained by Methods 1 and } 2 \\
(100 \mathrm{gpm} \text { at 8\% Slope) }\end{array}$} \\
\hline \multicolumn{2}{|c|}{ Results Based on Pitot Data } & Results from Three-Point Data \\
\hline $\begin{array}{c}\text { Average Velocity } \\
(\mathrm{mm} / \mathrm{s})\end{array}$ & 1800 & Average Velocity (mm/s) & 1630 \\
\hline Area $\left(\mathrm{mm}^{\wedge} 2\right)$ & 4670 & Area $\left(\mathrm{mm}^{\wedge} 2\right)$ & 3880 \\
\hline Alpha & 1.05 & Alpha & 1.70 \\
\hline
\end{tabular}

The values obtained from the three-point gage were presumed to be less accurate than the Pitot data and were not adopted. Since the value for the velocity correction factor was nearly equal to unity in the Pitot tube analysis and based on past research, it was not considered in the energy calculations and alpha was considered to equal unity.

\subsection{Test Culvert Analysis}

Since the flow was observed to be almost uniform near the culvert outlet, uniform flow depth was assumed at the test culvert outlet for a given flowrate and slope. To obtain the best representative value of uniform flow depth at the outlet of the test culvert, Piezometer data for each slope and flowrate for the six configurations was compiled in Microsoft Excel. The spreadsheet, titled Test Culvert Analysis, contained the depth data for all 19 piezometers for each configuration. Since the reading obtained from the Piezometer is the pressure head at the culvert invert, a conversion was necessary to give the depth of flow perpendicular to the culvert invert. The equation is simply a trigonometric operation and was performed as follows:

$$
y_{n}=\frac{\left(R_{a}-R_{t}\right)}{\operatorname{COS}(\Theta)}
$$

Where:

$$
\begin{aligned}
& R_{a}=\text { Actual reading from piezometer (pressure head) } \\
& R_{t}=\text { Tare reading for piezometer (zero depth and pressure head) } \\
& y_{n}=\text { Uniform depth perpendicular to the test culvert } \\
& \Theta=\text { Slope of test culvert (degrees) }
\end{aligned}
$$


The 19 piezometer tap values were examined and it was concluded that the values had reached uniform flow conditions from taps 10-19 in most instances. Where wave action was pronounced or presence of a jump was detected (due to backwater effects at the outlet, those tap readings were not included in the calculations. The taps that most accurately depicted uniform flow depth were then averaged and recorded for each slope and flowrate. The values were then summarized in a table for each riprap step and averaged again over the six experimental configurations. The result is the value used for uniform flow depth at the test culvert outlet for a given slope and flowrate, as shown in red in Table 5.5.

\begin{tabular}{|c|c|c|c|c|c|c|c|c|}
\hline \multicolumn{9}{|c|}{ Uniform Flow Depth in Test Culvert (m) } \\
\hline $\begin{array}{l}\text { Culvert } \\
\text { Slope (\%) }\end{array}$ & $\begin{array}{c}\text { Flowrate } \\
\text { (gpm) }\end{array}$ & 0.0 -inch & 0.5 -inch & 1.0-inch & 1.5-inch & 2.0-inch & 2.5-inch & $\begin{array}{c}\text { Average } \\
\text { Uniform } \\
\text { Flow Depth } \\
\text { Over Runs } \\
\text { (m) }\end{array}$ \\
\hline 2 & 50 & 0.0360 & 0.0360 & 0.0360 & 0.0360 & 0.0360 & 0.0370 & 0.0362 \\
\hline 2 & 75 & 0.0437 & 0.0445 & 0.0438 & 0.0440 & 0.0438 & 0.0440 & 0.0439 \\
\hline 2 & 100 & 0.0510 & 0.0510 & 0.0510 & 0.0510 & 0.0510 & 0.0510 & 0.0510 \\
\hline 2 & 125 & 0.0560 & 0.0560 & 0.0560 & 0.0570 & 0.0570 & 0.0570 & 0.0565 \\
\hline 2 & 150 & 0.0610 & 0.0610 & 0.0620 & 0.0610 & 0.0610 & 0.0600 & 0.0610 \\
\hline 4 & 50 & 0.0314 & 0.0316 & 0.0313 & 0.0313 & 0.0317 & 0.0330 & 0.0315 \\
\hline 4 & 75 & 0.0388 & 0.0388 & 0.0390 & 0.0392 & 0.0392 & 0.0390 & 0.0390 \\
\hline 4 & 100 & 0.0450 & 0.0455 & 0.0450 & 0.0450 & 0.0450 & 0.0450 & 0.0451 \\
\hline 4 & 125 & 0.0505 & 0.0505 & 0.0505 & 0.0505 & 0.0505 & 0.0507 & 0.0505 \\
\hline 4 & 150 & 0.0557 & 0.0553 & 0.0557 & 0.0557 & 0.0568 & 0.0553 & 0.0558 \\
\hline 6 & 50 & 0.0287 & 0.0284 & 0.0287 & 0.0282 & 0.0280 & 0.0278 & 0.0284 \\
\hline 6 & 75 & 0.0345 & 0.0345 & 0.0345 & 0.0345 & 0.0345 & 0.0345 & 0.0345 \\
\hline 6 & 100 & 0.0405 & 0.0405 & 0.0405 & 0.0405 & 0.0405 & 0.0400 & 0.0405 \\
\hline 6 & 125 & 0.0455 & 0.0465 & 0.0460 & 0.0455 & 0.0455 & 0.0455 & 0.0458 \\
\hline 6 & 150 & 0.0504 & 0.0504 & 0.0500 & 0.0500 & 0.0500 & 0.0500 & 0.0502 \\
\hline 8 & 50 & 0.0273 & 0.0272 & 0.0272 & 0.0273 & 0.0273 & 0.0282 & 0.0273 \\
\hline 8 & 75 & 0.0336 & 0.0334 & 0.0331 & 0.0330 & 0.0330 & 0.0330 & 0.0332 \\
\hline 8 & 100 & 0.0387 & 0.0387 & 0.0387 & 0.0387 & 0.0387 & 0.0385 & 0.0387 \\
\hline 8 & 125 & 0.0441 & 0.0441 & 0.0442 & 0.0444 & 0.0446 & 0.0446 & 0.0443 \\
\hline 8 & 150 & 0.0488 & 0.0493 & 0.0493 & 0.0490 & 0.0490 & 0.0485 & 0.0491 \\
\hline
\end{tabular}




\subsection{Equivalent Rectangular Froude Number}

In the early stages of channel data analysis, it became apparent that the calculated culvert outlet Froude number was misleading. The Froude number was calculated based on hydraulic depth for the circular cross-section of the test culvert. This resulted in the Froude number approaching zero as the culvert fills. A transformation from circular to rectangular cross-section was found in the development of the Contra Costa energy dissipator, reviewed in HEC-14 (1983). The circular to rectangular transform eliminates the decrease in hydraulic depth with the increase of flow depth in a circular cross-section. HEC-14 stated that for oval, circular, elliptical or shapes other than rectangular or square, the flow at the culvert must be converted to an equivalent rectangular cross-section with a width equal to twice the depth of flow. The equivalent rectangular flow depth, $\mathrm{y}_{\mathrm{e}}$, is determined from the following relationship:

$$
y_{e}=\left(\frac{A}{2}\right)^{0.5}
$$

Where:

$$
\begin{aligned}
& y_{e}=\text { Equivalent rectangular flow depth } \\
& A=\text { Area of the flow cross-section }
\end{aligned}
$$

Following the transform of the flow depth, the equivalent rectangular Froude number can be determined from using $y_{e}$ rather than the actual hydraulic depth at the culvert outlet. So, the relationship for the Froude number becomes:

$$
F r=\frac{V}{\sqrt{g y_{e}}}
$$

The introduction of the transformed rectangular cross-section produced Froude numbers that were better suited for non-dimensional reference use. Values obtained for the uniform flow depth, from Section 5.5, were converted to the equivalent rectangular flow depth and calculations proceeded further.

\subsection{Energy Calculations}

Based on the uniform flow depth established in Section 5.5, the following parameters were calculated using a spreadsheet: 
- Velocity at test culvert outlet

- Flow area

- Equivalent rectangular flow depth at culvert outlet, ye

- Culvert $\Phi$

Culvert $\Phi$ was the sector angle used to calculate the circular cross-sectional area of the flow at a given flow depth. Culvert $\Phi$ is depicted below in Figure 5.6.

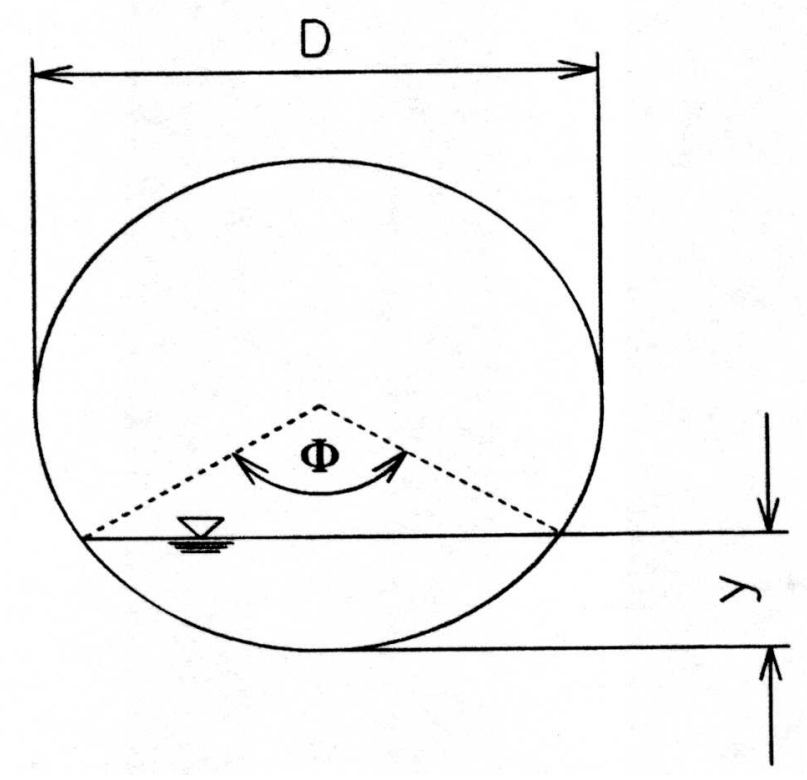

Figure 5.6 Culvert $\Phi$

Given a value for the depth of flow in the test culvert, $\Phi$ was determined from the following equation:

$\Phi=2 \cos ^{-1}\left(1-\frac{2 y}{D}\right)$

The flow area of the culvert was found from an equation relating the diameter of the test culvert and culvert $\Phi$, shown below.

$A=\frac{D^{2}}{8}(\Phi-\operatorname{SIN} \Phi)$

Since the cross-sectional area of the flow and the flowrate were both known, the velocity could be determined by dividing the flowrate by the cross-sectional area. The adopted values of uniform flow depth from Section 5.5, for the test culvert at fixed slopes and flowrates are shown in Table 5.6. 


\begin{tabular}{|c|c|c|c|c|c|c|}
\hline \multicolumn{7}{|c|}{ Table 5.6 Test Culvert Data } \\
\hline $\begin{array}{l}\text { Culvert } \\
\text { Slope }\end{array}$ & Flowrate & $\begin{array}{c}\text { Average } \\
\text { Uniform } \\
\text { Flow Depth } \\
\text { Over Runs } \\
\\
\text { (m) }\end{array}$ & $\begin{array}{l}\text { Test } \\
\text { Culvert } \\
\text { Phi } \\
\\
\text { (rad) }\end{array}$ & $\begin{array}{l}\text { Average } \\
\text { Flow Area }\end{array}$ & $\begin{array}{c}\text { Velocity } \\
@ \text { Test } \\
\text { Culvert } \\
\text { Outlet } \\
\\
(\mathrm{m} / \mathrm{s})\end{array}$ & \begin{tabular}{|c} 
Equivalent \\
Rectangular \\
Flow Depth \\
$@$ Test \\
Culvert \\
Outlet \\
$(\mathrm{m})$
\end{tabular} \\
\hline 2 & 50 & 0.0362 & 2.47 & 0.00269 & 1.17 & 0.0367 \\
\hline 2 & 75 & 0.0439 & 2.77 & 0.00350 & 1.35 & 0.0418 \\
\hline 2 & 100 & 0.0510 & 3.03 & 0.00426 & 1.48 & 0.0461 \\
\hline 2 & 125 & 0.0565 & 3.24 & 0.00485 & 1.63 & 0.0492 \\
\hline 2 & 150 & 0.0610 & 3.40 & 0.00533 & 1.78 & 0.0516 \\
\hline 4 & 50 & 0.0315 & 2.29 & 0.00224 & 1.41 & 0.0335 \\
\hline 4 & 75 & 0.0390 & 2.58 & 0.00298 & 1.59 & 0.0386 \\
\hline 4 & 100 & 0.0451 & 2.81 & 0.00362 & 1.74 & 0.0426 \\
\hline 4 & 125 & 0.0505 & 3.01 & 0.00420 & 1.88 & 0.0459 \\
\hline 4 & 150 & 0.0558 & 3.21 & 0.00477 & 1.99 & 0.0488 \\
\hline 6 & 50 & 0.0284 & 2.15 & 0.00191 & 1.65 & 0.0309 \\
\hline 6 & 75 & 0.0345 & 2.40 & 0.00252 & 1.88 & 0.0355 \\
\hline 6 & 100 & 0.0405 & 2.63 & 0.00313 & 2.02 & 0.0396 \\
\hline 6 & 125 & 0.0458 & 2.84 & 0.00369 & 2.14 & 0.0430 \\
\hline 6 & 150 & 0.0502 & 3.00 & 0.00416 & 2.28 & 0.0456 \\
\hline 8 & 50 & 0.0273 & 2.11 & 0.00183 & 1.73 & 0.0302 \\
\hline 8 & 75 & 0.0332 & 2.35 & 0.00239 & 1.98 & 0.0346 \\
\hline 8 & 100 & 0.0387 & 2.57 & 0.00294 & 2.15 & 0.0384 \\
\hline 8 & 125 & 0.0443 & 2.78 & 0.00354 & 2.23 & 0.0421 \\
\hline 8 & 150 & 0.0491 & 2.96 & 0.00404 & 2.35 & 0.0449 \\
\hline
\end{tabular}

Since the uniform flow depth was constant at a given slope and flowrate, the remainder of the calculations dealt with comparing the conditions at the culvert outlet with those downstream in the testing channel. The parameters obtained from the rectangular test channel are as follows:

- $\quad$ Average flow depth

- $\quad$ Flow area

- $\quad$ Velocity

The average flow depth was obtained by examining the values for flow depth from the three-point gage measurements along the designated seven channel positions shown in Figure 4.11. Plots of the water surface elevation for a given run were then examined to identify any values that were outliers due to wave action or experimental error. The points that were termed acceptable, as best displaying the observed flow depth in the testing channel, were then averaged to produce the mean flow depth in the testing channel. The flow area of the given run 
was determined from the product of the average flow depth with the width of the testing channel. The velocity was found by simply dividing the flowrate by the cross-sectional area of the flow. Next, the Froude number at the culvert outlet was calculated as described in Section 5.6. The Froude number was also calculated in the testing channel. The Froude number at the culvert outlet and testing channel were calculated to provide a non-dimensional reference to flow conditions. The energy at the culvert outlet was calculated from the following expression:

$$
\text { CulvertOutletEnergy }=\frac{V^{2}}{2 g}+y+z
$$

Where:

$$
\begin{aligned}
& V=\text { Average velocity at culvert outlet } \\
& g=\text { Acceleration due to gravity } \\
& y=\text { Uniform flow depth at culvert outlet (actual depth) } \\
& z=\text { Step height above zero datum }
\end{aligned}
$$

The energy in the testing channel and the EGL were calculated using Equation 5.7, except that velocity and uniform flow depth were those of the testing channel. The energy at the culvert outlet and testing channel are then compared in the form of a non-dimensional energy difference of the following form:

$$
\text { Non }- \text { DimensionalEnergyDifference }=\frac{\text { OutletEnergy }- \text { ChannelEnergy }}{\text { OutletEnergy }}
$$

\begin{tabular}{|c|c|c|c|c|c|c|c|c|}
\hline \multirow[b]{2}{*}{$\begin{array}{c}\text { Flowrate } \\
\text { (gpm) }\end{array}$} & \multicolumn{3}{|c|}{ Testing Channel Data - Zone 2} & \multicolumn{2}{|c|}{ Froude \# Calculations } & \multicolumn{3}{|c|}{ Energy Calculations } \\
\hline & $\begin{array}{c}\text { Average } \\
\text { Flow } \\
\text { Depth } \\
\\
(\mathrm{m})\end{array}$ & $\begin{array}{c}\text { Average } \\
\text { Flow Area } \\
\\
\left(\mathrm{m}^{2}\right)\end{array}$ & $\begin{array}{c}\text { Average } \\
\text { Flow Velocity } \\
\begin{array}{c}(\mathrm{m} / \mathrm{s})\end{array}\end{array}$ & $\begin{array}{c}\text { Fr \# } \\
\text { Based on } \\
\text { Circular } \\
\text { Cross- } \\
\text { Section }\end{array}$ & $\begin{array}{c}\text { Fr \# } \\
\text { Based on } \\
\text { Average } \\
\text { Zone } 2 \\
\text { Values }\end{array}$ & $\begin{array}{c}\text { Energy at } \\
\text { Culvert } \\
\text { Outlet } \\
\\
(\mathrm{mm})\end{array}$ & $\begin{array}{c}\text { Average } \\
\text { Energy in } \\
\text { Zone } 2 \\
\\
(\mathrm{~mm})\end{array}$ & $\begin{array}{c}\text { Non- } \\
\text { Dimensional } \\
\text { Energy } \\
\text { Difference }\end{array}$ \\
\hline 50 & & & & & & & & \\
\hline 75 & & & & & & & & \\
\hline 100 & & & & & & & & \\
\hline 125 & & & & & & & & \\
\hline 150 & & & & & & & & \\
\hline
\end{tabular}

An example of the spreadsheet format used for the energy calculations is shown in Table 5.7. In following sections, each type of step, either cast acrylic or riprap, and step height will be presented and discussed with the results presented in this latter format. 
After observing the flow characteristics in the test channel for the 0.0-inch smooth, cast acrylic step for several flowrates, it was determined that there was an extreme amount of wave action, making accurate measurements of depth impossible. Therefore, it was considered that analysis could not be completed due to excessive measurement error. Several sample calculations using data from these runs were completed. The sample calculations confirmed that there was too much wave action to obtain useful information. Since the riprap pallet with the equivalent step height and the matching 'smooth' cast acrylic step were to have been compared, it was decided that the calculations for the 0.0-inch riprap step would only be used as a reference for the five, riprap steps, 0.5-inch, 1.0-inch, 1.5-inch, 2.0-inch, and 2.5-inch. The 0.0-inch riprap step calculations in their entirety will be presented in a later section. 


\subsection{5-inch Cast Acrylic Step}

Graphs of the water surface elevation for tests conducted at 2, 4, 6, and 8\% slopes are shown in Figures 5.7, 5.8, 5.9, and 5.10. After the water surface elevation was established, average flow depth was determined. From the flow depth and the results from Section 5.5, the aforementioned energy calculations were conducted. The results for the energy calculations for the 0.5-inch cast acrylic step are shown in Tables 5.8, 5.9, 5.10, and 5.11.

\section{Smooth - Water Surface Elevation for 0.5" Step @ 2\% Slope}

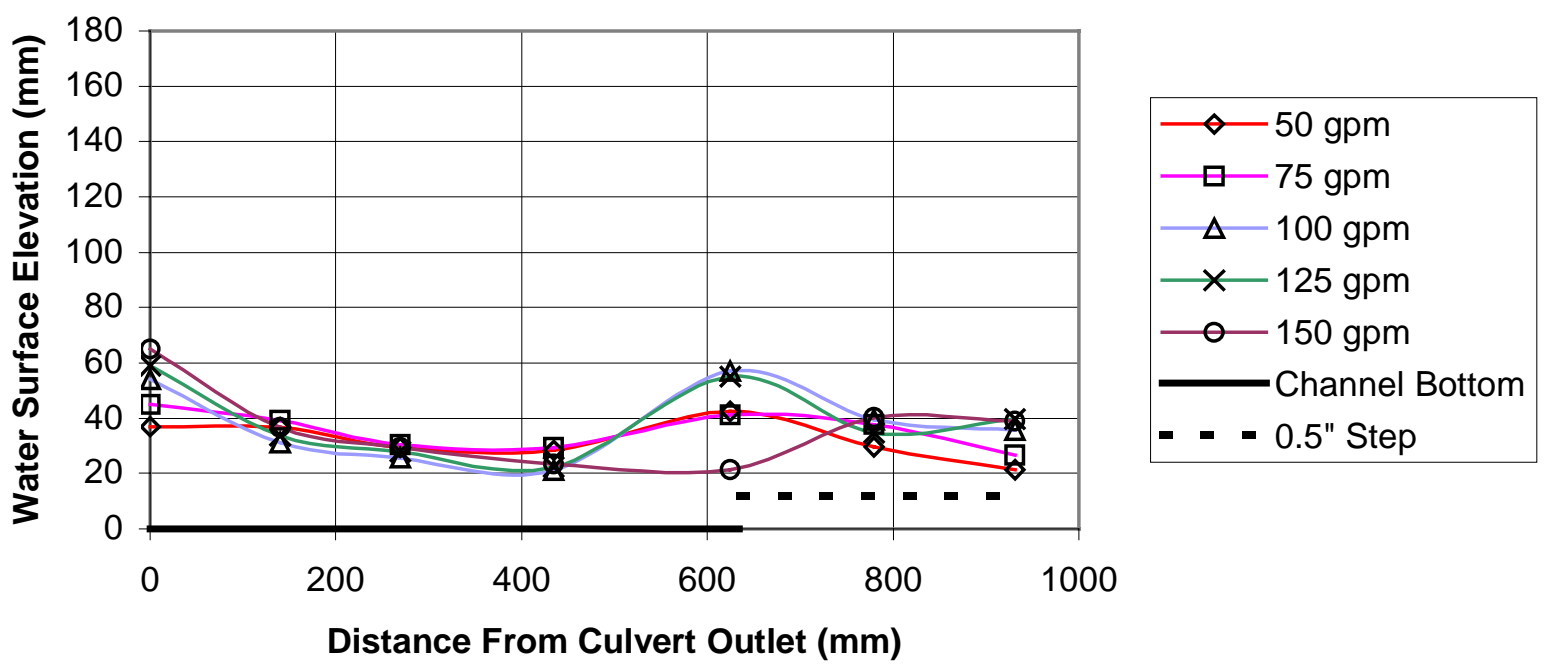

Figure 5.7 Plot of Water Surface Elevation for 0.5-inch Cast Acrylic Step at 2\% Culvert Slope 


\section{Smooth - Water Surface Elevation for 0.5" Step @ 4\% Slope}

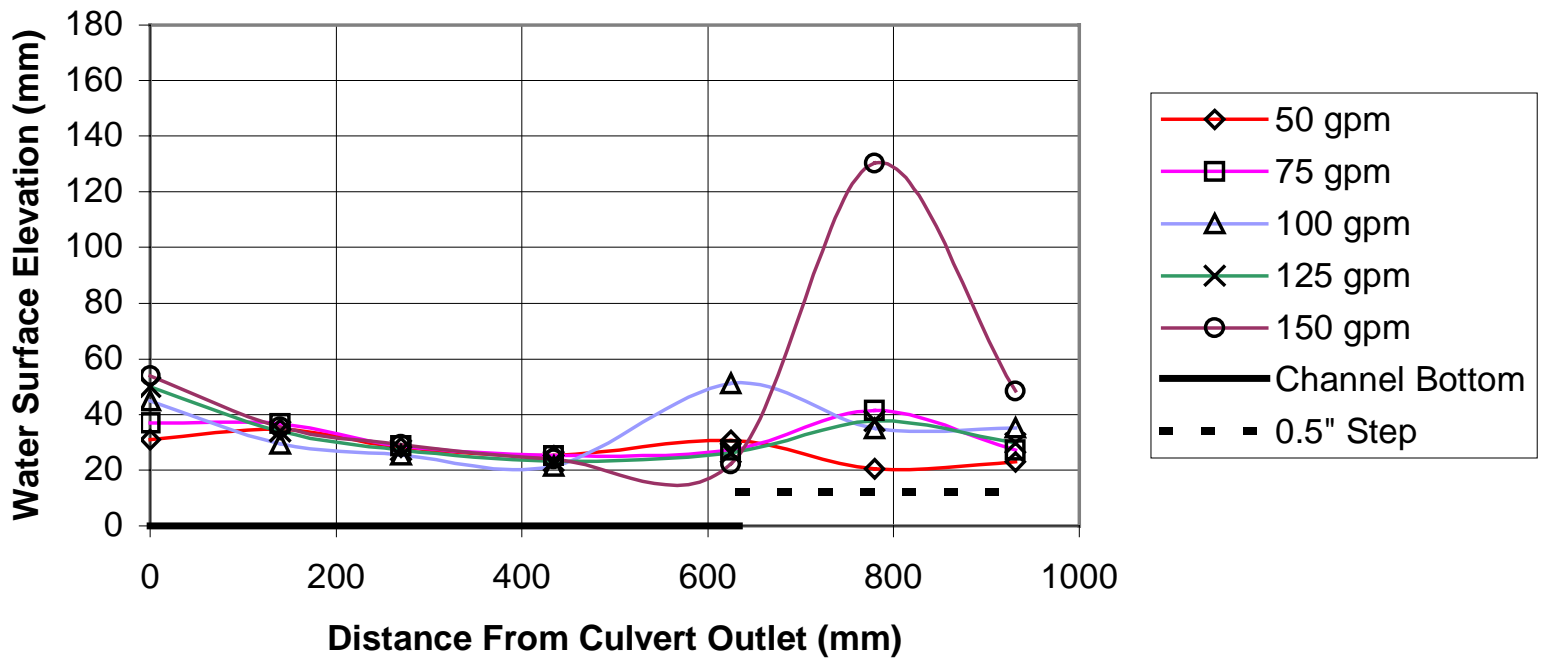

Figure 5.8 Plot of Water Surface Elevation for 0.5-inch Cast Acrylic Step at 4\% Culvert Slope

Smooth - Water Surface Elevation for 0.5" Step @ 6\% Slope

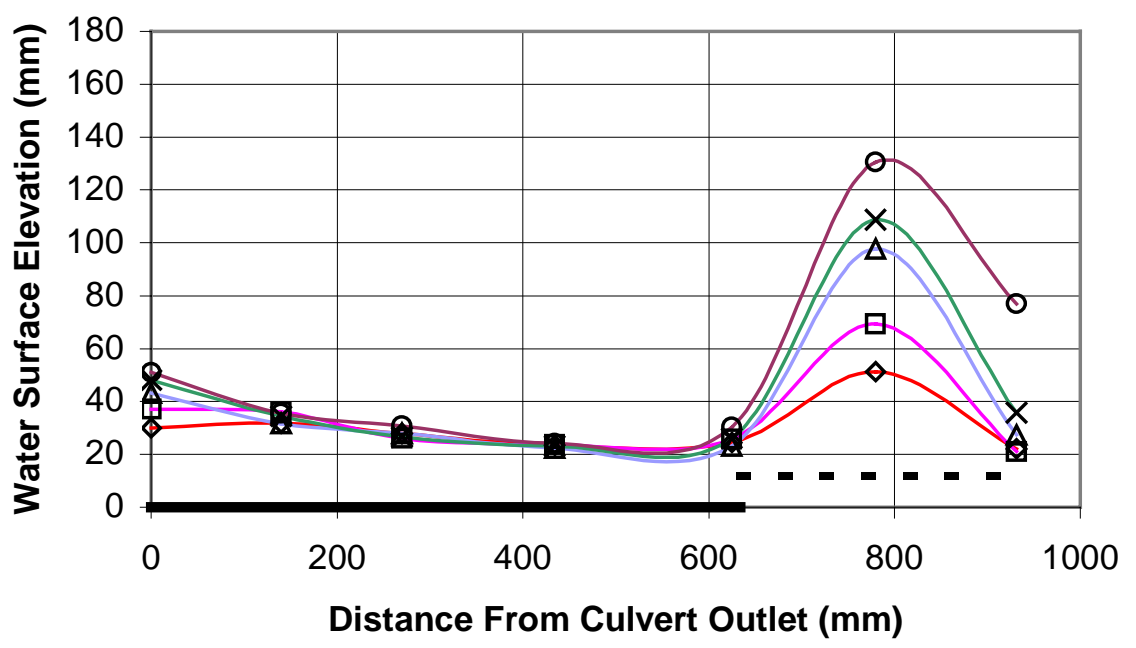

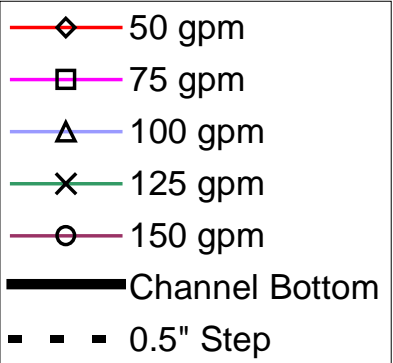

Figure 5.9 Plot of Water Surface Elevation for 0.5-inch Cast Acrylic Step at 6\% Culvert Slope 


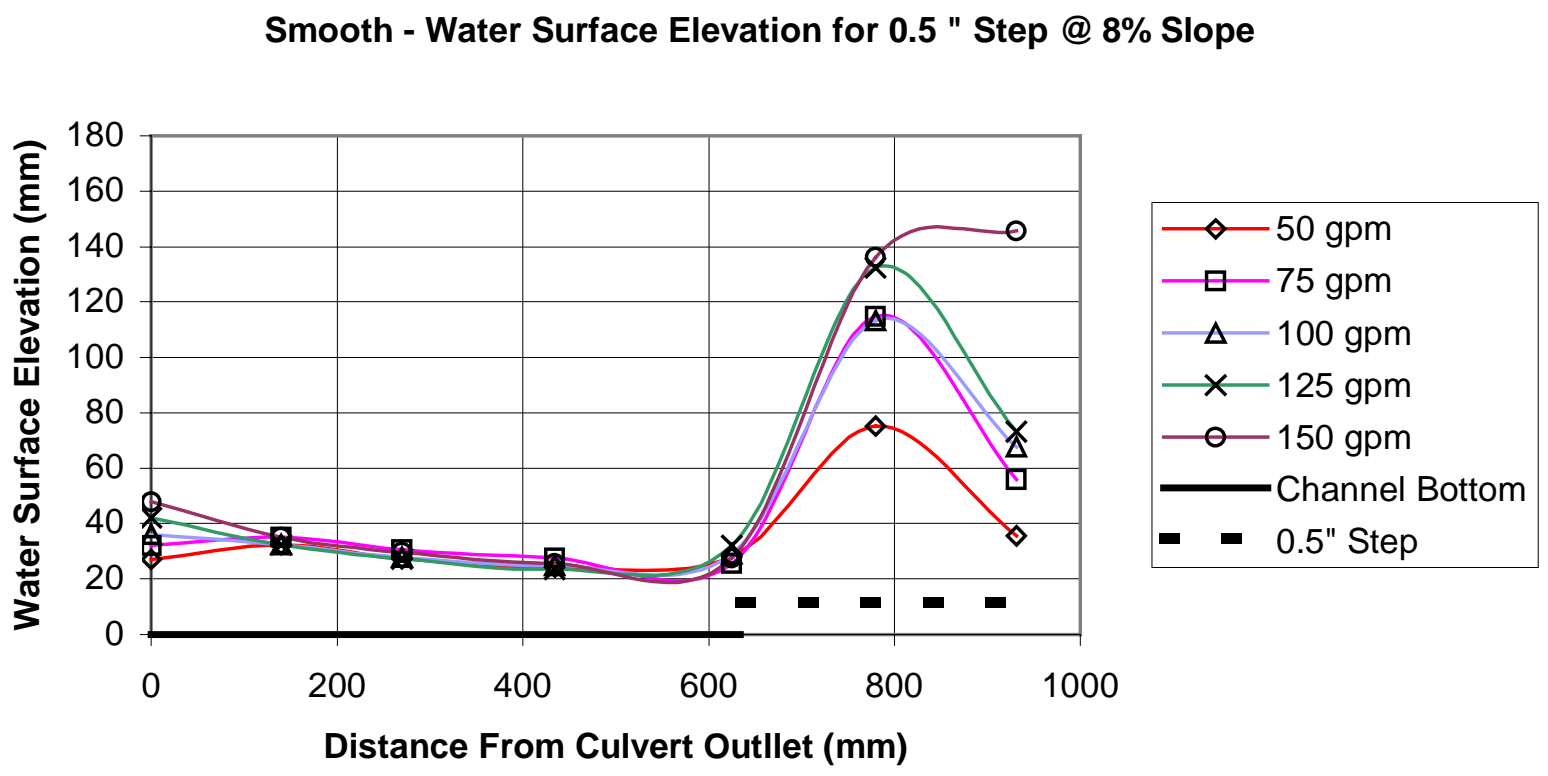

Figure 5.10 Plot of Water Surface Elevation for 0.5-inch Cast Acrylic Step at 8\% Culvert Slope

\begin{tabular}{|c|c|c|c|c|c|c|c|c|}
\hline \multirow[b]{2}{*}{ Flowrate } & \multicolumn{3}{|c|}{ Testing Channel Data - Zone 2} & \multicolumn{2}{|c|}{ Froude \# Calculations } & \multicolumn{3}{|c|}{ Energy Calculations } \\
\hline & $\begin{array}{c}\text { Average } \\
\text { Flow } \\
\text { Depth } \\
\text { (m) }\end{array}$ & $\begin{array}{c}\text { Average } \\
\text { Flow Area } \\
\left(\mathrm{m}^{2}\right)\end{array}$ & $\begin{array}{l}\text { Average } \\
\text { Flow } \\
\text { Velocity } \\
\\
(\mathrm{m} / \mathrm{s})\end{array}$ & $\begin{array}{c}\text { Fr \# } \\
\text { Based on } \\
\text { Circular } \\
\text { Cross- } \\
\text { Section }\end{array}$ & $\begin{array}{c}\text { Fr \# } \\
\text { Based on } \\
\text { Average } \\
\text { Zone } 2 \\
\text { Values }\end{array}$ & $\begin{array}{c}\text { Energy at } \\
\text { Culvert } \\
\text { Outlet } \\
\\
(\mathrm{mm})\end{array}$ & $\begin{array}{c}\text { Average } \\
\text { Energy in } \\
\text { Zone } 2 \\
\\
(\mathrm{~mm})\end{array}$ & $\begin{array}{c}\text { Non- } \\
\text { Dimensional } \\
\text { Energy } \\
\text { Difference }\end{array}$ \\
\hline 50 & 0.0136 & 0.00563 & 0.560 & 2.31 & 1.53 & 107 & 41.5 & 0.612 \\
\hline 75 & 0.0203 & 0.00837 & 0.566 & 2.38 & 1.27 & 135 & 48.5 & 0.640 \\
\hline 100 & 0.0256 & 0.0106 & 0.597 & 2.38 & 1.19 & 163 & 55.7 & 0.659 \\
\hline 125 & 0.0254 & 0.0105 & 0.753 & 2.45 & 1.51 & 194 & 66.2 & 0.659 \\
\hline 150 & 0.0277 & 0.0114 & 0.829 & 2.54 & 1.59 & 222 & 74.6 & 0.664 \\
\hline
\end{tabular}




\begin{tabular}{|c|c|c|c|c|c|c|c|c|}
\hline \multirow[b]{3}{*}{ Flowrate } & \multirow{2}{*}{\multicolumn{3}{|c|}{ Testing Channel Data - Zone 2}} & \multirow{2}{*}{\multicolumn{2}{|c|}{ Froude \# Calculations }} & \multirow{2}{*}{\multicolumn{3}{|c|}{ Energy Calculations }} \\
\hline & & & & & & & & \\
\hline & $\begin{array}{c}\text { Average } \\
\text { Flow } \\
\text { Depth }\end{array}$ & $\begin{array}{l}\text { Average } \\
\text { Flow Area }\end{array}$ & $\begin{array}{c}\text { Average } \\
\text { Flow } \\
\text { Velocity }\end{array}$ & $\begin{array}{c}\text { rr \# } \\
\text { Based on } \\
\text { Circular } \\
\text { Cross- } \\
\text { Section }\end{array}$ & $\begin{array}{l}\text { Fr \# } \\
\text { Based on } \\
\text { Average } \\
\text { Zone } 2 \\
\text { Values }\end{array}$ & $\begin{array}{c}\text { Energy at } \\
\text { Culvert } \\
\text { Outlet }\end{array}$ & $\begin{array}{c}\text { Average } \\
\text { Energy in } \\
\text { Zone } 2\end{array}$ & $\begin{array}{c}\text { Non- } \\
\text { Dimensional } \\
\text { Energy } \\
\text { Difference }\end{array}$ \\
\hline (gpm) & $(\mathrm{m})$ & $\left(m^{2}\right)$ & $(\mathrm{m} / \mathrm{s})$ & & & $(\mathrm{mm})$ & $(\mathrm{mm})$ & \\
\hline 50 & 0.00983 & 0.00406 & 0.777 & 2.97 & 2.51 & 134 & 52.6 & 0.607 \\
\hline 75 & 0.0224 & 0.00925 & 0.512 & 3.00 & 1.09 & 170 & 47.7 & 0.719 \\
\hline 100 & 0.0232 & 0.00957 & 0.660 & 3.02 & 1.38 & 197 & 57.3 & 0.709 \\
\hline 125 & 0.0219 & 0.00903 & 0.874 & 3.03 & 1.89 & 230 & 72.7 & 0.685 \\
\hline 150 & 0.0775 & 0.0320 & 0.296 & 3.02 & 0.340 & 260 & 93.8 & 0.640 \\
\hline
\end{tabular}

\begin{tabular}{|c|c|c|c|c|c|c|c|c|}
\hline \multirow[b]{3}{*}{ Flowrate } & \multirow{2}{*}{\multicolumn{3}{|c|}{ Testing Channel Data - Zone 2}} & \multirow{2}{*}{\multicolumn{2}{|c|}{ Froude \# Calculations }} & \multirow{2}{*}{\multicolumn{3}{|c|}{ Energy Calculations }} \\
\hline & & & & & & & & \\
\hline & $\begin{array}{l}\text { Average } \\
\text { Flow } \\
\text { Depth }\end{array}$ & $\begin{array}{c}\text { Average } \\
\text { Flow Area }\end{array}$ & $\begin{array}{l}\text { Average } \\
\text { Flow } \\
\text { Velocity }\end{array}$ & $\begin{array}{c}\text { Fr \# } \\
\text { Based on } \\
\text { Circular } \\
\text { Cross- } \\
\text { Section }\end{array}$ & $\begin{array}{c}\text { Fr \# } \\
\text { Based on } \\
\text { Average } \\
\text { Zone } 2 \\
\text { Values }\end{array}$ & $\begin{array}{c}\text { Energy at } \\
\text { Culvert } \\
\text { Outlet }\end{array}$ & $\begin{array}{c}\text { Average } \\
\text { Energy in } \\
\text { Zone } 2\end{array}$ & \begin{tabular}{|c|} 
Non- \\
Dimensional \\
Energy \\
Difference
\end{tabular} \\
\hline (gpm) & $(\mathrm{m})$ & $\left(m^{2}\right)$ & $(\mathrm{m} / \mathrm{s})$ & & & $(\mathrm{mm})$ & $(\mathrm{mm})$ & \\
\hline 50 & 0.0247 & 0.0102 & 0.309 & 3.71 & 0.629 & 166 & 41.5 & 0.750 \\
\hline 75 & 0.0333 & 0.0138 & 0.344 & 3.79 & 0.603 & 214 & 51.2 & 0.761 \\
\hline 100 & 0.0507 & 0.0209 & 0.302 & 3.73 & 0.428 & 247 & 67.2 & 0.728 \\
\hline 125 & 0.0604 & 0.0249 & 0.317 & 3.67 & 0.412 & 270 & 77.4 & 0.713 \\
\hline 150 & 0.0919 & 0.0380 & 0.250 & 3.70 & 0.263 & 311 & 107 & 0.656 \\
\hline
\end{tabular}

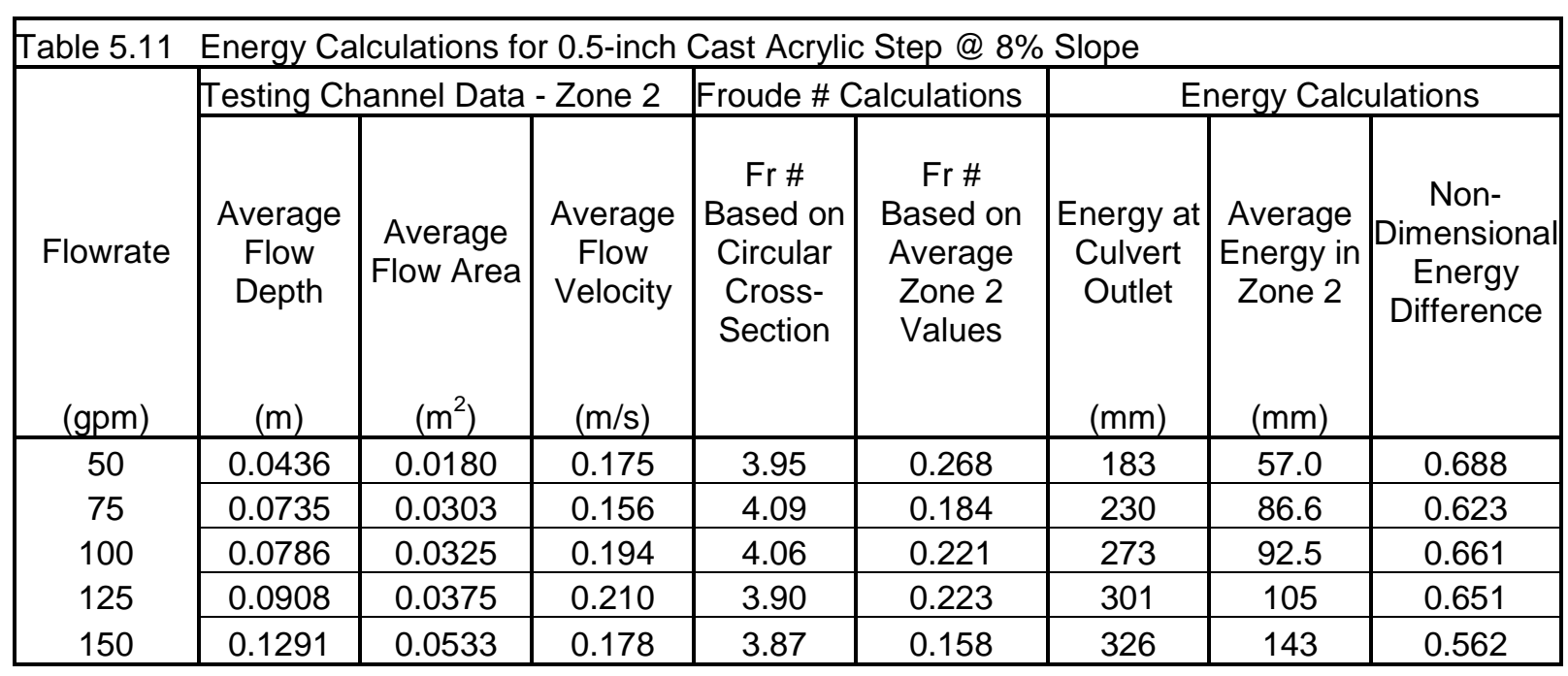




\subsection{0-inch Cast Acrylic Step}

Graphs of the water surface elevation for tests conducted at 2, 4, 6, and 8\% slopes are shown in Figures 5.11, 5.12, 5.13, and 5.14. After the water surface elevation was established, average flow depth was determined. From the flow depth and the results from Section 5.5, the aforementioned energy calculations were conducted. The results for the energy calculations for the 1.0-inch cast acrylic step are shown in Tables 5.12, 5.13, 5.14 and 5.15.

\section{Smooth - Water Surface Elevation for 1.0" Step @ 2\% Slope}

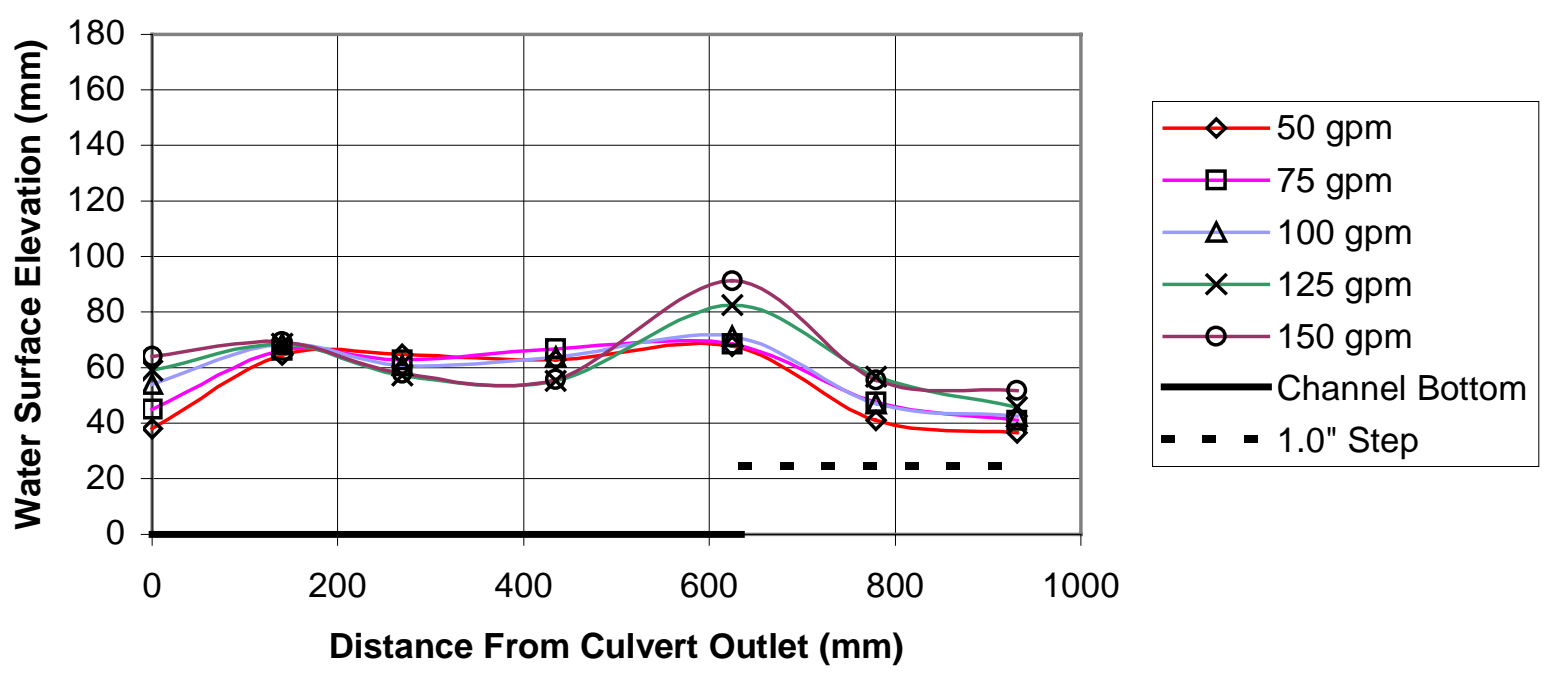

Figure 5.11 Plot of Water Surface Elevation for 1.0-inch Cast Acrylic Step at 2\% Culvert Slope 


\section{Smooth - Water Surface Elevation for 1.0" Step @ 4\% Slope}

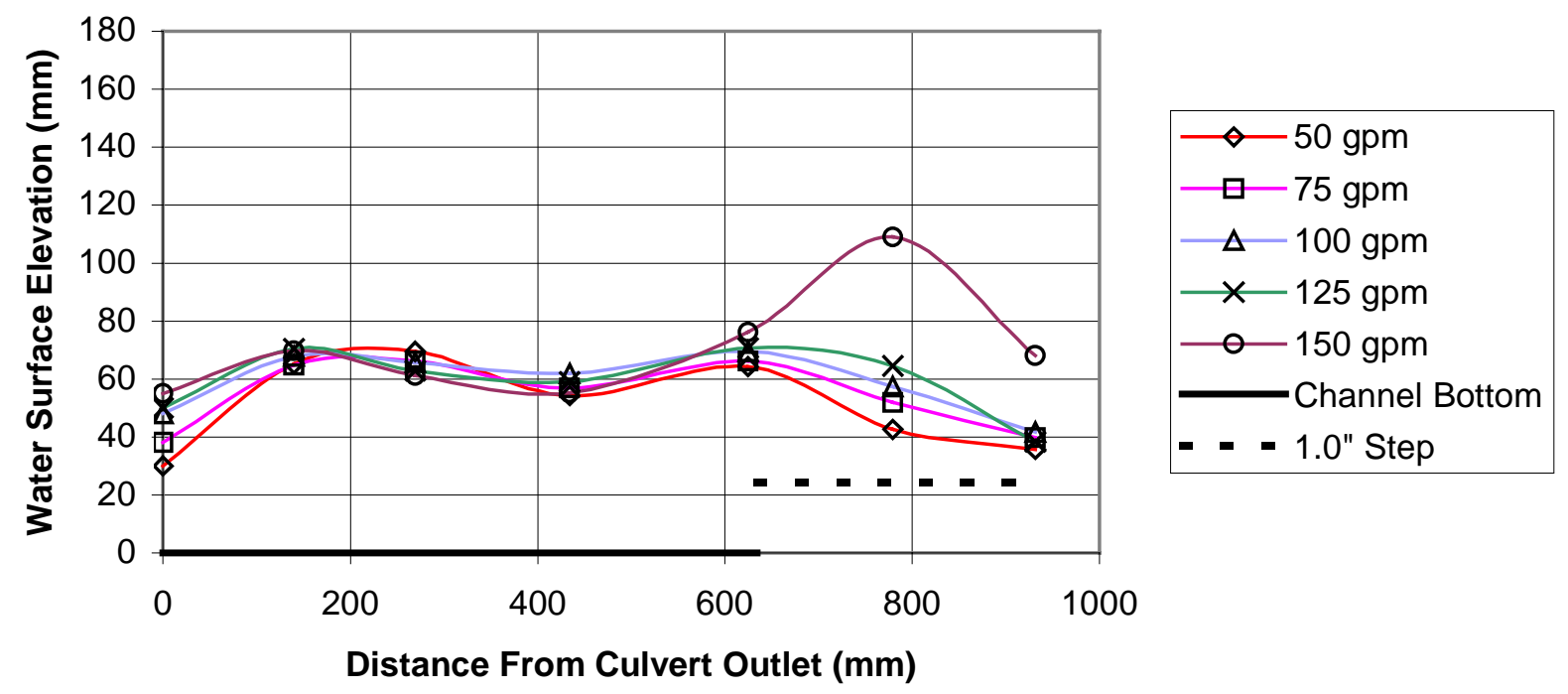

Figure 5.12 Plot of Water Surface Elevation for 1.0-inch Cast Acrylic Step at 4\% Culvert Slope

\section{Smooth - Water Surface Elevation for 1.0" Step @ 6\% Slope}

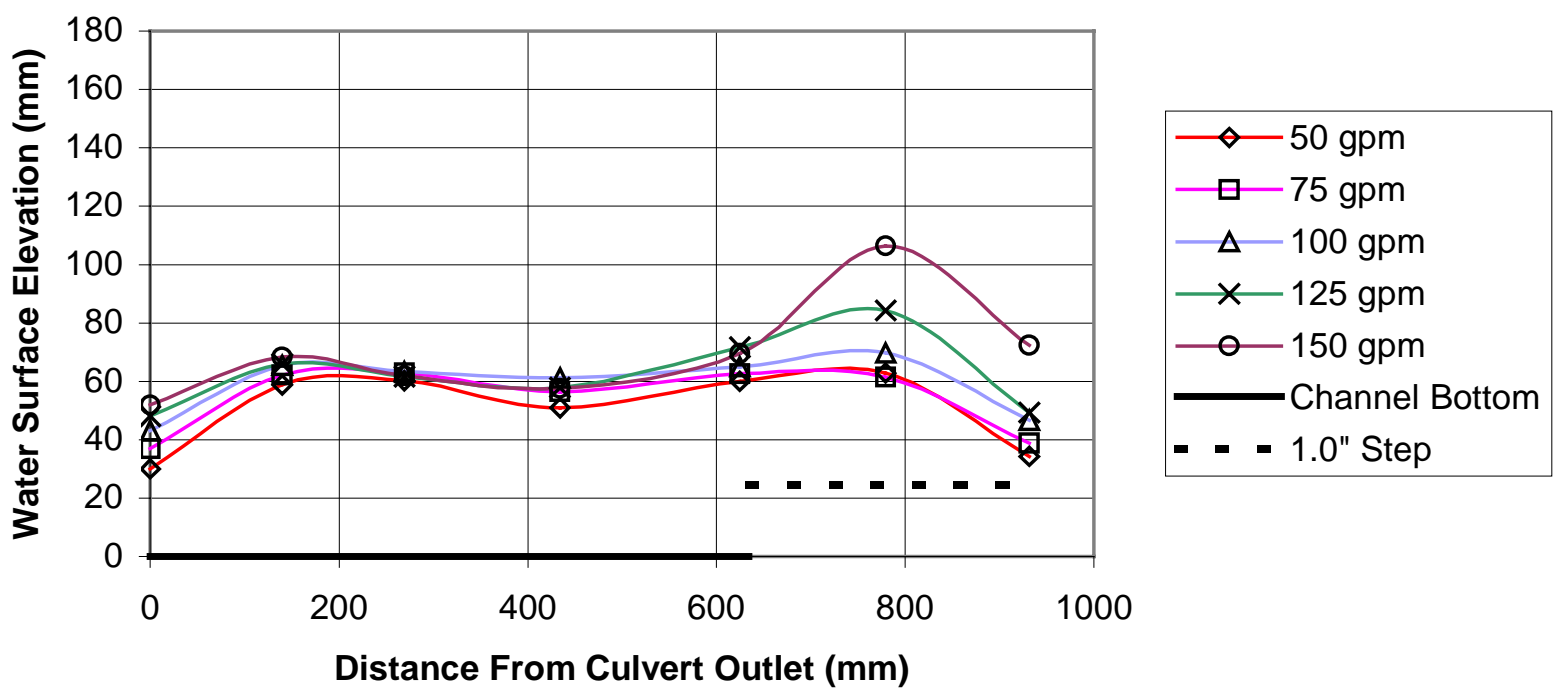

Figure 5.13 Plot of Water Surface Elevation for 1.0-inch Cast Acrylic Step at 6\% Culvert Slope 


\section{Smooth - Water Surface Elevation for 1.0" Step @ 8\% Slope}

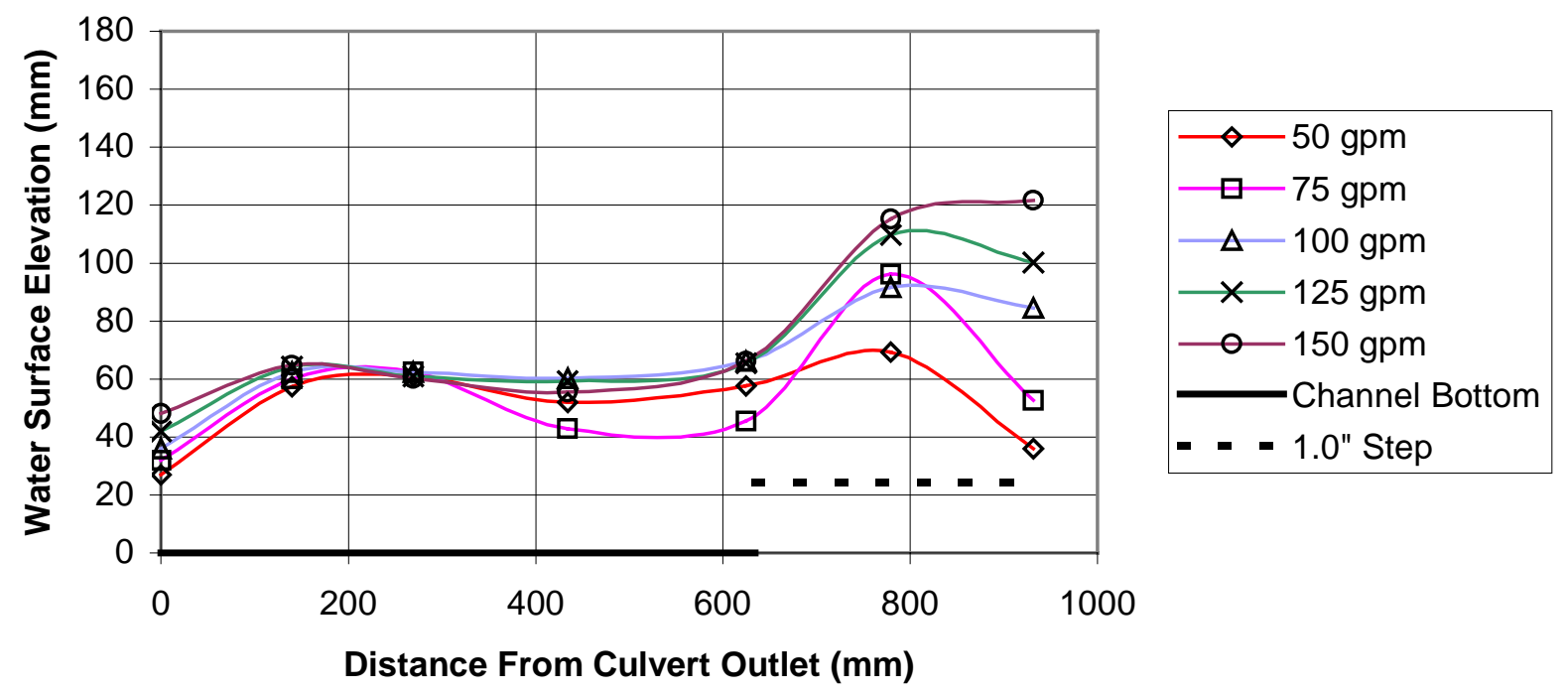

Figure 5.14 Plot of Water Surface Elevation for 1.0-inch Cast Acrylic Step at 8\% Culvert Slope

\begin{tabular}{|c|c|c|c|c|c|c|c|c|}
\hline \multirow[b]{2}{*}{ Flowrate } & \multicolumn{3}{|c|}{ Testing Channel Data - Zone 2} & \multicolumn{2}{|c|}{ Froude \# Calculations } & \multicolumn{3}{|c|}{ Energy Calculations } \\
\hline & $\begin{array}{c}\text { Average } \\
\text { Flow } \\
\text { Depth } \\
\\
\text { (m) }\end{array}$ & $\begin{array}{c}\text { Average } \\
\text { Flow Area } \\
\left(\mathrm{m}^{2}\right)\end{array}$ & $\begin{array}{l}\text { Average } \\
\text { Flow } \\
\text { Velocity } \\
\\
(\mathrm{m} / \mathrm{s})\end{array}$ & $\begin{array}{c}\text { Fr \# } \\
\text { Based on } \\
\text { Circular } \\
\text { Cross- } \\
\text { Section }\end{array}$ & \begin{tabular}{|c|} 
Fr \# \\
Based on \\
Average \\
Zone 2 \\
Values
\end{tabular} & $\begin{array}{c}\text { Energy at } \\
\text { Culvert } \\
\text { Outlet } \\
(\mathrm{mm})\end{array}$ & $\begin{array}{c}\text { Average } \\
\text { Energy in } \\
\text { Zone } 2 \\
(\mathrm{~mm})\end{array}$ & $\begin{array}{c}\text { Non- } \\
\text { Dimensional } \\
\text { Energy } \\
\text { Difference }\end{array}$ \\
\hline 50 & 0.0144 & 0.00595 & 0.530 & 2.31 & 1.41 & 107 & 53.2 & 0.504 \\
\hline 75 & 0.0199 & 0.00821 & 0.577 & 2.38 & 1.31 & 138 & 61.2 & 0.557 \\
\hline 100 & 0.0203 & 0.00840 & 0.752 & 2.38 & 1.68 & 163 & 73.5 & 0.550 \\
\hline 125 & 0.0269 & 0.0111 & 0.711 & 2.45 & 1.38 & 194 & 77.0 & 0.603 \\
\hline 150 & 0.0292 & 0.0121 & 0.786 & 2.54 & 1.47 & 217 & 85.1 & 0.607 \\
\hline
\end{tabular}




\begin{tabular}{|c|c|c|c|c|c|c|c|c|}
\hline \multirow[b]{3}{*}{ Flowrate } & \multirow{2}{*}{\multicolumn{3}{|c|}{ Testing Channel Data - Zone 2}} & \multirow{2}{*}{\multicolumn{2}{|c|}{ Froude \# Calculations }} & \multirow{2}{*}{\multicolumn{3}{|c|}{ Energy Calculations }} \\
\hline & & & & & & & & \\
\hline & $\begin{array}{c}\text { Average } \\
\text { Flow } \\
\text { Depth }\end{array}$ & $\begin{array}{l}\text { Average } \\
\text { Flow Area }\end{array}$ & $\begin{array}{l}\text { Average } \\
\text { Flow } \\
\text { Velocity }\end{array}$ & $\begin{array}{c}\text { Fr \# } \\
\text { Based on } \\
\text { Circular } \\
\text { Cross- } \\
\text { Section }\end{array}$ & $\begin{array}{c}\text { Fr \# } \\
\text { Based on } \\
\text { Average } \\
\text { Zone } 2 \\
\text { Values }\end{array}$ & $\begin{array}{c}\text { Energy at } \\
\text { Culvert } \\
\text { Outlet }\end{array}$ & $\begin{array}{l}\text { Average } \\
\text { Energy in } \\
\text { Zone } 2\end{array}$ & \begin{tabular}{|c|} 
Non- \\
Dimensional \\
Energy \\
Difference
\end{tabular} \\
\hline (gpm) & $(\mathrm{m})$ & $\left(m^{2}\right)$ & $(\mathrm{m} / \mathrm{s})$ & & & $(\mathrm{mm})$ & $(\mathrm{mm})$ & \\
\hline 50 & 0.0148 & 0.00611 & 0.517 & 2.97 & 1.36 & 136 & 52.8 & 0.611 \\
\hline 75 & 0.0214 & 0.00884 & 0.536 & 3.00 & 1.17 & 168 & 60.4 & 0.640 \\
\hline 100 & 0.0251 & 0.0104 & 0.608 & 3.02 & 1.22 & 201 & 68.4 & 0.659 \\
\hline 125 & 0.0271 & 0.0112 & 0.707 & 3.03 & 1.37 & 230 & 76.9 & 0.666 \\
\hline 150 & 0.0642 & 0.0265 & 0.357 & 3.02 & 0.450 & 258 & 95.1 & 0.631 \\
\hline
\end{tabular}

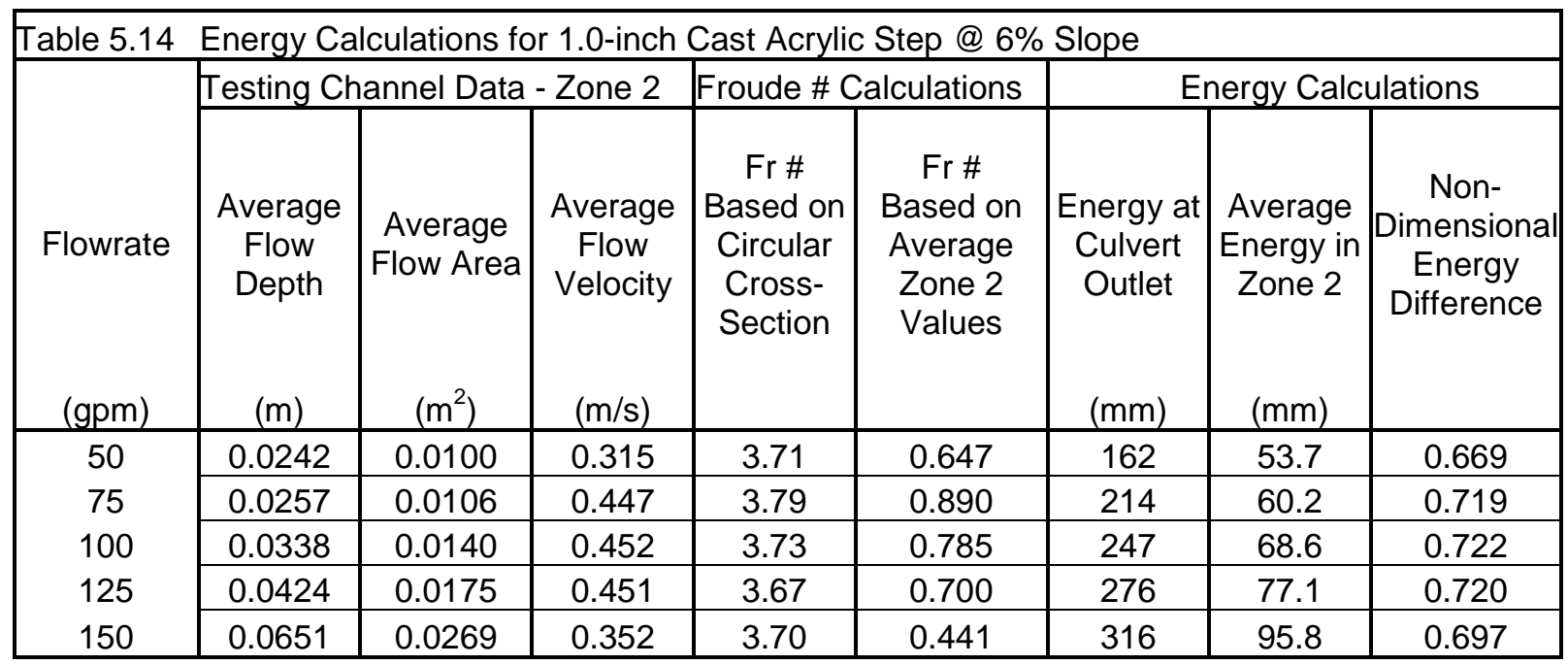

\begin{tabular}{|c|c|c|c|c|c|c|c|c|}
\hline \multirow[b]{3}{*}{ Flowrate } & \multirow{2}{*}{\multicolumn{3}{|c|}{ Testing Channel Data - Zone 2}} & \multirow{2}{*}{\multicolumn{2}{|c|}{ Froude \# Calculations }} & \multirow{2}{*}{\multicolumn{3}{|c|}{ Energy Calculations }} \\
\hline & & & & & & & & \\
\hline & $\begin{array}{l}\text { Average } \\
\text { Flow } \\
\text { Depth }\end{array}$ & $\begin{array}{l}\text { Average } \\
\text { Flow Area }\end{array}$ & $\begin{array}{l}\text { Average } \\
\text { Flow } \\
\text { Velocity }\end{array}$ & \begin{tabular}{|c} 
Fr \# \\
Based on \\
Circular \\
Cross- \\
Section
\end{tabular} & $\begin{array}{c}\text { Fr \# } \\
\text { Based on } \\
\text { Average } \\
\text { Zone } 2 \\
\text { Values }\end{array}$ & $\begin{array}{c}\text { Energy at } \\
\text { Culvert } \\
\text { Outlet }\end{array}$ & $\begin{array}{c}\text { Average } \\
\text { Energy in } \\
\text { Zone } 2\end{array}$ & \begin{tabular}{|c|} 
Non- \\
Dimensional \\
Energy \\
Difference
\end{tabular} \\
\hline (gpm) & (m) & $\left(m^{2}\right)$ & $(\mathrm{m} / \mathrm{s})$ & & & $(\mathrm{mm})$ & $(\mathrm{mm})$ & \\
\hline 50 & 0.0282 & 0.0116 & 0.271 & 3.95 & 0.516 & 183 & 56.3 & 0.692 \\
\hline 75 & 0.0500 & 0.0206 & 0.229 & 4.09 & 0.328 & 234 & 77.1 & 0.671 \\
\hline 100 & 0.0638 & 0.0263 & 0.240 & 4.06 & 0.303 & 273 & 91.1 & 0.666 \\
\hline 125 & 0.0806 & 0.0333 & 0.237 & 3.90 & 0.267 & 299 & 108 & 0.640 \\
\hline 150 & 0.0941 & 0.0389 & 0.244 & 3.87 & 0.254 & 326 & 122 & 0.627 \\
\hline
\end{tabular}




\subsection{5-inch Cast Acrylic Step}

Graphs of the water surface elevation for tests conducted at 2, 4, 6, and 8\% slopes are shown in Figures 5.15, 5.16, 5.17, and 5.18. After the water surface elevation was established, average flow depth was determined. From the flow depth and the results from Section 5.5, the aforementioned energy calculations were conducted. The results for the energy calculations for the 1.5-inch cast acrylic step are shown in Tables 5.16, 5.17, 5.18 and 5.19.

\section{Smooth - Water Surface Elevation for 1.5" Step @ 2\% Slope}

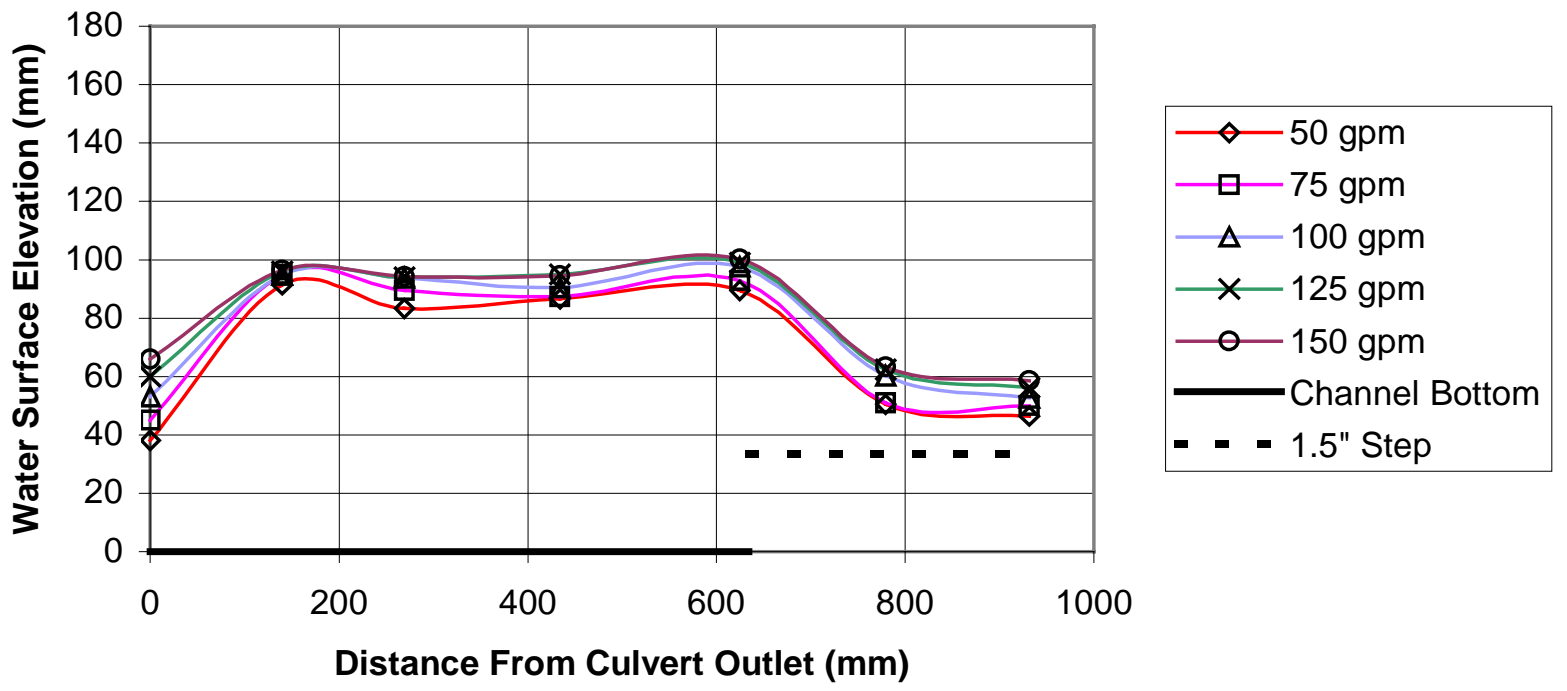

Figure 5.15 Plot of Water Surface Elevation for 1.5-inch Cast Acrylic Step at 2\% Culvert Slope 


\section{Smooth - Water Surface Elevation for 1.5" Step @ 4\% Slope}

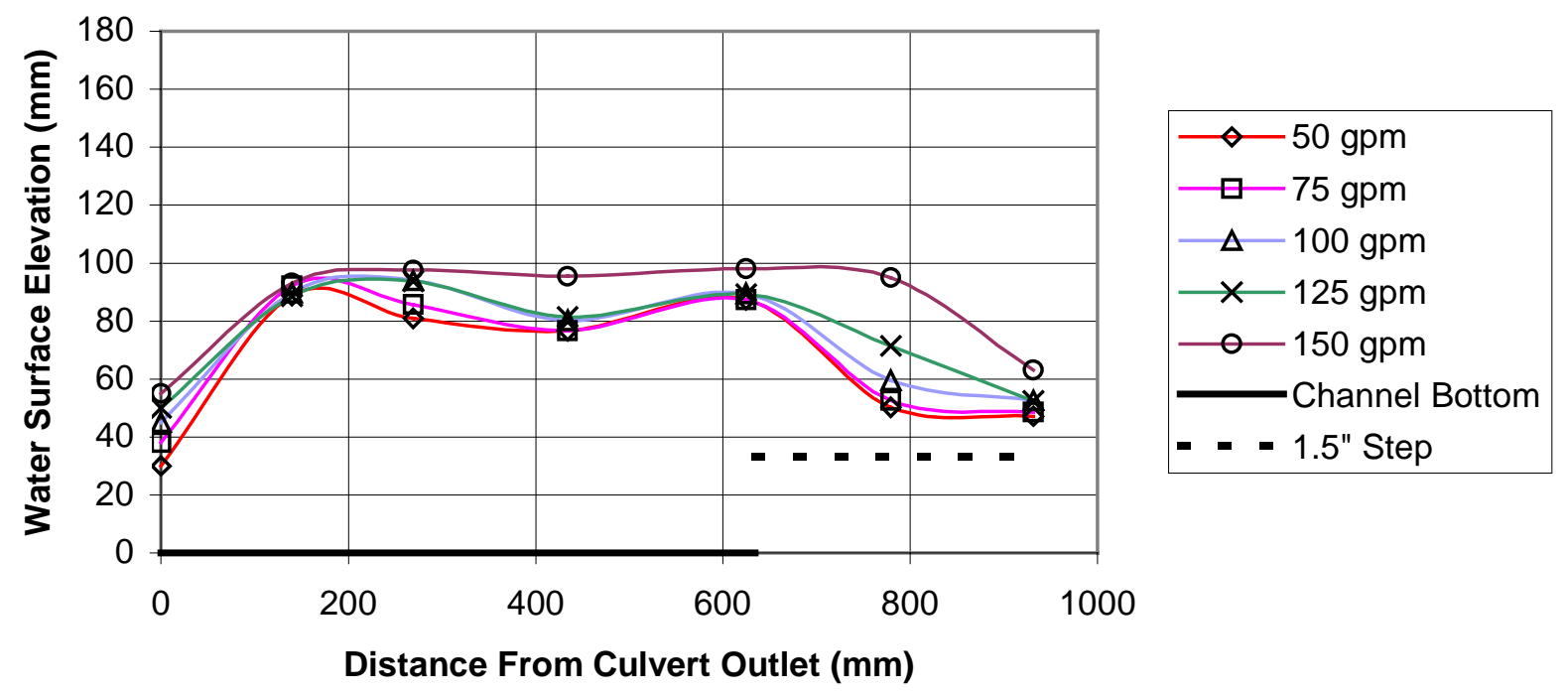

Figure 5.16 Plot of Water Surface Elevation for 1.5-inch Cast Acrylic Step at 4\% Culvert Slope

\section{Smooth - Water Surface Elevation for 1.5" Step @ 6\% Slope}

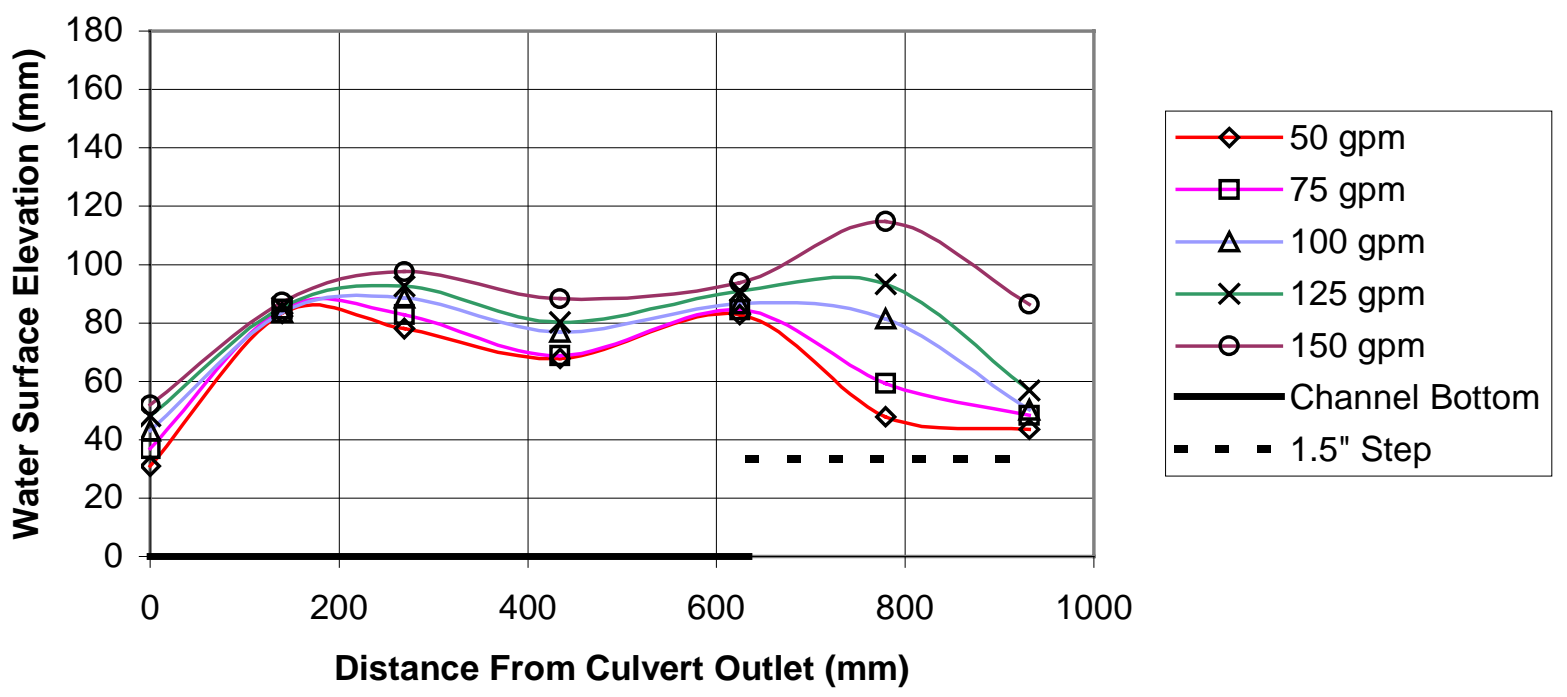

Figure 5.17 Plot of Water Surface Elevation for 1.5-inch Cast Acrylic Step at 6\% Culvert Slope 
Smooth - Water Surface Elevation for 1.5" Step @ 8\% Slope

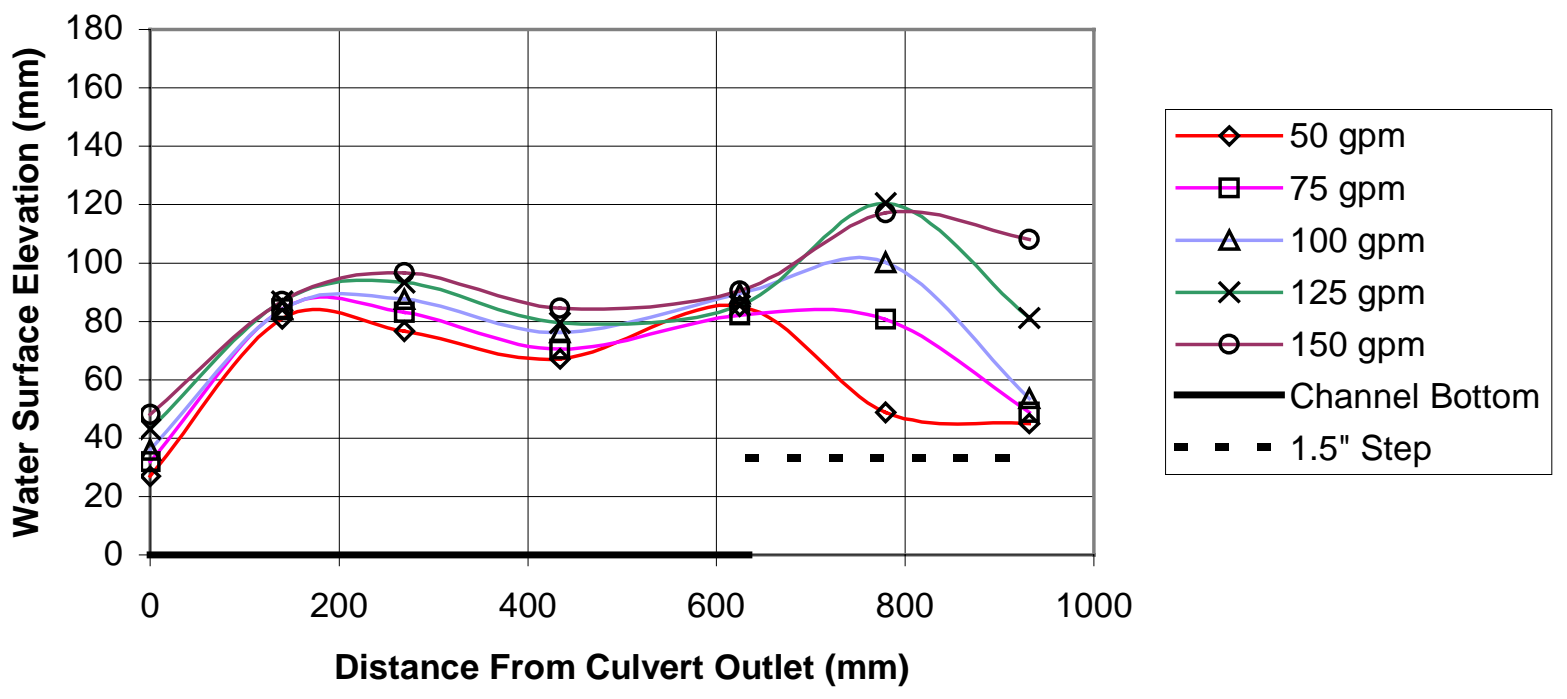

Figure 5.18 Plot of Water Surface Elevation for 1.5-inch Cast Acrylic Step at 8\% Culvert Slope

\begin{tabular}{|c|c|c|c|c|c|c|c|c|}
\hline & \\
\hline \multirow[b]{2}{*}{ Flowrate } & \multicolumn{3}{|c|}{ Testing Channel Data - Zone 2} & \multicolumn{2}{|c|}{ Froude \# Calculations } & \multicolumn{3}{|c|}{ Energy Calculations } \\
\hline & $\begin{array}{c}\text { Average } \\
\text { Flow } \\
\text { Depth } \\
\\
(\mathrm{m}) \\
\end{array}$ & \begin{tabular}{|c|} 
Average \\
Flow Area \\
$\left(\mathrm{m}^{2}\right)$ \\
\end{tabular} & $\begin{array}{c}\text { Average } \\
\text { Flow } \\
\text { Velocity } \\
\\
(\mathrm{m} / \mathrm{s})\end{array}$ & $\begin{array}{c}\text { Fr \# } \\
\text { Based on } \\
\text { Circular } \\
\text { Cross- } \\
\text { Section }\end{array}$ & $\begin{array}{c}\text { Fr \# } \\
\text { Based on } \\
\text { Average } \\
\text { Zone } 2 \\
\text { Values }\end{array}$ & $\begin{array}{c}\text { Energy at } \\
\text { Culvert } \\
\text { Outlet } \\
\\
(\mathrm{mm}) \\
\end{array}$ & $\begin{array}{c}\text { Average } \\
\text { Energy in } \\
\text { Zone } 2 \\
(\mathrm{~mm})\end{array}$ & $\begin{array}{c}\text { Non- } \\
\text { Dimensional } \\
\text { Energy } \\
\text { Difference }\end{array}$ \\
\hline 50 & 0.0152 & 0.00629 & 0.501 & 2.31 & 1.30 & 107 & 61.3 & 0.428 \\
\hline 75 & 0.0172 & 0.00711 & 0.666 & 2.38 & 1.62 & 137 & 73.1 & 0.467 \\
\hline 100 & 0.0233 & 0.00963 & 0.656 & 2.38 & 1.37 & 163 & 78.5 & 0.519 \\
\hline 125 & 0.0261 & 0.0108 & 0.731 & 2.45 & 1.44 & 189 & 86.6 & 0.542 \\
\hline 150 & 0.0278 & 0.0115 & 0.825 & 2.54 & 1.58 & 222 & 95.7 & 0.569 \\
\hline
\end{tabular}




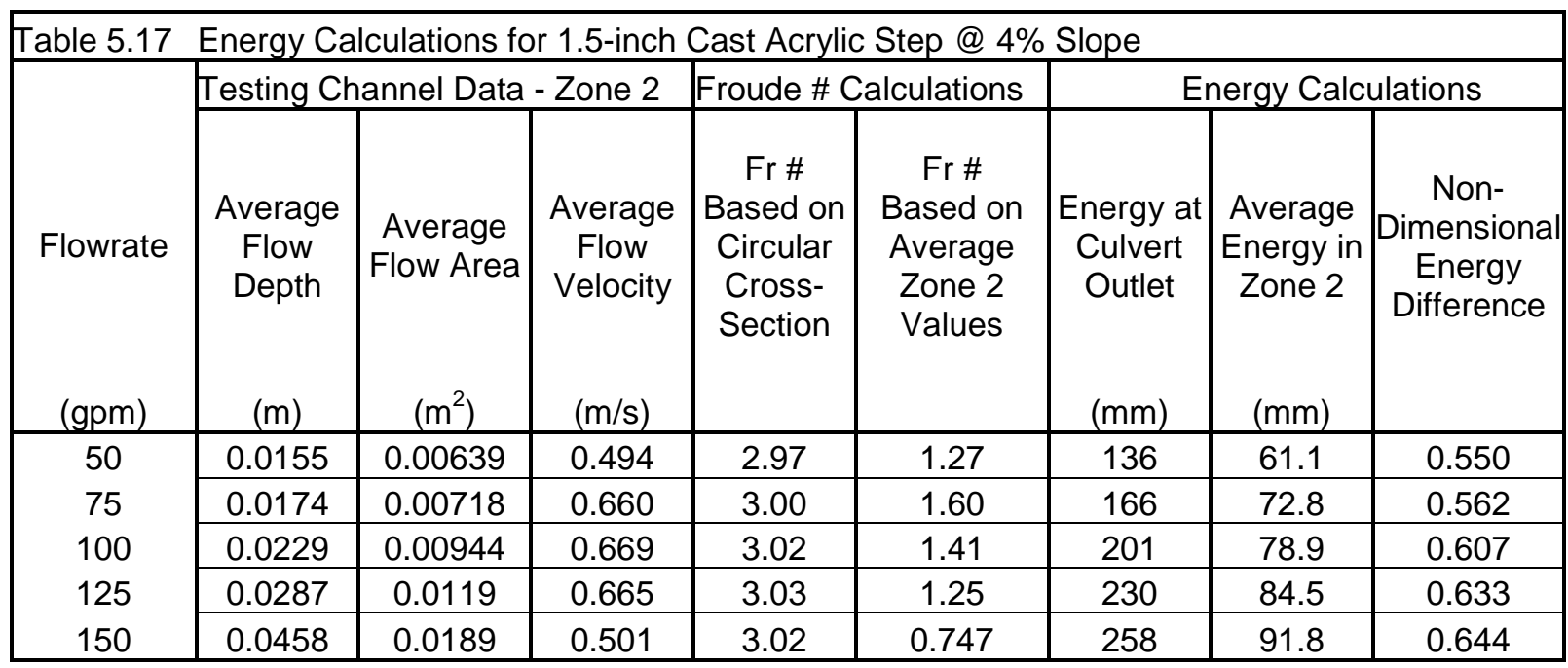

\begin{tabular}{|c|c|c|c|c|c|c|c|c|}
\hline \multirow[b]{3}{*}{ Flowrate } & \multirow{2}{*}{\multicolumn{3}{|c|}{ Testing Channel Data - Zone 2}} & \multirow{2}{*}{\multicolumn{2}{|c|}{ Froude \# Calculations }} & \multirow{2}{*}{\multicolumn{3}{|c|}{ Energy Calculations }} \\
\hline & & & & & & & & \\
\hline & $\begin{array}{l}\text { Average } \\
\text { Flow } \\
\text { Depth }\end{array}$ & $\begin{array}{c}\text { Average } \\
\text { Flow Area }\end{array}$ & $\begin{array}{l}\text { Average } \\
\text { Flow } \\
\text { Velocity }\end{array}$ & $\begin{array}{c}\text { Fr \# } \\
\text { Based on } \\
\text { Circular } \\
\text { Cross- } \\
\text { Section }\end{array}$ & $\begin{array}{l}\text { Fr \# } \\
\text { Based on } \\
\text { Average } \\
\text { Zone } 2 \\
\text { Values }\end{array}$ & $\begin{array}{c}\text { Energy at } \\
\text { Culvert } \\
\text { Outlet }\end{array}$ & $\begin{array}{l}\text { Average } \\
\text { Energy in } \\
\text { Zone } 2\end{array}$ & $\begin{array}{c}\text { Non- } \\
\text { Dimensional } \\
\text { Energy } \\
\text { Difference }\end{array}$ \\
\hline (gpm) & $(\mathrm{m})$ & $\left(m^{2}\right)$ & $(\mathrm{m} / \mathrm{s})$ & & & $(\mathrm{mm})$ & $(\mathrm{mm})$ & \\
\hline 50 & 0.0125 & 0.00516 & 0.611 & 3.71 & 1.75 & 168 & 64.8 & 0.615 \\
\hline 75 & 0.0206 & 0.00850 & 0.557 & 3.79 & 1.24 & 214 & 69.6 & 0.675 \\
\hline 100 & 0.0326 & 0.0135 & 0.469 & 3.73 & 0.829 & 247 & 77.0 & 0.688 \\
\hline 125 & 0.0418 & 0.0173 & 0.457 & 3.67 & 0.713 & 282 & 85.7 & 0.696 \\
\hline 150 & 0.0674 & 0.0278 & 0.341 & 3.70 & 0.419 & 316 & 106 & 0.663 \\
\hline
\end{tabular}

\begin{tabular}{|c|c|c|c|c|c|c|c|c|}
\hline \multirow[b]{3}{*}{ Flowrate } & \multirow{2}{*}{\multicolumn{3}{|c|}{ Testing Channel Data - Zone 2}} & & & & & \\
\hline & & & & \multicolumn{2}{|c|}{ Froude \# Calculations } & \multicolumn{3}{|c|}{ Energy Calculations } \\
\hline & $\begin{array}{l}\text { Average } \\
\text { Flow } \\
\text { Depth }\end{array}$ & $\begin{array}{l}\text { Average } \\
\text { Flow Area }\end{array}$ & $\begin{array}{l}\text { Average } \\
\text { Flow } \\
\text { Velocity }\end{array}$ & \begin{tabular}{|c} 
Fr \# \\
Based on \\
Circular \\
Cross- \\
Section
\end{tabular} & $\begin{array}{c}\text { Fr \# } \\
\text { Based on } \\
\text { Average } \\
\text { Zone } 2 \\
\text { Values }\end{array}$ & $\begin{array}{c}\text { Energy at } \\
\text { Culvert } \\
\text { Outlet }\end{array}$ & $\begin{array}{c}\text { Average } \\
\text { Energy in } \\
\text { Zone } 2\end{array}$ & \begin{tabular}{|c|} 
Non- \\
Dimensional \\
Energy \\
Difference
\end{tabular} \\
\hline (gpm) & (m) & $\left(m^{2}\right)$ & $(\mathrm{m} / \mathrm{s})$ & & & $(\mathrm{mm})$ & $(\mathrm{mm})$ & \\
\hline 50 & 0.0136 & 0.0056 & 0.560 & 3.95 & 1.53 & 181 & 62.9 & 0.653 \\
\hline 75 & 0.0315 & 0.0130 & 0.364 & 4.09 & 0.656 & 237 & 71.5 & 0.698 \\
\hline 100 & 0.0437 & 0.0180 & 0.350 & 4.06 & 0.535 & 273 & 83.1 & 0.695 \\
\hline 125 & 0.0677 & 0.0279 & 0.282 & 3.90 & 0.347 & 296 & 105 & 0.646 \\
\hline 150 & 0.0794 & 0.0328 & 0.289 & 3.87 & 0.327 & 329 & 117 & 0.645 \\
\hline
\end{tabular}




\subsection{0-inch Cast Acrylic Step}

Graphs of the water surface elevation for tests conducted at 2, 4, 6, and 8\% slopes are shown in Figures 5.19, 5.20, 5.21, and 5.22. After the water surface elevation was established, average flow depth was determined. From the flow depth and the results from Section 5.5, the aforementioned energy calculations were conducted. The results for the energy calculations for the 2.0-inch cast acrylic step are shown in Tables 5.20, 5.21, 5.22 and 5.23.

\section{Smooth - Water Surface Elevation for 2.0" Step @ 2\% Slope}

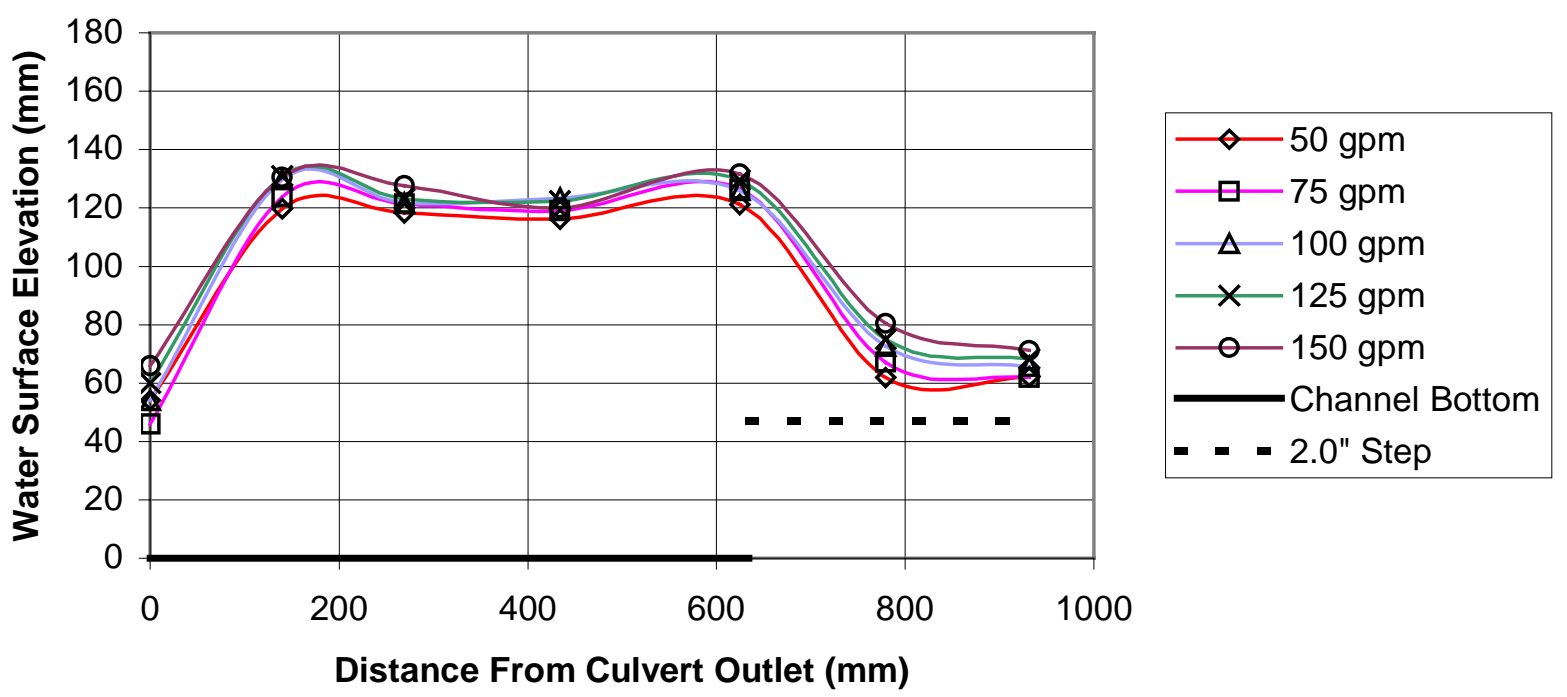

Figure 5.19 Plot of Water Surface Elevation for 2.0-inch Cast Acrylic Step at 2\% Culvert Slope 


\section{Smooth - Water Surface Elevation for 2.0" Step @ 4\% Slope}

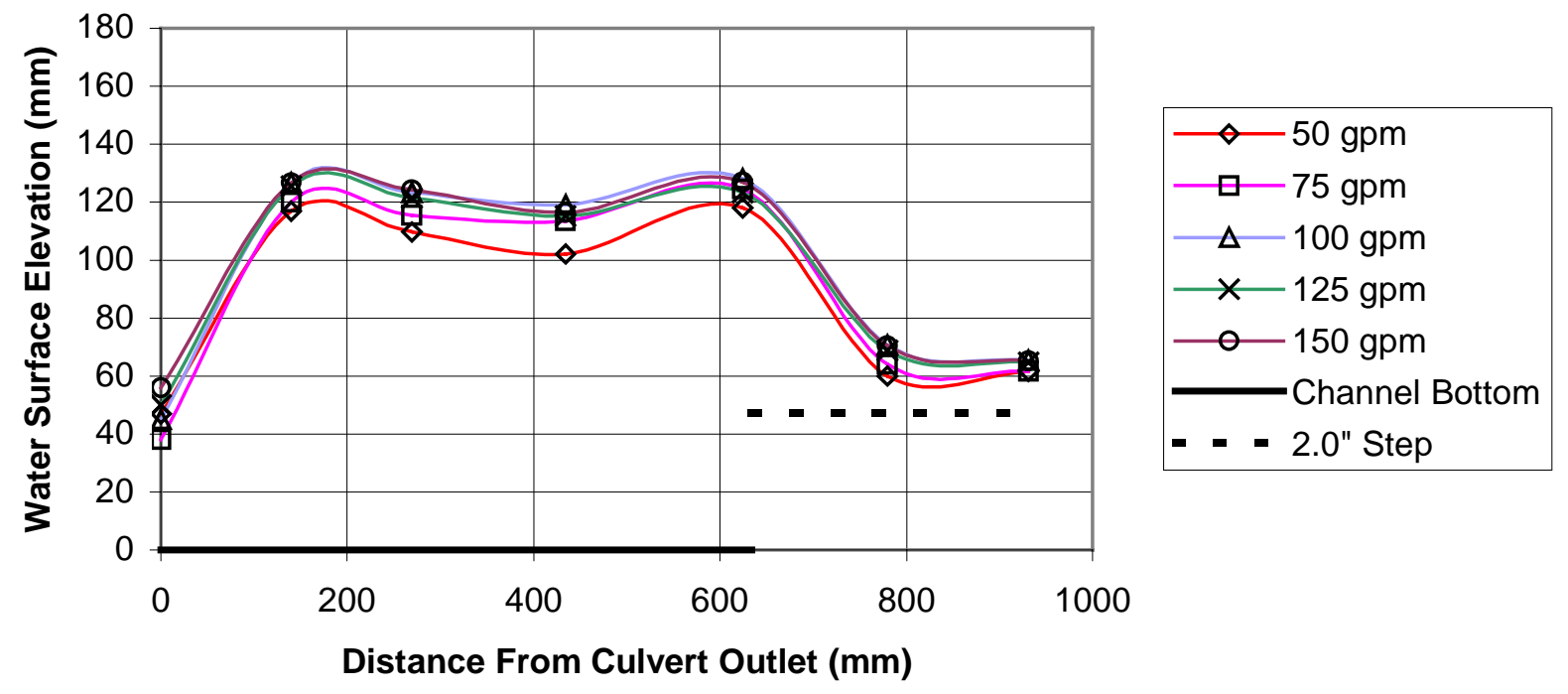

Figure 5.20 Plot of Water Surface Elevation for 2.0-inch Cast Acrylic Step at 4\% Culvert Slope

\section{Smooth - Water Surface Elevation for 2.0" Step @ 6\% Slope}

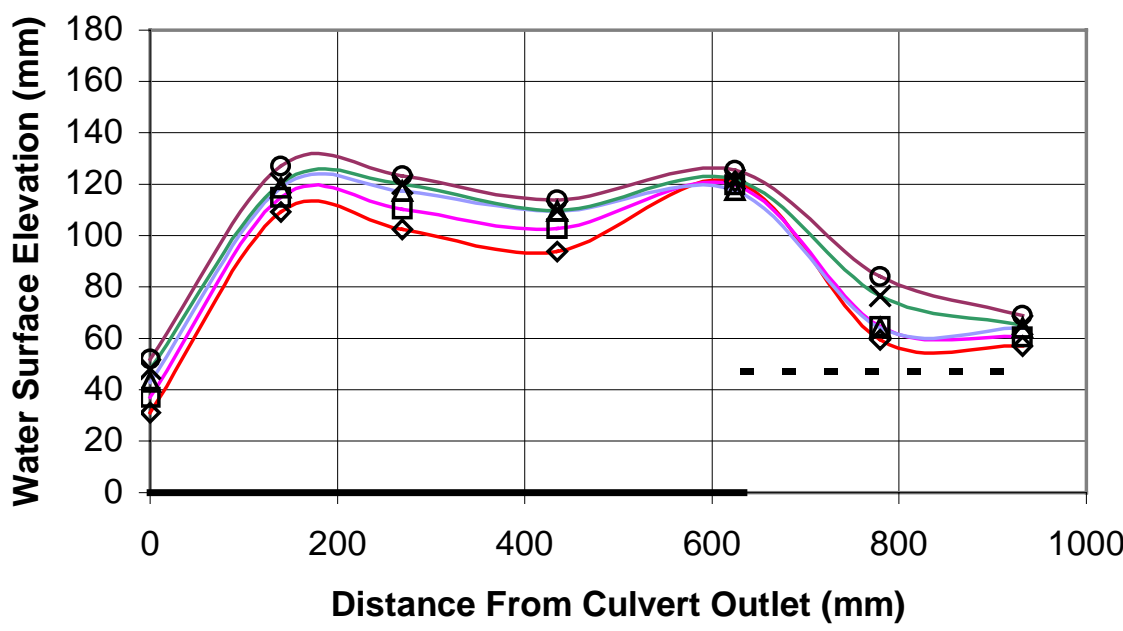

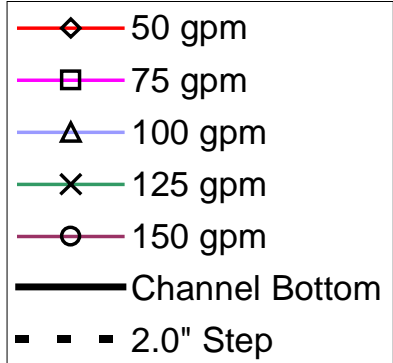

Figure 5.21 Plot of Water Surface Elevation for 2.0-inch Cast Acrylic Step at 6\% Culvert Slope 
Smooth - Water Surface Elevation for 2.0" Step @ 8\% Slope

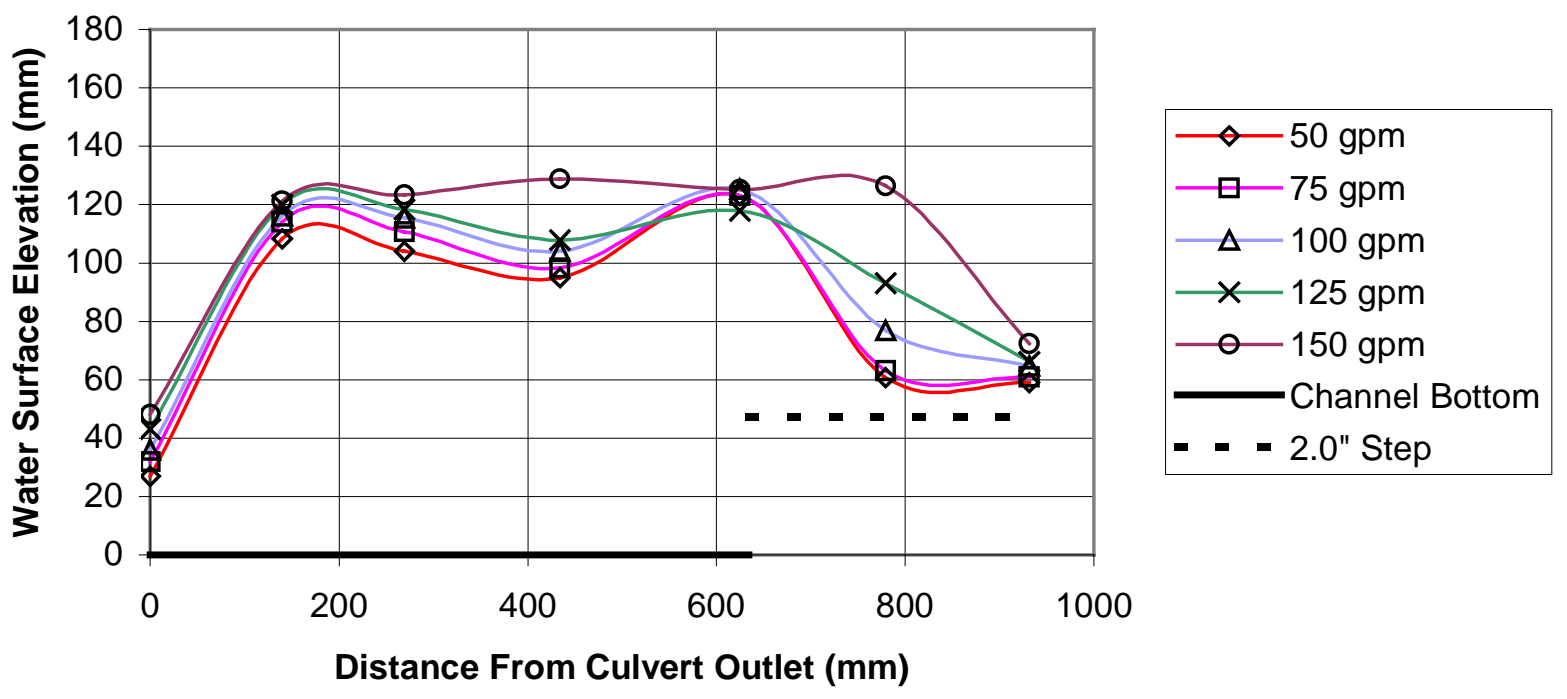

Figure 5.22 Plot of Water Surface Elevation for 2.0-inch Cast Acrylic Step at 8\% Culvert Slope

\begin{tabular}{|c|c|c|c|c|c|c|c|c|}
\hline able 5.20 & \multicolumn{8}{|c|}{ Energy Calculations for 2.0-inch Cast Acrylic Step @ 2\% Slope } \\
\hline \multirow[b]{2}{*}{ Flowrate } & \multicolumn{3}{|c|}{ Testing Channel Data - Zone 2} & \multicolumn{2}{|c|}{ Froude \# Calculations } & \multicolumn{3}{|c|}{ Energy Calculations } \\
\hline & $\begin{array}{c}\text { Average } \\
\text { Flow } \\
\text { Depth } \\
\\
(\mathrm{m})\end{array}$ & $\begin{array}{c}\text { Average } \\
\text { Flow Area } \\
\left(\mathrm{m}^{2}\right)\end{array}$ & $\begin{array}{l}\text { Average } \\
\text { Flow } \\
\text { Velocity } \\
\\
(\mathrm{m} / \mathrm{s})\end{array}$ & $\begin{array}{c}\text { Fr \# } \\
\text { Based on } \\
\text { Circular } \\
\text { Cross- } \\
\text { Section }\end{array}$ & $\begin{array}{c}\text { Fr \# } \\
\text { Based on } \\
\text { Average } \\
\text { Zone } 2 \\
\text { Values }\end{array}$ & $\begin{array}{c}\text { Energy at } \\
\text { Culvert } \\
\text { Outlet } \\
\\
(\mathrm{mm})\end{array}$ & $\begin{array}{c}\text { Average } \\
\text { Energy in } \\
\text { Zone } 2 \\
\\
(\mathrm{~mm})\end{array}$ & \begin{tabular}{|c} 
Non- \\
Dimensional \\
Energy \\
Difference
\end{tabular} \\
\hline 50 & 0.0148 & 0.00611 & 0.517 & 2.31 & 1.36 & 107 & 75.7 & 0.294 \\
\hline 75 & 0.0172 & 0.00711 & 0.666 & 2.38 & 1.62 & 137 & 98.5 & 0.281 \\
\hline 100 & 0.0219 & 0.00906 & 0.697 & 2.38 & 1.50 & 163 & 93.9 & 0.425 \\
\hline 125 & 0.0245 & 0.0101 & 0.781 & 2.45 & 1.60 & 189 & 103 & 0.456 \\
\hline 150 & 0.0286 & 0.0118 & 0.803 & 2.54 & 1.52 & 222 & 109 & 0.510 \\
\hline
\end{tabular}




\begin{tabular}{|c|c|c|c|c|c|c|c|c|}
\hline \multirow[b]{3}{*}{ Flowrate } & \multirow{2}{*}{\multicolumn{3}{|c|}{ Testing Channel Data - Zone 2}} & \multirow{2}{*}{\multicolumn{2}{|c|}{ Froude \# Calculations }} & \multirow{2}{*}{\multicolumn{3}{|c|}{ Energy Calculations }} \\
\hline & & & & & & & & \\
\hline & $\begin{array}{l}\text { Average } \\
\text { Flow } \\
\text { Depth }\end{array}$ & $\begin{array}{l}\text { Average } \\
\text { Flow Area }\end{array}$ & $\begin{array}{l}\text { Average } \\
\text { Flow } \\
\text { Velocity }\end{array}$ & $\begin{array}{c}\text { Fr \# } \\
\text { Based on } \\
\text { Circular } \\
\text { Cross- } \\
\text { Section }\end{array}$ & $\begin{array}{c}\text { Fr \# } \\
\text { Based on } \\
\text { Average } \\
\text { Zone } 2 \\
\text { Values }\end{array}$ & $\begin{array}{c}\text { Energy at } \\
\text { Culvert } \\
\text { Outlet }\end{array}$ & $\begin{array}{c}\text { Average } \\
\text { Energy in } \\
\text { Zone } 2\end{array}$ & $\begin{array}{c}\text { Non- } \\
\text { Dimensional } \\
\text { Energy } \\
\text { Difference }\end{array}$ \\
\hline (gpm) & (m) & $\left(m^{2}\right)$ & $(\mathrm{m} / \mathrm{s})$ & & & $(\mathrm{mm})$ & $(\mathrm{mm})$ & \\
\hline 50 & 0.0136 & 0.00563 & 0.560 & 2.97 & 1.53 & 133 & 76.9 & 0.422 \\
\hline 75 & 0.0156 & 0.00645 & 0.734 & 3.00 & 1.88 & 168 & 98.0 & 0.416 \\
\hline 100 & 0.0209 & 0.00862 & 0.732 & 3.02 & 1.62 & 201 & 95.5 & 0.525 \\
\hline 125 & 0.0195 & 0.00806 & 0.980 & 3.03 & 2.24 & 230 & 116 & 0.498 \\
\hline 150 & 0.0207 & 0.00853 & 1.111 & 3.02 & 2.47 & 249 & 131 & 0.475 \\
\hline
\end{tabular}

\begin{tabular}{|c|c|c|c|c|c|c|c|c|}
\hline \multirow[b]{2}{*}{ Flowrate } & \multicolumn{3}{|c|}{ Testing Channel Data - Zone 2} & \multicolumn{2}{|c|}{ Froude \# Calculations } & \multicolumn{3}{|c|}{ Energy Calculations } \\
\hline & $\begin{array}{l}\text { Average } \\
\text { Flow } \\
\text { Depth }\end{array}$ & $\begin{array}{l}\text { Average } \\
\text { Flow Area }\end{array}$ & $\begin{array}{l}\text { Average } \\
\text { Flow } \\
\text { Velocity }\end{array}$ & $\begin{array}{c}\text { Fr \# } \\
\text { Based on } \\
\text { Circular } \\
\text { Cross- } \\
\text { Section }\end{array}$ & $\begin{array}{c}\text { Fr \# } \\
\text { Based on } \\
\text { Average } \\
\text { Zone } 2 \\
\text { Values }\end{array}$ & $\begin{array}{c}\text { Energy at } \\
\text { Culvert } \\
\text { Outlet }\end{array}$ & $\begin{array}{l}\text { Average } \\
\text { Energy in } \\
\text { Zone } 2\end{array}$ & $\mid \begin{array}{c}\text { Non- } \\
\text { Dimensional } \\
\text { Energy } \\
\text { Difference }\end{array}$ \\
\hline (gpm) & $(\mathrm{m})$ & $\left(m^{2}\right)$ & $(\mathrm{m} / \mathrm{s})$ & & & $(\mathrm{mm})$ & $(\mathrm{mm})$ & \\
\hline 50 & 0.0110 & 0.00453 & 0.696 & 3.71 & 2.12 & 171 & 83.0 & 0.515 \\
\hline 75 & 0.0154 & 0.00636 & 0.745 & 3.79 & 1.92 & 214 & 103 & 0.519 \\
\hline 100 & 0.0169 & 0.00699 & 0.904 & 3.73 & 2.22 & 247 & 106 & 0.572 \\
\hline 125 & 0.0235 & 0.00969 & 0.814 & 3.67 & 1.70 & 282 & 105 & 0.629 \\
\hline 150 & 0.0293 & 0.0121 & 0.782 & 3.70 & 1.46 & 316 & 108 & 0.659 \\
\hline
\end{tabular}

\begin{tabular}{|c|c|c|c|c|c|c|c|c|}
\hline \multirow[b]{3}{*}{ Flowrate } & \multirow{2}{*}{\multicolumn{3}{|c|}{ Testing Channel Data - Zone 2}} & \multirow{2}{*}{\multicolumn{2}{|c|}{ Froude \# Calculations }} & \multirow{2}{*}{\multicolumn{3}{|c|}{ Energy Calculations }} \\
\hline & & & & & & & & \\
\hline & $\begin{array}{l}\text { Average } \\
\text { Flow } \\
\text { Depth }\end{array}$ & $\begin{array}{l}\text { Average } \\
\text { Flow Area }\end{array}$ & $\begin{array}{l}\text { Average } \\
\text { Flow } \\
\text { Velocity }\end{array}$ & \begin{tabular}{|c} 
Fr \# \\
Based on \\
Circular \\
Cross- \\
Section
\end{tabular} & $\begin{array}{c}\text { Fr \# } \\
\text { Based on } \\
\text { Average } \\
\text { Zone } 2 \\
\text { Values }\end{array}$ & $\begin{array}{c}\text { Energy at } \\
\text { Culvert } \\
\text { Outlet }\end{array}$ & $\begin{array}{c}\text { Average } \\
\text { Energy in } \\
\text { Zone } 2\end{array}$ & \begin{tabular}{|c|} 
Non- \\
Dimensional \\
Energy \\
Difference
\end{tabular} \\
\hline (gpm) & (m) & $\left(m^{2}\right)$ & $(\mathrm{m} / \mathrm{s})$ & & & $(\mathrm{mm})$ & $(\mathrm{mm})$ & \\
\hline 50 & 0.0126 & 0.00522 & 0.604 & 3.95 & 1.72 & 181 & 78.5 & 0.567 \\
\hline 75 & 0.0148 & 0.00611 & 0.776 & 4.09 & 2.04 & 237 & 104 & 0.559 \\
\hline 100 & 0.0235 & 0.00972 & 0.649 & 4.06 & 1.35 & 273 & 92.3 & 0.662 \\
\hline 125 & 0.0325 & 0.0134 & 0.589 & 3.90 & 1.04 & 295 & 97.4 & 0.669 \\
\hline 150 & 0.0521 & 0.0215 & 0.440 & 3.87 & 0.616 & 329 & 109 & 0.668 \\
\hline
\end{tabular}




\subsection{5-inch Cast Acrylic Step}

Graphs of the water surface elevation for tests conducted at 2, 4, 6, and 8\% slopes are shown in Figures 5.23, 5.24, 5.25, and 5.26. After the water surface elevation was established, average flow depth was determined. From the flow depth and the results from Section 5.5 the aforementioned energy calculations were conducted. The results for the energy calculations for the 2.5-inch cast acrylic step are shown in Tables 5.24, 5.25, 5.26 and 5.27.

Smooth - Water Surface Elevation for 2.5" Step @ 2\% Slope

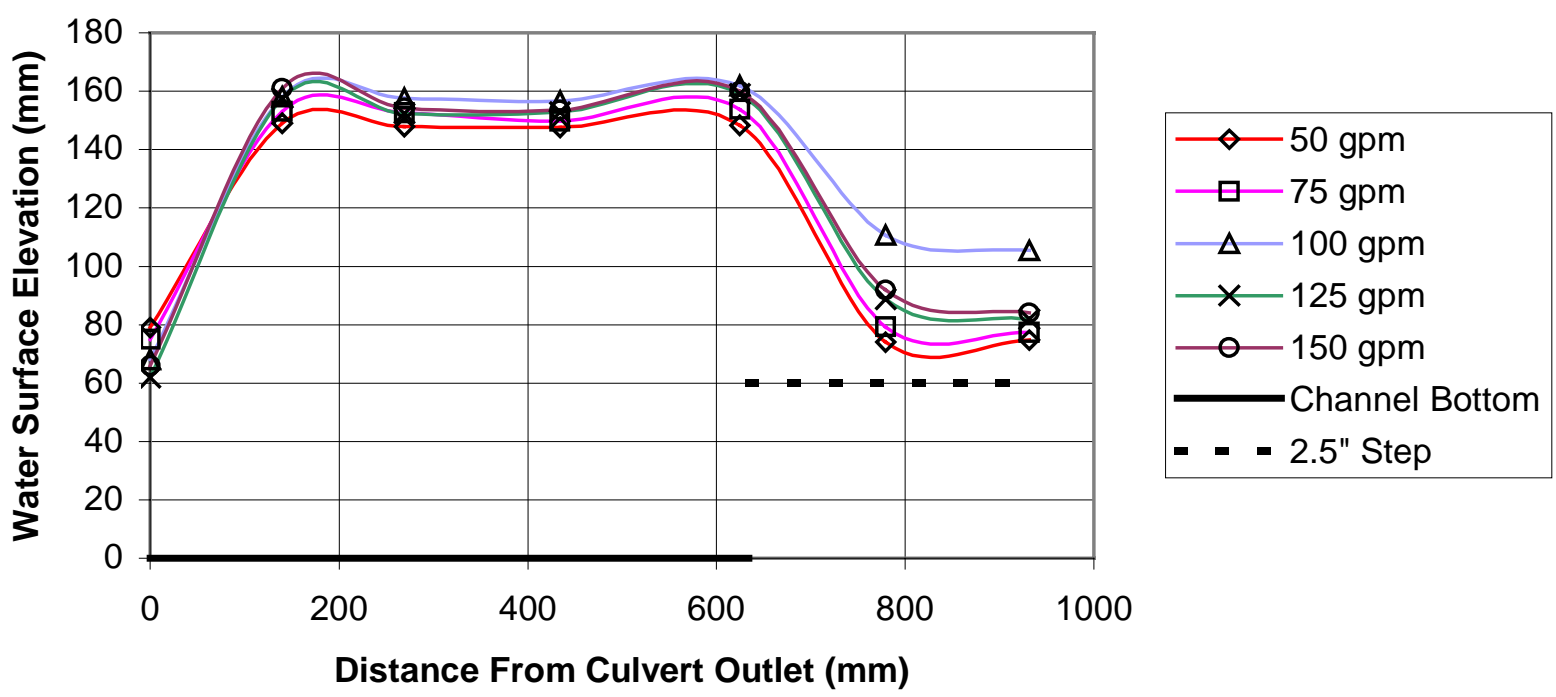

Figure 5.23 Plot of Water Surface Elevation for 2.5-inch Cast Acrylic Step at 2\% Culvert Slope 


\section{Smooth - Water Surface Elevation for 2.5" Step @ 4\% Slope}

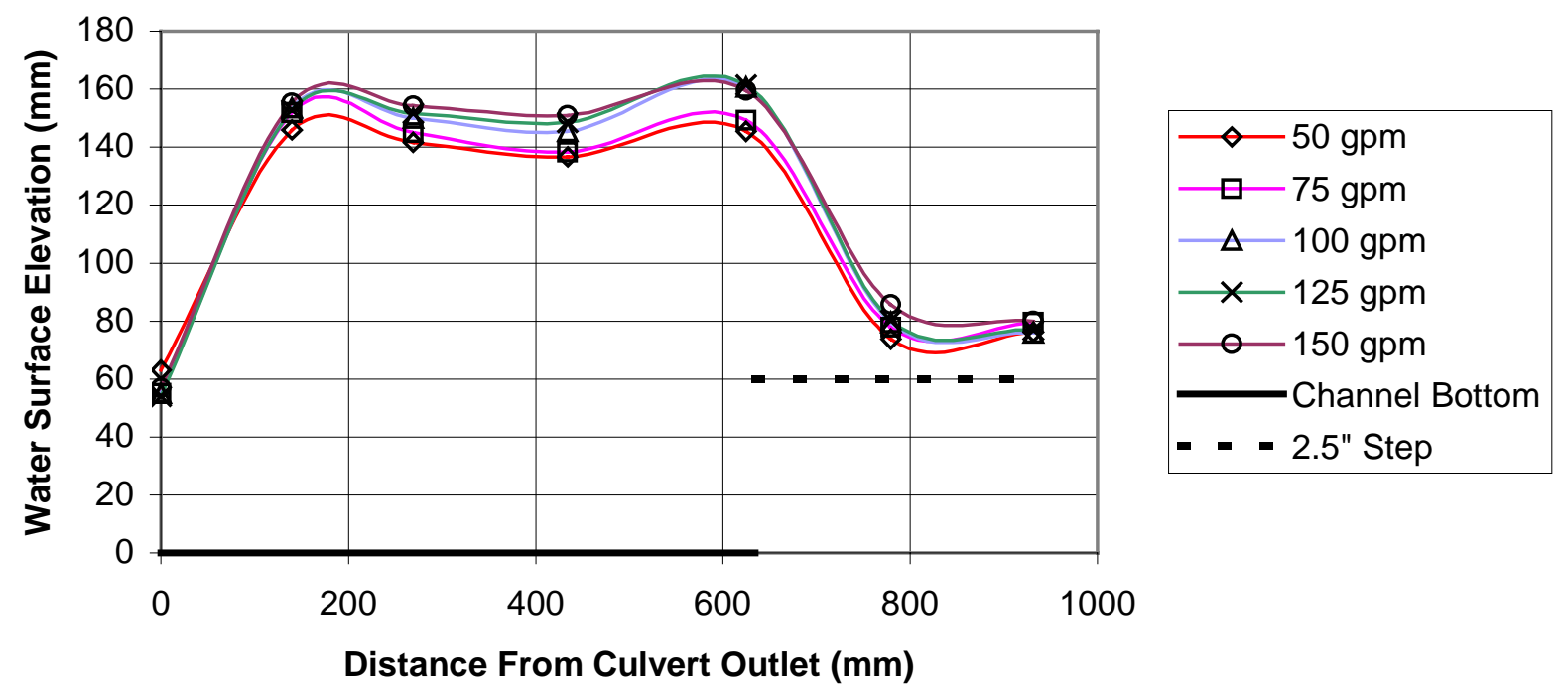

Figure 5.24 Plot of Water Surface Elevation for 2.5-inch Cast Acrylic Step at 4\% Culvert Slope

\section{Smooth - Water Surface Elevation for 2.5" Step @ 6\% Slope}

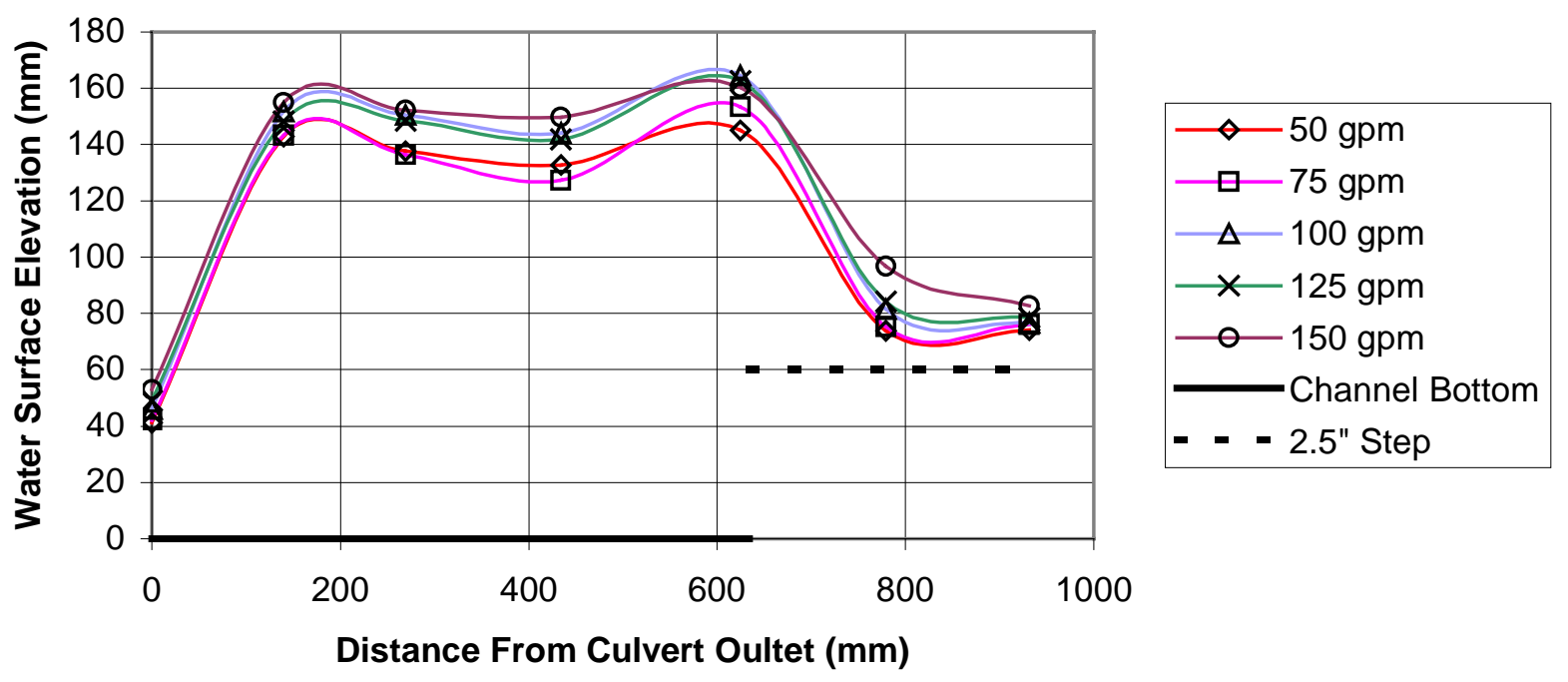

Figure 5.25 Plot of Water Surface Elevation for 2.5-inch Cast Acrylic Step at 6\% Culvert Slope 
Smooth - Water Surface Elevation for 2.5" Step @ 8\% Slope

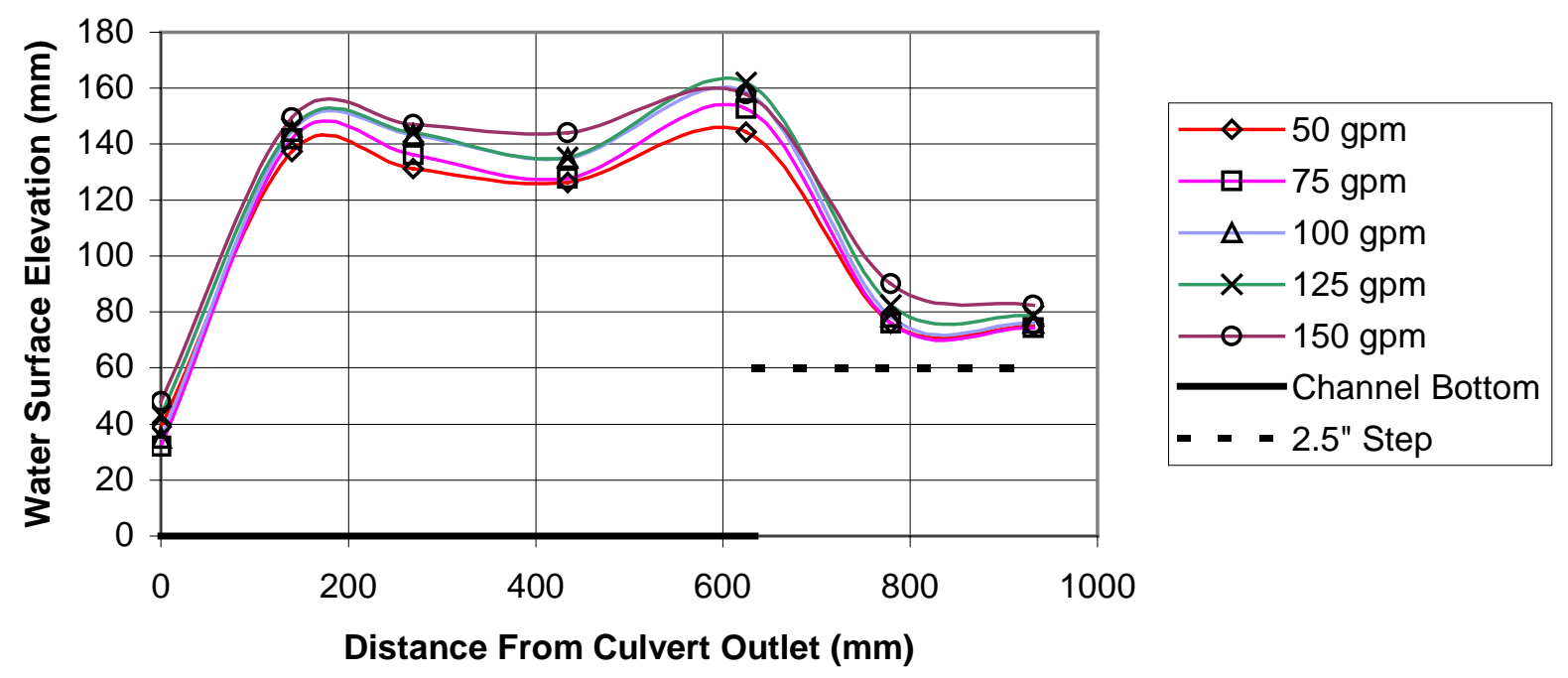

Figure 5.26 Plot of Water Surface Elevation for 2.5-inch Cast Acrylic Step at 8\% Culvert Slope

\begin{tabular}{|c|c|c|c|c|c|c|c|c|}
\hline \multirow[b]{2}{*}{ Flowrate } & \multicolumn{3}{|c|}{ Testing Channel Data - Zone 2} & \multicolumn{2}{|c|}{ Froude \# Calculations } & \multicolumn{3}{|c|}{ Energy Calculations } \\
\hline & $\begin{array}{c}\text { Average } \\
\text { Flow } \\
\text { Depth } \\
\\
\text { (m) }\end{array}$ & $\begin{array}{c}\text { Average } \\
\text { Flow Area } \\
\left(\mathrm{m}^{2}\right)\end{array}$ & $\begin{array}{c}\text { Average } \\
\text { Flow } \\
\text { Velocity } \\
\\
(\mathrm{m} / \mathrm{s})\end{array}$ & $\begin{array}{c}\text { Fr \# } \\
\text { Based on } \\
\text { Circular } \\
\text { Cross- } \\
\text { Section }\end{array}$ & $\begin{array}{c}\text { Fr \# } \\
\text { Based on } \\
\text { Average } \\
\text { Zone } 2 \\
\text { Values }\end{array}$ & $\begin{array}{c}\text { Energy at } \\
\text { Culvert } \\
\text { Outlet } \\
\\
(\mathrm{mm})\end{array}$ & $\begin{array}{c}\text { Average } \\
\text { Energy in } \\
\text { Zone } 2 \\
\\
(\mathrm{~mm})\end{array}$ & \begin{tabular}{|c|} 
Non- \\
Dimensional \\
Energy \\
Difference
\end{tabular} \\
\hline 50 & 0.0143 & 0.00592 & 0.533 & 2.31 & 1.42 & 103 & 88.9 & 0.137 \\
\hline 75 & 0.0182 & 0.00752 & 0.630 & 2.38 & 1.49 & 137 & 98.5 & 0.281 \\
\hline 100 & 0.0212 & 0.00875 & 0.722 & 2.38 & 1.58 & 163 & 108 & 0.340 \\
\hline 125 & 0.0253 & 0.0104 & 0.756 & 2.45 & 1.52 & 189 & 114 & 0.395 \\
\hline 150 & 0.0279 & 0.0115 & 0.822 & 2.54 & 1.57 & 228 & 122 & 0.462 \\
\hline
\end{tabular}




\begin{tabular}{|c|c|c|c|c|c|c|c|c|}
\hline \multirow[b]{3}{*}{ Flowrate } & \multirow{2}{*}{\multicolumn{3}{|c|}{ Testing Channel Data - Zone 2}} & \multirow{2}{*}{\multicolumn{2}{|c|}{ Froude \# Calculations }} & \multirow{2}{*}{\multicolumn{3}{|c|}{ Energy Calculations }} \\
\hline & & & & & & & & \\
\hline & $\begin{array}{l}\text { Average } \\
\text { Flow } \\
\text { Depth }\end{array}$ & $\begin{array}{l}\text { Average } \\
\text { Flow Area }\end{array}$ & $\begin{array}{l}\text { Average } \\
\text { Flow } \\
\text { Velocity }\end{array}$ & $\begin{array}{c}\text { Fr \# } \\
\text { Based on } \\
\text { Circular } \\
\text { Cross- } \\
\text { Section }\end{array}$ & $\begin{array}{c}\text { Fr \# } \\
\text { Based on } \\
\text { Average } \\
\text { Zone } 2 \\
\text { Values }\end{array}$ & $\begin{array}{c}\text { Energy at } \\
\text { Culvert } \\
\text { Outlet }\end{array}$ & $\begin{array}{c}\text { Average } \\
\text { Energy in } \\
\text { Zone } 2\end{array}$ & $\begin{array}{c}\text { Non- } \\
\text { Dimensional } \\
\text { Energy } \\
\text { Difference }\end{array}$ \\
\hline (gpm) & $(\mathrm{m})$ & $\left(m^{2}\right)$ & $(\mathrm{m} / \mathrm{s})$ & & & $(\mathrm{mm})$ & $(\mathrm{mm})$ & \\
\hline 50 & 0.0149 & 0.00617 & 0.511 & 2.97 & 1.34 & 123 & 88.3 & 0.284 \\
\hline 75 & 0.0187 & 0.00771 & 0.614 & 3.00 & 1.44 & 168 & 98.0 & 0.416 \\
\hline 100 & 0.0178 & 0.00733 & 0.861 & 3.02 & 2.06 & 201 & 116 & 0.424 \\
\hline 125 & 0.0186 & 0.00768 & 1.028 & 3.03 & 2.41 & 229 & 133 & 0.422 \\
\hline 150 & 0.0228 & 0.00941 & 1.007 & 3.02 & 2.13 & 260 & 135 & 0.483 \\
\hline
\end{tabular}

\begin{tabular}{|c|c|c|c|c|c|c|c|c|}
\hline \multirow[b]{3}{*}{ Flowrate } & \multirow{2}{*}{\multicolumn{3}{|c|}{ Testing Channel Data - Zone 2}} & \multirow{2}{*}{\multicolumn{2}{|c|}{ Froude \# Calculations }} & \multirow{2}{*}{\multicolumn{3}{|c|}{ Energy Calculations }} \\
\hline & & & & & & & & \\
\hline & $\begin{array}{l}\text { Average } \\
\text { Flow } \\
\text { Depth }\end{array}$ & $\begin{array}{c}\text { Average } \\
\text { Flow Area }\end{array}$ & $\begin{array}{l}\text { Average } \\
\text { Flow } \\
\text { Velocity }\end{array}$ & $\begin{array}{c}\text { Fr \# } \\
\text { Based on } \\
\text { Circular } \\
\text { Cross- } \\
\text { Section }\end{array}$ & $\begin{array}{c}\text { Fr \# } \\
\text { Based on } \\
\text { Average } \\
\text { Zone } 2 \\
\text { Values }\end{array}$ & $\begin{array}{c}\text { Energy at } \\
\text { Culvert } \\
\text { Outlet }\end{array}$ & $\begin{array}{c}\text { Average } \\
\text { Energy in } \\
\text { Zone } 2\end{array}$ & \begin{tabular}{|c|} 
Non- \\
Dimensional \\
Energy \\
Difference
\end{tabular} \\
\hline (gpm) & $(\mathrm{m})$ & $\left(m^{2}\right)$ & $(\mathrm{m} / \mathrm{s})$ & & & $(\mathrm{mm})$ & $(\mathrm{mm})$ & \\
\hline 50 & 0.0140 & 0.00579 & 0.545 & 3.71 & 1.47 & 174 & 89.2 & 0.487 \\
\hline 75 & 0.0156 & 0.00645 & 0.734 & 3.79 & 1.88 & 214 & 103 & 0.519 \\
\hline 100 & 0.0191 & 0.00787 & 0.803 & 3.73 & 1.86 & 254 & 112 & 0.559 \\
\hline 125 & 0.0214 & 0.00884 & 0.893 & 3.67 & 1.95 & 282 & 122 & 0.567 \\
\hline 150 & 0.0297 & 0.0123 & 0.772 & 3.70 & 1.43 & 316 & 120 & 0.620 \\
\hline
\end{tabular}

\begin{tabular}{|c|c|c|c|c|c|c|c|c|}
\hline able 5.27 & \multicolumn{8}{|c|}{ Energy Calculations for 2.5-inch Cast Acrylic Step @ 8\% Slope } \\
\hline \multirow[b]{2}{*}{ Flowrate } & \multicolumn{3}{|c|}{ Testing Channel Data - Zone 2} & \multicolumn{2}{|c|}{ Froude \# Calculations } & \multicolumn{3}{|c|}{ Energy Calculations } \\
\hline & $\begin{array}{l}\text { Average } \\
\text { Flow } \\
\text { Depth }\end{array}$ & $\begin{array}{l}\text { Average } \\
\text { Flow Area }\end{array}$ & $\begin{array}{l}\text { Average } \\
\text { Flow } \\
\text { Velocity }\end{array}$ & $\begin{array}{c}\text { Fr \# } \\
\text { Based on } \\
\text { Circular } \\
\text { Cross- } \\
\text { Section }\end{array}$ & $\begin{array}{c}\text { Fr \# } \\
\text { Based on } \\
\text { Average } \\
\text { Zone } 2 \\
\text { Values }\end{array}$ & $\begin{array}{c}\text { Energy at } \\
\text { Culvert } \\
\text { Outlet }\end{array}$ & $\begin{array}{c}\text { Average } \\
\text { Energy in } \\
\text { Zone } 2\end{array}$ & $\mid \begin{array}{c}\text { Non- } \\
\text { Dimensional } \\
\text { Energy } \\
\text { Difference }\end{array}$ \\
\hline (gpm) & (m) & $\left(m^{2}\right)$ & $(\mathrm{m} / \mathrm{s})$ & & & $(\mathrm{mm})$ & $(\mathrm{mm})$ & \\
\hline 50 & 0.0155 & 0.00639 & 0.494 & 3.95 & 1.27 & 169 & 88.0 & 0.479 \\
\hline 75 & 0.0152 & 0.00626 & 0.756 & 4.09 & 1.96 & 237 & 104 & 0.559 \\
\hline 100 & 0.0171 & 0.00708 & 0.892 & 4.06 & 2.18 & 275 & 118 & 0.573 \\
\hline 125 & 0.0206 & 0.00850 & 0.929 & 3.90 & 2.07 & 295 & 125 & 0.577 \\
\hline 150 & 0.0263 & 0.0109 & 0.872 & 3.87 & 1.72 & 336 & 125 & 0.628 \\
\hline
\end{tabular}




\subsection{0-inch Equivalent Riprap Step}

Graphs of the water surface elevation for tests conducted at 2, 4, 6, and 8\% slopes are shown in Figures 5.27, 5.28, 5.29, and 5.30. After the water surface elevation was established, average flow depth was determined.

From the flow depth and the results from Section 5.5, the aforementioned volumetric displacement tests and energy calculations were conducted. The results for the energy calculations for the 0.0-inch equivalent riprap step are shown in Tables 5.28, 5.29, 5.30, and 5.31.

Rough - Water Surface Elevation for 0.0" Step @ 2\% Slope

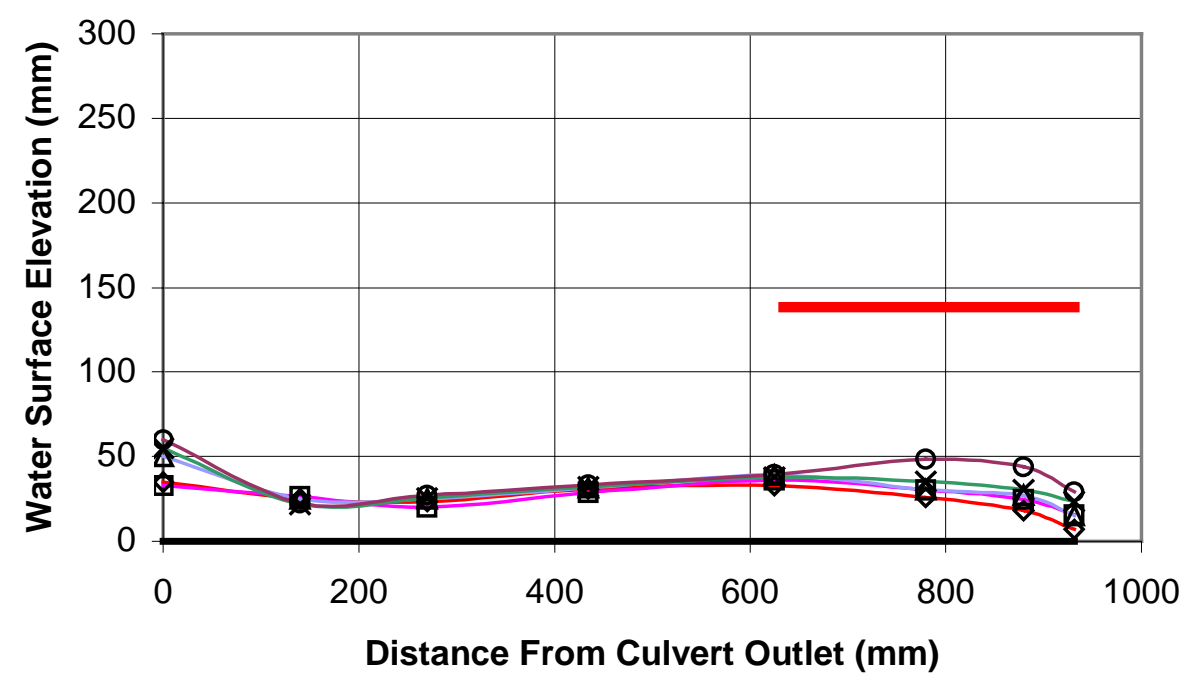

\begin{tabular}{|l|}
$\triangleleft-50 \mathrm{gpm}$ \\
$\square-75 \mathrm{gpm}$ \\
$\Delta-100 \mathrm{gpm}$ \\
$\times-125 \mathrm{gpm}$ \\
$-150 \mathrm{gpm}$ \\
- Channel Bottom \\
Top of Rock \\
\hline
\end{tabular}

Figure 5.27 Plot of Water Surface Elevation for 0.0-inch Equivalent Riprap Step at 2\% Culvert Slope 
Rough - Water Surface Elevation for 0.0" Step @ 4\% Slope

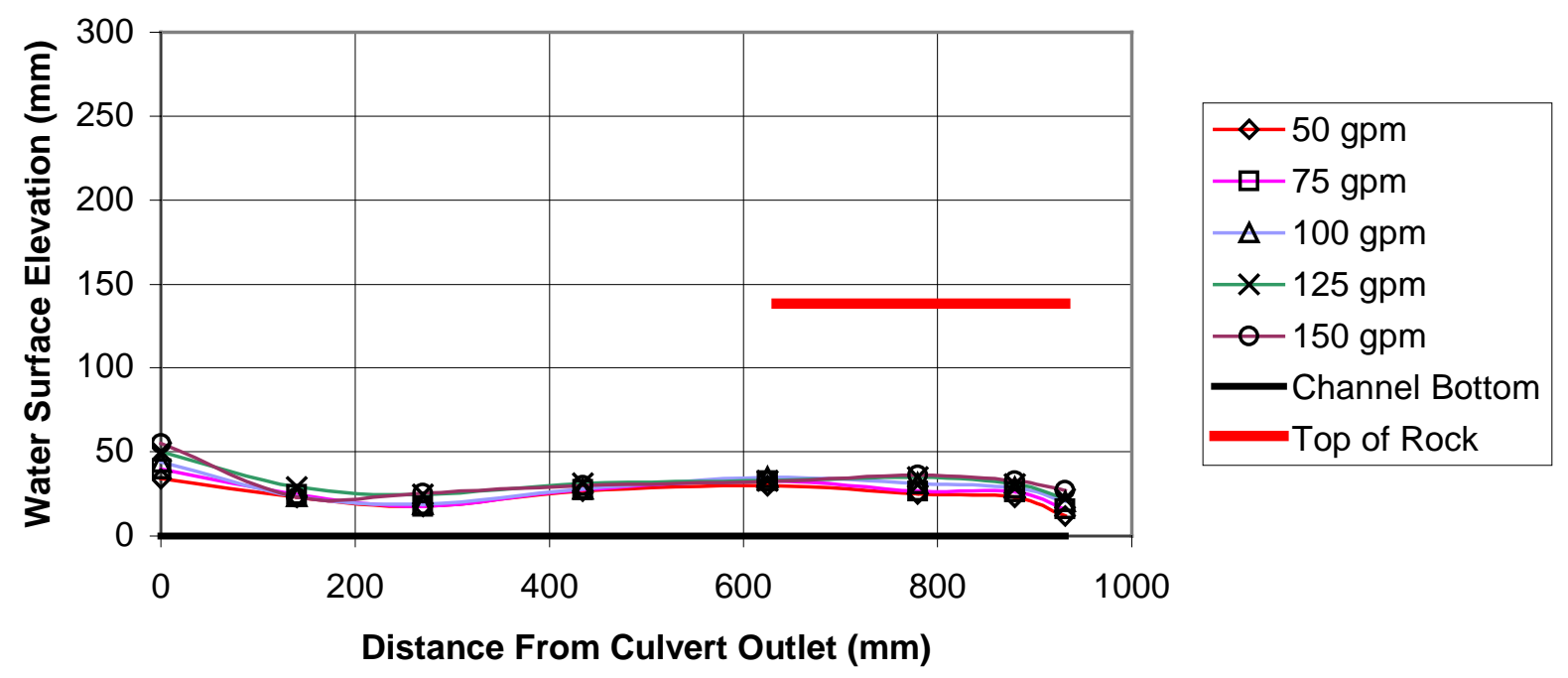

Figure 5.28 Plot of Water Surface Elevation for 0.0-inch Equivalent Riprap Step at 4\% Culvert Slope

Rough - Water Surface Elevation for 0.0" Step @ 6\% Slope

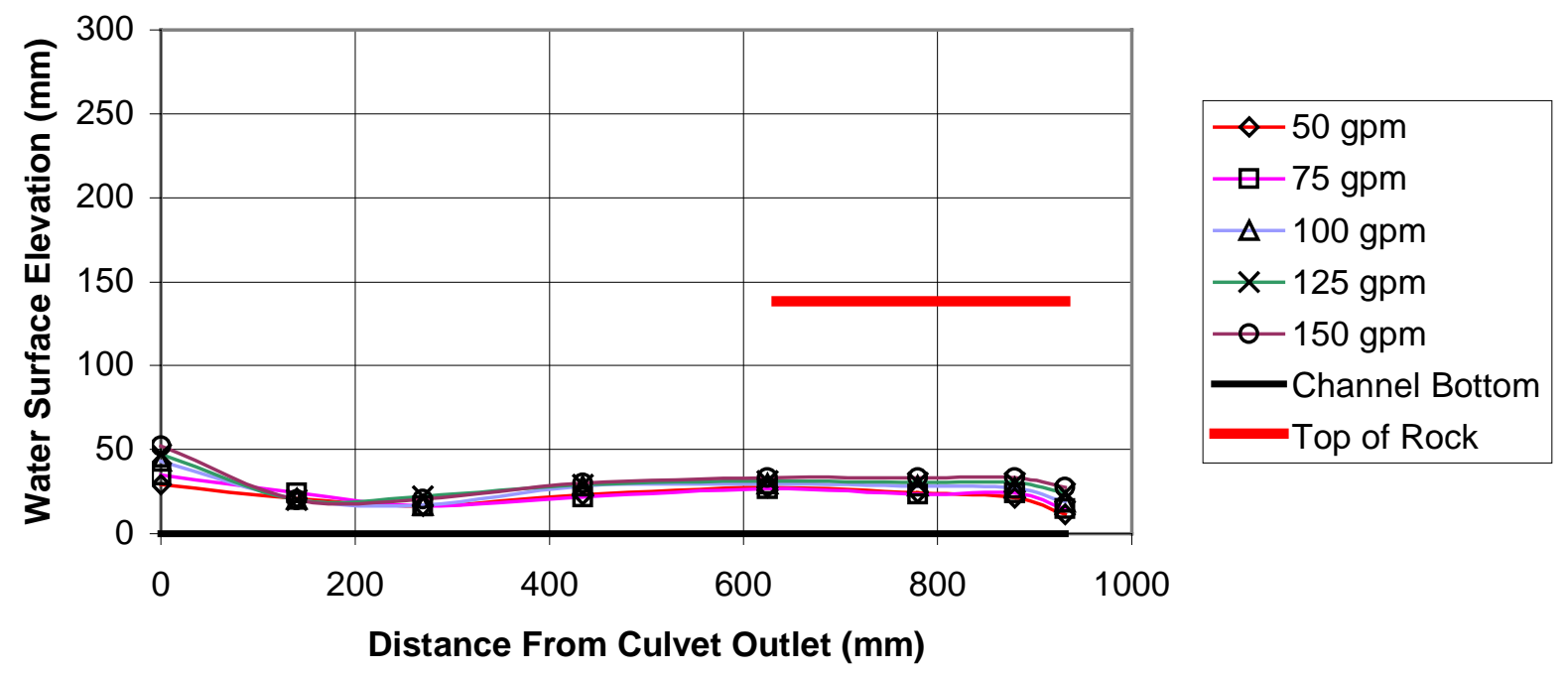

Figure 5.29 Plot of Water Surface Elevation for 0.0-inch Equivalent Riprap Step at 6\% Culvert Slope 


\section{Rough - Water Surface Elevation for 0.0" Step @ 8\% Slope}

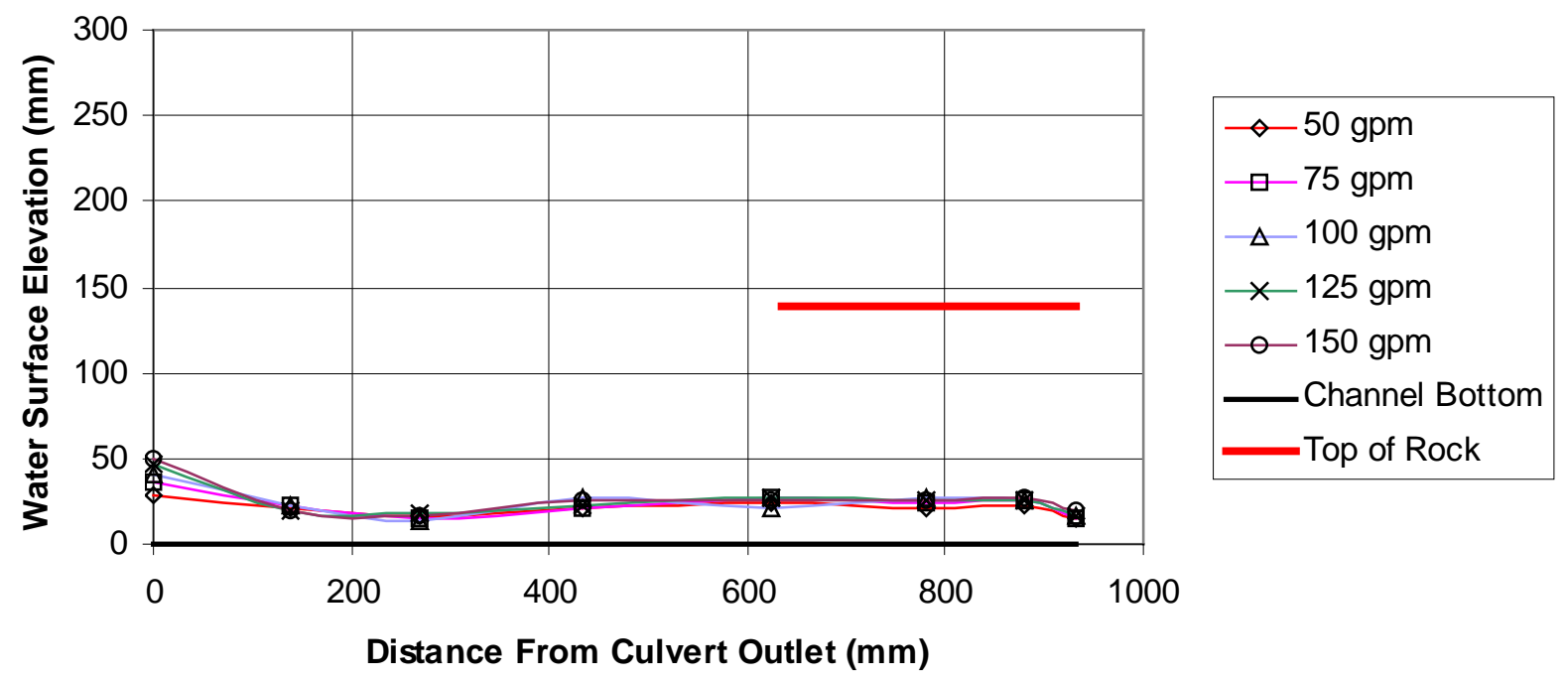

Figure 5.30 Plot of Water Surface Elevation for 0.0-inch Equivalent Riprap Step at 8\% Culvert Slope

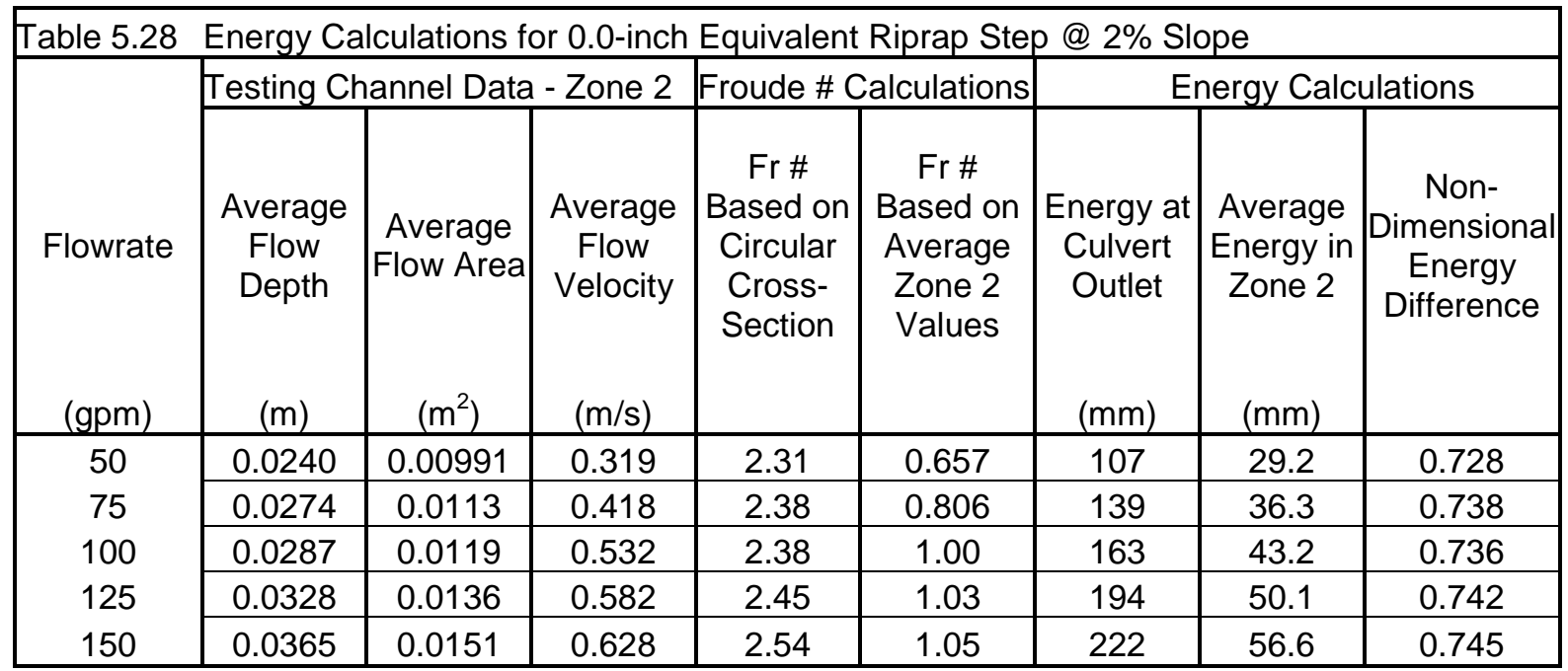




\begin{tabular}{|c|c|c|c|c|c|c|c|c|}
\hline \multirow[b]{3}{*}{ Flowrate } & \multirow{2}{*}{\multicolumn{3}{|c|}{ Testing Channel Data - Zone 2}} & \multirow{2}{*}{\multicolumn{2}{|c|}{ Froude \# Calculations }} & \multirow{2}{*}{\multicolumn{3}{|c|}{ Energy Calculations }} \\
\hline & & & & & & & & \\
\hline & $\begin{array}{c}\text { Average } \\
\text { Flow } \\
\text { Depth }\end{array}$ & $\begin{array}{c}\text { Average } \\
\text { Flow Area }\end{array}$ & $\begin{array}{l}\text { Average } \\
\text { Flow } \\
\text { Velocity }\end{array}$ & \begin{tabular}{|c} 
Fr \# \\
Based on \\
Circular \\
Cross- \\
Section
\end{tabular} & $\begin{array}{c}\text { Fr \# } \\
\text { Based on } \\
\text { Average } \\
\text { Zone } 2 \\
\text { Values }\end{array}$ & $\begin{array}{c}\text { Energy at } \\
\text { Culvert } \\
\text { Outlet }\end{array}$ & $\begin{array}{c}\text { Average } \\
\text { Energy in } \\
\text { Zone } 2\end{array}$ & $\begin{array}{c}\text { Non- } \\
\text { Dimensional } \\
\text { Energy } \\
\text { Difference }\end{array}$ \\
\hline (gpm) & $(\mathrm{m})$ & $\left(m^{2}\right)$ & $(\mathrm{m} / \mathrm{s})$ & & & $(\mathrm{mm})$ & $(\mathrm{mm})$ & \\
\hline 50 & 0.0239 & 0.00988 & 0.320 & 2.97 & 0.660 & 134 & 29.1 & 0.785 \\
\hline 75 & 0.0264 & 0.0109 & 0.434 & 3.00 & 0.852 & 170 & 36.0 & 0.788 \\
\hline 100 & 0.0301 & 0.0124 & 0.508 & 3.02 & 0.935 & 197 & 43.3 & 0.785 \\
\hline 125 & 0.0328 & 0.0135 & 0.583 & 3.03 & 1.03 & 230 & 50.1 & 0.783 \\
\hline 150 & 0.0344 & 0.0142 & 0.666 & 3.02 & 1.15 & 260 & 57.1 & 0.779 \\
\hline
\end{tabular}

\begin{tabular}{|c|c|c|c|c|c|c|c|c|}
\hline \multirow[b]{2}{*}{ Flowrate } & \multicolumn{3}{|c|}{ Testing Channel Data - Zone 2} & \multicolumn{2}{|c|}{ Froude \# Calculations } & \multicolumn{3}{|c|}{ Energy Calculations } \\
\hline & $\begin{array}{c}\text { Average } \\
\text { Flow } \\
\text { Depth } \\
\\
\text { (m) }\end{array}$ & $\begin{array}{c}\text { Average } \\
\text { Flow Area } \\
\\
\left(\mathrm{m}^{2}\right)\end{array}$ & $\begin{array}{c}\text { Average } \\
\text { Flow } \\
\text { Velocity } \\
\\
(\mathrm{m} / \mathrm{s})\end{array}$ & $\begin{array}{c}\text { Fr \# } \\
\text { Based on } \\
\text { Circular } \\
\text { Cross- } \\
\text { Section }\end{array}$ & $\begin{array}{c}\text { Fr \# } \\
\text { Based on } \\
\text { Average } \\
\text { Zone } 2 \\
\text { Values }\end{array}$ & $\begin{array}{c}\text { Energy at } \\
\text { Culvert } \\
\text { Outlet } \\
\\
(\mathrm{mm})\end{array}$ & $\begin{array}{c}\text { Average } \\
\text { Energy in } \\
\text { Zone } 2 \\
\\
(\mathrm{~mm})\end{array}$ & $\begin{array}{c}\text { Non- } \\
\text { Dimensional } \\
\text { Energy } \\
\text { Difference }\end{array}$ \\
\hline 50 & 0.0229 & 0.00944 & 0.334 & 3.71 & 0.706 & 166 & 28.6 & 0.824 \\
\hline 75 & 0.0239 & 0.00988 & 0.479 & 3.79 & 0.989 & 214 & 35.6 & 0.834 \\
\hline 100 & 0.0277 & 0.0115 & 0.551 & 3.73 & 1.06 & 247 & 43.2 & 0.825 \\
\hline 125 & 0.0305 & 0.0126 & 0.627 & 3.67 & 1.15 & 270 & 50.5 & 0.821 \\
\hline 150 & 0.0332 & 0.0137 & 0.690 & 3.70 & 1.21 & 311 & 57.5 & 0.815 \\
\hline
\end{tabular}

\begin{tabular}{|c|c|c|c|c|c|c|c|c|}
\hline \multirow[b]{2}{*}{ Flowrate } & \multicolumn{3}{|c|}{ Testing Channel Data - Zone 2} & \multicolumn{2}{|c|}{ Froude \# Calculations } & \multicolumn{3}{|c|}{ Energy Calculations } \\
\hline & $\begin{array}{c}\text { Average } \\
\text { Flow } \\
\text { Depth }\end{array}$ & $\begin{array}{c}\text { Average } \\
\text { Flow Area }\end{array}$ & $\begin{array}{l}\text { Average } \\
\text { Flow } \\
\text { Velocity }\end{array}$ & $\begin{array}{c}\text { Fr \# } \\
\text { Based on } \\
\text { Circular } \\
\text { Cross- } \\
\text { Section }\end{array}$ & $\begin{array}{c}\text { Fr \# } \\
\text { Based on } \\
\text { Average } \\
\text { Zone } 2 \\
\text { Values }\end{array}$ & $\begin{array}{c}\text { Energy at } \\
\text { Culvert } \\
\text { Outlet }\end{array}$ & $\begin{array}{c}\text { Average } \\
\text { Energy in } \\
\text { Zone } 2\end{array}$ & $\begin{array}{c}\text { Non- } \\
\text { Dimensional } \\
\text { Energy } \\
\text { Difference }\end{array}$ \\
\hline (gpm) & $(\mathrm{m})$ & $\left(m^{2}\right)$ & $(\mathrm{m} / \mathrm{s})$ & & & $(\mathrm{mm})$ & $(\mathrm{mm})$ & \\
\hline 50 & 0.0219 & 0.00903 & 0.350 & 3.95 & 0.755 & 183 & 28.1 & 0.844 \\
\hline 75 & 0.0249 & 0.0103 & 0.460 & 4.09 & 0.931 & 230 & 35.7 & 0.843 \\
\hline 100 & 0.0261 & 0.0108 & 0.585 & 4.06 & 1.16 & 273 & 43.6 & 0.840 \\
\hline 125 & 0.0262 & 0.0108 & 0.729 & 3.90 & 1.44 & 301 & 53.3 & 0.823 \\
\hline 150 & 0.0266 & 0.0110 & 0.862 & 3.87 & 1.69 & 326 & 64.5 & 0.806 \\
\hline
\end{tabular}




\subsection{5-inch Equivalent Riprap Step}

Graphs of the water surface elevation for tests conducted at 2, 4, 6, and 8\% slopes are shown in Figures 5.31, 5.32, 5.33, and 5.34. After the water surface elevation was established, average flow depth was determined. From the flow depth and the results from Section 5.5, the aforementioned volumetric displacement tests and energy calculations were conducted. The results for the energy calculations for the 0.5 -inch equivalent riprap step are shown in Tables 5.32, 5.33, 5.34, and 5.35.

\section{Rough - Water Surface Elevation for 0.5" Step @ 2\% Slope}

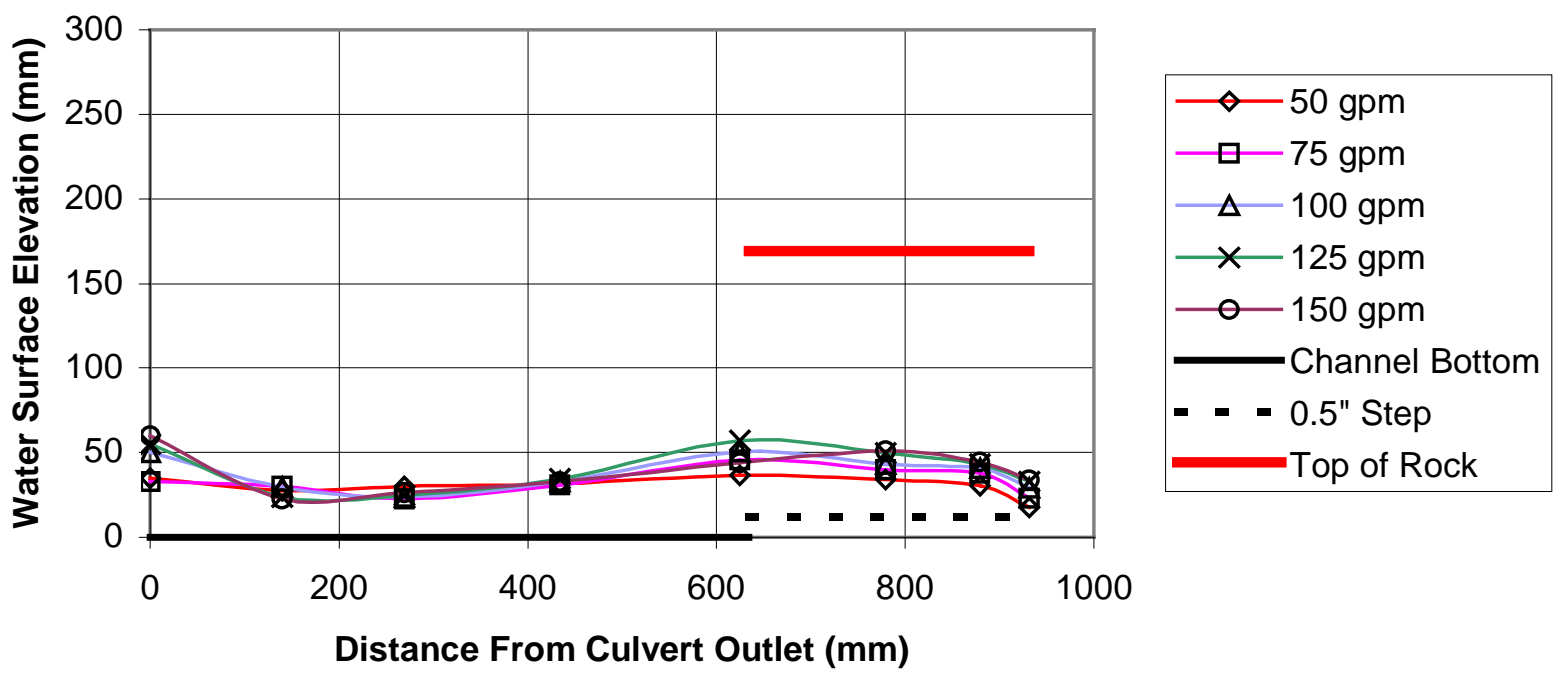

Figure 5.31 Plot of Water Surface Elevation for 0.5-inch Equivalent Riprap Step at 2\% Culvert Slope 
Rough - Water Surface Elevation for 0.5" Step @ 4\% Slope

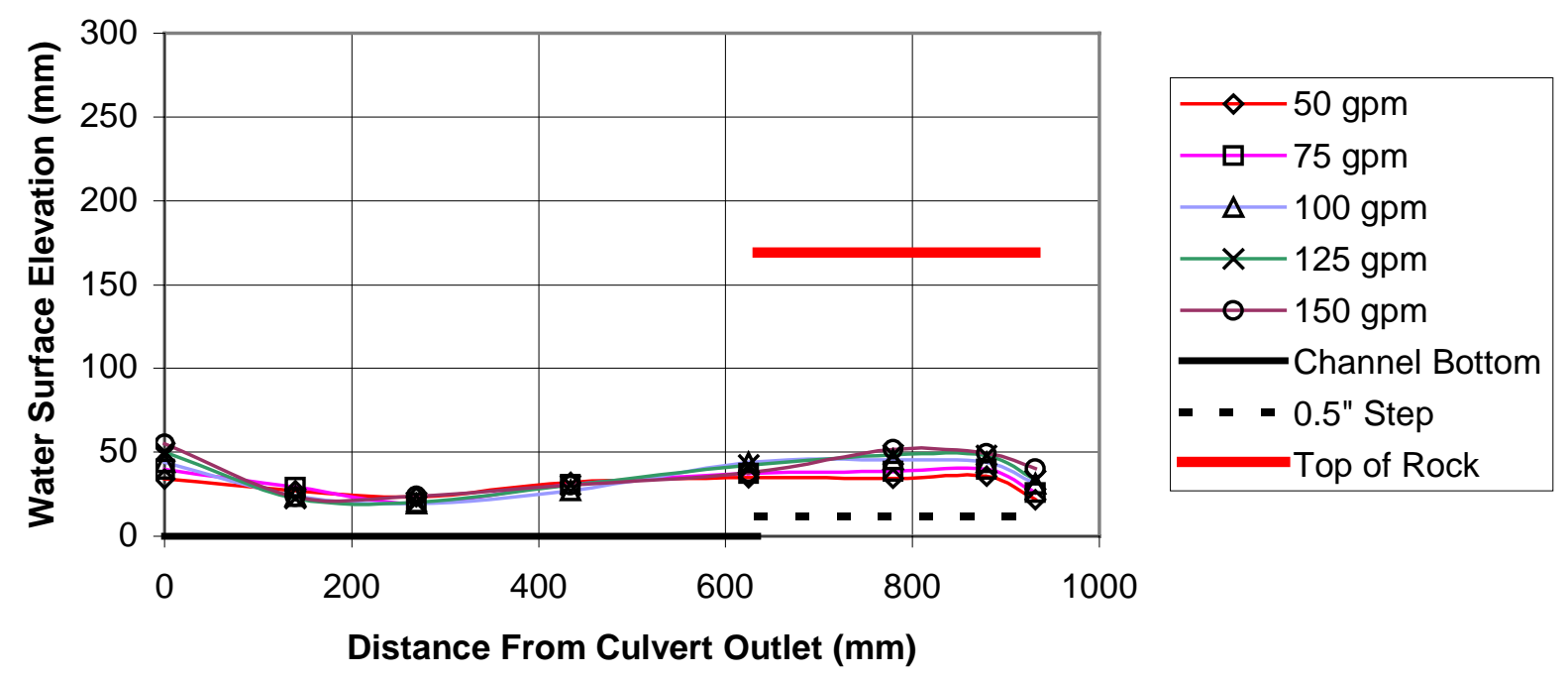

Figure 5.32 Plot of Water Surface Elevation for 0.5-inch Equivalent Riprap Step at 4\% Culvert Slope

Rough - Water Surface Elevation for 0.5" Step @ 6\% Slope

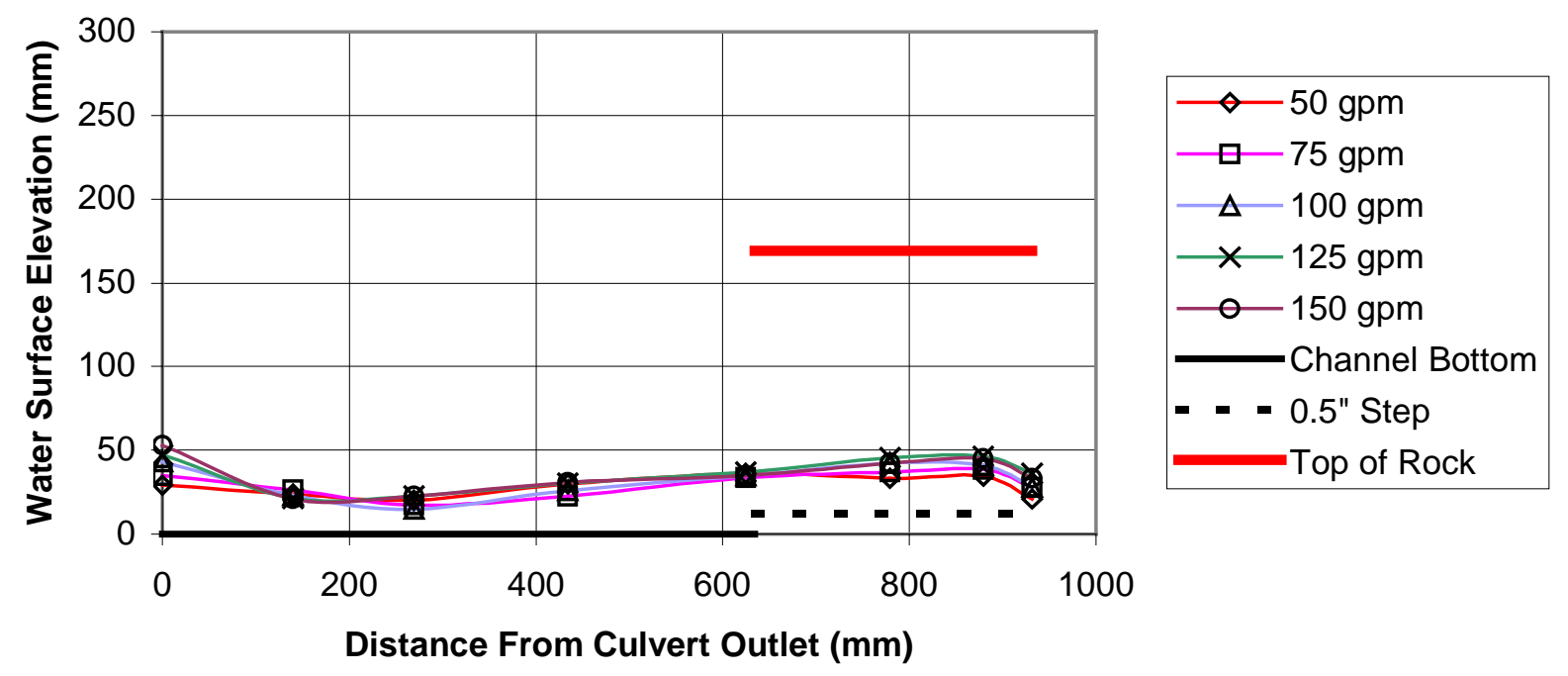

Figure 5.33 Plot of Water Surface Elevation for 0.5-inch Equivalent Riprap Step at 6\% Culvert Slope 


\section{Rough - Water Surface Elevation for 0.5" Step @ 8\% Slope}

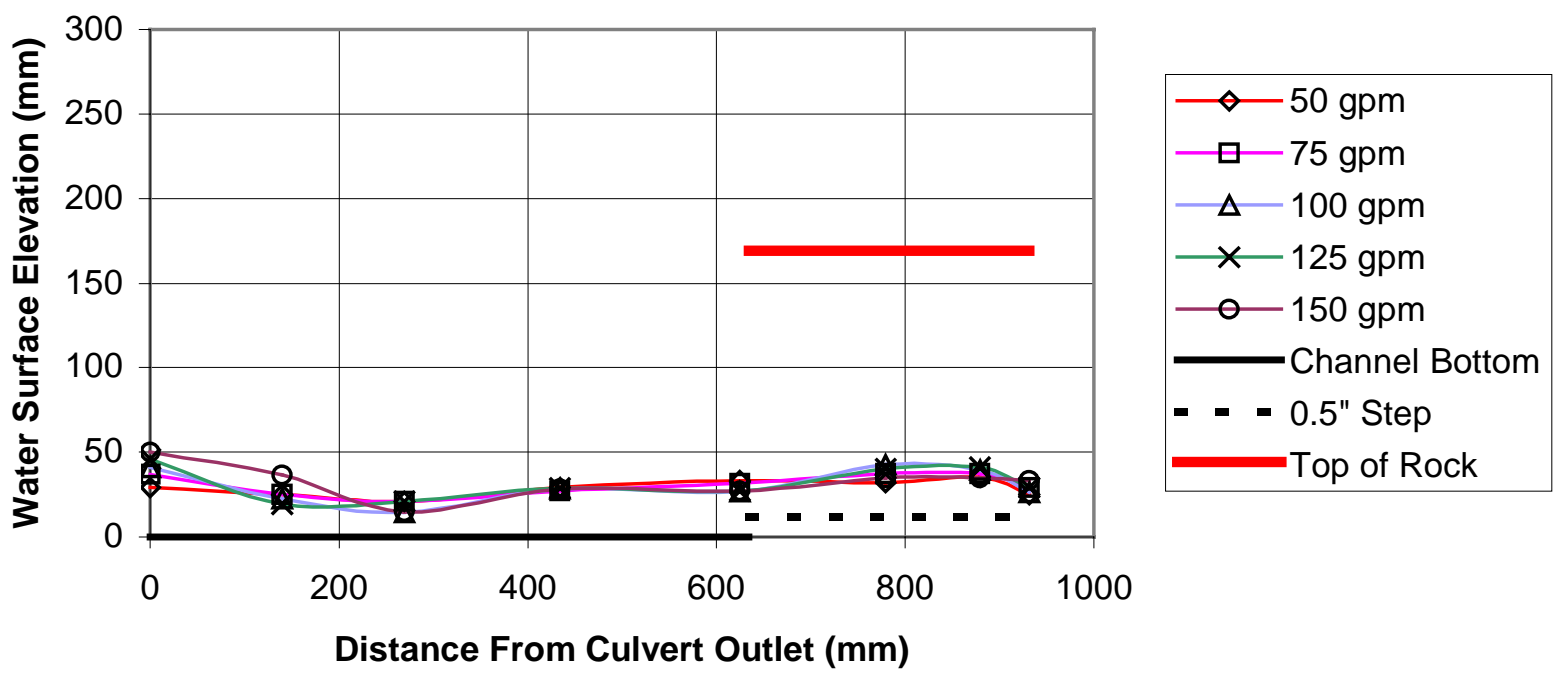

Figure 5.34 Plot of Water Surface Elevation for 0.5-inch Equivalent Riprap Step at 8\% Culvert Slope

\begin{tabular}{|c|c|c|c|c|c|c|c|c|}
\hline \multirow[b]{3}{*}{ Flowrate } & \multirow{2}{*}{\multicolumn{3}{|c|}{ Testing Channel Data - Zone 2}} & \multirow{2}{*}{\multicolumn{2}{|c|}{ Froude \# Calculations }} & \multirow{2}{*}{\multicolumn{3}{|c|}{ Energy Calculations }} \\
\hline & & & & & & & & \\
\hline & $\begin{array}{c}\text { Average } \\
\text { Flow } \\
\text { Depth }\end{array}$ & $\begin{array}{l}\text { Average } \\
\text { Flow Area }\end{array}$ & $\begin{array}{l}\text { Average } \\
\text { Flow } \\
\text { Velocity }\end{array}$ & $\begin{array}{c}\text { Fr \# } \\
\text { Based on } \\
\text { Circular } \\
\text { Cross- } \\
\text { Section }\end{array}$ & $\begin{array}{c}\text { Fr \# } \\
\text { Based on } \\
\text { Average } \\
\text { Zone } 2 \\
\text { Values }\end{array}$ & $\begin{array}{c}\text { Energy at } \\
\text { Culvert } \\
\text { Outlet }\end{array}$ & $\begin{array}{c}\text { Average } \\
\text { Energy in } \\
\text { Zone } 2\end{array}$ & $\begin{array}{c}\text { Non- } \\
\text { Dimensiona } \\
\text { Energy } \\
\text { Difference }\end{array}$ \\
\hline (gpm) & $(\mathrm{m})$ & $\left(m^{2}\right)$ & $(\mathrm{m} / \mathrm{s})$ & & & $(\mathrm{mm})$ & $(\mathrm{mm})$ & \\
\hline 50 & 0.0233 & 0.00964 & 0.327 & 2.31 & 0.684 & 107 & 37.6 & 0.649 \\
\hline 75 & 0.0291 & 0.0120 & 0.394 & 2.38 & 0.739 & 139 & 46.7 & 0.653 \\
\hline 100 & 0.0314 & 0.0130 & 0.487 & 2.38 & 0.878 & 163 & 54.0 & 0.669 \\
\hline 125 & 0.0347 & 0.0143 & 0.552 & 2.45 & 0.946 & 194 & 62.0 & 0.681 \\
\hline 150 & 0.0357 & 0.0147 & 0.643 & 2.54 & 1.09 & 222 & 68.8 & 0.690 \\
\hline
\end{tabular}




\begin{tabular}{|c|c|c|c|c|c|c|c|c|}
\hline \multirow[b]{3}{*}{ Flowrate } & \multirow{2}{*}{\multicolumn{3}{|c|}{ Testing Channel Data - Zone 2}} & \multirow{2}{*}{\multicolumn{2}{|c|}{ Froude \# Calculations }} & \multirow{2}{*}{\multicolumn{3}{|c|}{ Energy Calculations }} \\
\hline & & & & & & & & \\
\hline & $\begin{array}{c}\text { Average } \\
\text { Flow } \\
\text { Depth }\end{array}$ & $\begin{array}{c}\text { Average } \\
\text { Flow Area }\end{array}$ & $\begin{array}{l}\text { Average } \\
\text { Flow } \\
\text { Velocity }\end{array}$ & $\begin{array}{c}\text { Fr \# } \\
\text { Based on } \\
\text { Circular } \\
\text { Cross- } \\
\text { Section }\end{array}$ & $\begin{array}{c}\text { Fr \# } \\
\text { Based on } \\
\text { Average } \\
\text { Zone } 2 \\
\text { Values }\end{array}$ & $\begin{array}{c}\text { Energy at } \\
\text { Culvert } \\
\text { Outlet }\end{array}$ & $\begin{array}{c}\text { Average } \\
\text { Energy in } \\
\text { Zone } 2\end{array}$ & $\begin{array}{c}\text { Non- } \\
\text { Dimensional } \\
\text { Energy } \\
\text { Difference }\end{array}$ \\
\hline (gpm) & $(\mathrm{m})$ & $\left(m^{2}\right)$ & $(\mathrm{m} / \mathrm{s})$ & & & $(\mathrm{mm})$ & $(\mathrm{mm})$ & \\
\hline 50 & 0.0258 & 0.0106 & 0.297 & 2.97 & 0.590 & 134 & 39.4 & 0.705 \\
\hline 75 & 0.0294 & 0.0121 & 0.391 & 3.00 & 0.728 & 170 & 46.9 & 0.723 \\
\hline 100 & 0.0334 & 0.0138 & 0.458 & 3.02 & 0.801 & 197 & 55.3 & 0.719 \\
\hline 125 & 0.0360 & 0.0149 & 0.531 & 3.03 & 0.893 & 230 & 62.5 & 0.729 \\
\hline 150 & 0.0378 & 0.0156 & 0.607 & 3.02 & 1.00 & 260 & 69.4 & 0.734 \\
\hline
\end{tabular}

\begin{tabular}{|c|c|c|c|c|c|c|c|c|}
\hline \multirow[b]{2}{*}{ Flowrate } & \multicolumn{3}{|c|}{ Testing Channel Data - Zone 2} & \multicolumn{2}{|c|}{ Froude \# Calculations } & \multicolumn{3}{|c|}{ Energy Calculations } \\
\hline & $\begin{array}{c}\text { Average } \\
\text { Flow } \\
\text { Depth } \\
\\
\text { (m) }\end{array}$ & $\begin{array}{c}\text { Average } \\
\text { Flow Area } \\
\\
\left(\mathrm{m}^{2}\right)\end{array}$ & $\begin{array}{c}\text { Average } \\
\text { Flow } \\
\text { Velocity } \\
\\
(\mathrm{m} / \mathrm{s})\end{array}$ & $\begin{array}{c}\text { Fr \# } \\
\text { Based on } \\
\text { Circular } \\
\text { Cross- } \\
\text { Section }\end{array}$ & $\begin{array}{c}\text { Fr \# } \\
\text { Based on } \\
\text { Average } \\
\text { Zone } 2 \\
\text { Values }\end{array}$ & $\begin{array}{c}\text { Energy at } \\
\text { Culvert } \\
\text { Outlet } \\
\\
(\mathrm{mm})\end{array}$ & $\begin{array}{c}\text { Average } \\
\text { Energy in } \\
\text { Zone } 2 \\
\\
(\mathrm{~mm})\end{array}$ & $\begin{array}{c}\text { Non- } \\
\text { Dimensional } \\
\text { Energy } \\
\text { Difference }\end{array}$ \\
\hline 50 & 0.0249 & 0.0103 & 0.307 & 3.71 & 0.622 & 166 & 38.6 & 0.767 \\
\hline 75 & 0.0283 & 0.0117 & 0.406 & 3.79 & 0.771 & 214 & 46.2 & 0.785 \\
\hline 100 & 0.0311 & 0.0128 & 0.492 & 3.73 & 0.890 & 247 & 53.9 & 0.782 \\
\hline 125 & 0.0344 & 0.0142 & 0.556 & 3.67 & 0.958 & 270 & 61.7 & 0.771 \\
\hline 150 & 0.0327 & 0.0135 & 0.701 & 3.70 & 1.24 & 311 & 68.8 & 0.779 \\
\hline
\end{tabular}

\begin{tabular}{|c|c|c|c|c|c|c|c|c|}
\hline \multirow[b]{3}{*}{ Flowrate } & \multirow{2}{*}{\multicolumn{3}{|c|}{ Testing Channel Data - Zone 2}} & \multirow{2}{*}{\multicolumn{2}{|c|}{ Froude \# Calculations }} & \multirow{2}{*}{\multicolumn{3}{|c|}{ Energy Calculations }} \\
\hline & & & & & & & & \\
\hline & $\begin{array}{c}\text { Average } \\
\text { Flow } \\
\text { Depth }\end{array}$ & $\begin{array}{c}\text { Average } \\
\text { Flow Area }\end{array}$ & $\begin{array}{l}\text { Average } \\
\text { Flow } \\
\text { Velocity }\end{array}$ & \begin{tabular}{|c} 
Fr \# \\
Based on \\
Circular \\
Cross- \\
Section
\end{tabular} & $\begin{array}{c}\text { Fr \# } \\
\text { Based on } \\
\text { Average } \\
\text { Zone } 2 \\
\text { Values }\end{array}$ & $\begin{array}{c}\text { Energy at } \\
\text { Culvert } \\
\text { Outlet }\end{array}$ & $\begin{array}{c}\text { Average } \\
\text { Energy in } \\
\text { Zone } 2\end{array}$ & \begin{tabular}{|c} 
Non- \\
Dimensional \\
Energy \\
Difference
\end{tabular} \\
\hline (gpm) & (m) & $\left(m^{2}\right)$ & $(\mathrm{m} / \mathrm{s})$ & & & $(\mathrm{mm})$ & $(\mathrm{mm})$ & \\
\hline 50 & 0.0246 & 0.0102 & 0.310 & 3.95 & 0.631 & 183 & 38.5 & 0.790 \\
\hline 75 & 0.0280 & 0.0116 & 0.410 & 4.09 & 0.782 & 230 & 45.9 & 0.800 \\
\hline 100 & 0.0307 & 0.0127 & 0.498 & 4.06 & 0.907 & 273 & 53.6 & 0.803 \\
\hline 125 & 0.0303 & 0.0125 & 0.631 & 3.90 & 1.16 & 301 & 60.7 & 0.798 \\
\hline 150 & 0.0262 & 0.0108 & 0.875 & 3.87 & 1.73 & 326 & 74.1 & 0.773 \\
\hline
\end{tabular}




\subsection{0-inch Equivalent Riprap Step}

Graphs of the water surface elevation for tests conducted at 2, 4, 6, and 8\% slopes are shown in Figures 5.35, 5.36, 5.37, and 5.38. After the water surface elevation was established, average flow depth was determined. From the flow depth and the results from Section 5.5, the aforementioned volumetric displacement tests and energy calculations were conducted. The results for the energy calculations for the 1.0-inch equivalent riprap step are shown in Tables 5.36, 5.37, 5.38, and 5.39.

Rough - Water Surface Elevation for 1.0" Step @ 2\% Slope

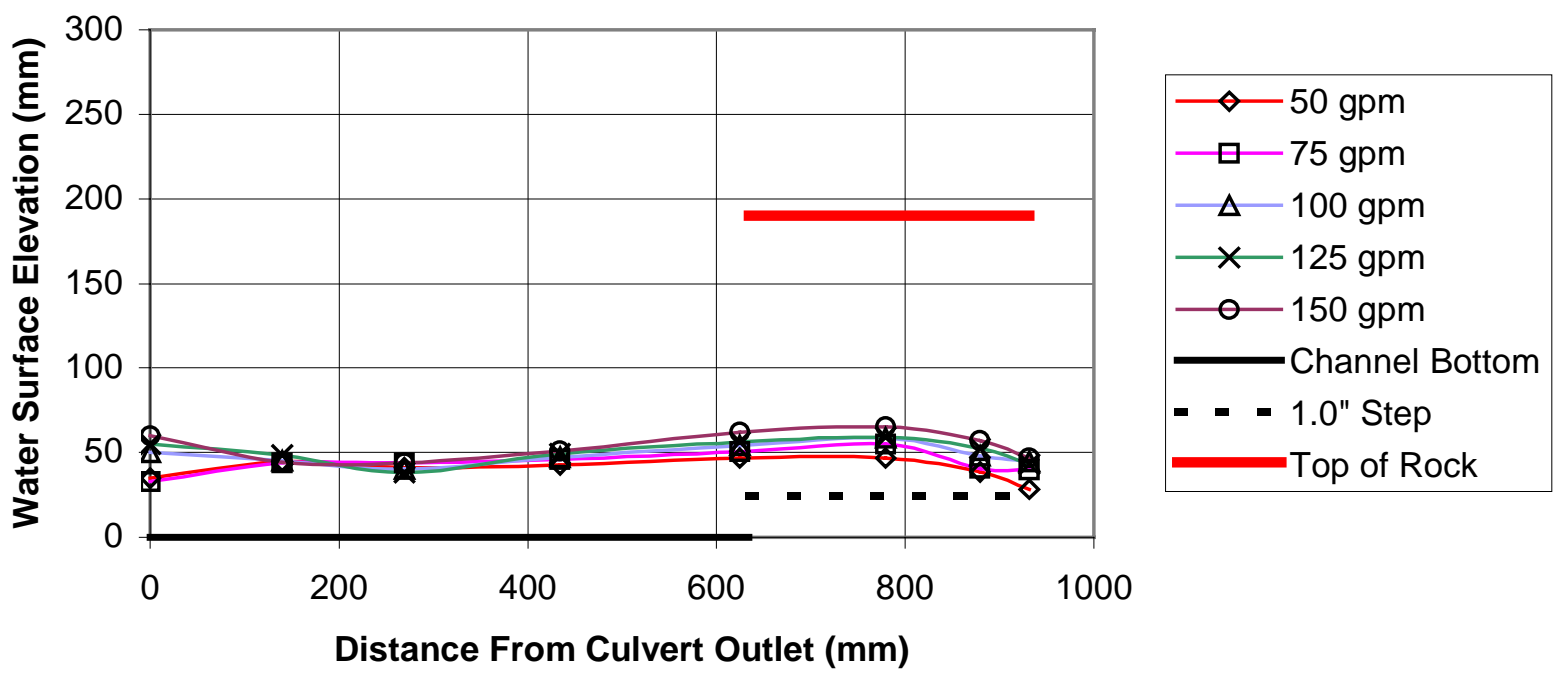

Figure 5.35 Plot of Water Surface Elevation for 1.0-inch Equivalent Riprap Step at 2\% Culvert Slope 
Rough - Water Surface Elevation for 1.0" Step @ 4\% Slope

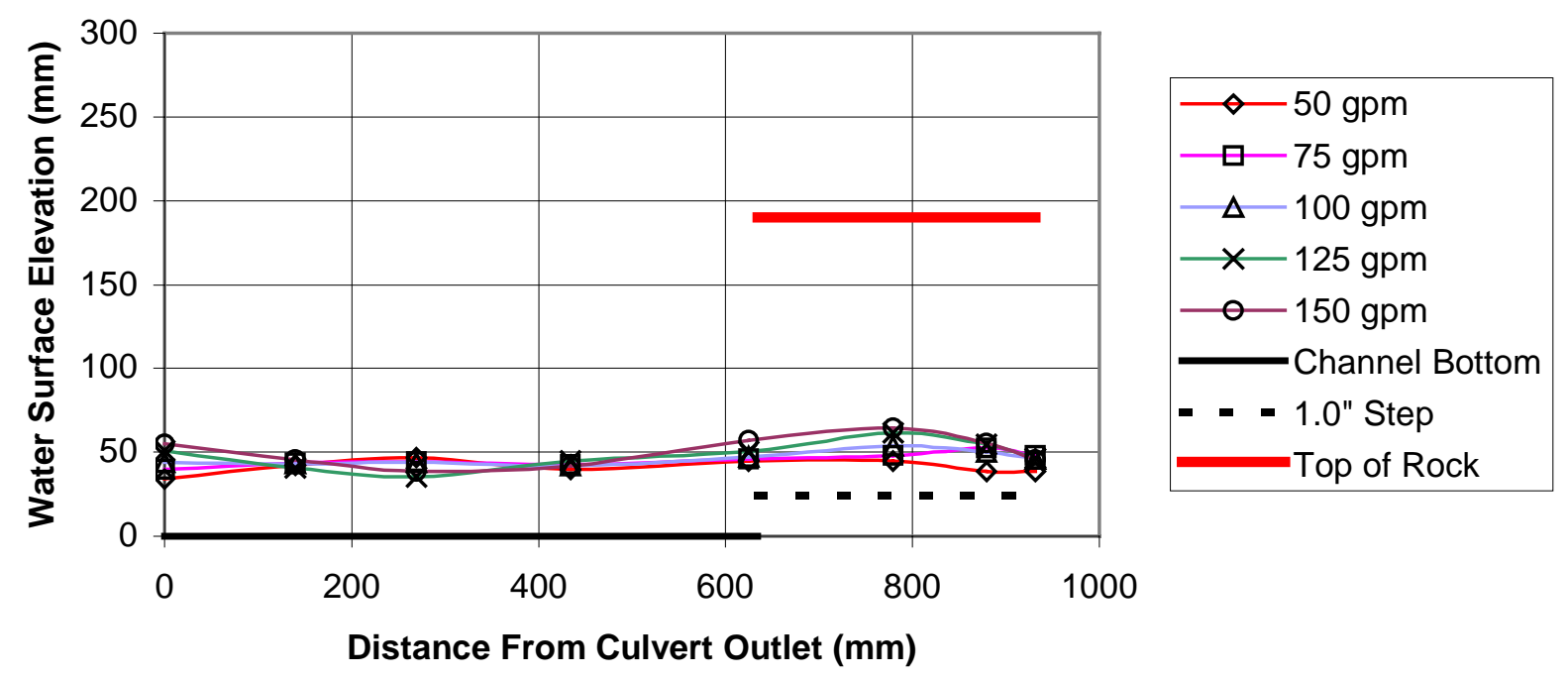

Figure 5.36 Plot of Water Surface Elevation for 1.0-inch Equivalent Riprap Step at 4\% Culvert Slope

Rough - Water Surface Elevation for 1.0" Step @ 6\% Slope

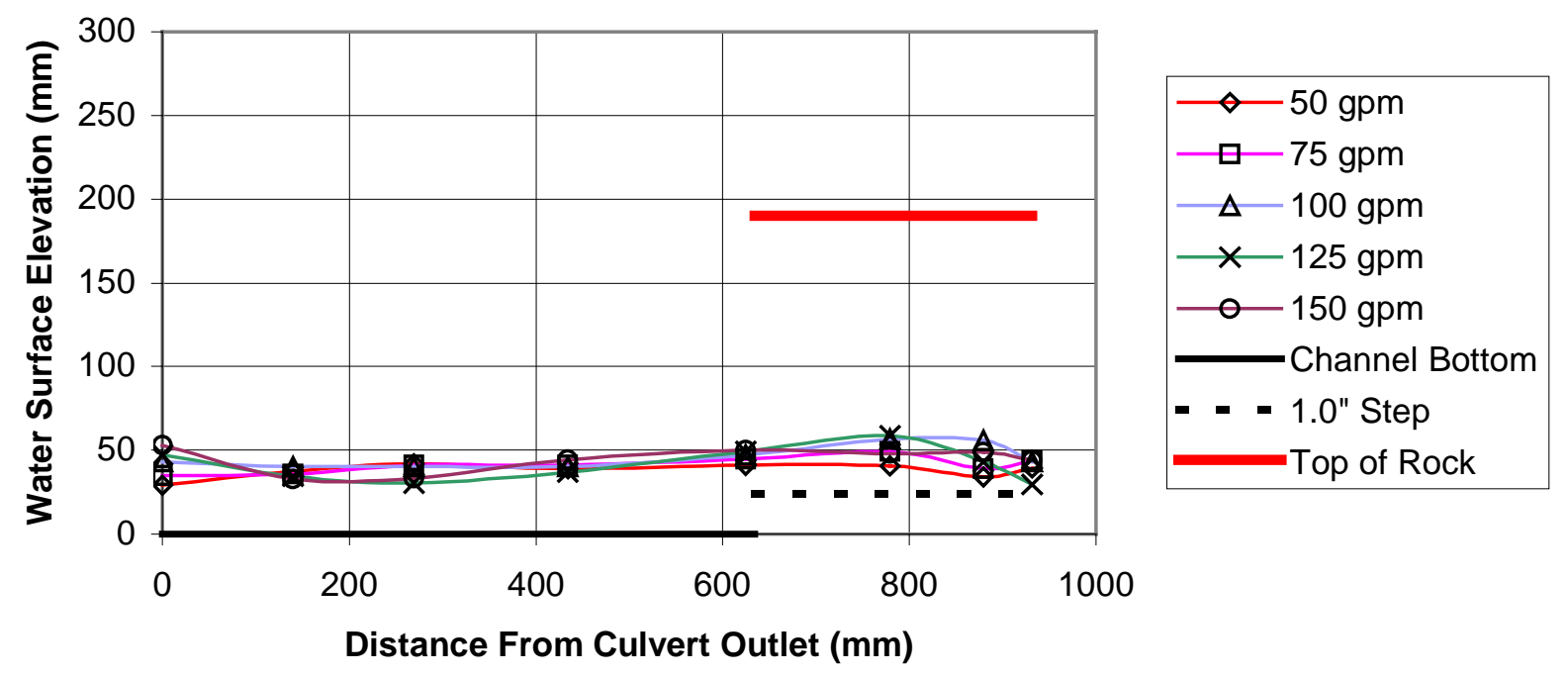

Figure 5.37 Plot of Water Surface Elevation for 1.0-inch Equivalent Riprap Step at 6\% Culvert Slope 
Rough - Water Surface Elevation for 1.0" Step @ 8\% Slope

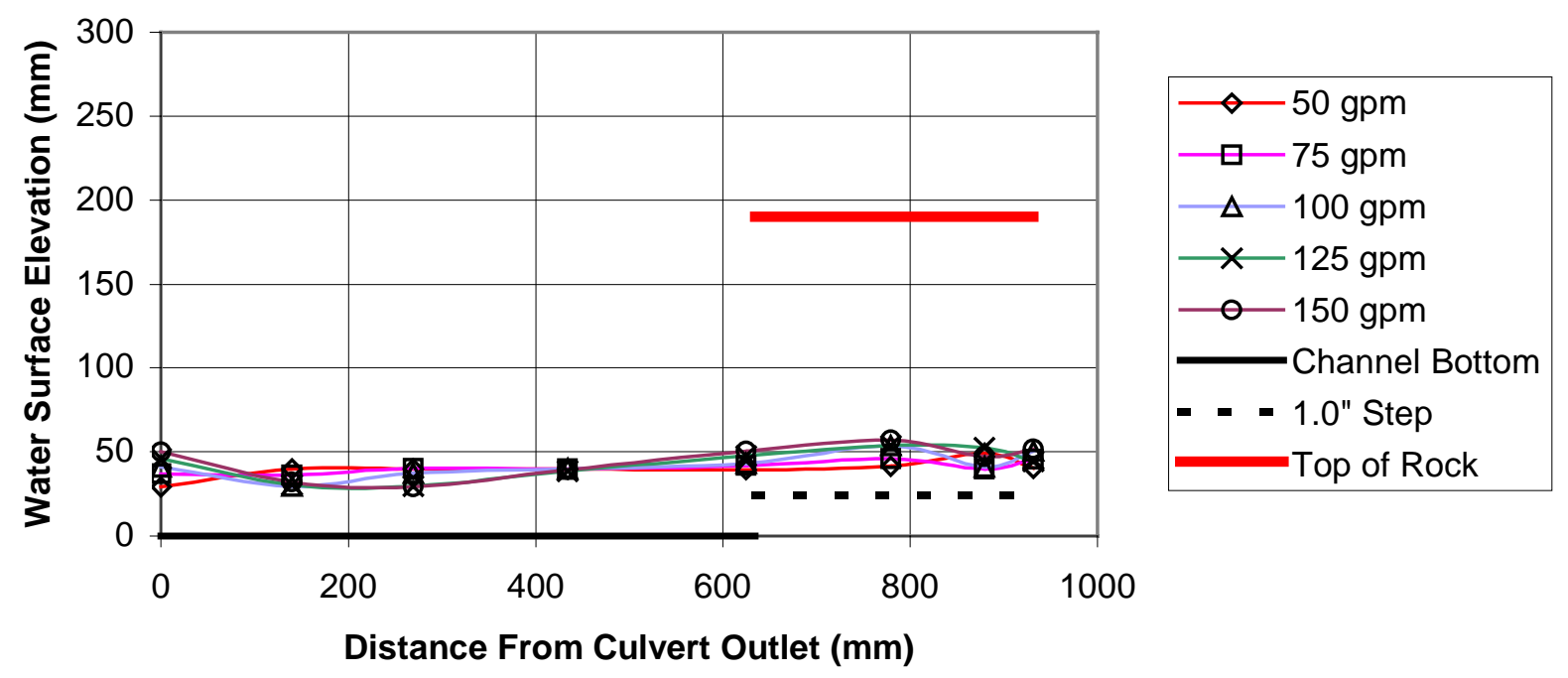

Figure 5.38 Plot of Water Surface Elevation for 1.0-inch Equivalent Riprap Step at 8\% Culvert Slope

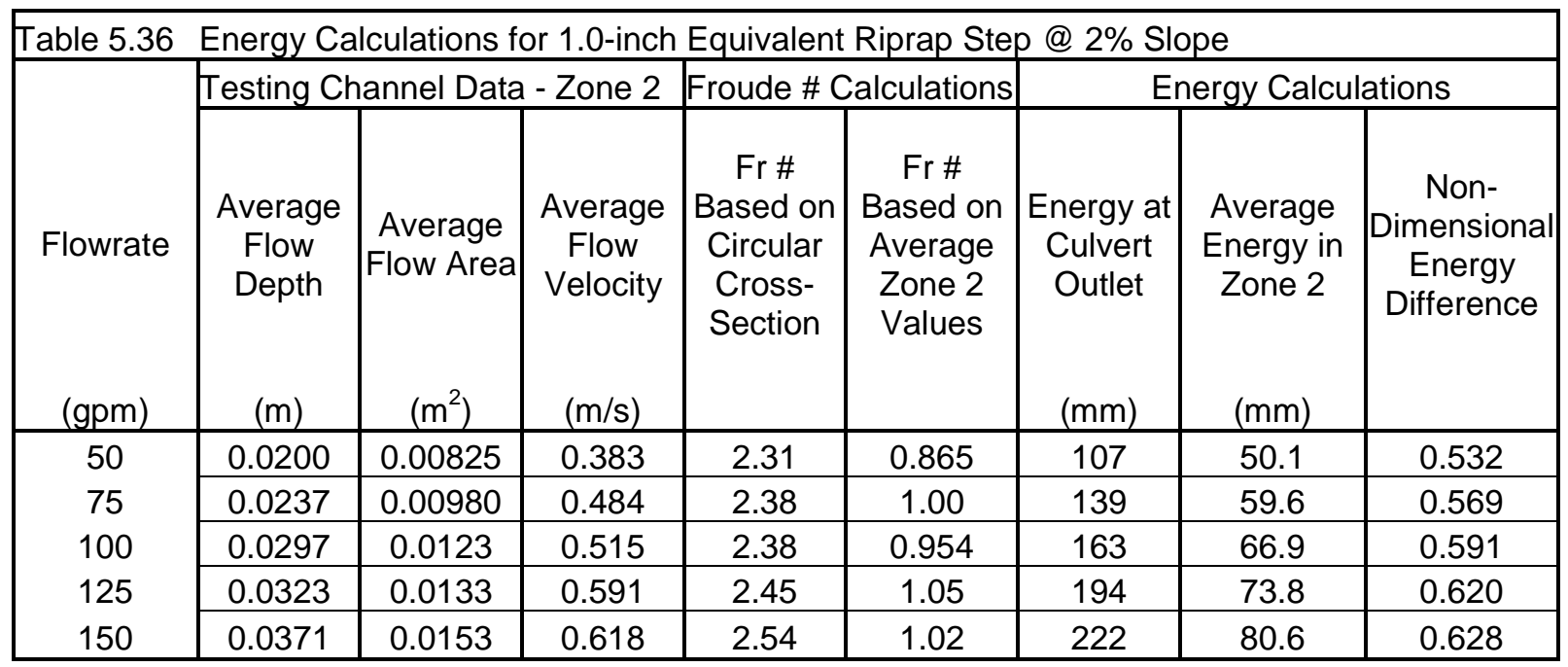




\begin{tabular}{|c|c|c|c|c|c|c|c|c|}
\hline \multirow[b]{3}{*}{ Flowrate } & \multirow{2}{*}{\multicolumn{3}{|c|}{ Testing Channel Data - Zone 2}} & \multirow{2}{*}{\multicolumn{2}{|c|}{ Froude \# Calculations }} & \multirow{2}{*}{\multicolumn{3}{|c|}{ Energy Calculations }} \\
\hline & & & & & & & & \\
\hline & $\begin{array}{l}\text { Average } \\
\text { Flow } \\
\text { Depth }\end{array}$ & $\begin{array}{c}\text { Average } \\
\text { Flow Area }\end{array}$ & $\begin{array}{l}\text { Average } \\
\text { Flow } \\
\text { Velocity }\end{array}$ & \begin{tabular}{|c} 
Fr \# \\
Based on \\
Circular \\
Cross- \\
Section
\end{tabular} & $\begin{array}{c}\text { Fr \# } \\
\text { Based on } \\
\text { Average } \\
\text { Zone } 2 \\
\text { Values }\end{array}$ & $\begin{array}{c}\text { Energy at } \\
\text { Culvert } \\
\text { Outlet }\end{array}$ & $\begin{array}{c}\text { Average } \\
\text { Energy in } \\
\text { Zone } 2\end{array}$ & $\begin{array}{c}\text { Non- } \\
\text { Dimensional } \\
\text { Energy } \\
\text { Difference }\end{array}$ \\
\hline (gpm) & $(\mathrm{m})$ & $\left(m^{2}\right)$ & $(\mathrm{m} / \mathrm{s})$ & & & $(\mathrm{mm})$ & $(\mathrm{mm})$ & \\
\hline 50 & 0.0185 & 0.00762 & 0.414 & 2.97 & 0.974 & 134 & 50.5 & 0.628 \\
\hline 75 & 0.0268 & 0.0111 & 0.429 & 3.00 & 0.837 & 170 & 59.7 & 0.644 \\
\hline 100 & 0.0284 & 0.0117 & 0.538 & 3.02 & 1.02 & 197 & 66.7 & 0.668 \\
\hline 125 & 0.0344 & 0.0142 & 0.555 & 3.03 & 0.956 & 230 & 73.8 & 0.680 \\
\hline 150 & 0.0359 & 0.0148 & 0.638 & 3.02 & 1.08 & 260 & 80.8 & 0.686 \\
\hline
\end{tabular}

\begin{tabular}{|c|c|c|c|c|c|c|c|c|}
\hline & \multirow{2}{*}{\multicolumn{5}{|c|}{\begin{tabular}{|l|l|} 
Testing Channel Data - Zone 2 & Froude \# Calculations \\
\end{tabular}}} & P & & \\
\hline \multirow[b]{2}{*}{ Flowrate } & & & & & & \multicolumn{3}{|c|}{ Energy Calculations } \\
\hline & $\begin{array}{c}\text { Average } \\
\text { Flow } \\
\text { Depth } \\
\\
(\mathrm{m})\end{array}$ & $\begin{array}{c}\text { Average } \\
\text { Flow Area } \\
\left(\mathrm{m}^{2}\right) \\
\end{array}$ & $\begin{array}{c}\text { Average } \\
\text { Flow } \\
\text { Velocity } \\
\\
(\mathrm{m} / \mathrm{s})\end{array}$ & $\begin{array}{c}\text { Fr \# } \\
\text { Based on } \\
\text { Circular } \\
\text { Cross- } \\
\text { Section }\end{array}$ & $\begin{array}{c}\text { Fr \# } \\
\text { Based on } \\
\text { Average } \\
\text { Zone } 2 \\
\text { Values }\end{array}$ & $\begin{array}{c}\text { Energy at } \\
\text { Culvert } \\
\text { Outlet } \\
\\
(\mathrm{mm})\end{array}$ & $\begin{array}{c}\text { Average } \\
\text { Energy in } \\
\text { Zone } 2 \\
\\
(\mathrm{~mm}) \\
\end{array}$ & \begin{tabular}{|c} 
Non- \\
Dimensional \\
Energy \\
Difference
\end{tabular} \\
\hline 50 & 0.0150 & 0.00618 & 0.511 & 3.71 & 1.33 & 166 & 50.7 & 0.687 \\
\hline 75 & 0.0211 & 0.00872 & 0.543 & 3.79 & 1.19 & 214 & 59.1 & 0.725 \\
\hline 100 & 0.0326 & 0.0135 & 0.469 & 3.73 & 0.830 & 247 & 67.5 & 0.727 \\
\hline 125 & 0.0273 & 0.0113 & 0.700 & 3.67 & 1.35 & 270 & 75.8 & 0.725 \\
\hline 150 & 0.0248 & 0.0102 & 0.924 & 3.70 & 1.87 & 311 & 91.9 & 0.709 \\
\hline
\end{tabular}

\begin{tabular}{|c|c|c|c|c|c|c|c|c|}
\hline \multirow[b]{3}{*}{ Flowrate } & \multirow{2}{*}{\multicolumn{5}{|c|}{\begin{tabular}{|l|l|} 
Testing Channel Data - Zone 2 & Froude \# Calculations \\
\end{tabular}}} & \multirow{2}{*}{\multicolumn{3}{|c|}{ Energy Calculations }} \\
\hline & & & & & & & & \\
\hline & $\begin{array}{c}\text { Average } \\
\text { Flow } \\
\text { Depth }\end{array}$ & $\begin{array}{c}\text { Average } \\
\text { Flow Area }\end{array}$ & $\begin{array}{l}\text { Average } \\
\text { Flow } \\
\text { Velocity }\end{array}$ & $\begin{array}{c}\text { Fr \# } \\
\text { Based on } \\
\text { Circular } \\
\text { Cross- } \\
\text { Section }\end{array}$ & $\begin{array}{c}\text { Fr \# } \\
\text { Based on } \\
\text { Average } \\
\text { Zone } 2 \\
\text { Values }\end{array}$ & $\begin{array}{c}\text { Energy at } \\
\text { Culvert } \\
\text { Outlet }\end{array}$ & $\begin{array}{c}\text { Average } \\
\text { Energy in } \\
\text { Zone } 2\end{array}$ & \begin{tabular}{|c} 
Non- \\
Dimensional \\
Energy \\
Difference
\end{tabular} \\
\hline (gpm) & $(\mathrm{m})$ & $\left(m^{2}\right)$ & $(\mathrm{m} / \mathrm{s})$ & & & $(\mathrm{mm})$ & $(\mathrm{mm})$ & \\
\hline 50 & 0.0219 & 0.00906 & 0.349 & 3.95 & 0.751 & 183 & 51.5 & 0.718 \\
\hline 75 & 0.0202 & 0.00835 & 0.567 & 4.09 & 1.27 & 230 & 59.3 & 0.747 \\
\hline 100 & 0.0246 & 0.0101 & 0.623 & 4.06 & 1.27 & 273 & 67.3 & 0.753 \\
\hline 125 & 0.0298 & 0.0123 & 0.642 & 3.90 & 1.19 & 301 & 74.4 & 0.751 \\
\hline 150 & 0.0287 & 0.0119 & 0.799 & 3.87 & 1.51 & 326 & 84.8 & 0.740 \\
\hline
\end{tabular}




\subsection{5-inch Equivalent Riprap Step}

Graphs of the water surface elevation for tests conducted at 2, 4, 6, and 8\% slopes are shown in Figures 5.39, 5.40, 5.41, and 5.42. After the water surface elevation was established, average flow depth was determined. From the flow depth and the results from Section 5.5, the aforementioned volumetric displacement tests and energy calculations were conducted. The results for the energy calculations for the 1.5-inch equivalent riprap step are shown in Tables 5.40, 5.41, 5.42, and 5.43.

Rough - Water Surface Elevation for 1.5" Step @ 2\% Slope

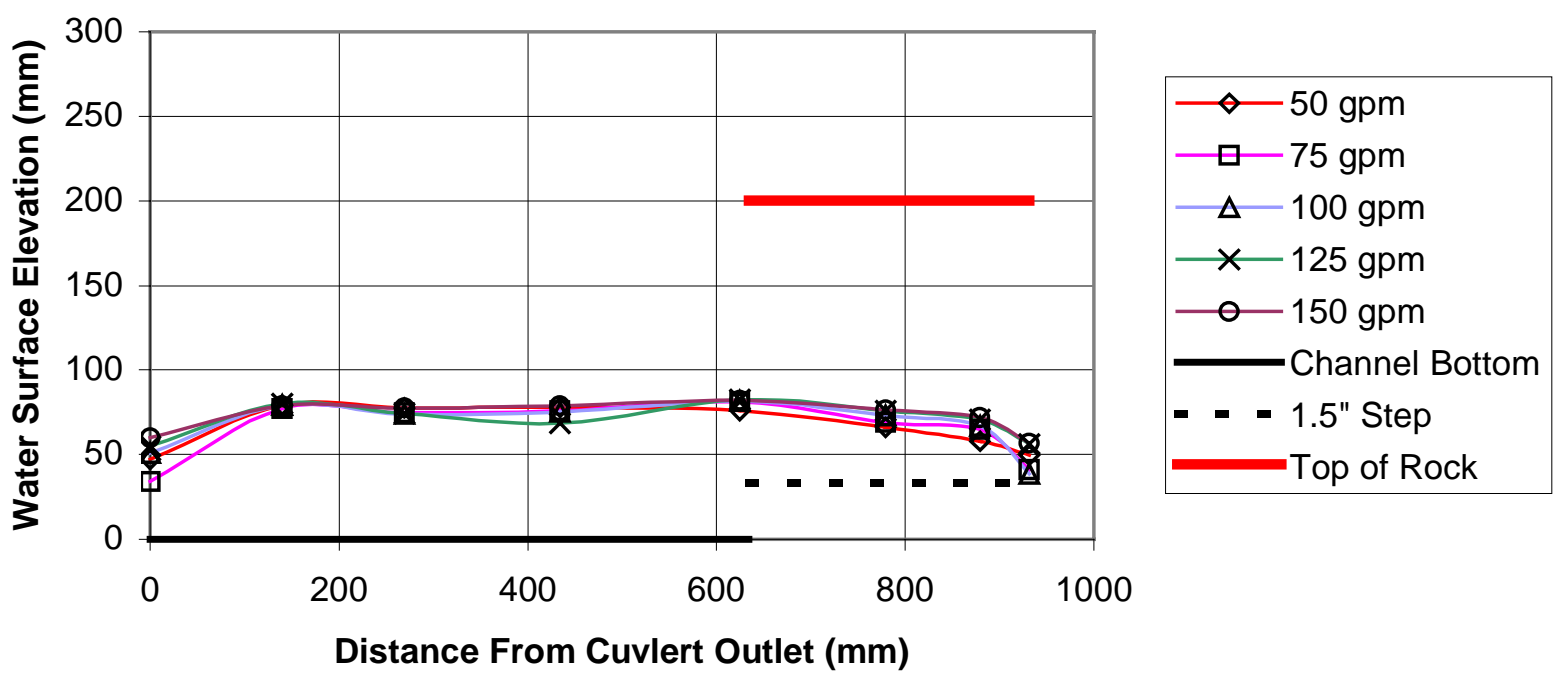

Figure 5.39 Plot of Water Surface Elevation for 1.5-inch Equivalent Riprap Step at 2\% Culvert Slope 
Rough - Water Surface Elevation for 1.5" Step @ 4\% Slope

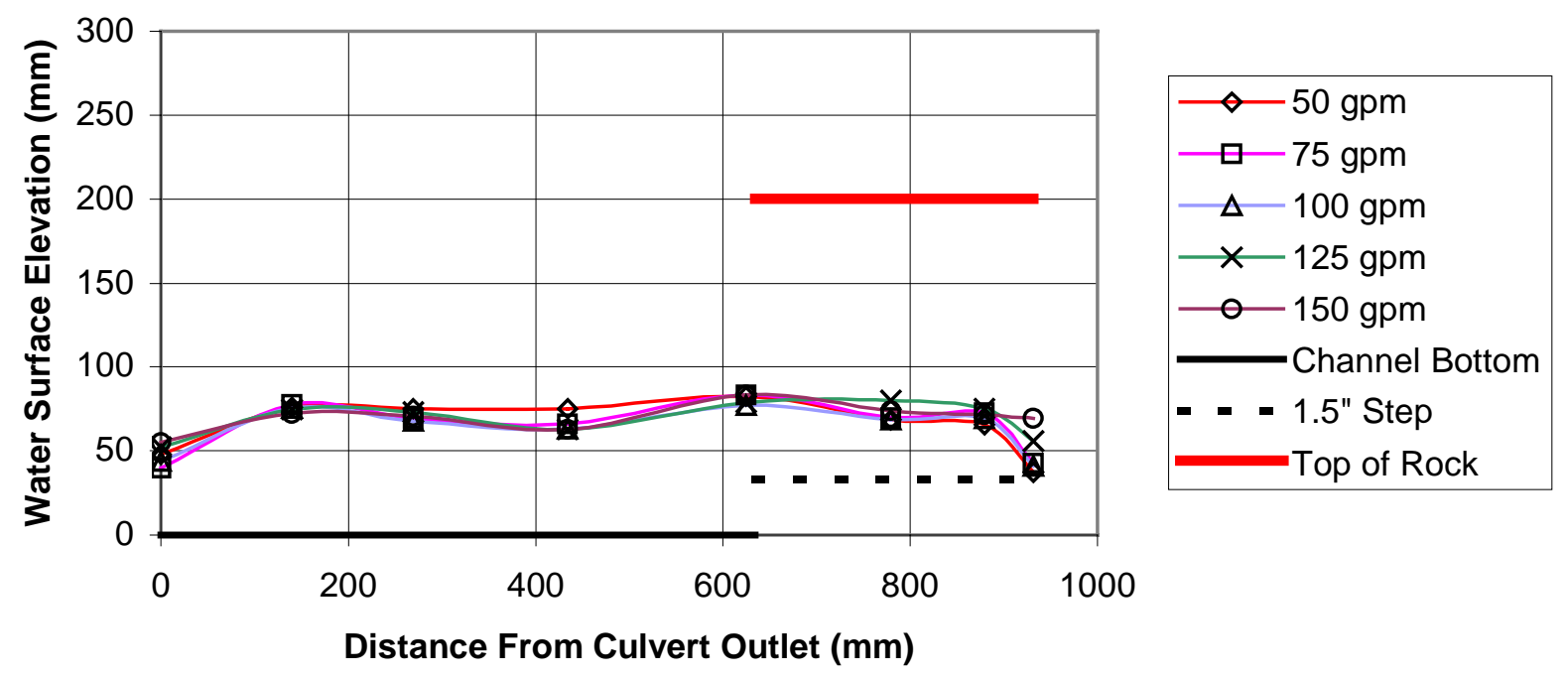

Figure 5.40 Plot of Water Surface Elevation for 1.5-inch Equivalent Riprap Step at 4\% Culvert Slope

\section{Rough - Water Surface Elevation for 1.5" Step @ 6\% Slope}

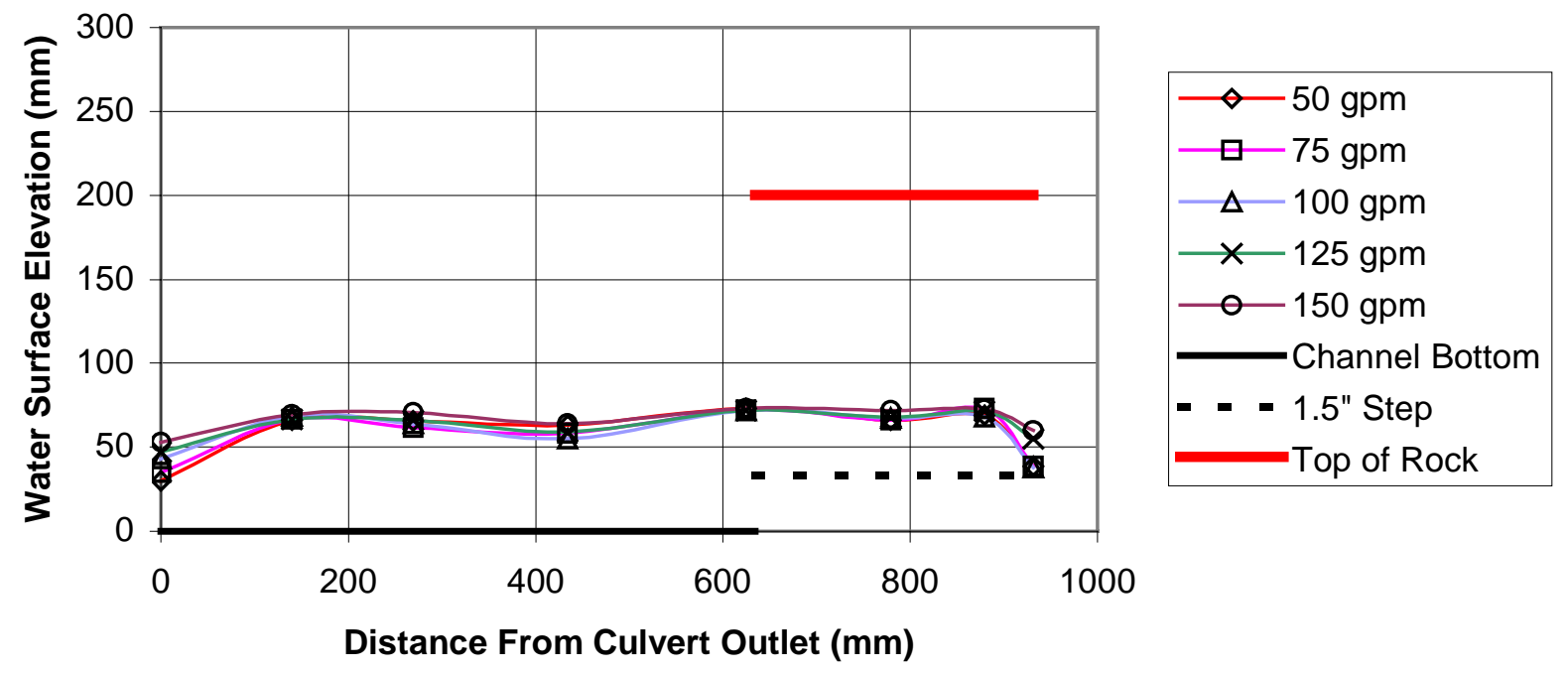

Figure 5.41 Plot of Water Surface Elevation for 1.5-inch Equivalent Riprap Step at 6\% Culvert Slope 


\section{Rough - Water Surface Elevation for 1.5" Step @ 8\% Slope}

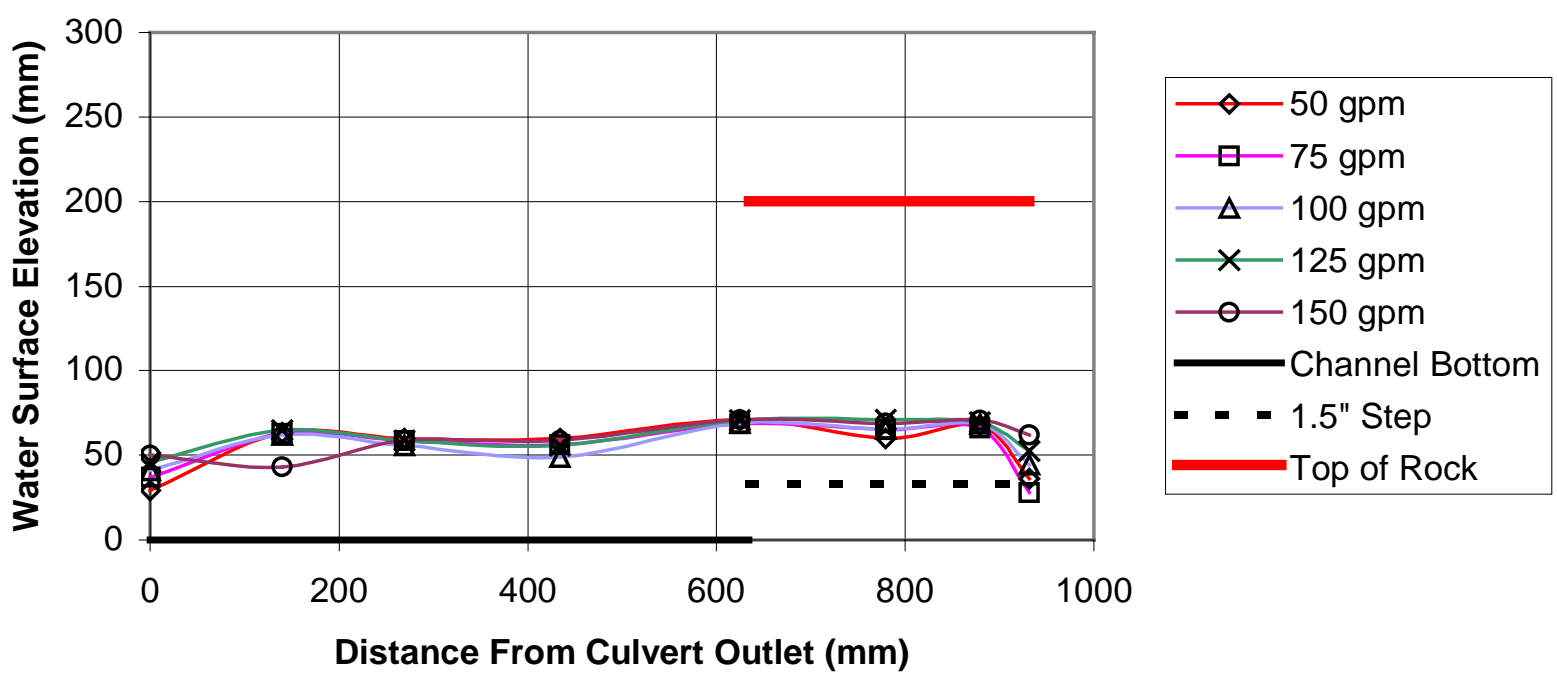

Figure 5.42 Plot of Water Surface Elevation for 1.5-inch Equivalent Riprap Step at 8\% Culvert Slope

\begin{tabular}{|c|c|c|c|c|c|c|c|c|}
\hline \multirow[b]{3}{*}{ Flowrate } & \multirow{2}{*}{\multicolumn{5}{|c|}{\begin{tabular}{|l|l|} 
Testing Channel Data - Zone 2 & Froude \# Calculations \\
\end{tabular}}} & \multirow{2}{*}{\multicolumn{3}{|c|}{ Energy Calculations }} \\
\hline & & & & & & & & \\
\hline & $\begin{array}{c}\text { Average } \\
\text { Flow } \\
\text { Depth }\end{array}$ & $\begin{array}{l}\text { Average } \\
\text { Flow Area }\end{array}$ & $\begin{array}{l}\text { Average } \\
\text { Flow } \\
\text { Velocity }\end{array}$ & \begin{tabular}{|c} 
Fr \# \\
Based on \\
Circular \\
Cross- \\
Section
\end{tabular} & \begin{tabular}{|c} 
Fr \# \\
Based on \\
Average \\
Zone 2 \\
Values
\end{tabular} & $\begin{array}{c}\text { Energy at } \\
\text { Culvert } \\
\text { Outlet }\end{array}$ & $\begin{array}{c}\text { Average } \\
\text { Energy in } \\
\text { Zone } 2\end{array}$ & $\begin{array}{c}\text { Non- } \\
\text { Dimensiona } \\
\text { Energy } \\
\text { Difference }\end{array}$ \\
\hline (gpm) & $(\mathrm{m})$ & $\left(m^{2}\right)$ & $(\mathrm{m} / \mathrm{s})$ & & & $(\mathrm{mm})$ & $(\mathrm{mm})$ & \\
\hline 50 & 0.0312 & 0.0129 & 0.245 & 2.31 & 0.444 & 107 & 65.2 & 0.392 \\
\hline 75 & 0.0375 & 0.0155 & 0.408 & 2.38 & 0.557 & 139 & 72.4 & 0.472 \\
\hline 100 & 0.0375 & 0.0155 & 0.408 & 2.38 & 0.673 & 163 & 78.3 & 0.521 \\
\hline 125 & 0.0404 & 0.0167 & 0.474 & 2.45 & 0.753 & 194 & 84.6 & 0.553 \\
\hline 150 & 0.0410 & 0.0169 & 0.560 & 2.54 & 0.883 & 222 & 89.9 & 0.595 \\
\hline
\end{tabular}




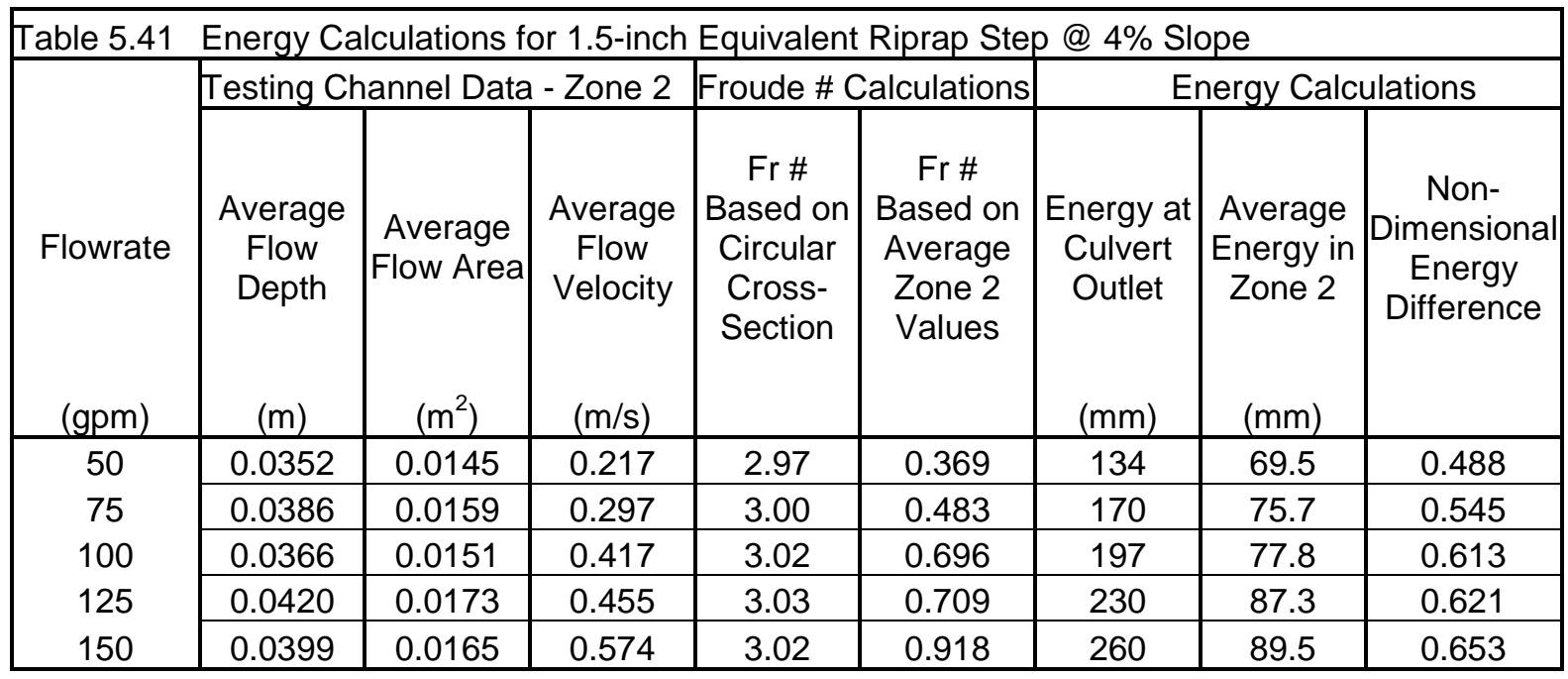

\begin{tabular}{|c|c|c|c|c|c|c|c|c|}
\hline \multirow[b]{2}{*}{ Flowrate } & \multicolumn{3}{|c|}{ Testing Channel Data - Zone 2} & \multicolumn{2}{|c|}{ Froude \# Calculations } & \multicolumn{3}{|c|}{ Energy Calculations } \\
\hline & $\begin{array}{c}\text { Average } \\
\text { Flow } \\
\text { Depth } \\
\\
\text { (m) }\end{array}$ & $\begin{array}{c}\text { Average } \\
\text { Flow Area } \\
\left(\mathrm{m}^{2}\right)\end{array}$ & $\begin{array}{l}\text { Average } \\
\text { Flow } \\
\text { Velocity } \\
\\
(\mathrm{m} / \mathrm{s})\end{array}$ & $\begin{array}{c}\text { Fr \# } \\
\text { Based on } \\
\text { Circular } \\
\text { Cross- } \\
\text { Section }\end{array}$ & $\begin{array}{c}\text { Fr \# } \\
\text { Based on } \\
\text { Average } \\
\text { Zone } 2 \\
\text { Values }\end{array}$ & $\begin{array}{c}\text { Energy at } \\
\text { Culvert } \\
\text { Outlet } \\
(\mathrm{mm})\end{array}$ & $\begin{array}{c}\text { Average } \\
\text { Energy in } \\
\text { Zone } 2 \\
\\
(\mathrm{~mm})\end{array}$ & \begin{tabular}{|c|} 
Non- \\
Dimensional \\
Energy \\
Difference
\end{tabular} \\
\hline 50 & 0.0356 & 0.0147 & 0.215 & 3.71 & 0.363 & 166 & 69.9 & 0.585 \\
\hline 75 & 0.0373 & 0.0154 & 0.307 & 3.79 & 0.508 & 214 & 74.3 & 0.653 \\
\hline 100 & 0.0358 & 0.0148 & 0.427 & 3.73 & 0.721 & 247 & 77.1 & 0.688 \\
\hline 125 & 0.0373 & 0.0154 & 0.512 & 3.67 & 0.847 & 270 & 83.0 & 0.706 \\
\hline 150 & 0.0394 & 0.0163 & 0.582 & 3.70 & 0.937 & 311 & 89.4 & 0.717 \\
\hline
\end{tabular}

\begin{tabular}{|c|c|c|c|c|c|c|c|c|}
\hline & \multicolumn{8}{|c|}{ nch Equivalent Riprap Step @ 8\% Slop } \\
\hline \multirow[b]{2}{*}{ Flowrate } & \multicolumn{3}{|c|}{ Testing Channel Data - Zone 2} & \multicolumn{2}{|c|}{ Froude \# Calculations } & \multicolumn{3}{|c|}{ Energy Calculations } \\
\hline & $\begin{array}{l}\text { Average } \\
\text { Flow } \\
\text { Depth }\end{array}$ & $\begin{array}{c}\text { Average } \\
\text { Flow Area }\end{array}$ & $\begin{array}{l}\text { Average } \\
\text { Flow } \\
\text { Velocity }\end{array}$ & $\begin{array}{c}\text { Fr \# } \\
\text { Based on } \\
\text { Circular } \\
\text { Cross- } \\
\text { Section }\end{array}$ & $\begin{array}{c}\text { Fr \# } \\
\text { Based on } \\
\text { Average } \\
\text { Zone } 2 \\
\text { Values }\end{array}$ & $\begin{array}{c}\text { Energy at } \\
\text { Culvert } \\
\text { Outlet }\end{array}$ & $\begin{array}{c}\text { Average } \\
\text { Energy in } \\
\text { Zone } 2\end{array}$ & \begin{tabular}{|c|} 
Non- \\
Dimensional \\
Energy \\
Difference
\end{tabular} \\
\hline (gpm) & $(\mathrm{m})$ & $\left(m^{2}\right)$ & $(\mathrm{m} / \mathrm{s})$ & & & $(\mathrm{mm})$ & $(\mathrm{mm})$ & \\
\hline 50 & 0.0325 & 0.0134 & 0.236 & 3.95 & 0.418 & 183 & 66.5 & 0.633 \\
\hline 75 & 0.0339 & 0.0140 & 0.338 & 4.09 & 0.586 & 230 & 71.4 & 0.698 \\
\hline 100 & 0.0351 & 0.0145 & 0.435 & 4.06 & 0.742 & 273 & 76.6 & 0.719 \\
\hline 125 & 0.0377 & 0.0156 & 0.506 & 3.90 & 0.833 & 301 & 83.3 & 0.719 \\
\hline 150 & 0.0376 & 0.0155 & 0.610 & 3.87 & 1.00 & 326 & 88.9 & 0.730 \\
\hline
\end{tabular}




\subsection{0-inch Equivalent Riprap Step}

Graphs of the water surface elevation for tests conducted at 2, 4, 6, and 8\% slopes are shown in Figures 5.43, 5.44, 5.45, and 5.46. After the water surface elevation was established, average flow depth was determined. From the flow depth and the results from Section 5.5, the aforementioned volumetric displacement tests and energy calculations were conducted. The results for the energy calculations for the 2.0-inch equivalent riprap step are shown in Tables 5.44, 5.45, 5.46, and 5.47.

\section{Rough - Water Surface Elevation for 2.0" Step @ 2\% Slope}

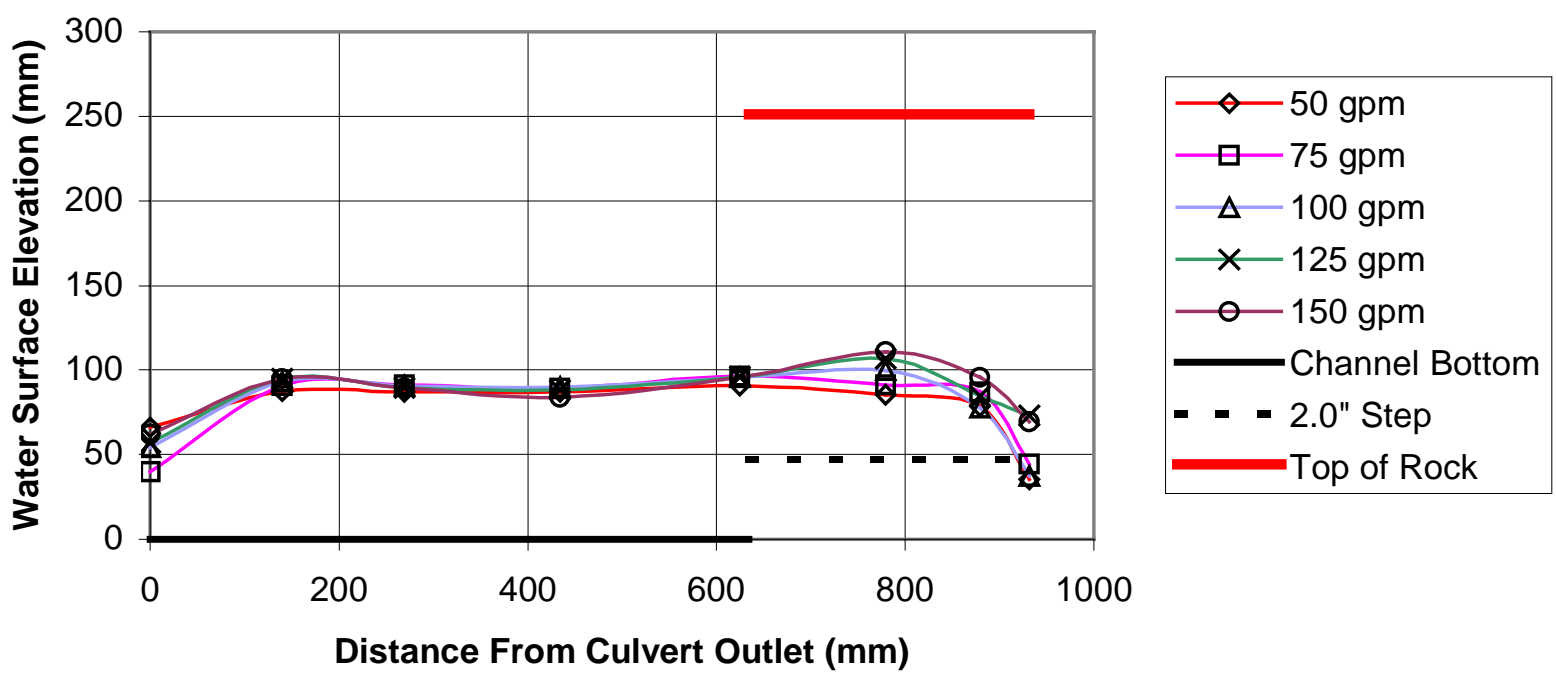

Figure 5.43 Plot of Water Surface Elevation for 2.0-inch Equivalent Riprap Step at 2\% Culvert Slope 
Rough - Water Surface Elevation for 2.0" Step @ 4\% Slope

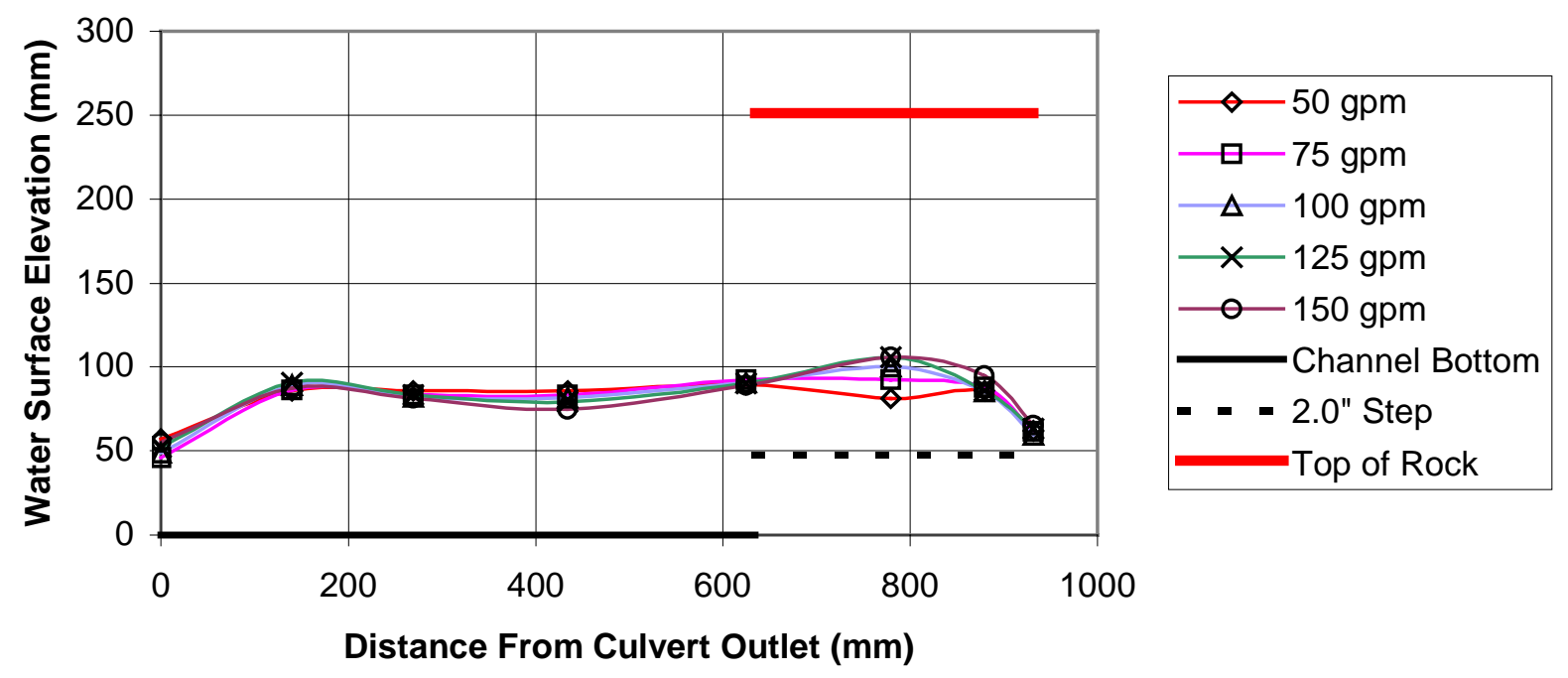

Figure 5.44 Plot of Water Surface Elevation for 2.0-inch Equivalent Riprap Step at 4\% Culvert Slope

\section{Rough - Water Surface Elevation for 2.0" Step @ 6\% Slope}

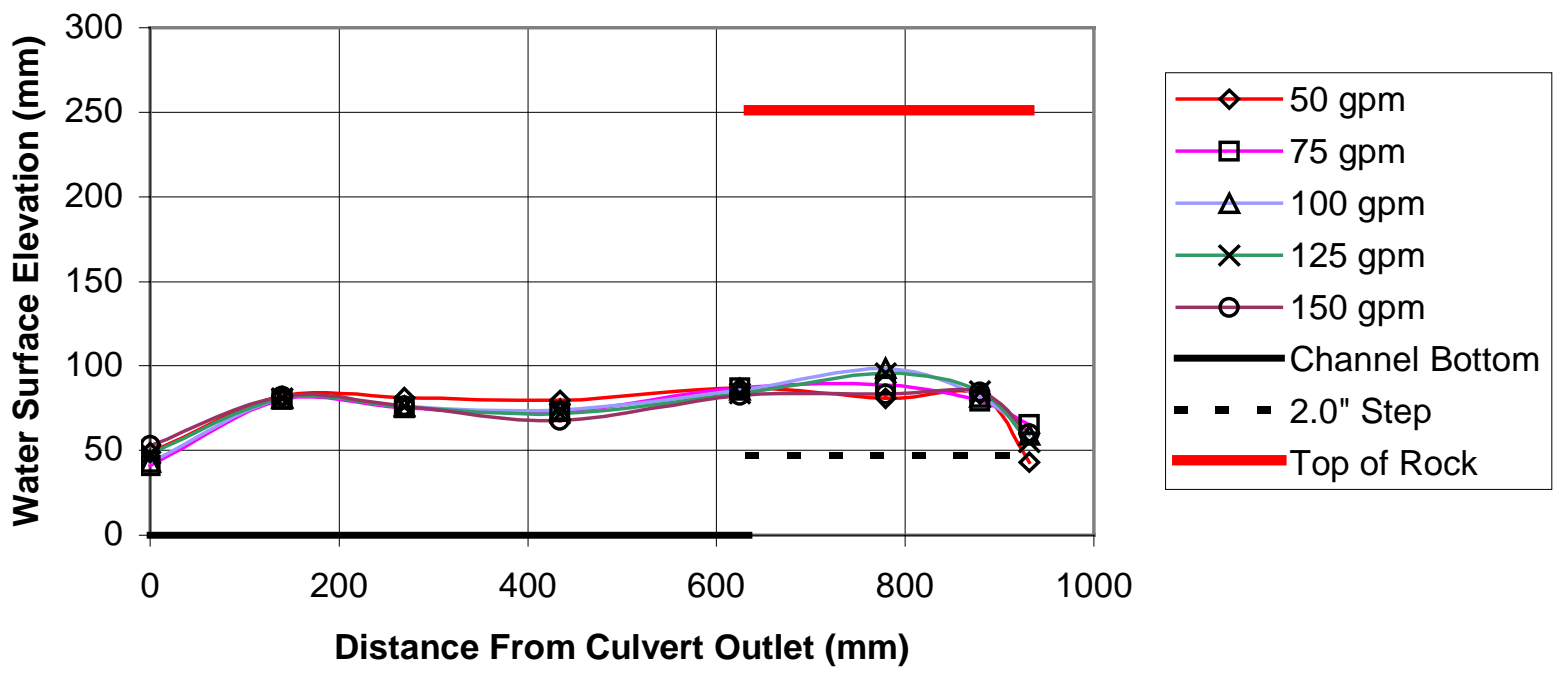

Figure 5.45 Plot of Water Surface Elevation for 2.0-inch Equivalent Riprap Step at 6\% Culvert Slope 
Rough - Water Surface Elevation for 2.0" Step @ 8\% Slope

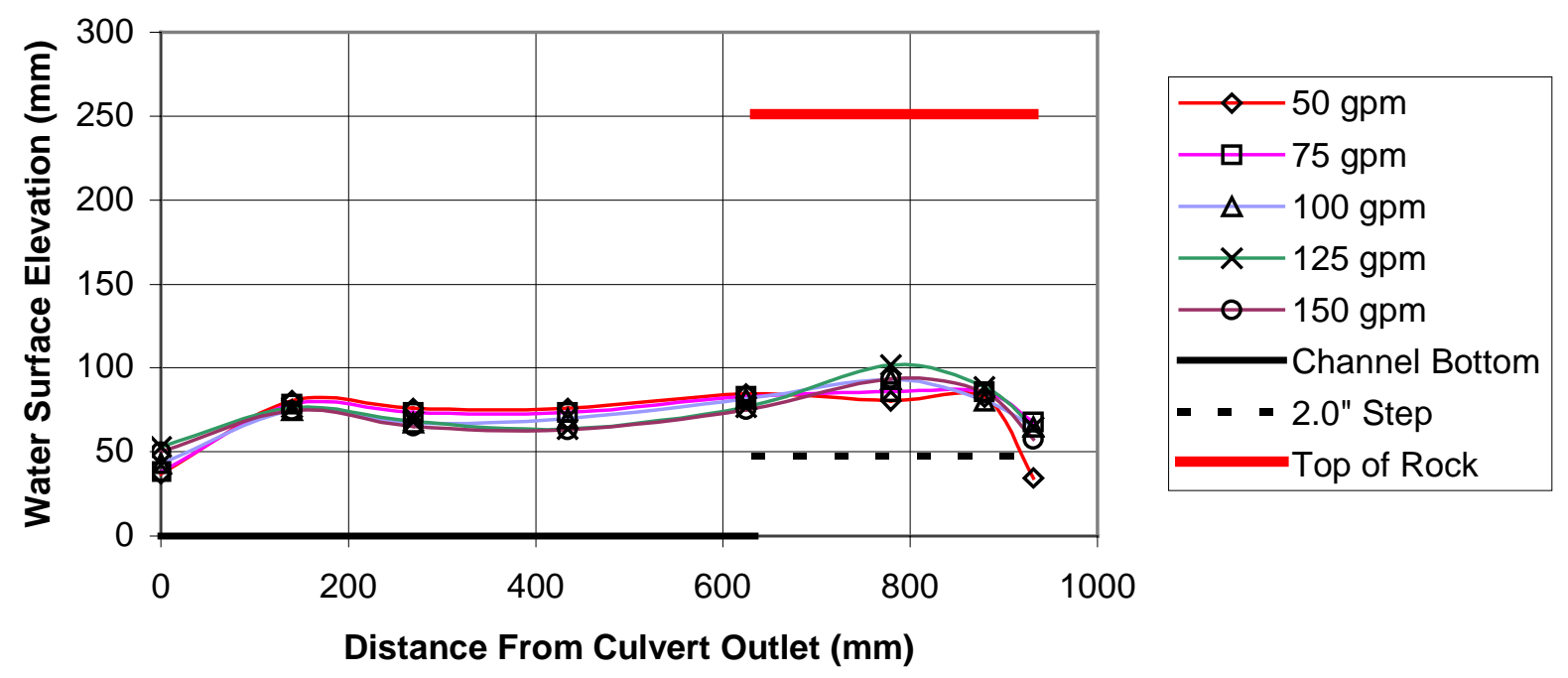

Figure 5.46 Plot of Water Surface Elevation for 2.0-inch Equivalent Riprap Step at 8\% Culvert Slope

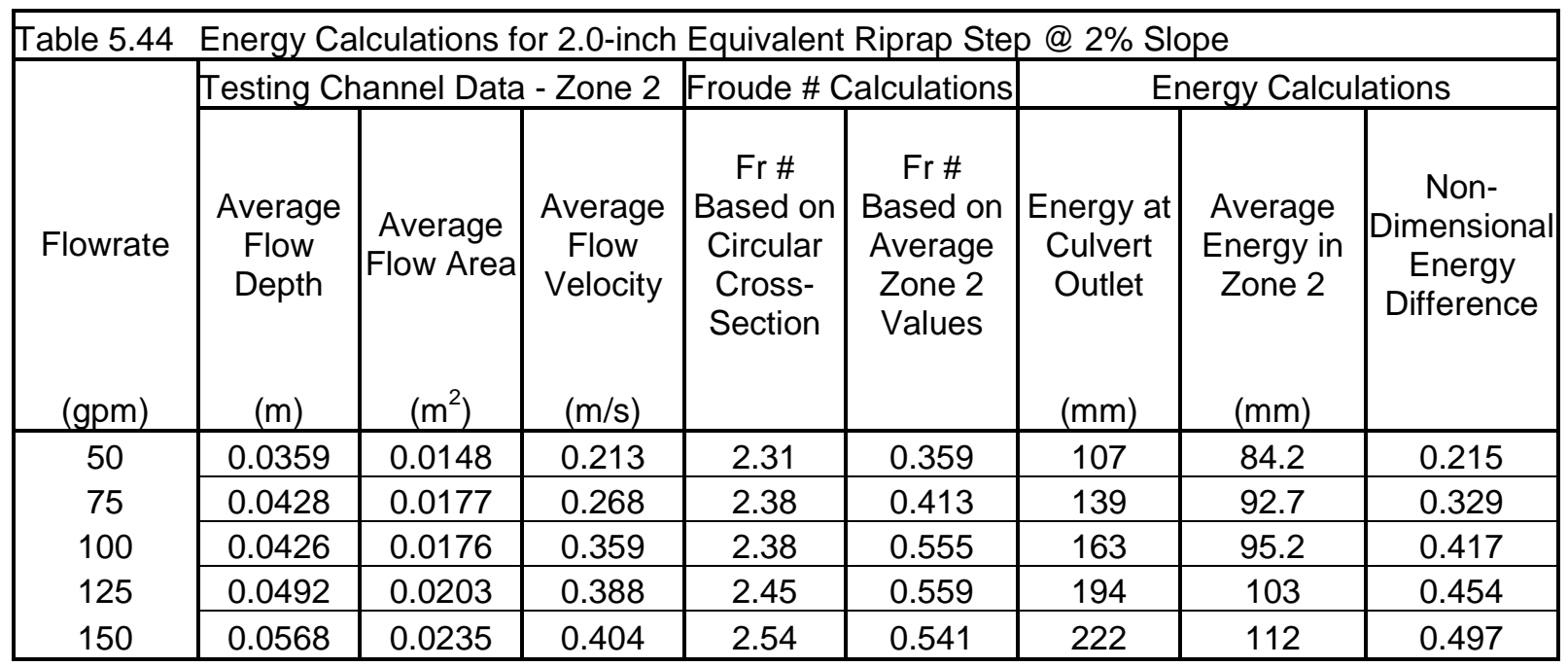




\begin{tabular}{|c|c|c|c|c|c|c|c|c|}
\hline \multirow[b]{3}{*}{ Flowrate } & \multirow{2}{*}{\multicolumn{3}{|c|}{ Testing Channel Data - Zone 2}} & \multirow{2}{*}{\multicolumn{2}{|c|}{ Froude \# Calculations }} & \multirow{2}{*}{\multicolumn{3}{|c|}{ Energy Calculations }} \\
\hline & & & & & & & & \\
\hline & $\begin{array}{c}\text { Average } \\
\text { Flow } \\
\text { Depth }\end{array}$ & $\begin{array}{c}\text { Average } \\
\text { Flow Area }\end{array}$ & $\begin{array}{l}\text { Average } \\
\text { Flow } \\
\text { Velocity }\end{array}$ & $\begin{array}{c}\text { Fr \# } \\
\text { Based on } \\
\text { Circular } \\
\text { Cross- } \\
\text { Section }\end{array}$ & $\begin{array}{c}\text { Fr \# } \\
\text { Based on } \\
\text { Average } \\
\text { Zone } 2 \\
\text { Values }\end{array}$ & $\begin{array}{c}\text { Energy at } \\
\text { Culvert } \\
\text { Outlet }\end{array}$ & $\begin{array}{c}\text { Average } \\
\text { Energy in } \\
\text { Zone } 2\end{array}$ & $\begin{array}{c}\text { Non- } \\
\text { Dimensional } \\
\text { Energy } \\
\text { Difference }\end{array}$ \\
\hline (gpm) & $(\mathrm{m})$ & $\left(m^{2}\right)$ & $(\mathrm{m} / \mathrm{s})$ & & & $(\mathrm{mm})$ & $(\mathrm{mm})$ & \\
\hline 50 & 0.0375 & 0.0155 & 0.204 & 2.97 & 0.337 & 134 & 85.6 & 0.357 \\
\hline 75 & 0.0438 & 0.0181 & 0.262 & 3.00 & 0.399 & 170 & 93.6 & 0.438 \\
\hline 100 & 0.0464 & 0.0192 & 0.329 & 3.02 & 0.488 & 197 & 98.3 & 0.511 \\
\hline 125 & 0.0495 & 0.0205 & 0.386 & 3.03 & 0.554 & 230 & 103 & 0.551 \\
\hline 150 & 0.0541 & 0.0223 & 0.424 & 3.02 & 0.583 & 260 & 110 & 0.560 \\
\hline
\end{tabular}

\begin{tabular}{|c|c|c|c|c|c|c|c|c|}
\hline \multirow[b]{3}{*}{ Flowrate } & \multirow{2}{*}{\multicolumn{5}{|c|}{ Testing Channel Data - Zone 2 Froude \# Calculations }} & \multirow{2}{*}{\multicolumn{3}{|c|}{ Energy Calculations }} \\
\hline & & & & & & & & \\
\hline & $\begin{array}{c}\text { Average } \\
\text { Flow } \\
\text { Depth } \\
\\
(\mathrm{m})\end{array}$ & $\begin{array}{c}\text { Average } \\
\text { Flow Area } \\
\\
\left(\mathrm{m}^{2}\right)\end{array}$ & $\begin{array}{c}\text { Average } \\
\text { Flow } \\
\text { Velocity } \\
\\
(\mathrm{m} / \mathrm{s})\end{array}$ & $\begin{array}{c}\text { Fr \# } \\
\text { Based on } \\
\text { Circular } \\
\text { Cross- } \\
\text { Section }\end{array}$ & $\begin{array}{c}\text { Fr \# } \\
\text { Based on } \\
\text { Average } \\
\text { Zone } 2 \\
\text { Values }\end{array}$ & $\begin{array}{c}\text { Energy at } \\
\text { Culvert } \\
\text { Outlet } \\
\\
(\mathrm{mm})\end{array}$ & $\begin{array}{c}\text { Average } \\
\text { Energy in } \\
\text { Zone } 2 \\
\\
(\mathrm{~mm}) \\
\end{array}$ & $\begin{array}{c}\text { Non- } \\
\text { Dimensional } \\
\text { Energy } \\
\text { Difference }\end{array}$ \\
\hline 50 & 0.0361 & 0.0149 & 0.212 & 3.71 & 0.356 & 166 & 84.4 & 0.507 \\
\hline 75 & 0.0379 & 0.0157 & 0.302 & 3.79 & 0.496 & 214 & 88.6 & 0.587 \\
\hline 100 & 0.0439 & 0.0181 & 0.349 & 3.73 & 0.531 & 247 & 96.2 & 0.611 \\
\hline 125 & 0.0445 & 0.0184 & 0.429 & 3.67 & 0.650 & 270 & 100 & 0.646 \\
\hline 150 & 0.0499 & 0.0206 & 0.460 & 3.70 & 0.658 & 311 & 107 & 0.662 \\
\hline
\end{tabular}

\begin{tabular}{|c|c|c|c|c|c|c|c|c|}
\hline \multirow[b]{3}{*}{ Flowrate } & \multirow{2}{*}{\multicolumn{3}{|c|}{ Testing Channel Data - Zone 2}} & \multirow{2}{*}{\multicolumn{2}{|c|}{ Froude \# Calculations }} & \multirow{2}{*}{\multicolumn{3}{|c|}{ Energy Calculations }} \\
\hline & & & & & & & & \\
\hline & $\begin{array}{c}\text { Average } \\
\text { Flow } \\
\text { Depth }\end{array}$ & $\begin{array}{c}\text { Average } \\
\text { Flow Area }\end{array}$ & $\begin{array}{l}\text { Average } \\
\text { Flow } \\
\text { Velocity }\end{array}$ & $\begin{array}{c}\text { Fr \# } \\
\text { Based on } \\
\text { Circular } \\
\text { Cross- } \\
\text { Section }\end{array}$ & $\begin{array}{l}\text { Fr \# } \\
\text { Based on } \\
\text { Average } \\
\text { Zone } 2 \\
\text { Values }\end{array}$ & $\begin{array}{c}\text { Energy at } \\
\text { Culvert } \\
\text { Outlet }\end{array}$ & $\begin{array}{l}\text { Average } \\
\text { Energy in } \\
\text { Zone } 2\end{array}$ & $\begin{array}{c}\text { Non- } \\
\text { Dimensional } \\
\text { Energy } \\
\text { Difference }\end{array}$ \\
\hline (gpm) & $(\mathrm{m})$ & $\left(m^{2}\right)$ & $(\mathrm{m} / \mathrm{s})$ & & & $(\mathrm{mm})$ & $(\mathrm{mm})$ & \\
\hline 50 & 0.0355 & 0.0146 & 0.216 & 3.95 & 0.365 & 183 & 83.9 & 0.537 \\
\hline 75 & 0.0396 & 0.0164 & 0.289 & 4.09 & 0.464 & 230 & 90.0 & 0.619 \\
\hline 100 & 0.0407 & 0.0168 & 0.376 & 4.06 & 0.594 & 273 & 94.0 & 0.656 \\
\hline 125 & 0.0488 & 0.0201 & 0.392 & 3.90 & 0.567 & 301 & 103 & 0.651 \\
\hline 150 & 0.0431 & 0.0178 & 0.532 & 3.87 & 0.818 & 326 & 104 & 0.685 \\
\hline
\end{tabular}




\subsection{5-inch Equivalent Riprap Step}

Graphs of the water surface elevation for tests conducted at 2, 4, 6, and 8\% slopes are shown in Figures 5.47, 5.48, 5.49, and 5.50. After the water surface elevation was established, average flow depth was determined. From the flow depth and the results from Section 5.5, the aforementioned volumetric displacement tests and energy calculations were conducted. The results for the energy calculations for the 2.5 -inch equivalent riprap step are shown in Tables 5.48, 5.49, 5.50, and 5.51.

Rough - Water Surface Elevation for 2.5" Step @ 2\% Slope

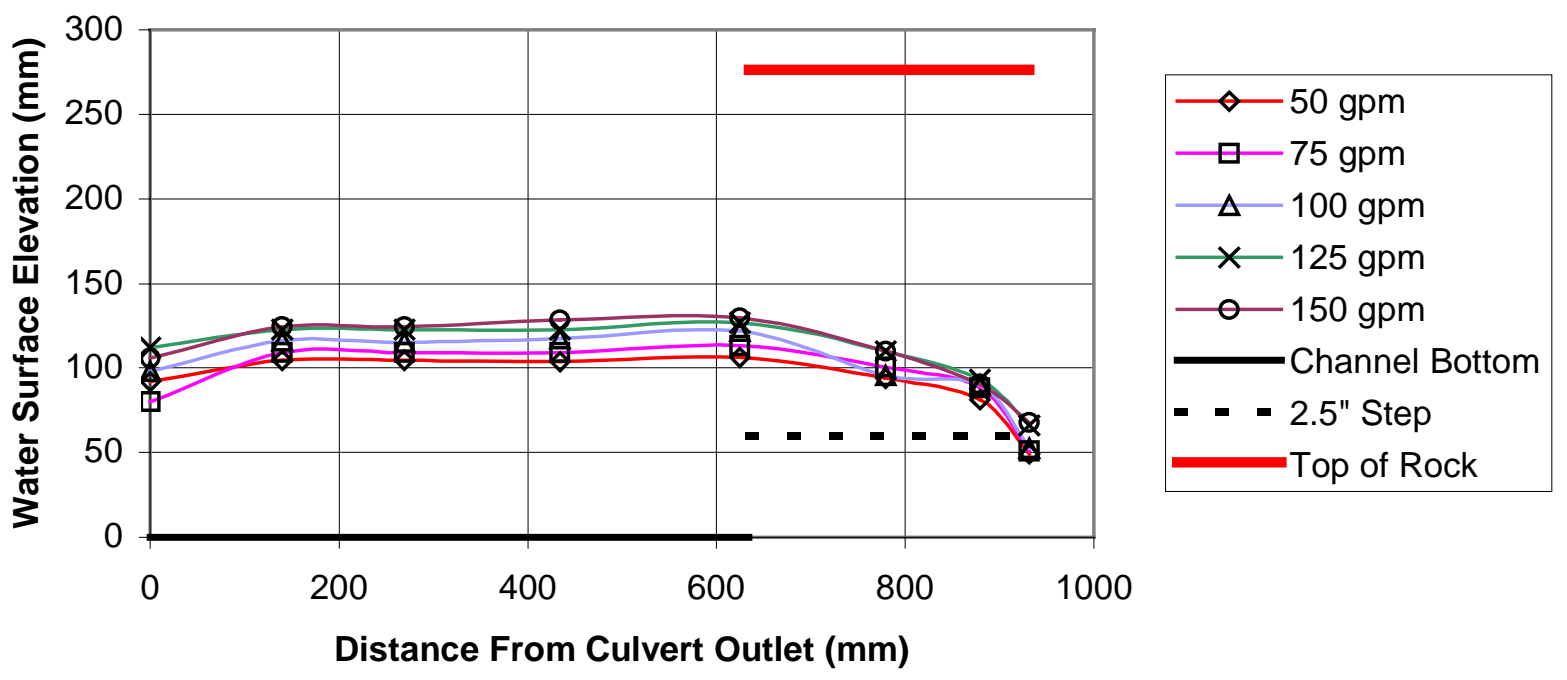

Figure 5.47 Plot of Water Surface Elevation for 2.5-inch Equivalent Riprap Step at 2\% Culvert Slope 


\section{Rough - Water Surface Elevation for 2.5" Step @ 4\% Slope}

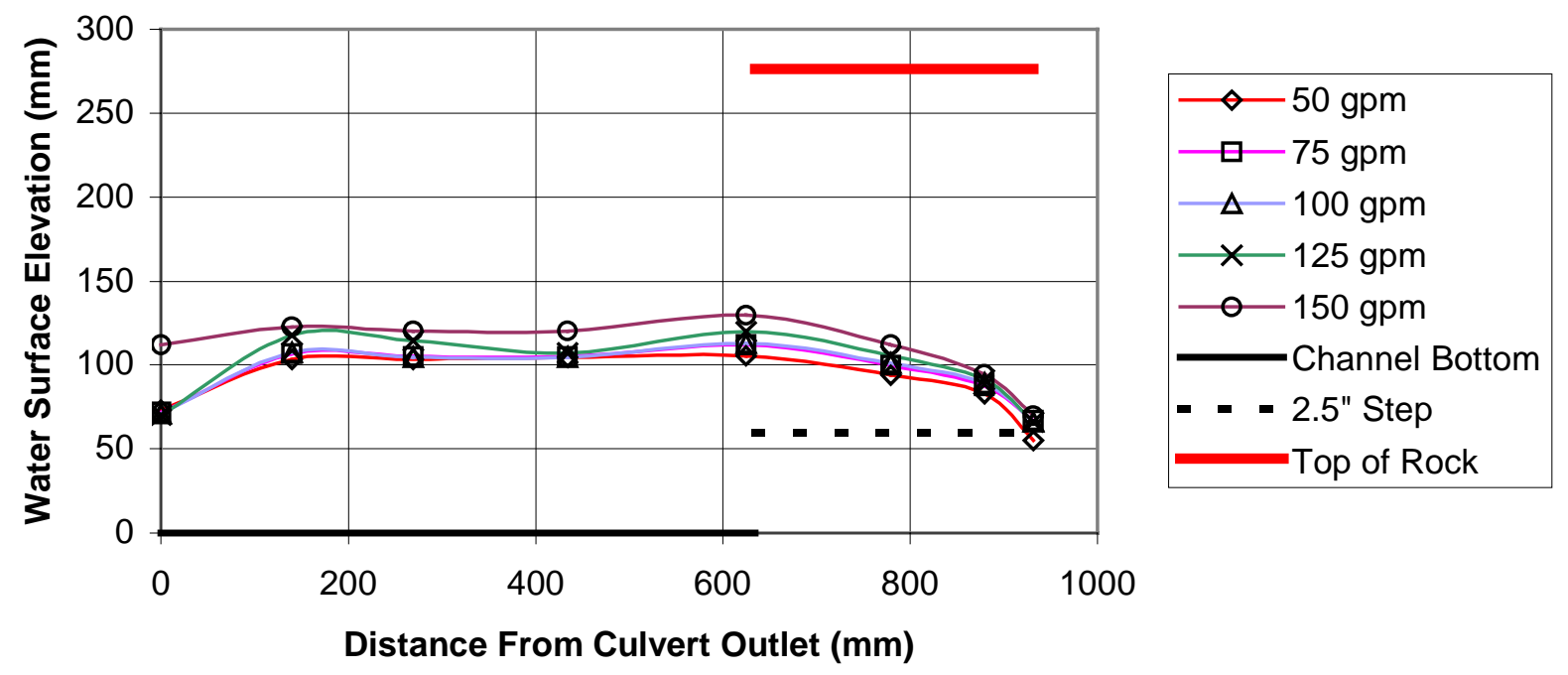

Figure 5.48 Plot of Water Surface Elevation for 2.5-inch Equivalent Riprap Step at 4\% Culvert Slope

\section{Rough - Water Surface Elevation for 2.5" Step @ 6\% Slope}

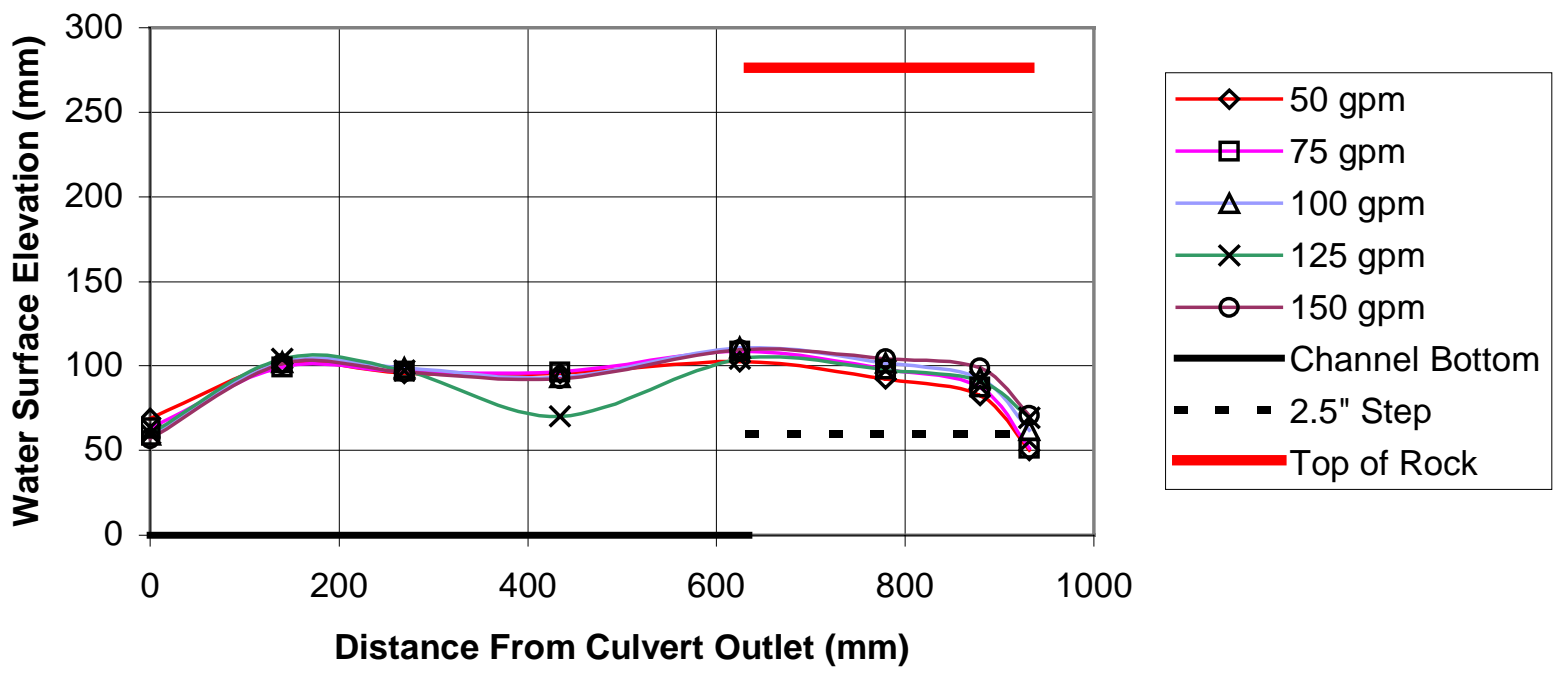

Figure 5.49 Plot of Water Surface Elevation for 2.5-inch Equivalent Riprap Step at 6\% Culvert Slope 
Rough - Water Surface Elevation for 2.5" Step @ 8\% Slope

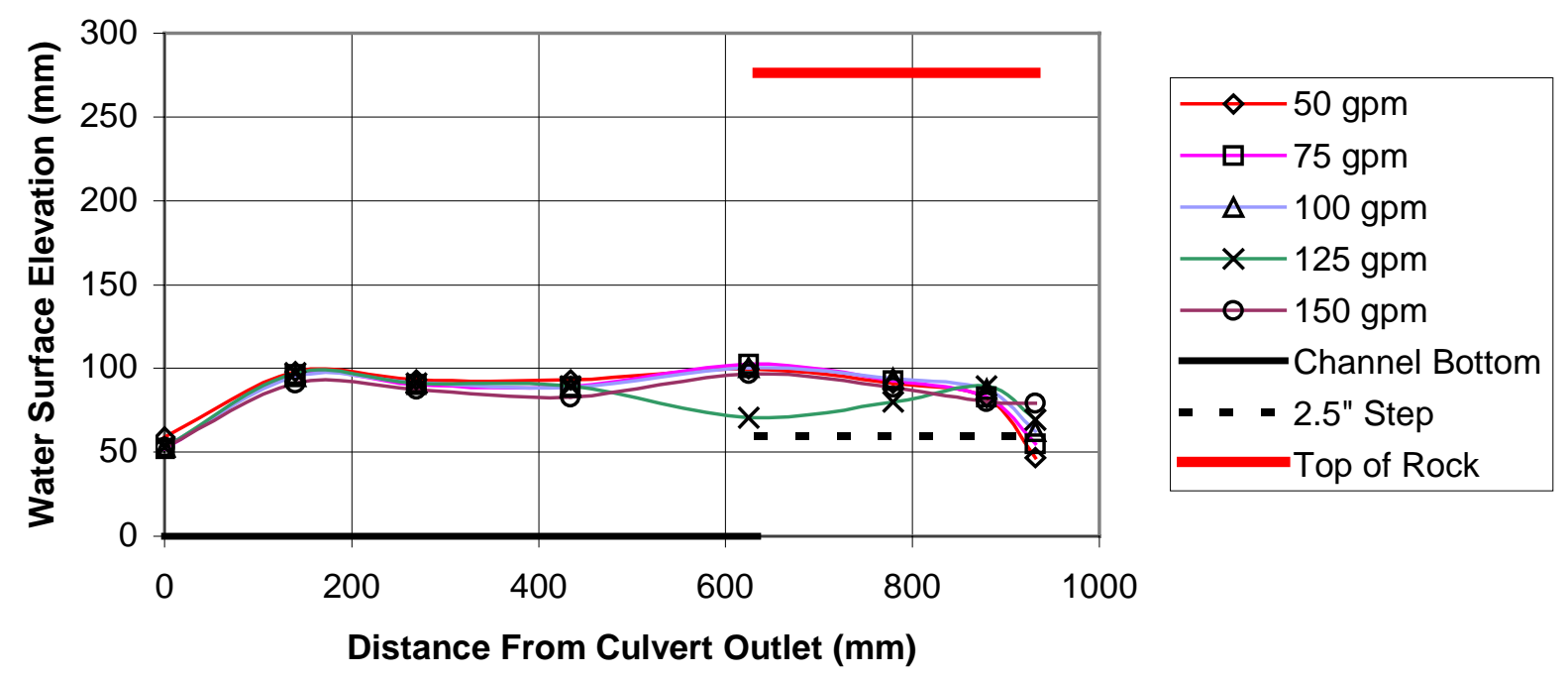

Figure 5.50 Plot of Water Surface Elevation for 2.5-inch Equivalent Riprap Step at 8\% Culvert Slope

\begin{tabular}{|c|c|c|c|c|c|c|c|c|}
\hline \multirow[b]{2}{*}{ Flowrate } & \multicolumn{3}{|c|}{ Testing Channel Data - Zone 2} & \multicolumn{2}{|c|}{ Froude \# Calculations } & \multicolumn{3}{|c|}{ Energy Calculations } \\
\hline & $\begin{array}{c}\text { Average } \\
\text { Flow } \\
\text { Depth }\end{array}$ & $\begin{array}{l}\text { Average } \\
\text { Flow Area }\end{array}$ & $\begin{array}{l}\text { Average } \\
\text { Flow } \\
\text { Velocity }\end{array}$ & $\begin{array}{c}\text { Fr \# } \\
\text { Based on } \\
\text { Circular } \\
\text { Cross- } \\
\text { Section }\end{array}$ & $\begin{array}{c}\text { Fr \# } \\
\text { Based on } \\
\text { Average } \\
\text { Zone } 2 \\
\text { Values }\end{array}$ & $\begin{array}{c}\text { Energy at } \\
\text { Culvert } \\
\text { Outlet }\end{array}$ & $\begin{array}{c}\text { Average } \\
\text { Energy in } \\
\text { Zone } 2\end{array}$ & $\begin{array}{c}\text { Non- } \\
\text { Dimensional } \\
\text { Energy } \\
\text { Difference }\end{array}$ \\
\hline (gpm) & $(\mathrm{m})$ & $\left(\mathrm{m}^{2}\right)$ & $(\mathrm{m} / \mathrm{s})$ & & & $(\mathrm{mm})$ & $(\mathrm{mm})$ & \\
\hline 50 & 0.0509 & 0.0210 & 0.150 & 2.31 & 0.212 & 107 & 102 & 0.0146 \\
\hline 75 & 0.0576 & 0.0238 & 0.199 & 2.38 & 0.265 & 139 & 109 & 0.202 \\
\hline 100 & 0.0428 & 0.0177 & 0.357 & 2.38 & 0.552 & 163 & 99.4 & 0.391 \\
\hline 125 & 0.0644 & 0.0266 & 0.297 & 2.45 & 0.373 & 194 & 119 & 0.371 \\
\hline 150 & 0.0631 & 0.0261 & 0.364 & 2.54 & 0.462 & 222 & 120 & 0.474 \\
\hline
\end{tabular}




\begin{tabular}{|c|c|c|c|c|c|c|c|c|}
\hline \multirow[b]{3}{*}{ Flowrate } & \multirow{2}{*}{\multicolumn{3}{|c|}{ Testing Channel Data - Zone 2}} & \multirow{2}{*}{\multicolumn{2}{|c|}{ Froude \# Calculations }} & \multirow{2}{*}{\multicolumn{3}{|c|}{ Energy Calculations }} \\
\hline & & & & & & & & \\
\hline & $\begin{array}{c}\text { Average } \\
\text { Flow } \\
\text { Depth }\end{array}$ & $\begin{array}{c}\text { Average } \\
\text { Flow Area }\end{array}$ & $\begin{array}{l}\text { Average } \\
\text { Flow } \\
\text { Velocity }\end{array}$ & $\begin{array}{c}\text { Fr \# } \\
\text { Based on } \\
\text { Circular } \\
\text { Cross- } \\
\text { Section }\end{array}$ & $\begin{array}{c}\text { Fr \# } \\
\text { Based on } \\
\text { Average } \\
\text { Zone } 2 \\
\text { Values }\end{array}$ & $\begin{array}{c}\text { Energy at } \\
\text { Culvert } \\
\text { Outlet }\end{array}$ & $\begin{array}{c}\text { Average } \\
\text { Energy in } \\
\text { Zone } 2\end{array}$ & $\begin{array}{c}\text { Non- } \\
\text { Dimensional } \\
\text { Energy } \\
\text { Difference }\end{array}$ \\
\hline (gpm) & $(\mathrm{m})$ & $\left(m^{2}\right)$ & $(\mathrm{m} / \mathrm{s})$ & & & $(\mathrm{mm})$ & $(\mathrm{mm})$ & \\
\hline 50 & 0.0518 & 0.0214 & 0.148 & 2.97 & 0.207 & 134 & 102 & 0.170 \\
\hline 75 & 0.0567 & 0.0234 & 0.202 & 3.00 & 0.271 & 170 & 109 & 0.353 \\
\hline 100 & 0.0580 & 0.0239 & 0.264 & 3.02 & 0.350 & 197 & 111 & 0.446 \\
\hline 125 & 0.0614 & 0.0253 & 0.311 & 3.03 & 0.401 & 230 & 116 & 0.493 \\
\hline 150 & 0.0659 & 0.0272 & 0.348 & 3.02 & 0.433 & 260 & 122 & 0.530 \\
\hline
\end{tabular}

\begin{tabular}{|c|c|c|c|c|c|c|c|c|}
\hline \multirow[b]{3}{*}{ Flowrate } & \multirow{2}{*}{\multicolumn{3}{|c|}{ Testing Channel Data - Zone 2}} & & & \multirow{2}{*}{\multicolumn{3}{|c|}{ Energy Calculations }} \\
\hline & & & & \multicolumn{2}{|c|}{ Froude \# Calculations } & & & \\
\hline & $\begin{array}{c}\text { Average } \\
\text { Flow } \\
\text { Depth } \\
\\
(\mathrm{m})\end{array}$ & $\begin{array}{c}\text { Average } \\
\text { Flow Area } \\
\left(\mathrm{m}^{2}\right)\end{array}$ & $\begin{array}{c}\text { Average } \\
\text { Flow } \\
\text { Velocity } \\
\\
(\mathrm{m} / \mathrm{s})\end{array}$ & $\begin{array}{c}\text { Fr \# } \\
\text { Based on } \\
\text { Circular } \\
\text { Cross- } \\
\text { Section }\end{array}$ & $\begin{array}{c}\text { Fr \# } \\
\text { Based on } \\
\text { Average } \\
\text { Zone } 2 \\
\text { Values }\end{array}$ & $\begin{array}{c}\text { Energy at } \\
\text { Culvert } \\
\text { Outlet } \\
\\
(\mathrm{mm}) \\
\end{array}$ & $\begin{array}{c}\text { Average } \\
\text { Energy in } \\
\text { Zone } 2 \\
\\
(\mathrm{~mm}) \\
\end{array}$ & \begin{tabular}{|c} 
Non- \\
Dimensional \\
Energy \\
Difference
\end{tabular} \\
\hline 50 & 0.0508 & 0.0210 & 0.150 & 3.71 & 0.213 & 166 & 101 & 0.416 \\
\hline 75 & 0.0558 & 0.0231 & 0.205 & 3.79 & 0.277 & 214 & 108 & 0.498 \\
\hline 100 & 0.0601 & 0.0248 & 0.255 & 3.73 & 0.332 & 247 & 113 & 0.553 \\
\hline 125 & 0.0574 & 0.0237 & 0.333 & 3.67 & 0.444 & 270 & 113 & 0.599 \\
\hline 150 & 0.0638 & 0.0263 & 0.360 & 3.70 & 0.455 & 311 & 121 & 0.616 \\
\hline
\end{tabular}

\begin{tabular}{|c|c|c|c|c|c|c|c|c|}
\hline \multirow[b]{2}{*}{ Flowrate } & \multicolumn{3}{|c|}{ Testing Channel Data - Zone 2} & \multicolumn{2}{|c|}{ Froude \# Calculations } & \multicolumn{3}{|c|}{ Energy Calculations } \\
\hline & $\begin{array}{c}\text { Average } \\
\text { Flow } \\
\text { Depth }\end{array}$ & $\begin{array}{c}\text { Average } \\
\text { Flow Area }\end{array}$ & $\begin{array}{l}\text { Average } \\
\text { Flow } \\
\text { Velocity }\end{array}$ & $\begin{array}{c}\text { Fr \# } \\
\text { Based on } \\
\text { Circular } \\
\text { Cross- } \\
\text { Section }\end{array}$ & $\begin{array}{c}\text { Fr \# } \\
\text { Based on } \\
\text { Average } \\
\text { Zone } 2\end{array}$ & $\begin{array}{c}\text { Energy at } \\
\text { Culvert } \\
\text { Outlet }\end{array}$ & $\begin{array}{l}\text { Average } \\
\text { Energy in } \\
\text { Zone } 2\end{array}$ & $\begin{array}{c}\text { Non- } \\
\text { Dimensional } \\
\text { Energy } \\
\text { Difference }\end{array}$ \\
\hline (gpm) & (m) & $\left(\mathrm{m}^{2}\right)$ & $(\mathrm{m} / \mathrm{s})$ & & & $(\mathrm{mm})$ & $(\mathrm{mm})$ & \\
\hline 50 & 0.0499 & 0.0206 & 0.153 & 3.95 & 0.219 & 183 & 101 & 0.404 \\
\hline 75 & 0.0510 & 0.0211 & 0.225 & 4.09 & 0.318 & 230 & 103 & 0.564 \\
\hline 100 & 0.0538 & 0.0222 & 0.284 & 4.06 & 0.391 & 273 & 108 & 0.609 \\
\hline 125 & 0.0478 & 0.0197 & 0.400 & 3.90 & 0.584 & 301 & 106 & 0.641 \\
\hline 150 & 0.0488 & 0.0202 & 0.470 & 3.87 & 0.679 & 326 & 96.0 & 0.715 \\
\hline
\end{tabular}




\subsection{Comparison to "Natural” Energy Grade Line}

As stated in the beginning of this chapter, one criterion that needed to be met was to re-establish natural flow conditions downstream of the outlet. In order for this parameter to be examined, the headwater elevations above the invert of the culvert inlet, for the tested flowrates, were used to establish the "natural" energy grade line. The headwater elevation was taken as the location of the energy grade line above the culvert inlet and was extended parallel to the culvert (at the respective slope setting). A representation of the physical setting for this calculation is shown in Figure 5.51.

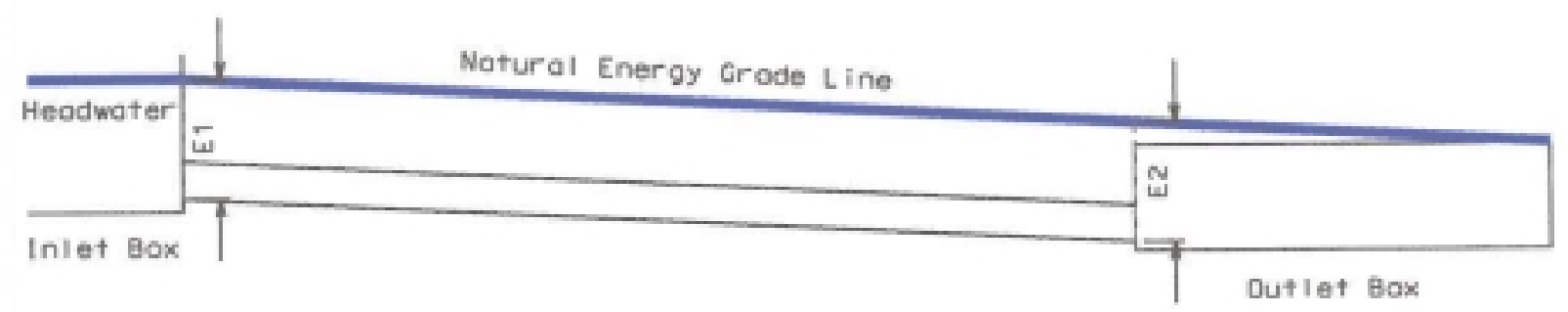

Figure 5.51 Energy Grade Line Establishment

Notice that the height of the energy grade line above the invert at the culvert inlet, E1, is equal to the height of the energy grade line above the invert at the culvert outlet, E2. Since E1 and E2 were equal, the calculations to find the elevation of the energy grade line at a point in the testing channel could be determined from simple trigonometry. The point selected to perform the comparison between the natural energy grade line and the total energy grade calculated from the three-point gage data was the center point of Zone 2. Following the selection of the point for comparison, the elevation of the natural energy grade line was calculated based on trigonometric relationships. The values for the elevation of the natural energy grade line, shown in red in Tables 5.52 and 5.53, were then compared to the values for total average energy in Zone 2 of the testing channel. The values for the elevation of the total average energy in Zone 2 of the testing channel shown in blue represent those cases where the energy remaining in the flow over Zone 2 exceeds that estimated for the so-called "natural condition". The 'smooth' cast acrylic steps are compared in Table 5.52 and the 'rough' riprap steps are compared in Table 5.53. 


\begin{tabular}{|c|c|c|c|c|c|c|c|}
\hline \multicolumn{8}{|c|}{ Cast Acrylic Steps } \\
\hline \multirow{2}{*}{$\begin{array}{l}\text { Slope } \\
(\%) \\
\end{array}$} & \multirow{2}{*}{$\begin{array}{c}\text { Flowrate } \\
\text { (gpm) }\end{array}$} & \multirow{2}{*}{$\begin{array}{c}\text { "Natural" } \\
\text { Energy Grade } \\
\text { Line } \\
\text { (mm) } \\
\end{array}$} & 0.5-inch & 1.0-inch & 1.5-inch & 2.0-inch & 2.5-inch \\
\hline & & & \multicolumn{5}{|c|}{ Total Average Energy In Zone 2 of Testing Channel $(\mathrm{mm})$} \\
\hline 2 & 50 & 65.3 & 41.5 & 53.2 & 61.3 & 75.7 & 88.9 \\
\hline 2 & 75 & 84.3 & 48.5 & 61.2 & 73.1 & 98.5 & 98.5 \\
\hline 2 & 100 & 108 & 55.7 & 73.5 & 78.5 & 93.9 & 108 \\
\hline 2 & 125 & 137 & 66.2 & 77.0 & 86.6 & 103 & 114 \\
\hline 2 & 150 & 171 & 74.6 & 85.1 & 95.7 & 109 & 122 \\
\hline 4 & 50 & 65.3 & 52.6 & 52.8 & 61.1 & 76.9 & 88.3 \\
\hline 4 & 75 & 85.3 & 47.7 & 60.4 & 72.8 & 98.0 & 98.0 \\
\hline 4 & 100 & 108 & 57.3 & 68.4 & 78.9 & 95.5 & 116 \\
\hline 4 & 125 & 136 & 72.7 & 76.9 & 84.5 & 116 & 133 \\
\hline 4 & 150 & 172 & 93.8 & 95.1 & 91.8 & 131 & 135 \\
\hline 6 & 50 & 64.3 & 41.5 & 53.7 & 64.8 & 83.0 & 89.2 \\
\hline 6 & 75 & 85.3 & 51.2 & 60.2 & 69.6 & 103 & 103 \\
\hline 6 & 100 & 108 & 67.2 & 68.6 & 77.0 & 106 & 112 \\
\hline 6 & 125 & 136 & 77.4 & 77.1 & 85.7 & 105 & 122 \\
\hline 6 & 150 & 172 & 107 & 95.8 & 106 & 108 & 120 \\
\hline 8 & 50 & 63.3 & 57.0 & 56.3 & 62.9 & 78.5 & 88.0 \\
\hline 8 & 75 & 83.3 & 86.6 & 77.1 & 71.5 & 104 & 104 \\
\hline 8 & 100 & 108 & 92.5 & 91.1 & 83.1 & 92.3 & 118 \\
\hline 8 & 125 & 135 & 105 & 108 & 105 & 97.4 & 125 \\
\hline 8 & 150 & 170 & 143 & 122 & 117 & 109 & 125 \\
\hline
\end{tabular}




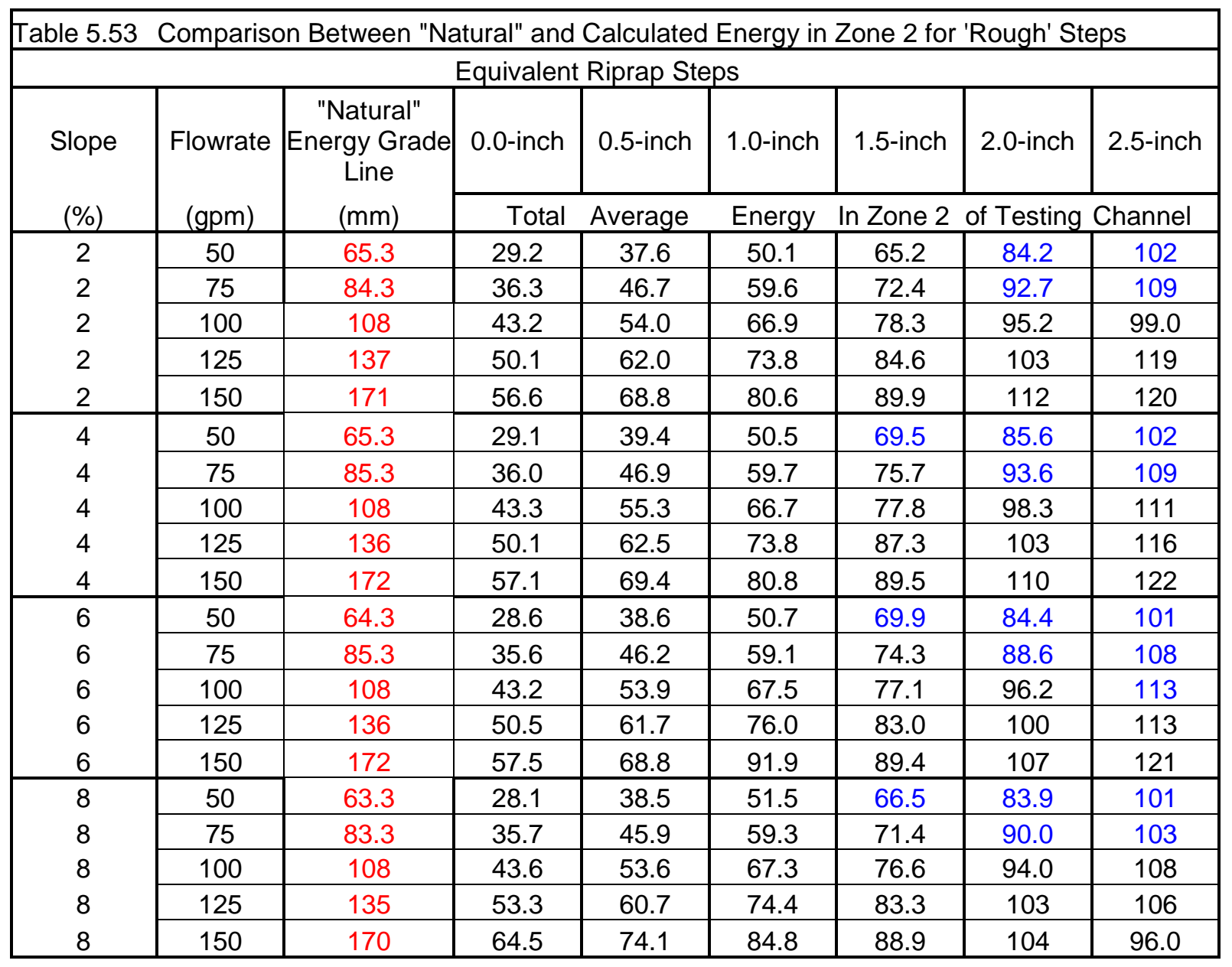

From Tables 5.52 and 5.53, one can see that the effectiveness of the step increases with the increase in flowrate. It appears that the low riprap steps are providing better energy dissipation than the higher riprap steps due partially to the low flow depths. 


\subsection{Flow Characteristics}

The flow from each experimental test run was characterized in Tables 5.54 and 5.55 as discussed in Section 5.3

Where:

$$
\begin{array}{ll}
\mathrm{R}=\text { Reverse flow } & \mathrm{J} 0=\text { No jump } \\
\mathrm{X}=\text { Not fully expanded jet } & \mathrm{J} 1=\text { Weak jump } \\
\mathrm{P}=\text { Spurting flow } & \mathrm{J} 2=\text { Oscillating jump } \\
\mathrm{W}=\text { Swirling flow } & \wedge=\text { Jump in test channel } \\
\mathrm{S}=\text { Slashing flow } & *=\text { Jump in test culvert } \\
\mathrm{L}=\text { Pooling } &
\end{array}
$$

\begin{tabular}{|c|c|c|c|c|c|c|}
\hline \multirow{3}{*}{\begin{tabular}{|c|} 
Table 5.54 \\
$\begin{array}{c}\text { Flowrate } \\
\text { (gpm) }\end{array}$ \\
\end{tabular}} & \multirow{3}{*}{$\begin{array}{c}\text { Elow C } \\
\text { Slope } \\
(\%)\end{array}$} & I & 10 & yic & & \\
\hline & & \multicolumn{5}{|c|}{ Flow Types } \\
\hline & & 0.5 -inch & 1.0-inch & 1.5-inch & 2.0-inch & 2.5-inch \\
\hline 50 & \multirow{5}{*}{$\begin{array}{l}2 \\
2 \\
2 \\
2 \\
2 \\
\end{array}$} & RXJ0 & RXJO & RXJ0 & RXLJ0 & RXLJ0 \\
\hline 75 & & RXJ0 & RXJO & RXJO & RXLJO & RXLJ0 \\
\hline 100 & & RXPJ0 & RXJO & RXJ0 & RXLJ0 & RXLJ0 \\
\hline 125 & & RXPJ0 & RXPJO & RXJ0 & RXLJO & RXLJ0 \\
\hline 150 & & RXJ0 & RXPJ0 & RXJO & RXLJ0 & RXLJ0 \\
\hline 50 & \multirow{5}{*}{$\begin{array}{l}4 \\
4 \\
4 \\
4 \\
4 \\
\end{array}$} & RXJ0 & RXJO & $\mathrm{JO}$ & $\mathrm{RX}$ & J0 \\
\hline 75 & & RXJ0 & RXJ0 & RXJ0 & RXLJ0 & J0 \\
\hline 100 & & RXPJ0 & RXJO & RXJO & RXLJ0 & RXLJ0 \\
\hline 125 & & RXJ0 & RXJ0 & RXJ0 & RXLJ0 & J0 \\
\hline 150 & & $\mathrm{RXPJ2}^{\wedge}$ & $\mathrm{RXPJ2}^{\wedge}$ & $\mathrm{RXJ}^{\wedge}$ & RXLJO & RXLJ0 \\
\hline 50 & \multirow{5}{*}{$\begin{array}{l}6 \\
6 \\
6 \\
6 \\
6 \\
\end{array}$} & $\mathrm{RXPJ2}^{\wedge}$ & $\mathrm{RXJ}^{\wedge}$ & RXJO & RXJO & RXLJ0 \\
\hline 75 & & RXPJ2^ & $\mathrm{RXJ2^{ \wedge }}$ & XJO & RXLJ0 & J0 \\
\hline 100 & & $\mathrm{RXPJ}^{\wedge}$ & $\mathrm{RXJ} 2^{\wedge}$ & $\mathrm{RXJ2}^{\wedge}$ & RXLJ0 & RXLJ0 \\
\hline 125 & & $\mathrm{RXPJ2}^{\wedge}$ & RXPJ2^ & $\mathrm{RXPJ2}^{\wedge}$ & RXLJO & RXLJ0 \\
\hline 150 & & $\mathrm{RXPJ2^{ \wedge }}$ & $\mathrm{RXPJ2^{ \wedge }}$ & $\mathrm{RXPJ}^{\wedge}$ & RXLJ0 & RXLJ0 \\
\hline 50 & \multirow{5}{*}{$\begin{array}{l}8 \\
8 \\
8 \\
8 \\
8\end{array}$} & RXPJ2^ & RXPJ2^ & RXJO & RXJO & RXLJ0 \\
\hline 75 & & $\mathrm{RXPJ}^{\wedge}$ & RXPJ2^ & $\mathrm{RXJ}^{\wedge}{ }^{\wedge}$ & RXJO & RXLJ0 \\
\hline 100 & & $\mathrm{RXPJ2}^{\wedge}$ & $\mathrm{RXPJ2}^{\wedge}$ & $\mathrm{RXPJ2}^{\wedge}$ & RXLJ0 & RXLJ0 \\
\hline 125 & & RXPJ2^ & $\mathrm{RXPJ2^{ \wedge }}$ & RXPJ2^ & RXLJ0 & RXLJ0 \\
\hline 150 & & $\mathrm{RXPJ}^{\wedge}$ & RXPJ2^ & $\mathrm{RXPJ2}^{\wedge}$ & RXPLJO & RXLJ0 \\
\hline
\end{tabular}




\begin{tabular}{|c|c|c|c|c|c|c|c|}
\hline \multicolumn{8}{|c|}{ Table 5.55 Flow Characteristics for Riprap Steps } \\
\hline \multirow{2}{*}{$\begin{array}{c}\text { Flowrate } \\
\text { (gpm) }\end{array}$} & \multirow{2}{*}{$\begin{array}{c}\text { Slope } \\
(\%)\end{array}$} & \multicolumn{6}{|c|}{ Flow Types } \\
\hline & & 0.0 -inch & 0.5 -inch & 1.0-inch & 1.5-inch & 2.0-inch & 2.5-inch \\
\hline 50 & 2 & $\mathrm{RXJ1 \wedge}$ & $\mathrm{RXJ1 \wedge}$ & $\mathrm{RXJ1 \wedge}$ & RXSLJ1* & RXSLJ1* & RXSLJ1* \\
\hline 75 & 2 & $\mathrm{RXJ1 \wedge}$ & $\mathrm{RXJ1 \wedge}$ & RXJ1^ & RXSLJ1* & RXSLJ1* & RXSLJ1* \\
\hline 100 & 2 & RXJO & $\mathrm{RXJ1}^{\wedge}$ & $\mathrm{RXJ1 \wedge}$ & RXSLJ1^ & RXSLJ1* & RXSLJ1* \\
\hline 125 & 2 & RXJ0 & $\mathrm{RXJ1}^{\wedge}$ & RXJ0 & RXSLJ1^ & RXSLJ1* & RXSLJ1* \\
\hline 150 & 2 & RXJO & RXJO & RXJ0 & RXSLJ1^ & RXSLJ2* & RXSLJ2* \\
\hline 50 & 4 & $\mathrm{RXJ2}^{\wedge}$ & $\mathrm{RXJ}^{\wedge}$ & $\mathrm{RXJ2}^{\wedge}$ & RXSLJ2* & RXSLJ2* & RXSLJ2* \\
\hline 75 & 4 & $\mathrm{RXJ2} 2^{\wedge}$ & $\mathrm{RXJ2}^{\wedge}$ & $\mathrm{RXJ2^{ \wedge }}$ & RXSLJ2* & RXSLJ2* & RXSLJ2* \\
\hline 100 & 4 & RXJ2^ & $\mathrm{RXJ}^{\wedge}$ & RXJO & RXSLJ2^ & RXSLJ2* & RXSLJ2* \\
\hline 125 & 4 & RXJO & $\mathrm{RXJ2}^{\wedge}$ & $\mathrm{RXJ}^{\wedge}$ & RXSLJ2^ & $\mathrm{RXSLJ2}^{\wedge}$ & RXSLJ2* \\
\hline 150 & 4 & RXJO & $\mathrm{RXJ2}^{\wedge}$ & RXJ0 & $\mathrm{RXSLJ2}^{\wedge}$ & RXSLJ2* & RXSLJ2* \\
\hline 50 & 6 & $\mathrm{RXJ2}^{\wedge}$ & $\mathrm{RXJ}^{\wedge}$ & RXJ0 & $\mathrm{RXSLJ2}^{*}$ & RXSLJ2* & RXSLJ2* \\
\hline 75 & 6 & $\mathrm{RXJ2}^{\wedge}$ & $\mathrm{RXJ}^{\wedge}$ & RXJ0 & RXSLJ2^ & RXSLJ2* & $\mathrm{RXSLJ2}^{*}$ \\
\hline 100 & 6 & RXJO & $\mathrm{RXJ2}^{\wedge}$ & $\mathrm{RXJ2}^{\wedge}$ & $\mathrm{RXSLJ2}^{\wedge}$ & RXSLJ2* & RXSLJ2* \\
\hline 125 & 6 & RXJO & $\mathrm{RXJ} 2^{\wedge}$ & RXJ0 & RXSLJ2^ & RXSLJ2* & RXSLJ2* \\
\hline 150 & 6 & RXJO & RXJ0 & RXJO & RXSLJ2^ & RXSLJ2* & RXSLJ2* \\
\hline 50 & 8 & $\mathrm{RXJ}^{\wedge}$ & $\mathrm{RXJ}^{\wedge}$ & $\mathrm{RXJ2}^{\wedge}$ & RXSJ2* & RXSLJ2* & RXSLJ2* \\
\hline 75 & 8 & $\mathrm{RXJ2}^{\wedge}$ & $\mathrm{RXJ}^{\wedge}$ & RXJO & $\mathrm{RXSJ2}^{*}$ & RXSLJ2* & RXSLJ2* \\
\hline 100 & 8 & RXJO & $\mathrm{RXJ2}^{\wedge}$ & RXJO & RXSJ2* & RXSLJ2* & RXSLJ2* \\
\hline 125 & 8 & RXJ0 & RXJO & RXJ0 & RXSJ2* & RXSLJ2* & RXSLJ2* \\
\hline 150 & 8 & RXJ0 & RXJ0 & RXJ0 & RXSLJ0* & $\mathrm{RXSLJ2}^{*}$ & RXSLJ2* \\
\hline
\end{tabular}




\subsection{Error Analysis}

A unique design for the testing flume was necessary in order to satisfy the requirements of research. Several modifications were made throughout the process of experimentation; therefore it was difficult to perform an error analysis. There were several reasons that made an in-depth error analysis impractical. The number of significant changes that occurred in design and in methods of calculation during the course of the research made it difficult to follow the propagation of error to the final results. As this research was a preliminary investigation, an in-depth error analysis should be performed in follow-up research experiments with the testing flume. The raw depth measurements taken in the testing channel were influenced by waves, turbulence, and aeration. These influences created the greatest source of error in the various experiments. Also, due to the time restraints of the project, establishing repeatability in depth measurements for a specific situation was not feasible. However, trends in the data can easily be seen and explained.

The primary measuring devices used in experiments performed with the testing flume include the following:

- Metric scales

- Headwater depth

- Longitudinal distance along testing channel

○ Piezometer depth

- Pitot tube readings

- Slope adjustment

- Digital Scales

- Flowmeter

- Vernier Scale

- Depth in testing channel

All of the metric scales were read to the nearest millimeter, based on the convention of best estimate. The Vernier scale was accurate to $0.001-\mathrm{ft}$ and measurements were taken accordingly. Three significant figures applied for all measures of length. The flowmeter had a range of $40-450 \mathrm{gpm}$ with a plus or minus of $2.0 \%$ full-scale linearity and a plus or minus of $1.0 \%$ full-scale repeatability. Expected values of uncertainty for several variables measured in the experiments are shown in Table 5.56. 


\begin{tabular}{|c|c|}
\hline Table 5.56 & $\begin{array}{c}\text { Expected Error For Various } \\
\text { Calculated Values }\end{array}$ \\
\hline Value & $\begin{array}{c}\text { Expected Error } \\
(\%)\end{array}$ \\
\hline Area (Culvert) & 3.40 \\
\hline Area (Channel) & 8.40 \\
\hline Depth (Culvert) & 3.30 \\
\hline Depth (Channel) & 8.30 \\
\hline Energy (Culvert) & 9.00 \\
\hline Energy (Channel) & 21.3 \\
\hline Froude Number (Culvert) & 5.65 \\
\hline Froude Number (Channel) & 11.2 \\
\hline Velocity (Culvert) & 5.40 \\
\hline Velocity (Channel) & 10.4 \\
\hline
\end{tabular}




\section{Chapter 6}

\section{Results}

\subsection{Non-Dimensional Comparison of Cast Acrylic and Riprap Step}

In order to compare the performance of each step type and height, the values of NDED (Equation 5.8) for each slope and discharge were compiled into two tables. NDED with respect to total energy will be referred to as EDT. Tables 6.1 and 6.2 summarize the data in terms of EDT with respect to cast acrylic steps and riprap steps, respectively. By only examining the non-dimensional energy difference in terms of total energy, a possible misinterpretation could occur. For example, if a higher riprap step was tested and the energy difference was less than that of a smaller step, a possible conclusion would be that the higher riprap step was not as effective in attenuating energy in the test channel as the smaller step. When a higher riprap step is placed in the channel, not only does the step height increase, but the 'pooling' of water at Zone 2 increases the height of the energy grade line as well. A closer examination of the NDED in terms of velocity head, EDV, in Tables 6.3 and 6.4, was necessary. EDV is defined in Equation 6.1.

$E D V=\frac{\left(\frac{V^{2}}{2 g}\right)_{\text {Culvertoutlet }}-\left(\frac{V^{2}}{2 g}\right)_{\text {TestChannel }}}{\text { TotalEnergyAtCulvertOutlet }}$

Where:

$$
\begin{aligned}
& V=\text { Flow velocity } \\
& g=\text { Acceleration due to gravity } \\
& \text { TotalEnergyAtCulvertOutlet }=\frac{V^{2}}{2 g}+y+z
\end{aligned}
$$

Where:

$$
\begin{aligned}
& y=\text { Depth of flow } \\
& z=\text { Distance from zero datum }
\end{aligned}
$$




\begin{tabular}{|c|c|c|c|c|c|c|}
\hline \multirow{2}{*}{$\begin{array}{c}\text { Flowrate } \\
\text { (gpm) }\end{array}$} & \multirow{2}{*}{$\begin{array}{c}\text { Slope } \\
(\%)\end{array}$} & \multicolumn{5}{|c|}{ NDED } \\
\hline & & 0.5-inch & 1.0-inch & 1.5-inch & 2.0-inch & 2.5-inch \\
\hline 50 & 2 & 0.612 & 0.504 & 0.428 & 0.294 & 0.137 \\
\hline 75 & 2 & 0.640 & 0.557 & 0.467 & 0.281 & 0.281 \\
\hline 100 & 2 & 0.659 & 0.550 & 0.519 & 0.425 & 0.340 \\
\hline 125 & 2 & 0.659 & 0.603 & 0.542 & 0.456 & 0.395 \\
\hline 150 & 2 & 0.664 & 0.607 & 0.569 & 0.510 & 0.462 \\
\hline 50 & 4 & 0.607 & 0.611 & 0.550 & 0.422 & 0.284 \\
\hline 75 & 4 & 0.719 & 0.640 & 0.562 & 0.416 & 0.416 \\
\hline 100 & 4 & 0.709 & 0.659 & 0.607 & 0.525 & 0.424 \\
\hline 125 & 4 & 0.685 & 0.666 & 0.633 & 0.498 & 0.422 \\
\hline 150 & 4 & 0.640 & 0.631 & 0.644 & 0.475 & 0.483 \\
\hline 50 & 6 & 0.750 & 0.669 & 0.615 & 0.515 & 0.487 \\
\hline 75 & 6 & 0.761 & 0.719 & 0.675 & 0.519 & 0.519 \\
\hline 100 & 6 & 0.728 & 0.722 & 0.688 & 0.572 & 0.559 \\
\hline 125 & 6 & 0.713 & 0.720 & 0.696 & 0.629 & 0.567 \\
\hline 150 & 6 & 0.656 & 0.697 & 0.663 & 0.659 & 0.620 \\
\hline 50 & 8 & 0.688 & 0.692 & 0.653 & 0.567 & 0.479 \\
\hline 75 & 8 & 0.623 & 0.671 & 0.698 & 0.559 & 0.559 \\
\hline 100 & 8 & 0.661 & 0.666 & 0.695 & 0.662 & 0.573 \\
\hline 125 & 8 & 0.651 & 0.640 & 0.646 & 0.669 & 0.577 \\
\hline 150 & 8 & 0.562 & 0.627 & 0.645 & 0.668 & 0.628 \\
\hline
\end{tabular}




\begin{tabular}{|c|c|c|c|c|c|c|c|}
\hline \multirow{3}{*}{\begin{tabular}{|c|} 
Table 6.2 \\
$\begin{array}{c}\text { Flowrate } \\
\text { (gpm) }\end{array}$
\end{tabular}} & \multicolumn{7}{|c|}{ Comparison of Values for EDT for Riprap Steps } \\
\hline & \multirow{2}{*}{$\begin{array}{c}\text { Slope } \\
(\%)\end{array}$} & \multicolumn{5}{|c|}{ NDED } & \multirow[b]{2}{*}{ 2.5-inch } \\
\hline & & 0.0-inch & 0.5-inch & 1.0-inch & 1.5-inch & 2.0-inch & \\
\hline 50 & 2 & 0.728 & 0.649 & 0.532 & 0.392 & 0.215 & 0.01463 \\
\hline 75 & 2 & 0.738 & 0.653 & 0.569 & 0.472 & 0.329 & 0.202 \\
\hline 100 & 2 & 0.736 & 0.669 & 0.591 & 0.521 & 0.417 & 0.391 \\
\hline 125 & 2 & 0.742 & 0.681 & 0.620 & 0.553 & 0.454 & 0.371 \\
\hline 150 & 2 & 0.745 & 0.690 & 0.628 & 0.595 & 0.497 & 0.474 \\
\hline 50 & 4 & 0.785 & 0.705 & 0.628 & 0.488 & 0.357 & 0.170 \\
\hline 75 & 4 & 0.788 & 0.723 & 0.644 & 0.545 & 0.438 & 0.353 \\
\hline 100 & 4 & 0.785 & 0.719 & 0.668 & 0.613 & 0.511 & 0.446 \\
\hline 125 & 4 & 0.783 & 0.729 & 0.680 & 0.621 & 0.551 & 0.493 \\
\hline 150 & 4 & 0.779 & 0.734 & 0.686 & 0.653 & 0.560 & 0.530 \\
\hline 50 & 6 & 0.824 & 0.767 & 0.687 & 0.585 & 0.507 & 0.416 \\
\hline 75 & 6 & 0.834 & 0.785 & 0.725 & 0.653 & 0.587 & 0.498 \\
\hline 100 & 6 & 0.825 & 0.782 & 0.727 & 0.688 & 0.611 & 0.553 \\
\hline 125 & 6 & 0.821 & 0.771 & 0.725 & 0.706 & 0.646 & 0.599 \\
\hline 150 & 6 & 0.815 & 0.779 & 0.709 & 0.717 & 0.662 & 0.616 \\
\hline 50 & 8 & 0.844 & 0.790 & 0.718 & 0.633 & 0.537 & 0.404 \\
\hline 75 & 8 & 0.843 & 0.800 & 0.747 & 0.698 & 0.619 & 0.564 \\
\hline 100 & 8 & 0.840 & 0.803 & 0.753 & 0.719 & 0.656 & 0.609 \\
\hline 125 & 8 & 0.823 & 0.798 & 0.751 & 0.719 & 0.651 & 0.641 \\
\hline 150 & 8 & 0.806 & 0.773 & 0.740 & 0.730 & 0.685 & 0.715 \\
\hline
\end{tabular}




\begin{tabular}{|c|c|c|c|c|c|c|}
\hline \multirow{3}{*}{\begin{tabular}{|c|} 
Table 6.3 \\
$\begin{array}{c}\text { Flowrate } \\
\text { (gpm) }\end{array}$ \\
\end{tabular}} & \multirow{3}{*}{$\begin{array}{c}\text { Compar } \\
\text { Slope } \\
(\%)\end{array}$} & \multirow{2}{*}{\multicolumn{5}{|c|}{ NDED }} \\
\hline & & & & & & \\
\hline & & 0.5-inch & 1.0-inch & 1.5-inch & 2.0-inch & 2.5-inch \\
\hline 50 & 2 & 0.507 & 0.522 & 0.536 & 0.529 & 0.541 \\
\hline 75 & 2 & 0.572 & 0.553 & 0.516 & 0.516 & 0.534 \\
\hline 100 & 2 & 0.576 & 0.511 & 0.553 & 0.536 & 0.525 \\
\hline 125 & 2 & 0.547 & 0.563 & 0.570 & 0.550 & 0.560 \\
\hline 150 & 2 & 0.567 & 0.597 & 0.569 & 0.577 & 0.555 \\
\hline 50 & 4 & 0.525 & 0.643 & 0.652 & 0.638 & 0.710 \\
\hline 75 & 4 & 0.681 & 0.682 & 0.641 & 0.605 & 0.654 \\
\hline 100 & 4 & 0.675 & 0.678 & 0.659 & 0.636 & 0.584 \\
\hline 125 & 4 & 0.611 & 0.669 & 0.682 & 0.567 & 0.549 \\
\hline 150 & 4 & 0.756 & 0.756 & 0.732 & 0.556 & 0.575 \\
\hline 50 & 6 & 0.809 & 0.825 & 0.711 & 0.667 & 0.711 \\
\hline 75 & 6 & 0.811 & 0.792 & 0.765 & 0.707 & 0.711 \\
\hline 100 & 6 & 0.822 & 0.799 & 0.795 & 0.672 & 0.690 \\
\hline 125 & 6 & 0.845 & 0.808 & 0.789 & 0.707 & 0.682 \\
\hline 150 & 6 & 0.839 & 0.816 & 0.817 & 0.737 & 0.740 \\
\hline 50 & 8 & 0.823 & 0.811 & 0.751 & 0.737 & 0.827 \\
\hline 75 & 8 & 0.866 & 0.844 & 0.818 & 0.717 & 0.724 \\
\hline 100 & 8 & 0.853 & 0.849 & 0.837 & 0.781 & 0.705 \\
\hline 125 & 8 & 0.835 & 0.837 & 0.842 & 0.800 & 0.711 \\
\hline 150 & 8 & 0.857 & 0.853 & 0.840 & 0.823 & 0.720 \\
\hline
\end{tabular}




\begin{tabular}{|c|c|c|c|c|c|c|c|}
\hline \multirow{2}{*}{$\begin{array}{c}\text { Flowrate } \\
\text { (gpm) }\end{array}$} & \multirow{2}{*}{$\begin{array}{c}\text { Slope } \\
(\%)\end{array}$} & \multicolumn{6}{|c|}{ NDED } \\
\hline & & 0.0-inch & 0.5 -inch & 1.0-inch & 1.5-inch & 2.0-inch & 2.5-inch \\
\hline 50 & 2 & 0.607 & 0.605 & 0.586 & 0.627 & 0.634 & 0.671 \\
\hline 75 & 2 & 0.609 & 0.634 & 0.589 & 0.619 & 0.349 & 0.666 \\
\hline 100 & 2 & 0.599 & 0.613 & 0.605 & 0.636 & 0.647 & 0.648 \\
\hline 125 & 2 & 0.607 & 0.616 & 0.604 & 0.654 & 0.674 & 0.690 \\
\hline 150 & 2 & 0.634 & 0.630 & 0.653 & 0.653 & 0.668 & 0.677 \\
\hline 50 & 4 & 0.708 & 0.722 & 0.679 & 0.726 & 0.742 & 0.809 \\
\hline 75 & 4 & 0.703 & 0.714 & 0.713 & 0.748 & 0.754 & 0.756 \\
\hline 100 & 4 & 0.707 & 0.733 & 0.699 & 0.728 & 0.745 & 0.754 \\
\hline 125 & 4 & 0.704 & 0.717 & 0.711 & 0.734 & 0.747 & 0.763 \\
\hline 150 & 4 & 0.694 & 0.701 & 0.701 & 0.716 & 0.771 & 0.749 \\
\hline 50 & 6 & 0.821 & 0.809 & 0.774 & 0.810 & 0.798 & 0.792 \\
\hline 75 & 6 & 0.785 & 0.800 & 0.769 & 0.817 & 0.817 & 0.829 \\
\hline 100 & 6 & 0.778 & 0.791 & 0.795 & 0.803 & 0.816 & 0.806 \\
\hline 125 & 6 & 0.755 & 0.805 & 0.755 & 0.779 & 0.793 & 0.806 \\
\hline 150 & 6 & 0.771 & 0.769 & 0.698 & 0.781 & 0.802 & 0.815 \\
\hline 50 & 8 & 0.808 & 0.804 & 0.797 & 0.824 & 0.826 & 0.893 \\
\hline 75 & 8 & 0.832 & 0.834 & 0.785 & 0.822 & 0.829 & 0.836 \\
\hline 100 & 8 & 0.796 & 0.814 & 0.788 & 0.825 & 0.834 & 0.837 \\
\hline 125 & 8 & 0.752 & 0.775 & 0.776 & 0.811 & 0.833 & 0.832 \\
\hline 150 & 8 & 0.730 & 0.742 & 0.762 & 0.795 & 0.809 & 0.802 \\
\hline
\end{tabular}

Several conclusions can be drawn from the comparison of these results. Generally, the value for NDED, both EDT and EDV, increases with the increase of culvert slope. This trend seems plausible since the velocity head at the culvert outlet increases with slope more rapidly than the corresponding value in the testing channel. The difference between the energy at the outlet and channel must increase to account for the divergence of the velocity heads. Examination of the EDV from left to right in the table for all of the tested configurations shows an increase in the value of non-dimensional energy loss in most cases. The opposite occurs with the EDT in terms of total energy. Therefore, progressively increasing the riprap steps heights effectively increased the attenuation of dynamic energy. By inspecting only the EDT, the 'pooling' effect disguised the increase in step height efficiency. The values for average flow depths in Zone 2 and at the culvert outlet are displayed in Tables 6.5 and 6.6, cast acrylic steps and riprap steps, respectively. The first value for the test culvert was obtained from Section 5.5 and is the depth at the outlet. The depths for each configuration are the average depths, established in the testing channel over the stone bed in Zone 2. Performance judgments cannot be based solely on the basis of non-dimensional energy difference. The effect of entire rock bed, including geometry and rock mobility plays a large role in energy attenuation of flows. 
In the field however, the downstream rock would not be held in place rigidly, as in the laboratory model, and incipient motion and failure of the supporting bed material would likely occur under high velocity flows. The mobility of the rock in the field would significantly effect the energy attenuation and maintenance and should be investigated in future studies.

\begin{tabular}{|c|c|c|c|c|c|c|c|}
\hline Table 6.5 & Flow Dep & at Culvert & Outlet an & esting $\mathrm{C}$ & $\mathrm{el}-\mathrm{C}$ & crylic & Steps \\
\hline & & & & Average $\mathrm{F}$ & Depth ( $r$ & & \\
\hline Flowrate & Slope & Culvert & & Zone 2 of & st Channe & & \\
\hline (gpm) & $(\%)$ & Outlet & 0.5 -inch & 1.0-inch & 1.5-inch & 2.0-inch & 2.5-inch \\
\hline 50 & 2 & 36.2 & 13.6 & 14.4 & 15.2 & 14.8 & 14.3 \\
\hline 75 & 2 & 43.9 & 20.3 & 19.9 & 17.2 & 17.2 & 18.2 \\
\hline 100 & 2 & 51.0 & 25.6 & 20.3 & 23.3 & 21.9 & 21.2 \\
\hline 125 & 2 & 56.5 & 25.4 & 26.9 & 26.1 & 24.5 & 25.3 \\
\hline 150 & 2 & 61.0 & 27.7 & 29.2 & 27.8 & 28.6 & 27.9 \\
\hline 50 & 4 & 31.5 & 9.83 & 14.8 & 15.5 & 13.6 & 14.9 \\
\hline 75 & 4 & 39.0 & 22.4 & 21.4 & 17.4 & 15.6 & 18.7 \\
\hline 100 & 4 & 45.1 & 23.2 & 25.1 & 22.9 & 20.9 & 17.8 \\
\hline 125 & 4 & 50.5 & 21.9 & 27.1 & 28.7 & 19.5 & 18.6 \\
\hline 150 & 4 & 55.8 & 77.5 & 64.2 & 45.8 & 20.7 & 22.8 \\
\hline 50 & 6 & 28.4 & 24.7 & 24.2 & 12.5 & 11.0 & 14.0 \\
\hline 75 & 6 & 34.5 & 33.3 & 25.7 & 20.6 & 15.4 & 15.6 \\
\hline 100 & 6 & 40.5 & 50.7 & 33.8 & 32.6 & 16.9 & 19.1 \\
\hline 125 & 6 & 45.8 & 60.4 & 42.4 & 41.8 & 23.5 & 21.4 \\
\hline 150 & 6 & 50.2 & 91.9 & 65.1 & 67.4 & 29.3 & 29.7 \\
\hline 50 & 8 & 27.3 & 43.6 & 28.2 & 13.6 & 12.6 & 15.5 \\
\hline 75 & 8 & 33.2 & 73.5 & 50.0 & 31.5 & 14.8 & 15.2 \\
\hline 100 & 8 & 38.7 & 78.6 & 63.8 & 43.7 & 23.5 & 17.1 \\
\hline 125 & 8 & 44.3 & 90.8 & 80.6 & 67.7 & 32.5 & 20.6 \\
\hline 150 & 8 & 49.1 & 129.1 & 94.1 & 79.4 & 52.1 & 26.3 \\
\hline
\end{tabular}




\begin{tabular}{|c|c|c|c|c|c|c|c|c|}
\hline \multirow{4}{*}{$\begin{array}{c}\text { Flowrate } \\
\text { (gpm) }\end{array}$} & \multirow{4}{*}{$\begin{array}{c}\text { Slope } \\
(\%)\end{array}$} & \multirow{2}{*}{\multicolumn{7}{|c|}{ Average Flow Depth (mm) }} \\
\hline & & & & & & & & \\
\hline & & \multirow{2}{*}{$\begin{array}{c}\text { Culvert } \\
\text { Outlet }\end{array}$} & \multicolumn{6}{|c|}{ Zone 2 of Test Channel } \\
\hline & & & 0.0 -inch & 0.5 -inch & 1.0-inch & 1.5-inch & 2.0-inch & 2.5-inch \\
\hline 50 & 2 & 36.2 & 24.0 & 23.3 & 20.0 & 31.2 & 35.9 & 50.9 \\
\hline 75 & 2 & 43.9 & 27.4 & 29.1 & 23.7 & 37.5 & 42.8 & 57.6 \\
\hline 100 & 2 & 51.0 & 28.7 & 31.4 & 29.7 & 37.5 & 42.6 & 42.8 \\
\hline 125 & 2 & 56.5 & 32.8 & 34.7 & 32.3 & 40.4 & 49.2 & 64.4 \\
\hline 150 & 2 & 61.0 & 36.5 & 35.7 & 37.1 & 41.0 & 56.8 & 63.1 \\
\hline 50 & 4 & 31.5 & 23.9 & 25.8 & 18.5 & 35.2 & 37.5 & 51.8 \\
\hline 75 & 4 & 39.0 & 26.4 & 29.4 & 26.8 & 38.6 & 43.8 & 56.7 \\
\hline 100 & 4 & 45.1 & 30.1 & 33.4 & 28.4 & 36.6 & 46.4 & 58.0 \\
\hline 125 & 4 & 50.5 & 32.8 & 36.0 & 34.4 & 42.0 & 49.5 & 61.4 \\
\hline 150 & 4 & 55.8 & 34.4 & 37.8 & 35.9 & 39.9 & 54.1 & 65.9 \\
\hline 50 & 6 & 28.4 & 22.9 & 24.9 & 15.0 & 35.6 & 36.1 & 50.8 \\
\hline 75 & 6 & 34.5 & 23.9 & 28.3 & 21.1 & 37.3 & 37.9 & 55.8 \\
\hline 100 & 6 & 40.5 & 27.7 & 31.1 & 32.6 & 35.8 & 43.9 & 60.1 \\
\hline 125 & 6 & 45.8 & 30.5 & 34.4 & 27.3 & 37.3 & 44.5 & 57.4 \\
\hline 150 & 6 & 50.2 & 33.2 & 32.7 & 24.8 & 39.4 & 49.9 & 63.8 \\
\hline 50 & 8 & 27.3 & 21.9 & 24.6 & 21.9 & 32.5 & 35.5 & 49.9 \\
\hline 75 & 8 & 33.2 & 24.9 & 28.0 & 20.2 & 33.9 & 39.6 & 51.0 \\
\hline 100 & 8 & 38.7 & 26.1 & 30.7 & 24.6 & 35.1 & 40.7 & 53.8 \\
\hline 125 & 8 & 44.3 & 26.2 & 30.3 & 29.8 & 37.7 & 48.8 & 47.8 \\
\hline 150 & 8 & 49.1 & 26.6 & 26.2 & 28.7 & 37.6 & 43.1 & 48.8 \\
\hline
\end{tabular}




\subsection{Froude Number and Non-Dimensional Energy Difference}

Graphical representation of hydraulic performance measurements were desired to support further understanding of the test results obtained. The plots were made non-dimensional to provide the best comparative presentation of the experiments formed. Froude number is plotted versus non-dimensional energy difference, (EDT). At first, the plots seemed inconclusive but once the data was separated by slope, several interesting conclusions could be made. For the following discussion, refer to the Figures listed below:

- $\quad$ Figure 6.1 Froude Number at Culvert Outlet vs. EDT for 0.5-inch Cast Acrylic Step

- $\quad$ Figure 6.2 Froude Number at Culvert Outlet vs. EDT for 1.0-inch Cast Acrylic Step

- $\quad$ Figure 6.3 Froude Number at Culvert Outlet vs. EDT for 1.5-inch Cast Acrylic Step

- $\quad$ Figure 6.4 Froude Number at Culvert Outlet vs. EDT for 2.0-inch Cast Acrylic Step

- $\quad$ Figure 6.5 Froude Number at Culvert Outlet vs. EDT for 2.5-inch Cast Acrylic Step

- $\quad$ Figure 6.6 Froude Number at Culvert Outlet vs. EDT for 0.0-inch Riprap Step

- $\quad$ Figure 6.7 Froude Number at Culvert Outlet vs. EDT for 0.5-inch Riprap Step

- $\quad$ Figure 6.8 Froude Number at Culvert Outlet vs. EDT for 1.0-inch Riprap Step

- $\quad$ Figure 6.9 Froude Number at Culvert Outlet vs. EDT for 1.5-inch Riprap Step

- $\quad$ Figure 6.10 Froude Number at Culvert Outlet vs. EDT for 2.0-inch Riprap Step

- $\quad$ Figure 6.11 Froude Number at Culvert Outlet vs. EDT for 2.5-inch Riprap Step

Simply allowing the flowing water to expand and collect, or pool, in an area is one form of energy

dissipation. The high velocity flow from the culvert outlet enters an area of low velocity flow. Due to complex flow characteristics including reversed flow, re-circulation, etc, energy is dissipated and exits at a lower velocity flow. Under conditions of supercritical flow upstream, a hydraulic jump may be forced by the pooling flow, adding to the energy dissipation. By introducing steps, smooth cast acrylic or rough riprap, into the path of the flow, Zone 1 becomes a pooling area.

The majority of the energy attenuation in Figures 6.1 through 6.5 was due to the impact of the flow on the step, causing turbulence. After having observed the plotted data pattern for each particular culvert slope and step height in Figures 6.1 through 6.11, one may or may not have distinguished a defined 'arc' shape or trend depending on the degree of energy dissipation in that instance. A more defined, compact 'arc' pattern indicated less energy. A less defined or less compact 'arc' indicated more energy dissipation. In Figures 6.1 and 6.2, four less visible, more compact, arcs are formed. The higher cast acrylic step heights, in Figures 6.4 and 6.5, produced more visible and less compact arcs. Expansion of the exit jet from the outlet of the culvert onto the apron floor, across Zone 1, and then impacting against the step of Zone 2 helped reduce the energy in the flow. As the step height increased, 
pooling disguised the increase in energy dissipation and gave the appearance of the lower steps having the greatest amount of energy dissipation and the higher steps producing the lowest amount of energy dissipation.

In Figures 6.6 through 6.11, energy attenuation was due to the impact of the flow on the step as well as the additional turbulence created by the roughened riprap surface. The flow was greatly affected by the addition of the roughened test channel surface. Regarding riprap steps, the greatest energy difference was seen in Figure 6.6 with the 0.0-inch equivalent riprap step and regressing to the least energy difference as seen in Figure 6.11 with the 2.5inch equivalent riprap step. The effect of pooling in Zone 1 decreased dramatically due to the wave action created by the roughened test channel surface. The 0.5 -inch equivalent riprap step produced a less visible arc whereas the 2.5-inch equivalent ripraps step produced a more visible arc.

Overall, the riprap steps produced the greatest range of energy difference.

Froude Number @ Culvert Outlet vs EDT for 0.5" Step

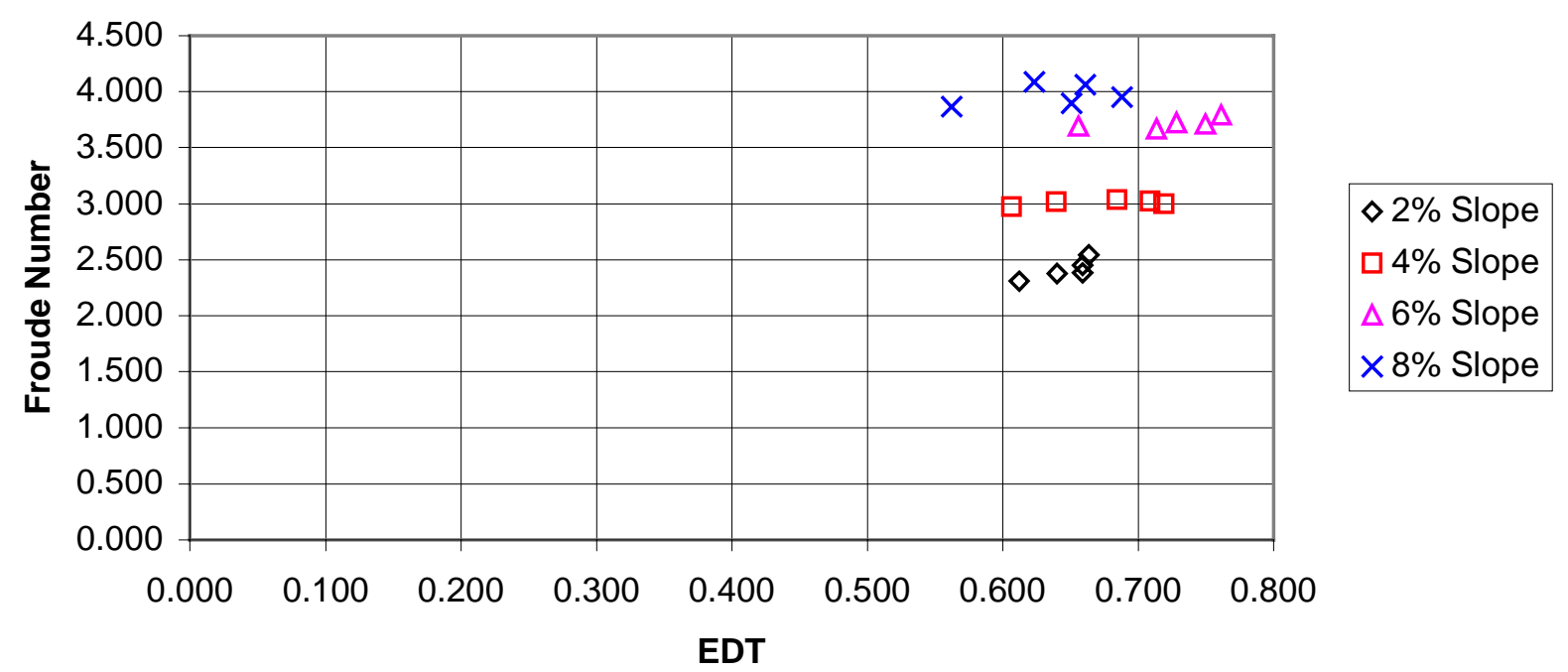

Figure 6.1 Froude Number at Culvert Outlet vs. EDT for 0.5-inch Cast Acrylic Step 
Froude Number @ Culvert Outlet vs EDT for 1.0" Step

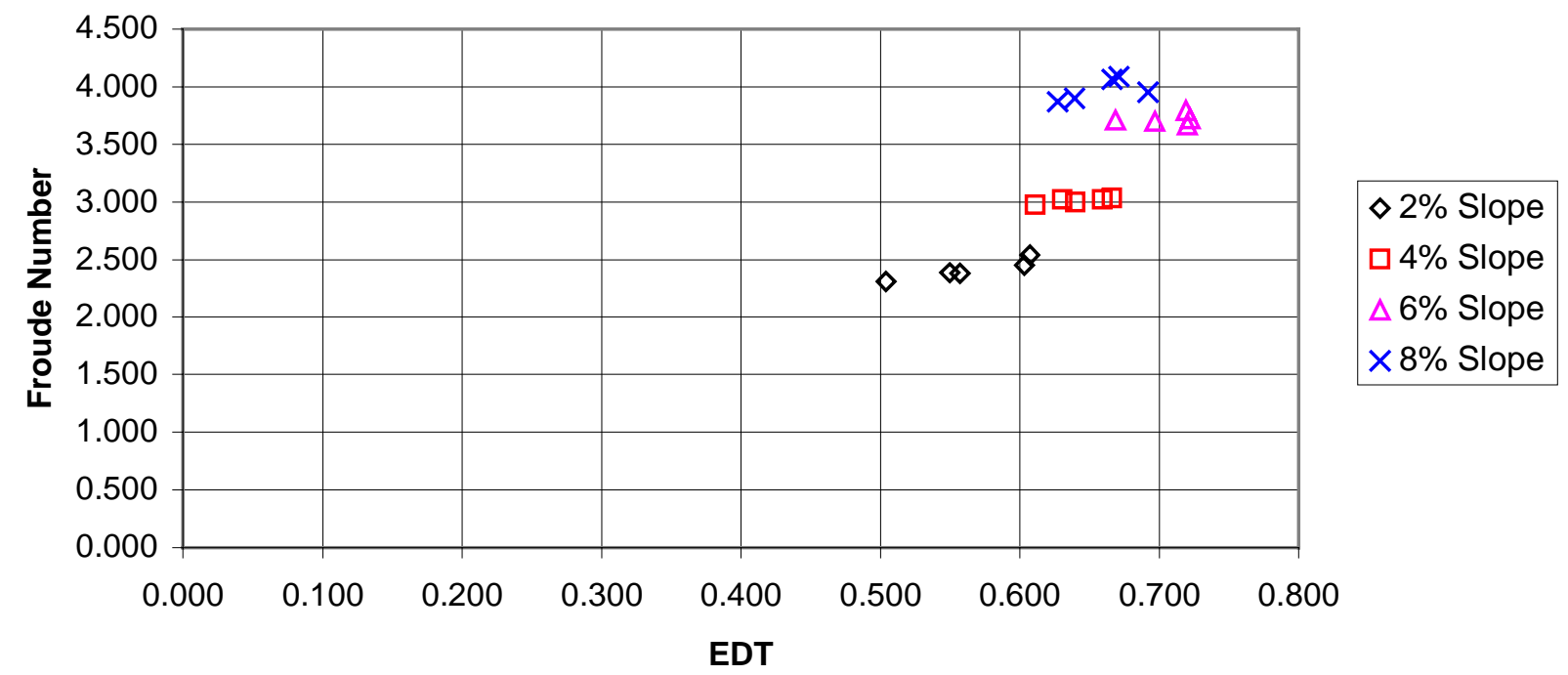

Figure 6.2 Froude Number at Culvert Outlet vs. EDT for 1.0-inch Cast Acrylic Step

Froude Number @ Culvert Outlet vs EDT for 1.5" Step

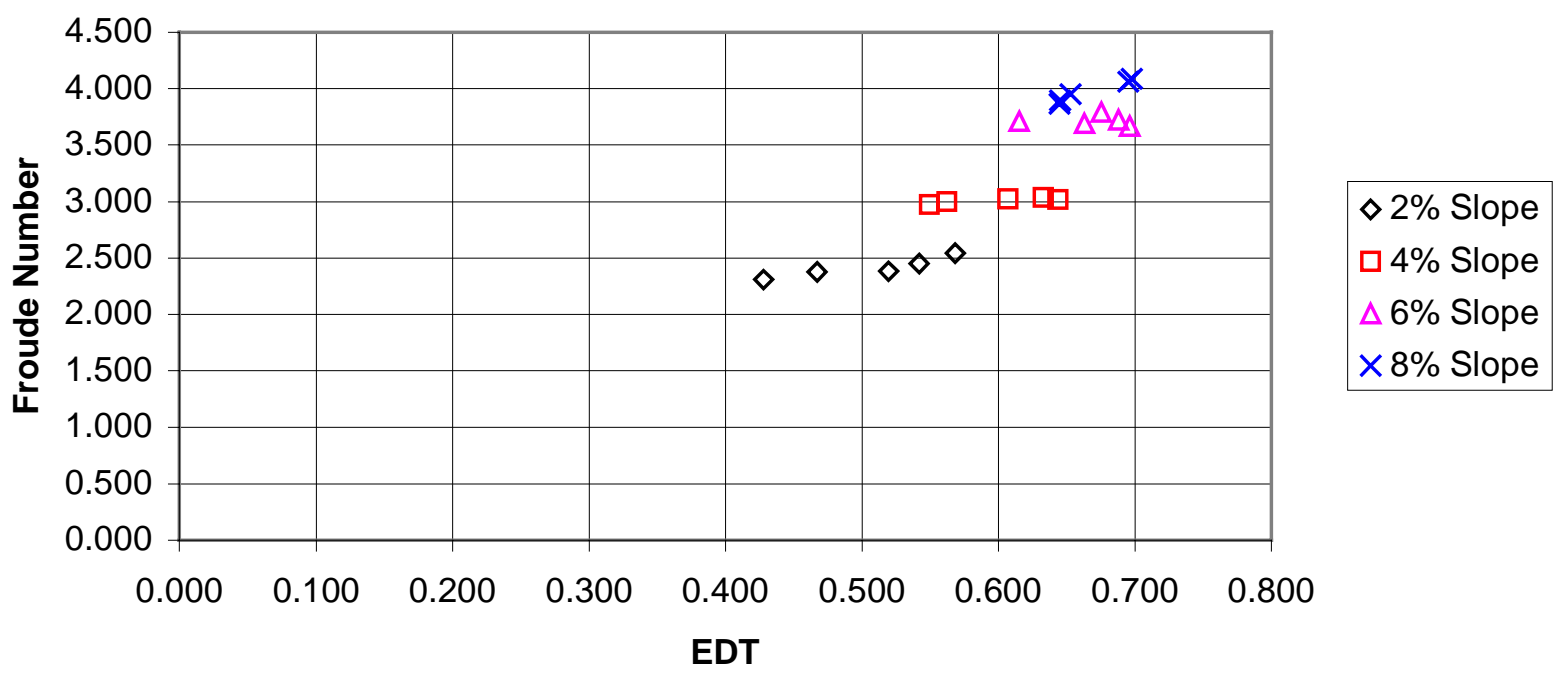

Figure 6.3 Froude Number at Culvert Outlet vs. EDT for 1.5-inch Cast Acrylic Step 
Froude Number @ Culvert Outlet vs EDT for 2.0" Step

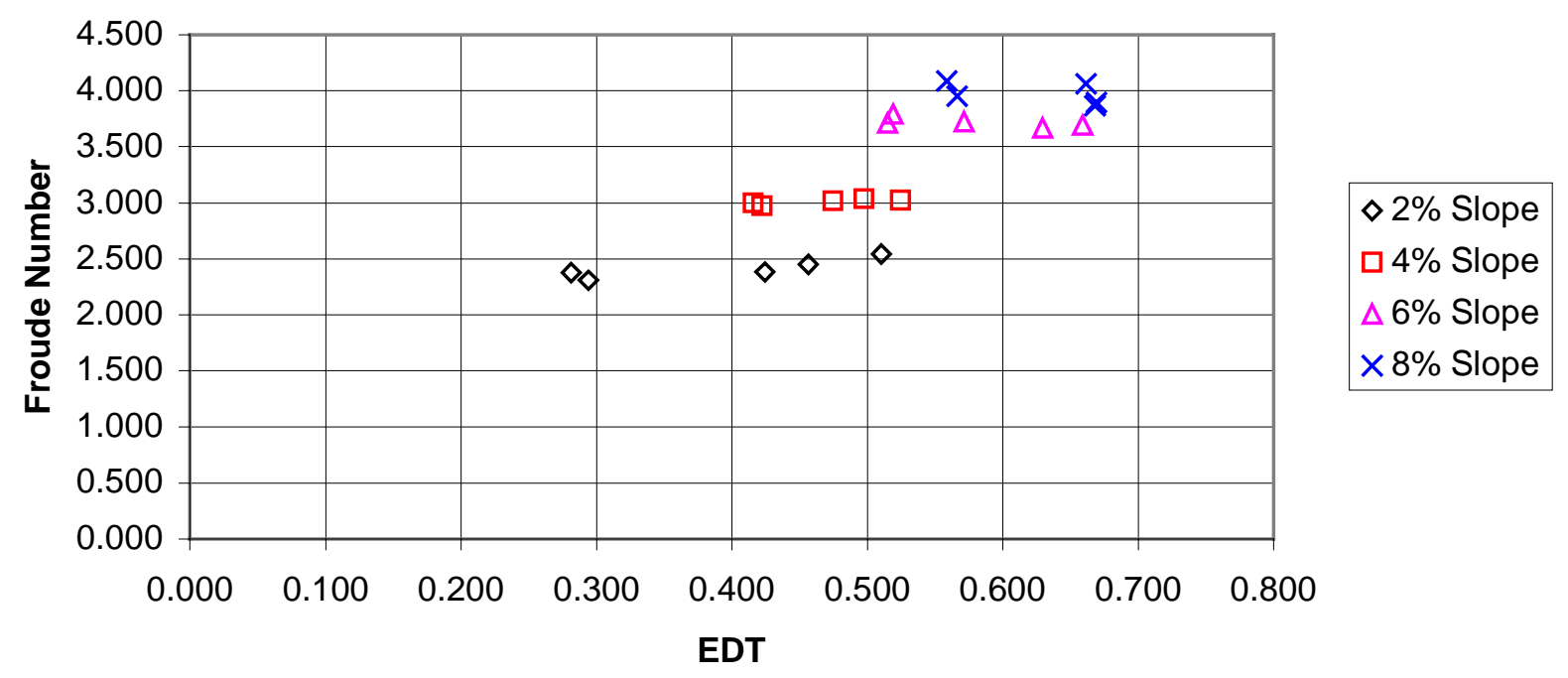

Figure 6.4 Froude Number at Culvert Outlet vs. EDT for 2.0-inch Cast Acrylic Step

Froude Number @ Culvert Outlet vs EDT for 2.5" Step

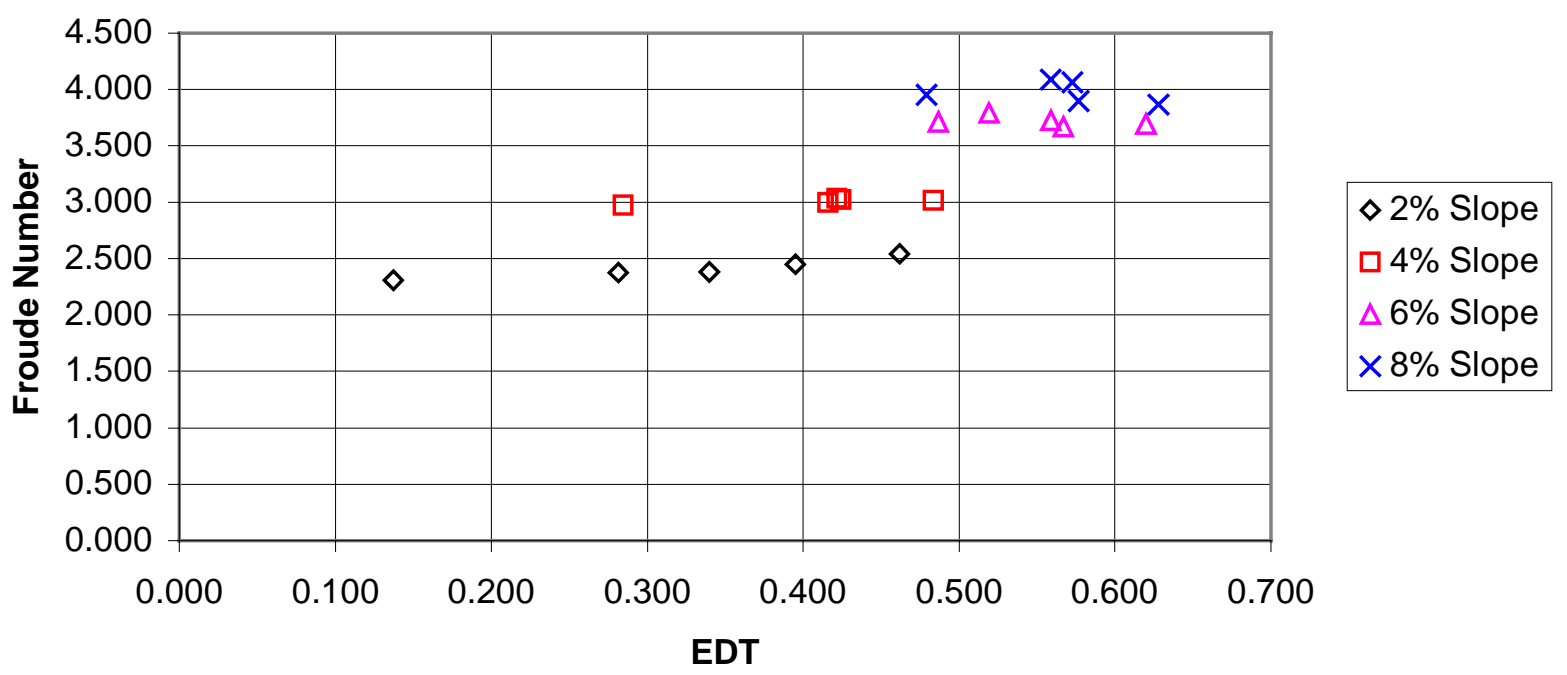

Figure 6.5 Froude Number at Culvert Outlet vs. EDT for 2.5-inch Cast Acrylic Step 
Froude Number @ Culvert Outlet vs EDT for 0.0" Riprap Step

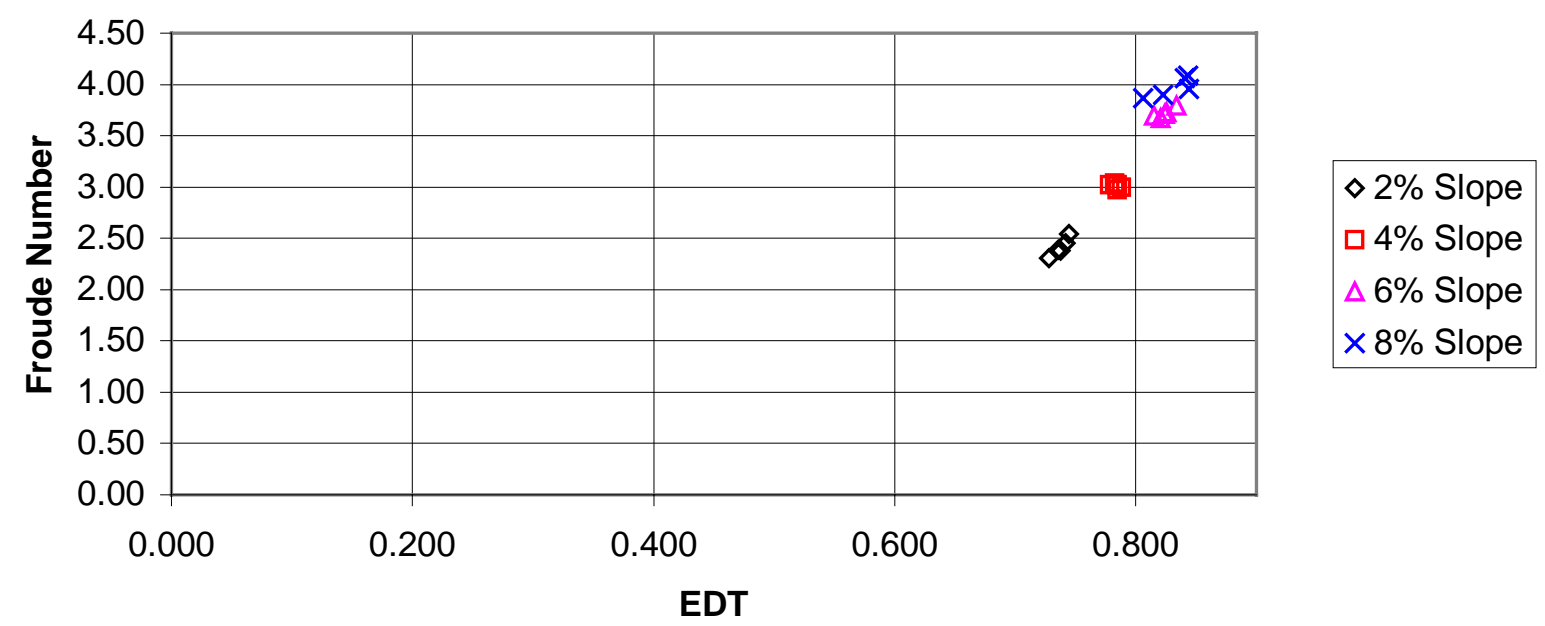

Figure 6.6 Froude Number at Culvert Outlet vs. EDT for 0.0-inch Riprap Step

Froude Number @ Culvert Outlet vs EDT for 0.5" Riprap Step

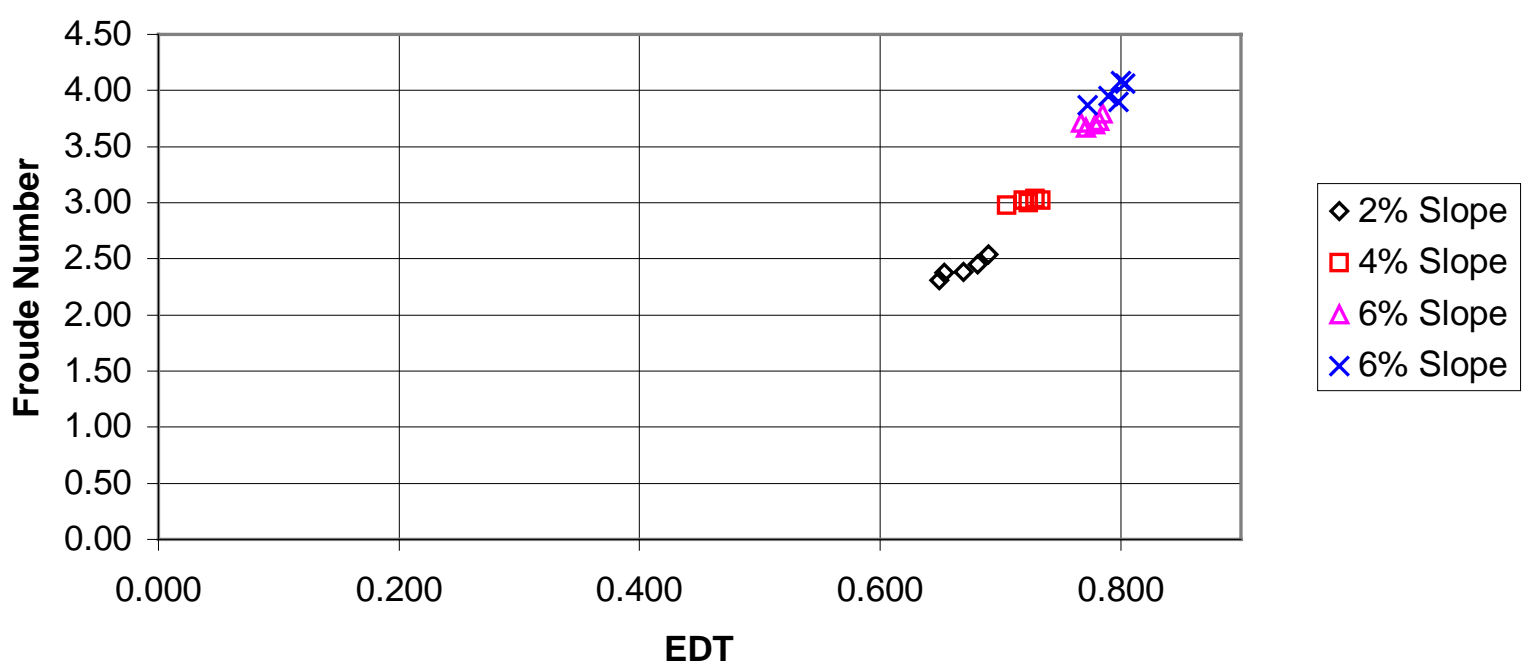

Figure 6.7 Froude Number at Culvert Outlet vs. EDT for 0.5-inch Riprap Step 
Froude Number @ Culvert Outlet vs EDT for 1.0" Riprap Step

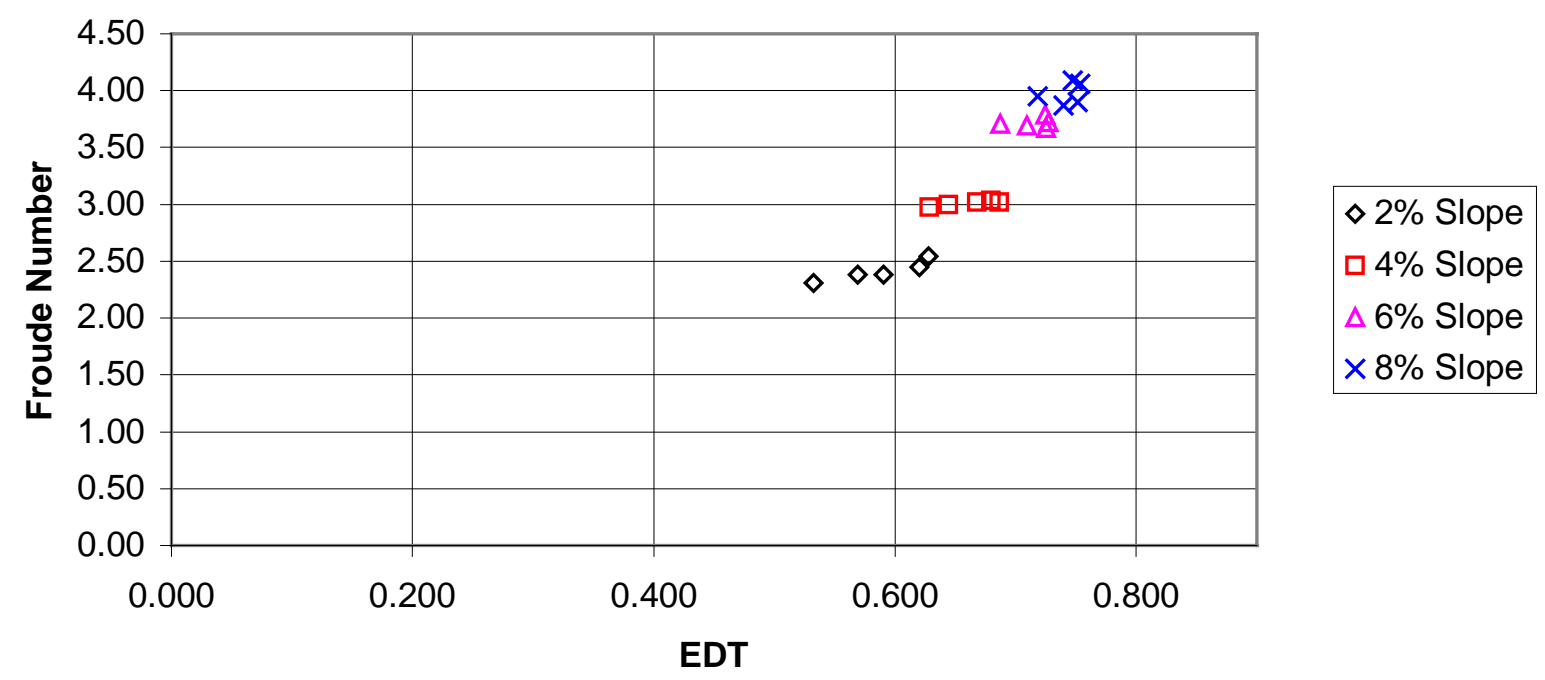

Figure 6.8 Froude Number at Culvert Outlet vs. EDT for 1.0-inch Riprap Step

Froude Number @ Culvert Outlet vs EDT for 1.5" Riprap Step

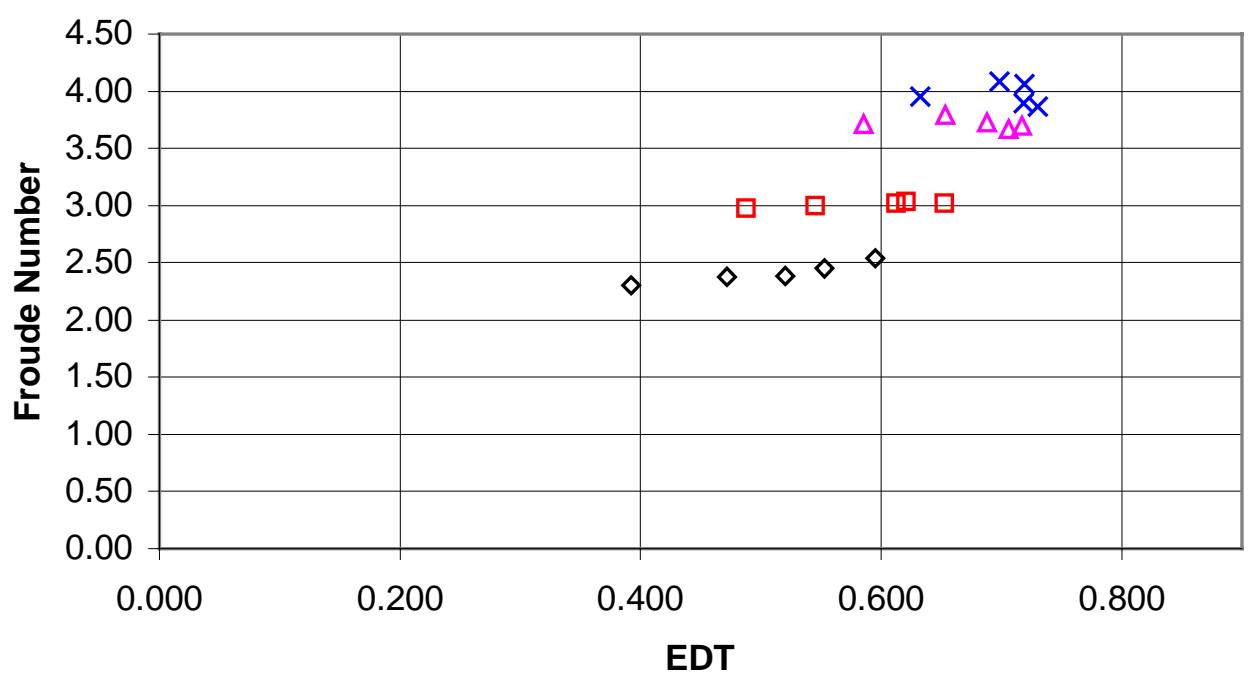

$\diamond 2 \%$ Slope

$\square 4 \%$ Slope

$\triangle 6 \%$ Slope

$\times 8 \%$ Slope

Figure 6.9 Froude Number at Culvert Outlet vs. EDT for 1.5-inch Riprap Step 
Froude Number @ Culvert Outlet vs EDT for 2.0" Riprap Step

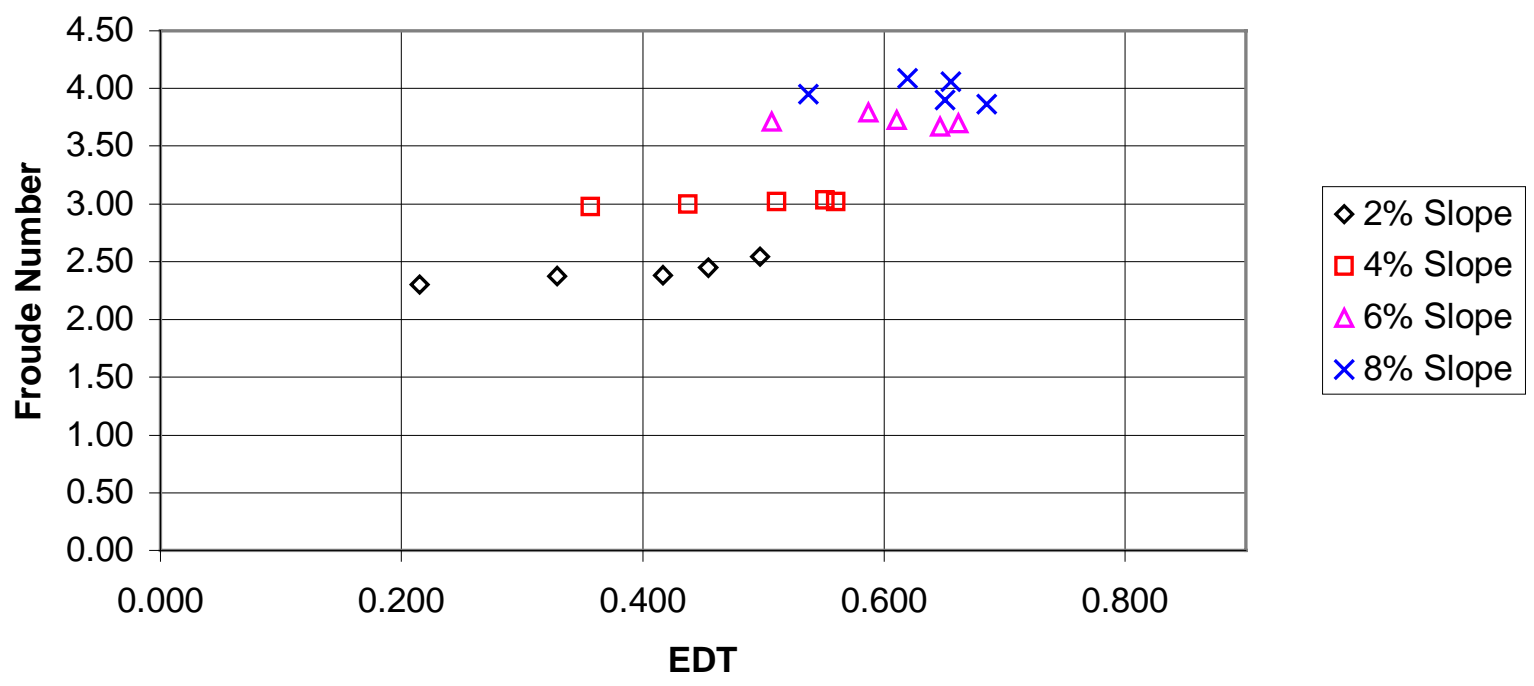

Figure 6.10 Froude Number at Culvert Outlet vs. EDT for 2.0-inch Riprap Step

Froude Number @ Culvert Outlet vs EDT for 2.5" Riprap Step

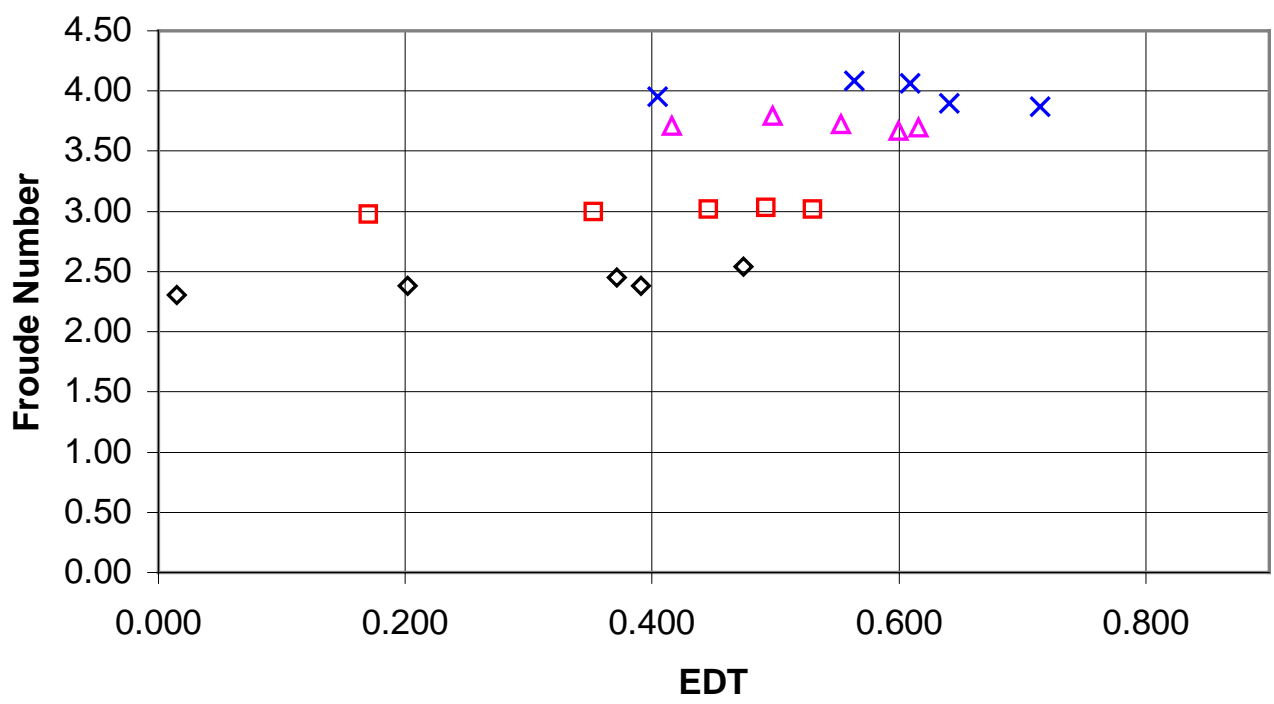

$\diamond 2 \%$ Slope

$\square 4 \%$ Slope

$\triangle 6 \%$ Slope

$\times 8 \%$ Slope

Figure 6.11 Froude Number at Culvert Outlet vs. EDT for 2.5-inch Riprap Step 


\subsection{Energy Dissipation Performance Parameter}

The next conclusion, drawn from the experimental data in evaluation of the various step types and heights was based on the deviation from the natural energy grade line, established in Section 5.19. It was decided to present the data in graphical and tabular form in order to draw conclusions about the performance of each step. The difference between the elevation of the natural energy grade line and the total energy, calculated in the testing channel, was non-dimensionalized and termed the energy difference performance parameter (EDPP). One variable used to create this non-dimensional parameter was the magnitude of the natural energy grade line deviation from the horizontal at the culvert outlet, shown as E3 in Zone 2 in Figure 6.12 (not to scale). The values for E3 are shown for each culvert slope in Table 6.7.

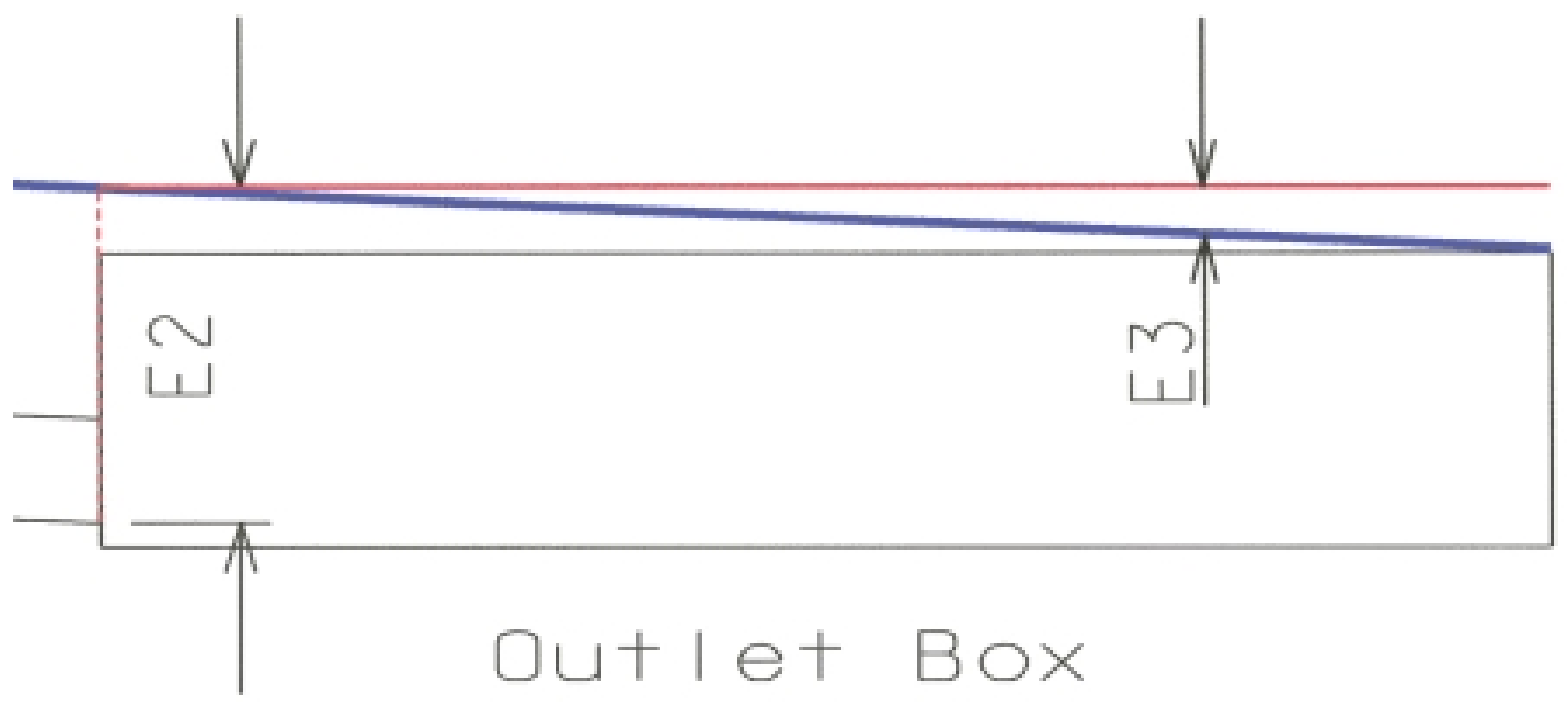

Figure 6.12 Schematic of E3, Value for Establishing the Energy Dissipation Performance Parameter

\begin{tabular}{|c|c|}
\hline Table 6.7 & $\begin{array}{c}\text { Values for E3 at Given } \\
\text { Culvert Slopes }\end{array}$ \\
\hline $\begin{array}{c}\text { Slope } \\
(\%)\end{array}$ & $\begin{array}{c}\text { E3 } \\
(\mathrm{mm})\end{array}$ \\
\hline 2 & 15.7 \\
\hline 4 & 31.4 \\
\hline 6 & 47.1 \\
\hline 8 & 62.9 \\
\hline
\end{tabular}


The following expression was used to determine the values for the energy dissipation performance parameter.

$E D P P=\frac{E 2-E_{f}}{E 3}$

Where:

$$
\begin{aligned}
& E D P P=\text { Energy Dissipation Performance Parameter } \\
& E 2=\text { Elevation of the natural energy grade line at the culvert outlet } \\
& E_{f}=\text { Total average energy from the three-point gage at the center of Zone } 2 \text { (EGL) } \\
& E 3=\text { Values from Table } 6.7 \text { calculated for the center of Zone } 2
\end{aligned}
$$

The values of EDPP were then organized for comparison. Their values are shown in Table 6.8 for cast acrylic and in Table 6.9 for riprap steps. Positive values indicate that the energy in the flow has been decreased below the natural energy grade line assumption established at the culvert inlet. Negative values, in blue, indicate no effect in decreasing the energy of the flow below the assumed natural value at the culvert outlet.

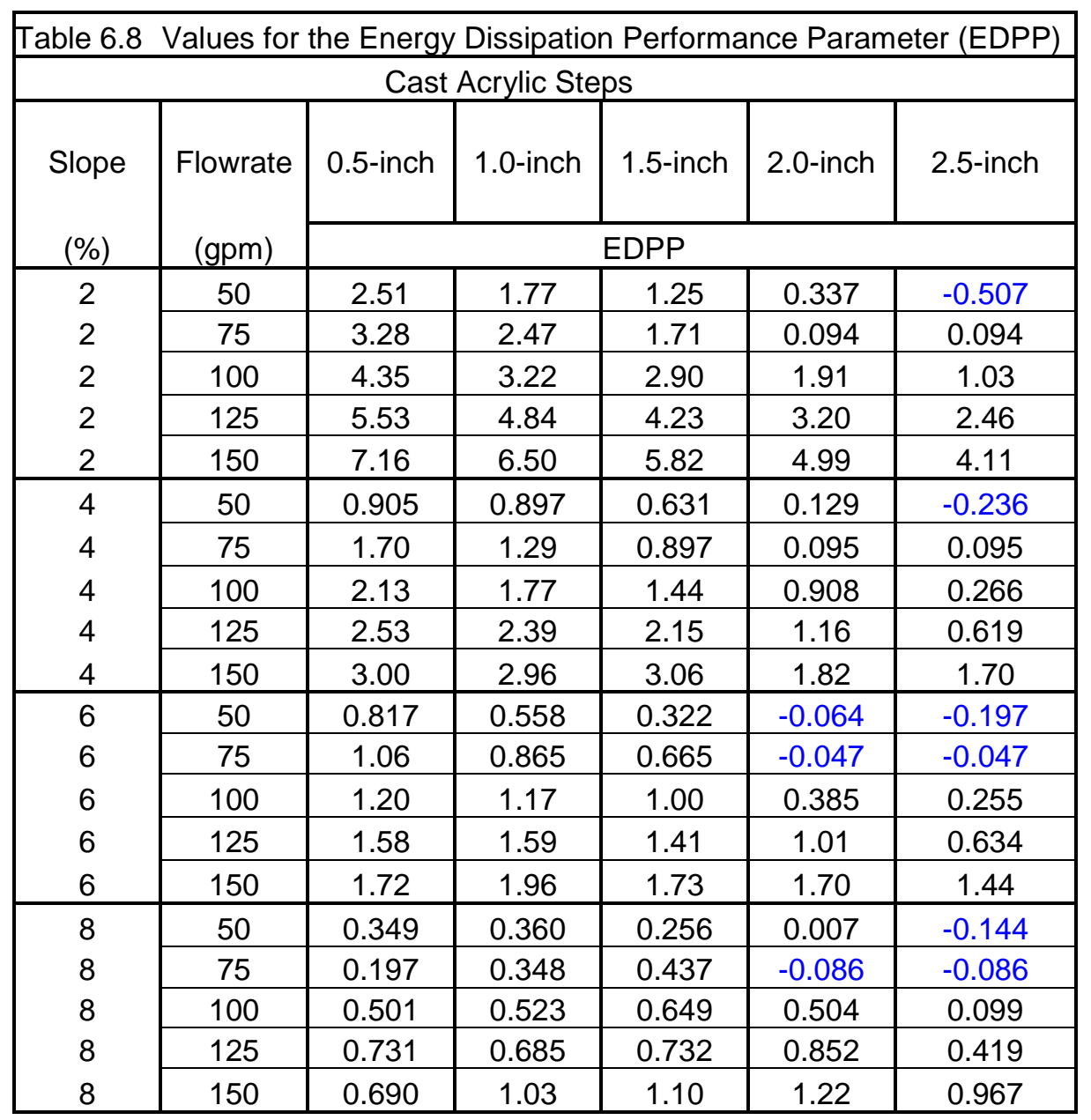




\begin{tabular}{|c|c|c|c|c|c|c|c|}
\hline \multicolumn{8}{|c|}{ Equivalent Riprap Steps } \\
\hline Slope & Flowrate & 0.0-inch & 0.5-inch & 1.0-inch & 1.5-inch & 2.0-inch & 2.5-inch \\
\hline (\%) & (gpm) & \multicolumn{6}{|c|}{ EDPP } \\
\hline 2 & 50 & 3.30 & 2.76 & 1.96 & 1.007 & -0.204 & -1.31 \\
\hline 2 & 75 & 4.06 & 3.39 & 2.57 & 1.76 & 0.460 & -0.603 \\
\hline 2 & 100 & 5.15 & 4.46 & 3.64 & 2.91 & 1.83 & 1.57 \\
\hline 2 & 125 & 6.56 & 5.80 & 5.04 & 4.36 & 3.17 & 2.17 \\
\hline 2 & 150 & 8.31 & 7.53 & 6.78 & 6.19 & 4.81 & 4.29 \\
\hline 4 & 50 & 1.65 & 1.32 & 0.970 & 0.364 & -0.149 & -0.684 \\
\hline 4 & 75 & 2.07 & 1.72 & 1.32 & 0.806 & 0.235 & -0.242 \\
\hline 4 & 100 & 2.57 & 2.19 & 1.82 & 1.47 & 0.819 & 0.402 \\
\hline 4 & 125 & 3.25 & 2.85 & 2.49 & 2.06 & 1.55 & 1.137 \\
\hline 4 & 150 & 4.17 & 3.78 & 3.41 & 3.14 & 2.50 & 2.09 \\
\hline 6 & 50 & 1.091 & 0.879 & 0.622 & 0.214 & -0.094 & -0.457 \\
\hline 6 & 75 & 1.387 & 1.163 & 0.889 & 0.565 & 0.262 & -0.144 \\
\hline 6 & 100 & 1.714 & 1.49 & 1.199 & 0.996 & 0.589 & 0.224 \\
\hline 6 & 125 & 2.153 & 1.92 & 1.62 & 1.46 & 1.109 & 0.828 \\
\hline 6 & 150 & 2.769 & 2.53 & 2.04 & 2.09 & 1.72 & 1.41 \\
\hline 8 & 50 & 0.809 & 0.643 & 0.436 & 0.198 & -0.078 & -0.344 \\
\hline 8 & 75 & 1.006 & 0.844 & 0.631 & 0.439 & 0.142 & -0.066 \\
\hline 8 & 100 & 1.279 & 1.119 & 0.901 & 0.753 & 0.477 & 0.259 \\
\hline 8 & 125 & 1.553 & 1.44 & 1.218 & 1.077 & 0.764 & 0.718 \\
\hline 8 & 150 & 1.932 & 1.78 & 1.61 & 1.54 & 1.31 & 1.43 \\
\hline
\end{tabular}

Plots of the energy dissipation performance parameter were then made for each of the steps shown in Figures 6.13 through 6.23. Each plot shows the energy dissipation performance parameter versus flowrate. The effectiveness of all the steps increased with flowrate and decreased with increasing slope. In general, energy dissipation 'appeared' to decrease with increasing step heights. Efficiencies of the steps varied greatly with the highest efficiency at $2 \%$ culvert slope, $150 \mathrm{gpm}$, with a 0.0 -inch equivalent riprap step and the lowest efficiency at $2 \%$ culvert slope, $50 \mathrm{gpm}$, with a 2.5-inch equivalent riprap step. 
Energy Dissipation Performance Parameter vs. Flowrate for 0.5 -inch Cast Acrylic Step

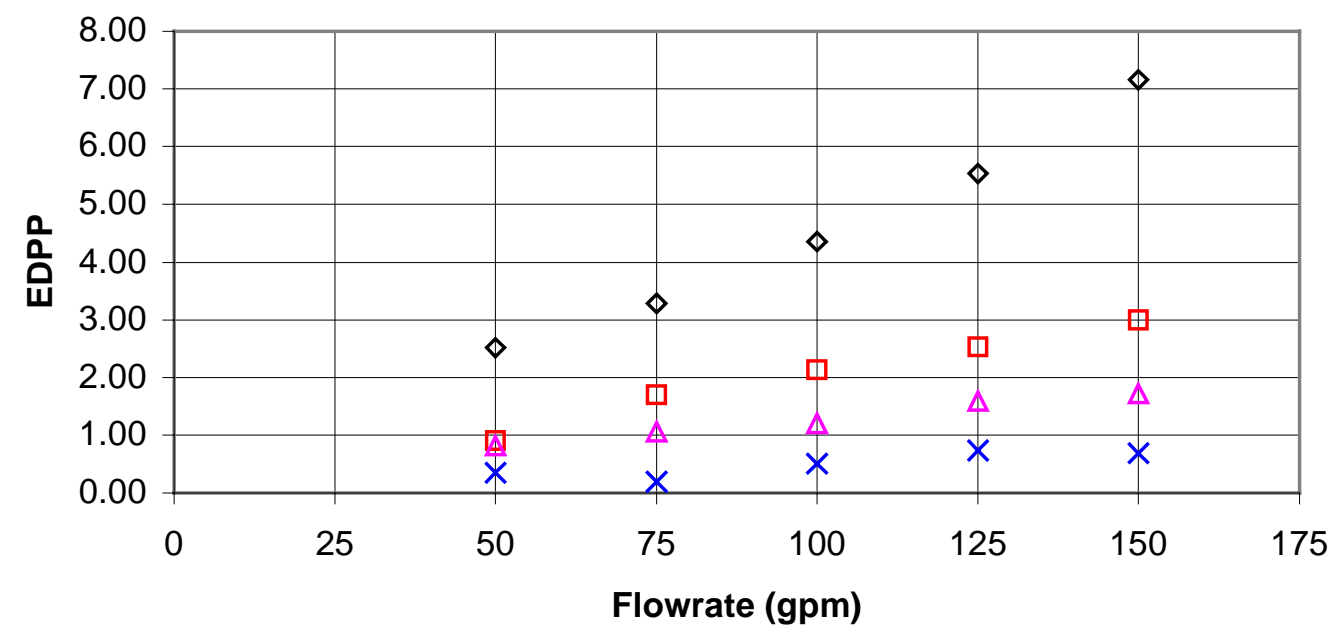

$\diamond 2 \%$ Slope $\square 4 \%$ Slope $\triangle 6 \%$ Slope $\times 8 \%$ Slope

Figure 6.13 EDPP versus Flowrate for 0.5-inch Cast Acrylic Step

Energy Dissipation Performance Parameter vs. Flowrate for 1.0-inch Cast Acrylic Step

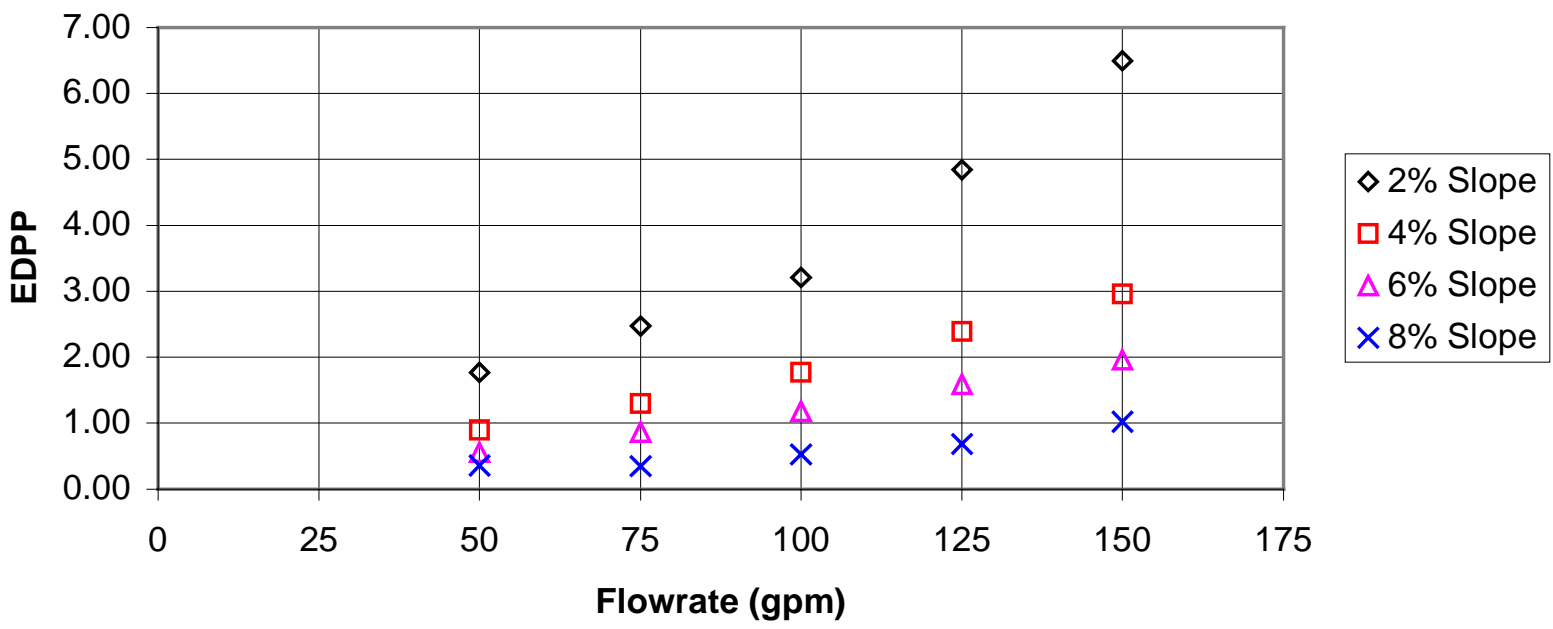

Figure 6.14 EDPP versus Flowrate for 1.0-inch Cast Acrylic Step 
Energy Dissipation Performance Parameter vs. Flowrate for 1.5-inch Cast Acrylic Step

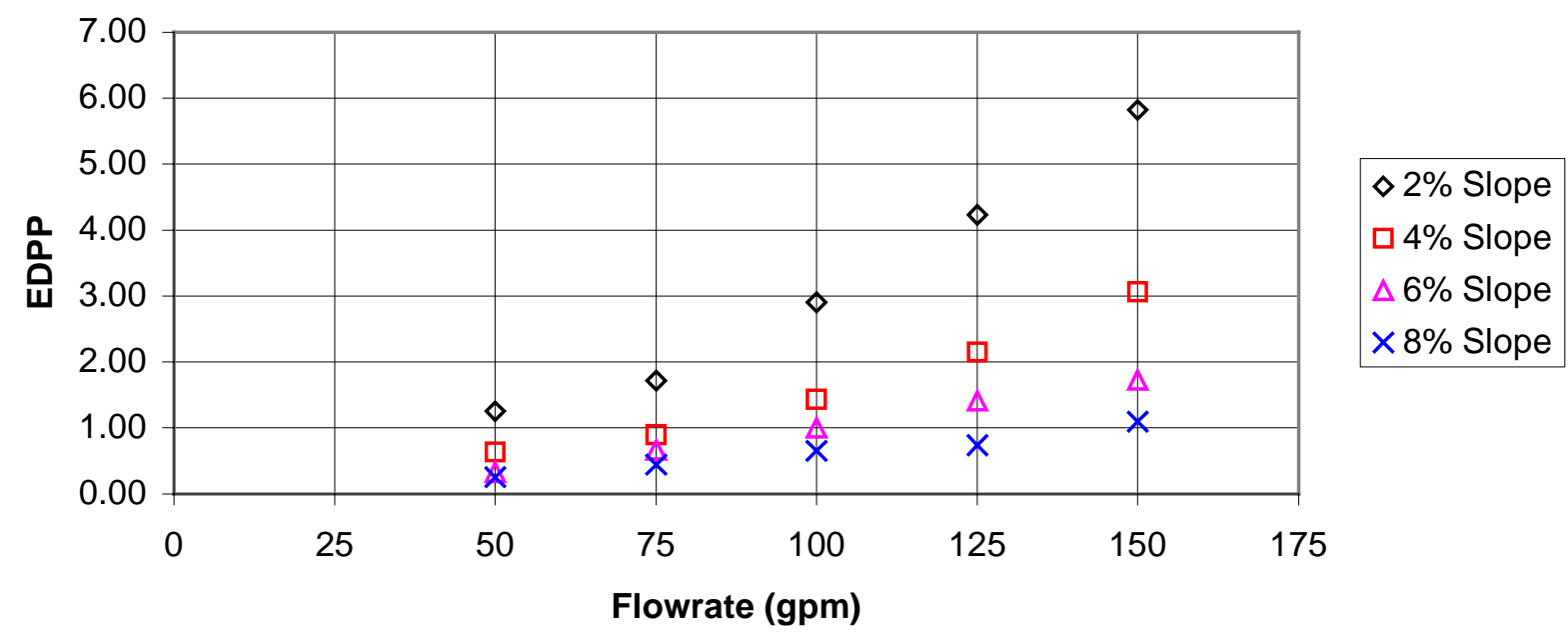

Figure 6.15 EDPP versus Flowrate for 1.5-inch Cast Acrylic Step

Energy Dissipation Performance Parameter vs. Flowrate for 2.0-inch Cast Acrylic Step

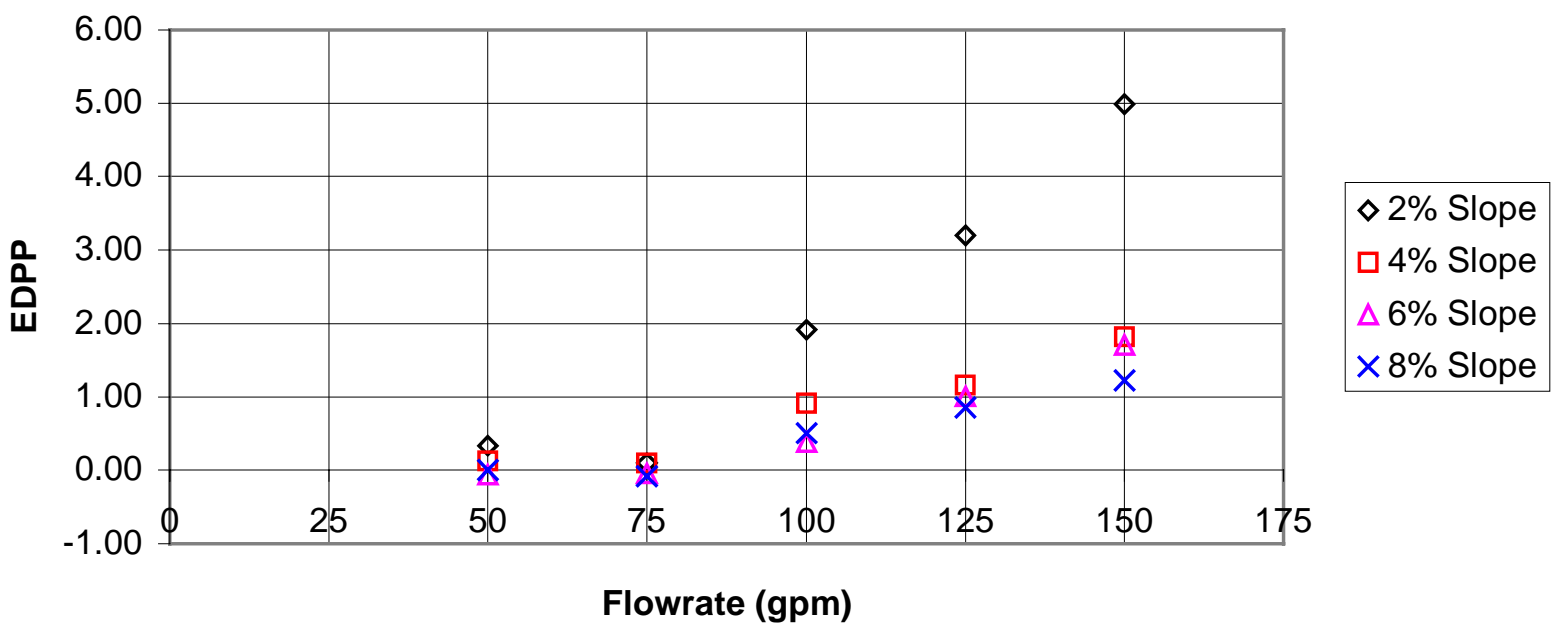

Figure 6.16 EDPP versus Flowrate for 2.0-inch Cast Acrylic Step 
Energy Dissipation Performance Parameter vs. Flowrate for 2.5-inch Cast Acrylic Step

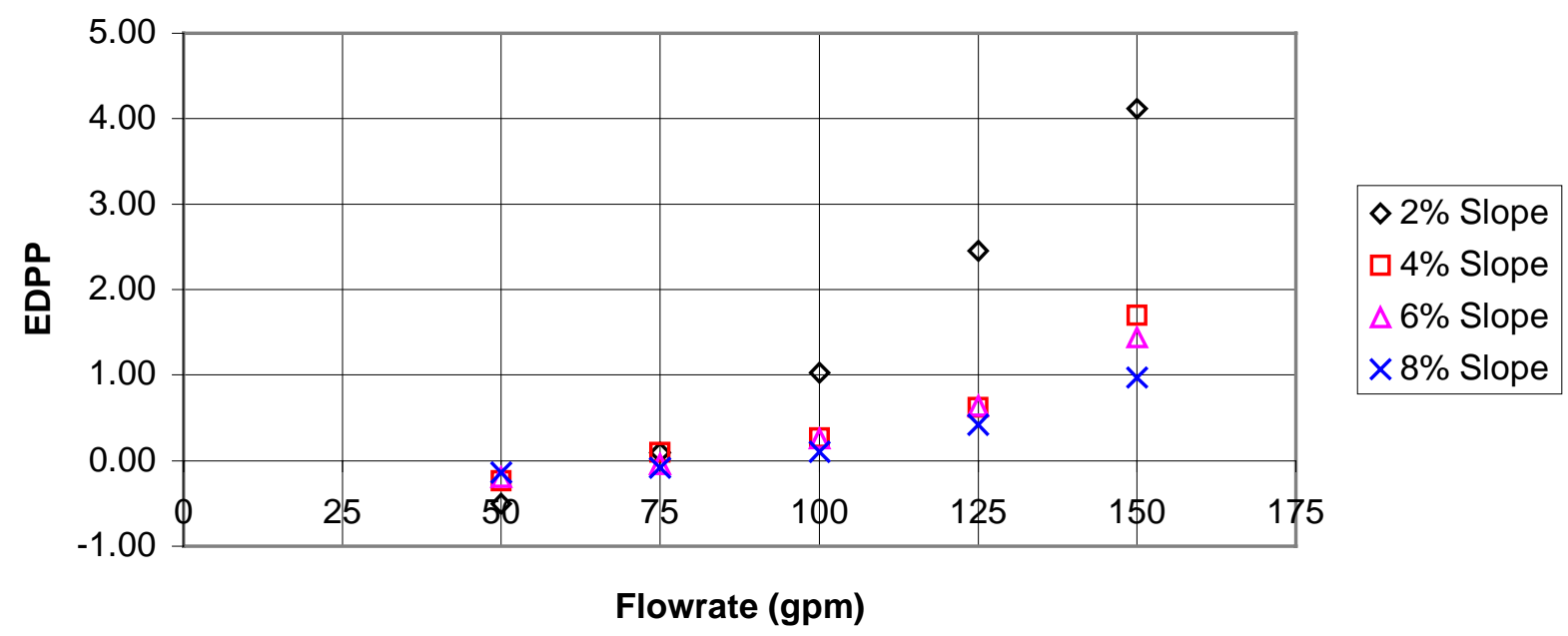

Figure 6.17 EDPP versus Flowrate for 2.5-inch Cast Acrylic Step

\section{Energy Dissipation Performance Parameter vs Flowrate for 0.0-inch Equivalent Riprap Step}

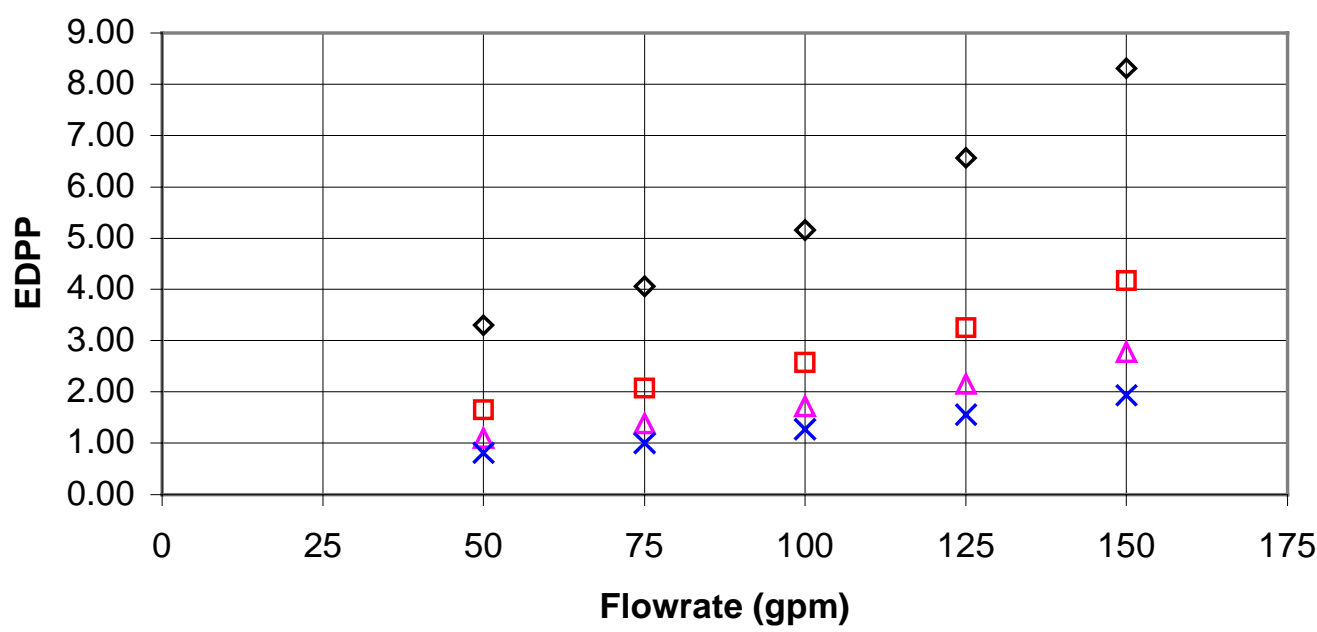

$\diamond 2 \%$ Slope $\square 4 \%$ Slope $\triangle 6 \%$ Slope $\times 8 \%$ Slope

Figure 6.18 EDPP versus Flowrate for 0.0-inch Equivalent Riprap Step 
Energy Dissipation Performance Parameter vs. Flowrate for 0.5-inch

Equivalent Riprap Step

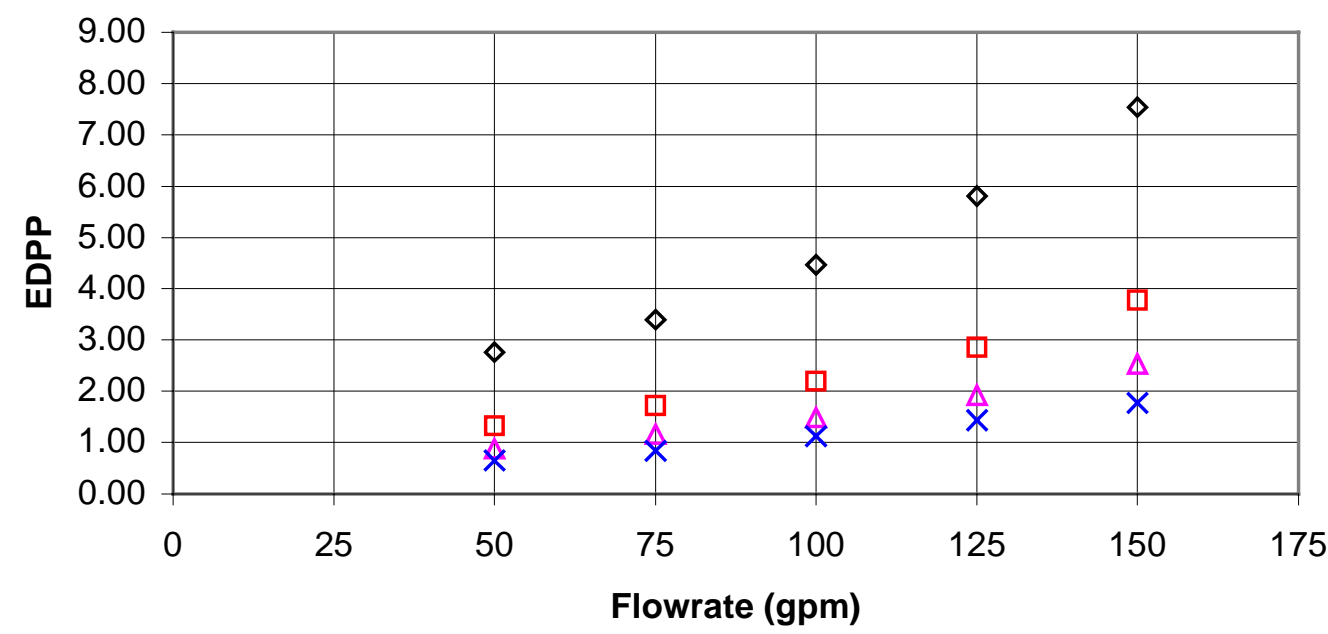

$\diamond 2 \%$ Slope $\square 4 \%$ Slope $\triangle 6 \%$ Slope $\times 8 \%$ Slope

Figure 6.19 EDPP versus Flowrate for 0.5-inch Equivalent Riprap Step

Energy Dissipation Performance Parameter vs. Flowrate for 0.5-inch Equivalent Riprap Step

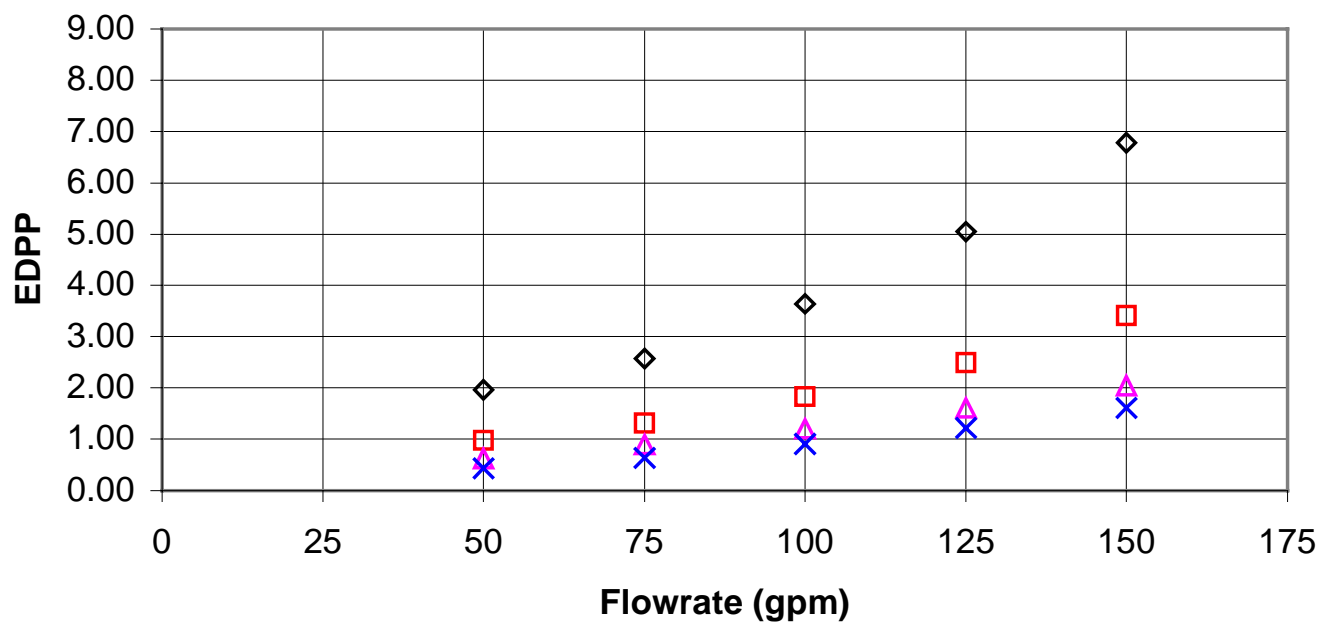

$\diamond 2 \%$ Slope $\square 4 \%$ Slope $\triangle 6 \%$ Slope $\times 8 \%$ Slope

Figure 6.20 EDPP versus Flowrate for 1.0-inch Equivalent Riprap Step 
Energy Dissipation Performance Parameter vs. Flowrate for 1.5-inch

Equivalent Riprap Step

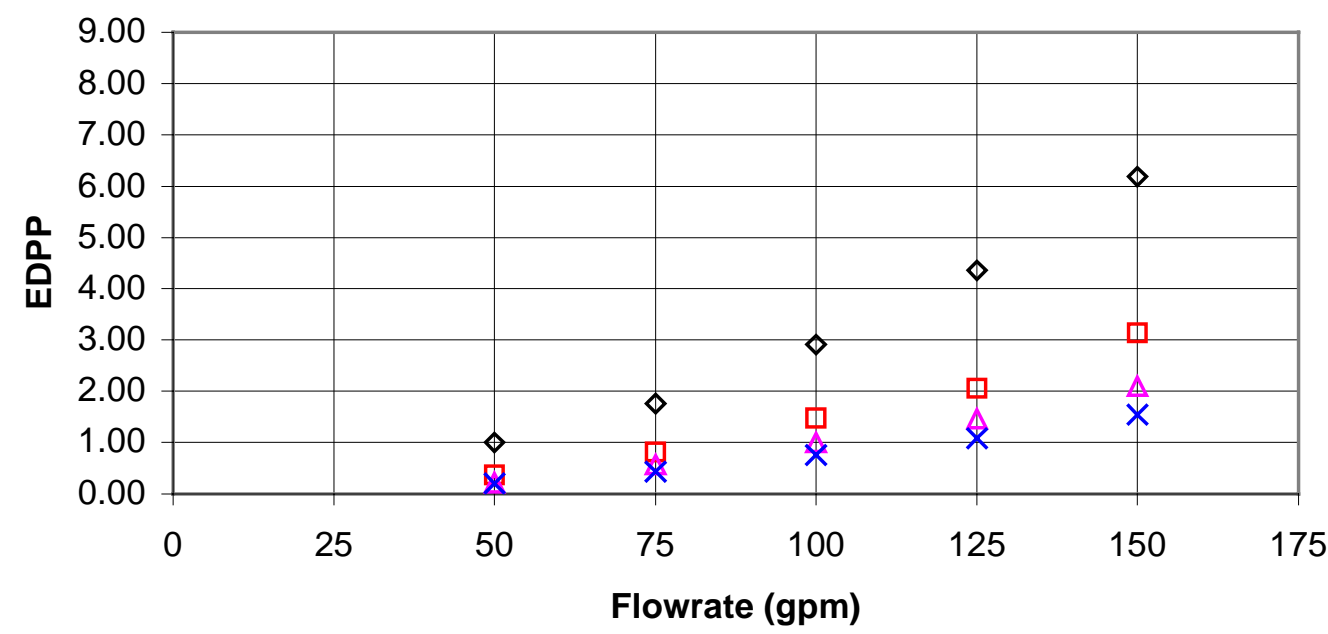

$\diamond 2 \%$ Slope $\square 4 \%$ Slope $\triangle 6 \%$ Slope $\times 8 \%$ Slope

Figure 6.21 EDPP versus Flowrate for 1.5-inch Equivalent Riprap Step

Energy Dissipation Performance Parameter vs. Flowrate for 2.0-inch Equivalent Riprap Step

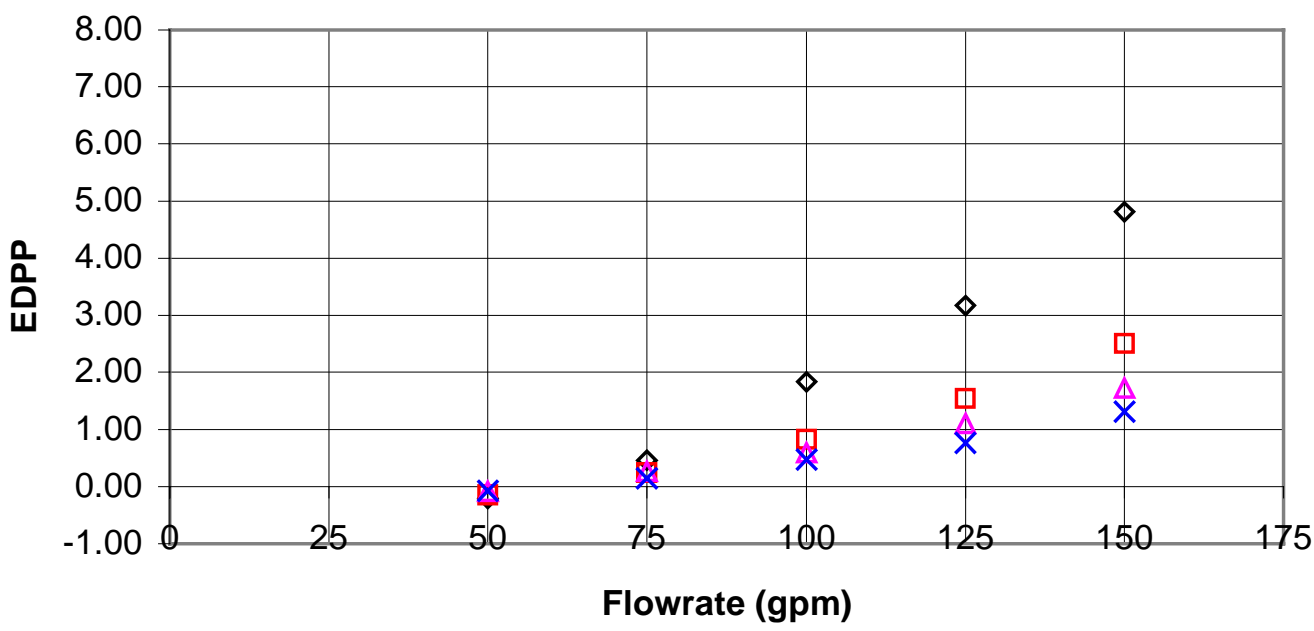

Figure 6.22 EDPP versus Flowrate for 2.0-inch Equivalent Riprap Step 


\section{Energy Dissipation Performance Parameter vs. Flowrate for 2.5-inch}

Equivalent Riprap Step

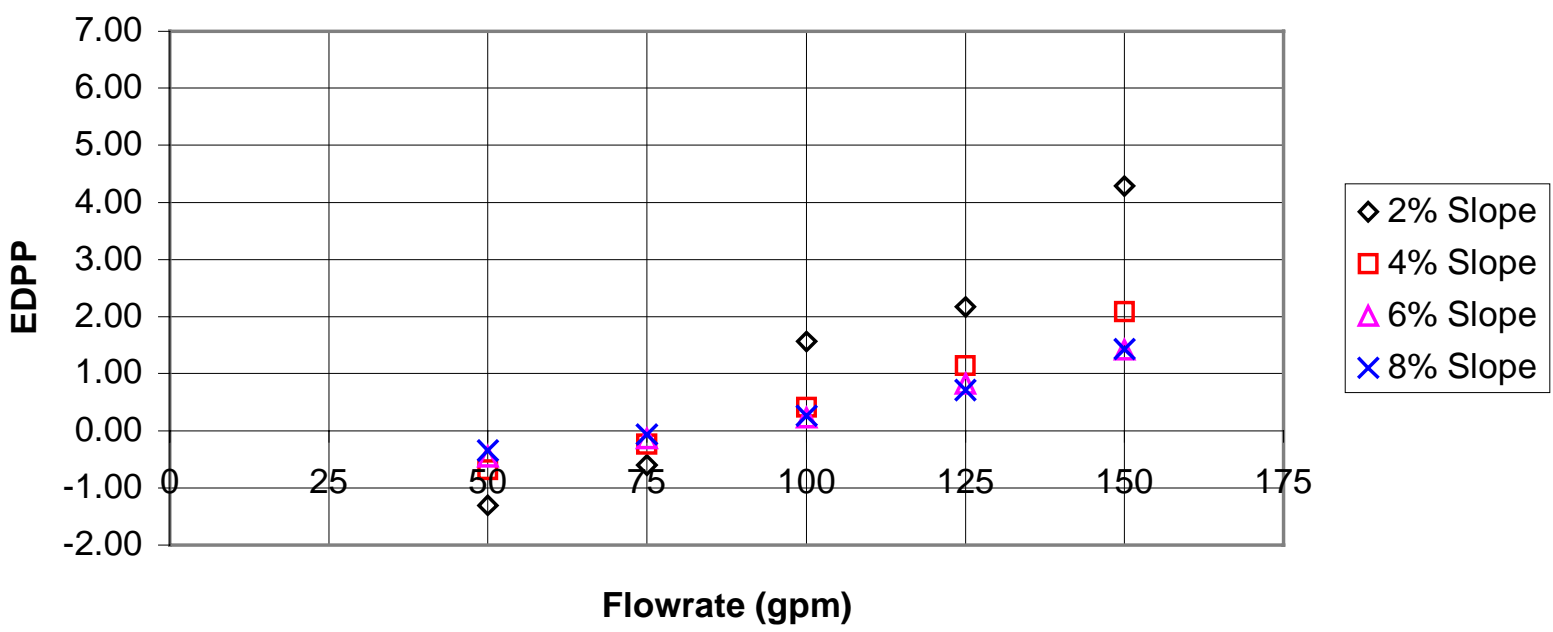

Figure 6.23 EDPP versus Flowrate for 2.5-inch Equivalent Riprap Step 


\subsection{Cast Acrylic and Riprap Step Comparison - EDPP}

The purpose of creating two types of steps to be placed in the testing channel was to use the cast acrylic steps with uniform, even features as the standard and compare the riprap step results to the standard. In order to compare the results and prevent confusion, this section will focus on the 'effective' riprap step height and not the referenced 'equivalent' step height. Refer to Table 5.1 in Section 5.2. It was necessary to compare the energy attenuating efficiency of the riprap step to the standard cast acrylic step. First, plots were constructed for EDPP values for the range of step heights at culvert slopes of 2, 4, 6, and $8 \%$, at each flowrate in Figures 6.24 through 6.28. Then, plots were constructed for the percent difference between the riprap EDPP values and the cast acrylic EDPP values for three step heights, 0.5-inch (12.7-mm), 1.0-inch (25.4-mm), and 1.5-inch (38.1-mm) in Figures 6.29 through 6.33. As discussed previously in Section 5.2, actual 'melted' riprap step heights never actually reached 2.0-inch or 2.5-inch heights. Therefore, comparisons between the standard, cast acrylic steps, and the riprap steps were limited to only three step heights.

\section{Energy Dissipation Performance Parameter Comparison for Cast Acrylic (CA) and Riprap (RR) Steps at $50 \mathrm{gpm}$}

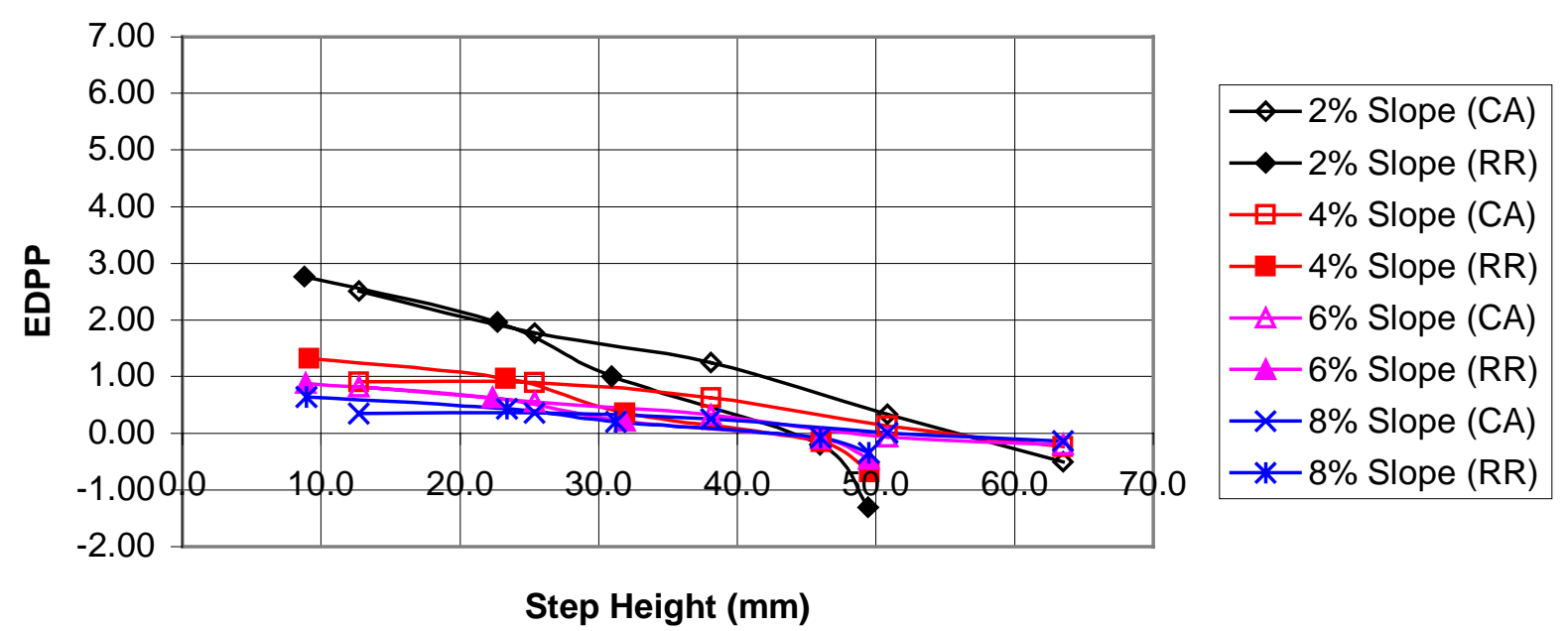

Figure 6.24 EDPP for Cast Acrylic and Riprap Steps at 50 gpm 
Energy Dissipation Performance Parameter Comparison for Cast Acrylic

(CA) and Riprap (RR) Steps at 75 gpm

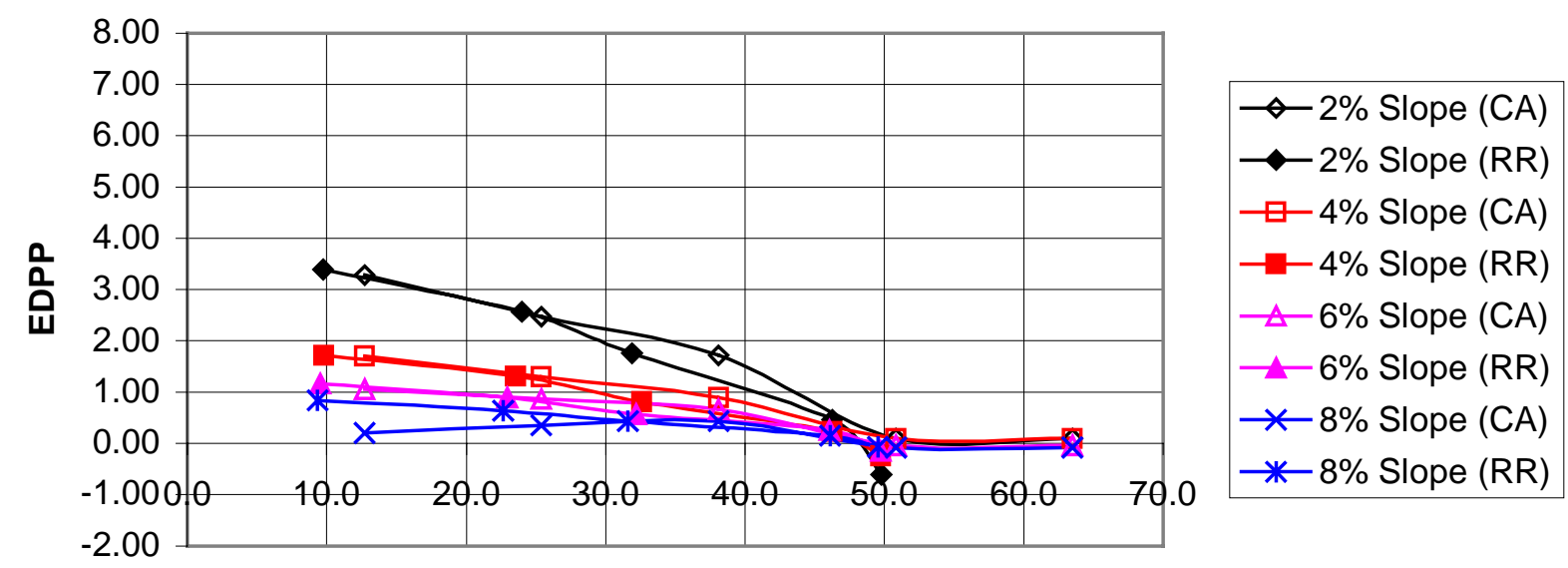

Step Height (mm)

Figure 6.25 EDPP for Cast Acrylic and Riprap Steps at 75 gpm

\section{Energy Dissipation Performance Parameter Comparison for Cast Acrylic} (CA) and Riprap (RR) Steps at $100 \mathrm{gpm}$

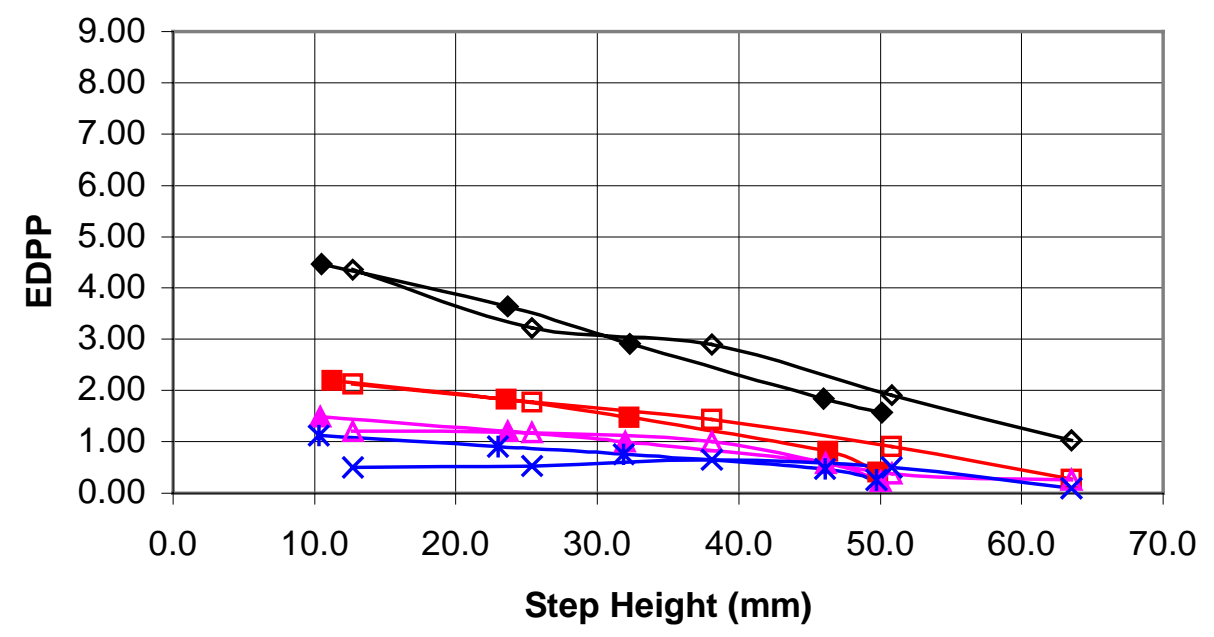

$\rightarrow-2 \%$ Slope (CA)
$\rightarrow-2 \%$ Slope (RR)
$-4 \%$ Slope (CA)
$-4 \%$ Slope (RR)
$-6 \%$ Slope (CA)
$-6 \%$ Slope (RR)
$\rightarrow-8 \%$ Slope (CA)
$\rightarrow-8 \%$ Slope (RR)

Figure 6.26 EDPP for Cast Acrylic and Riprap Steps at $100 \mathrm{gpm}$ 


\section{Energy Dissipation Performance Parameter Comparison for Cast Acrylic}

(CA) and Riprap (RR) Steps at $125 \mathrm{gpm}$

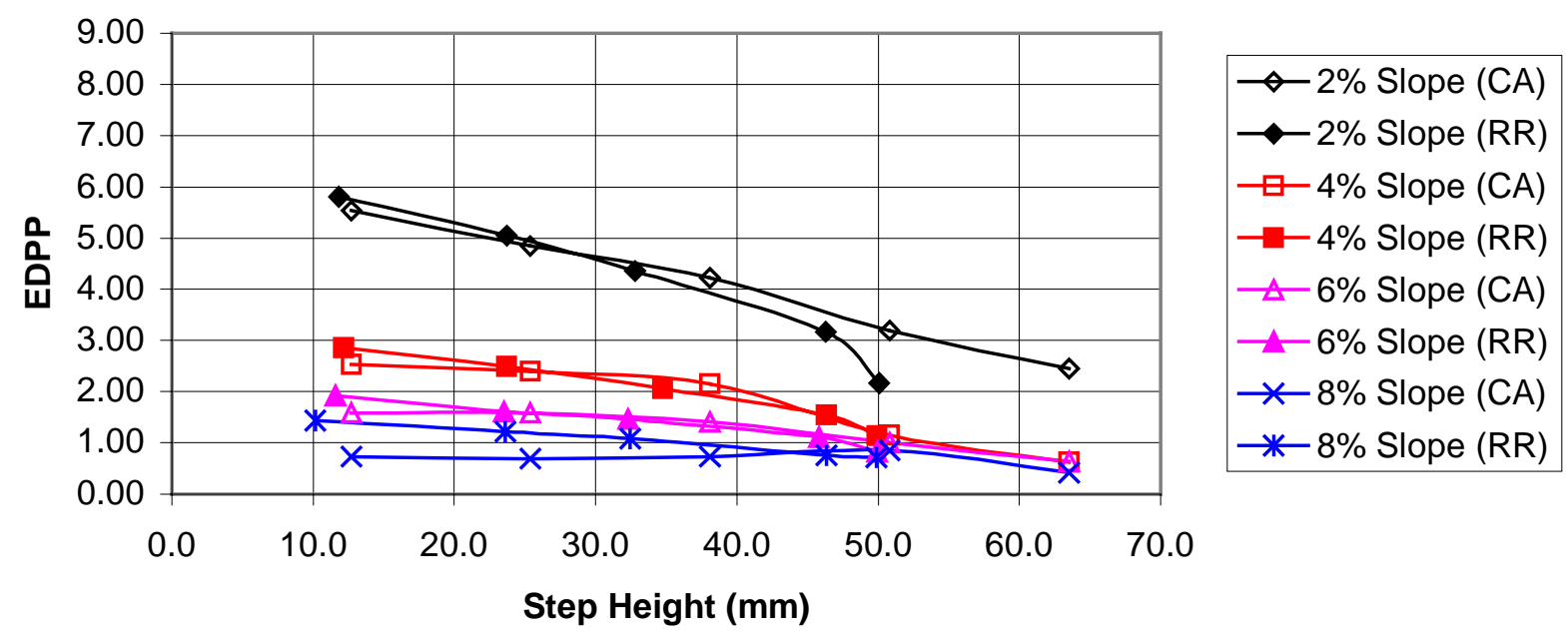

Figure 6.27 EDPP for Cast Acrylic and Riprap Steps at $125 \mathrm{gpm}$

Energy Dissipation Performance Parameter Comparison for Cast Acrylic (CA) and Riprap (RR) Steps at $150 \mathrm{gpm}$

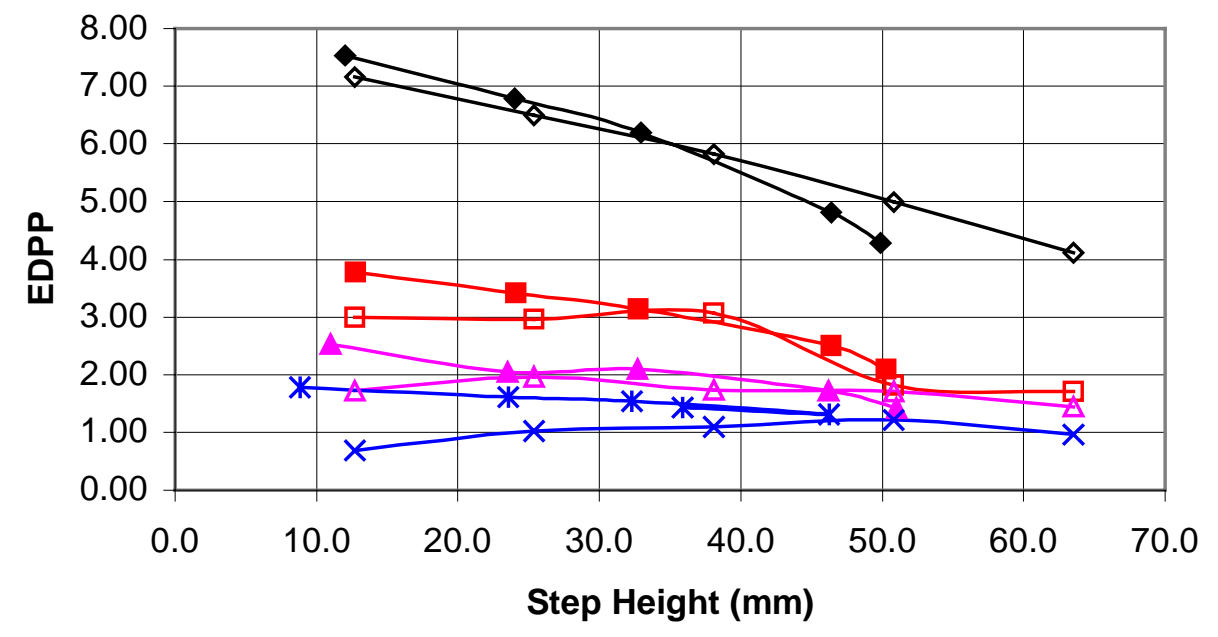

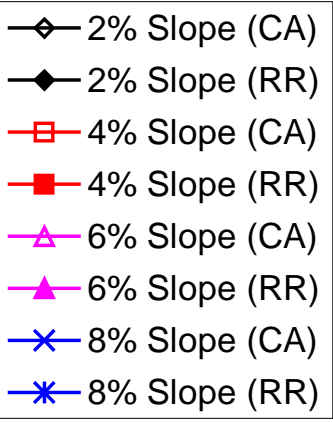

Figure 6.28 EDPP for Cast Acrylic and Riprap Steps at $150 \mathrm{gpm}$ 


\section{Riprap Energy Dissipation Performance Parameter \% Difference From Cast Acrylic at $50 \mathrm{gpm}$}

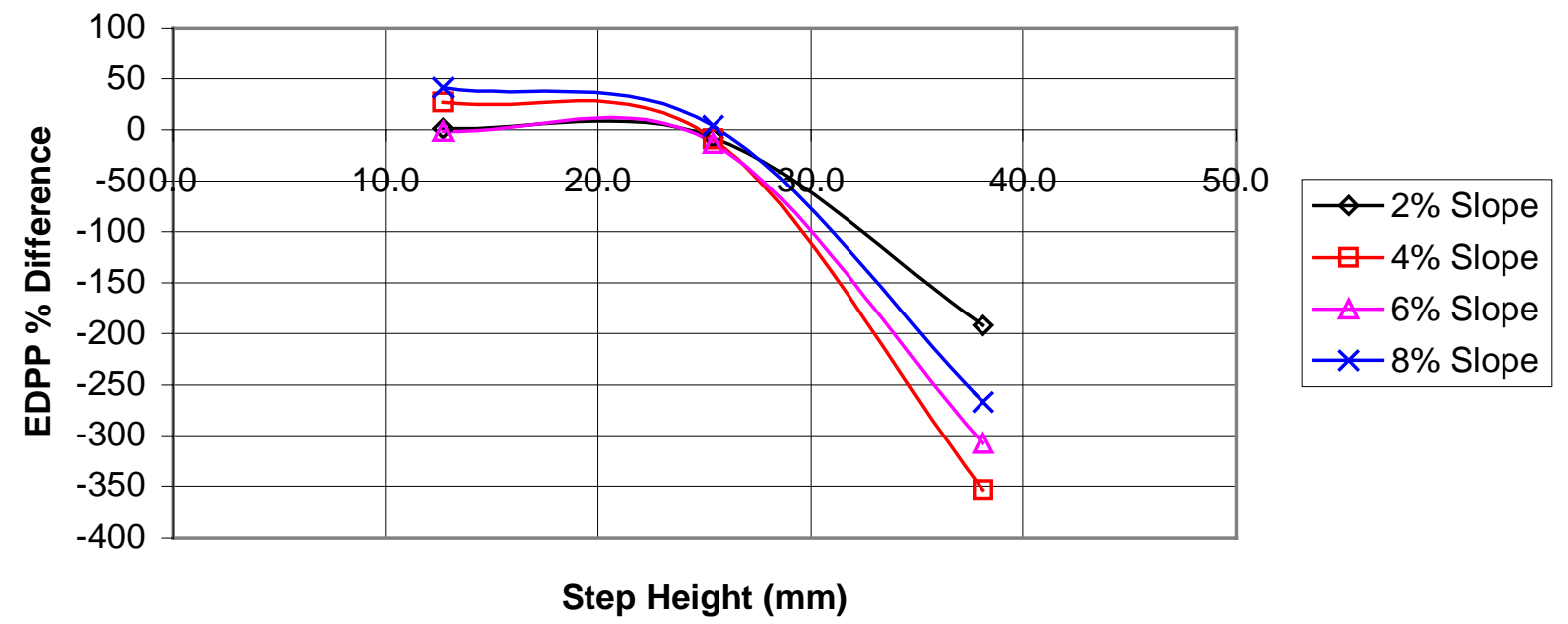

Figure 6.29 Riprap EDPP Percent Difference From Cast Acrylic at 50 gpm

\section{Riprap Energy Dissipation Performance Parameter \% Difference From Cast Acrylic at $75 \mathrm{gpm}$}

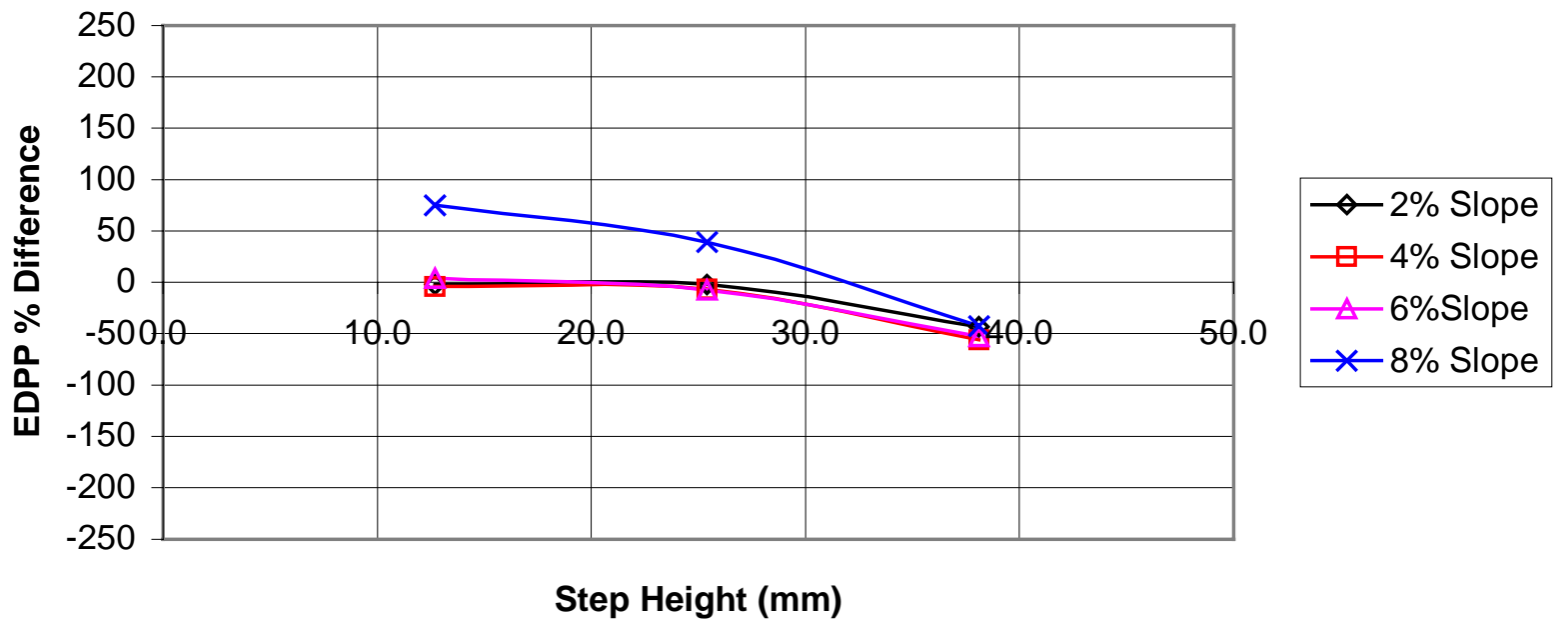

Figure 6.30 Riprap EDPP Percent Difference From Cast Acrylic at 75 gpm 
Riprap Energy Dissipation Performance Parameter \% Difference From Cast Acrylic at $100 \mathrm{gpm}$

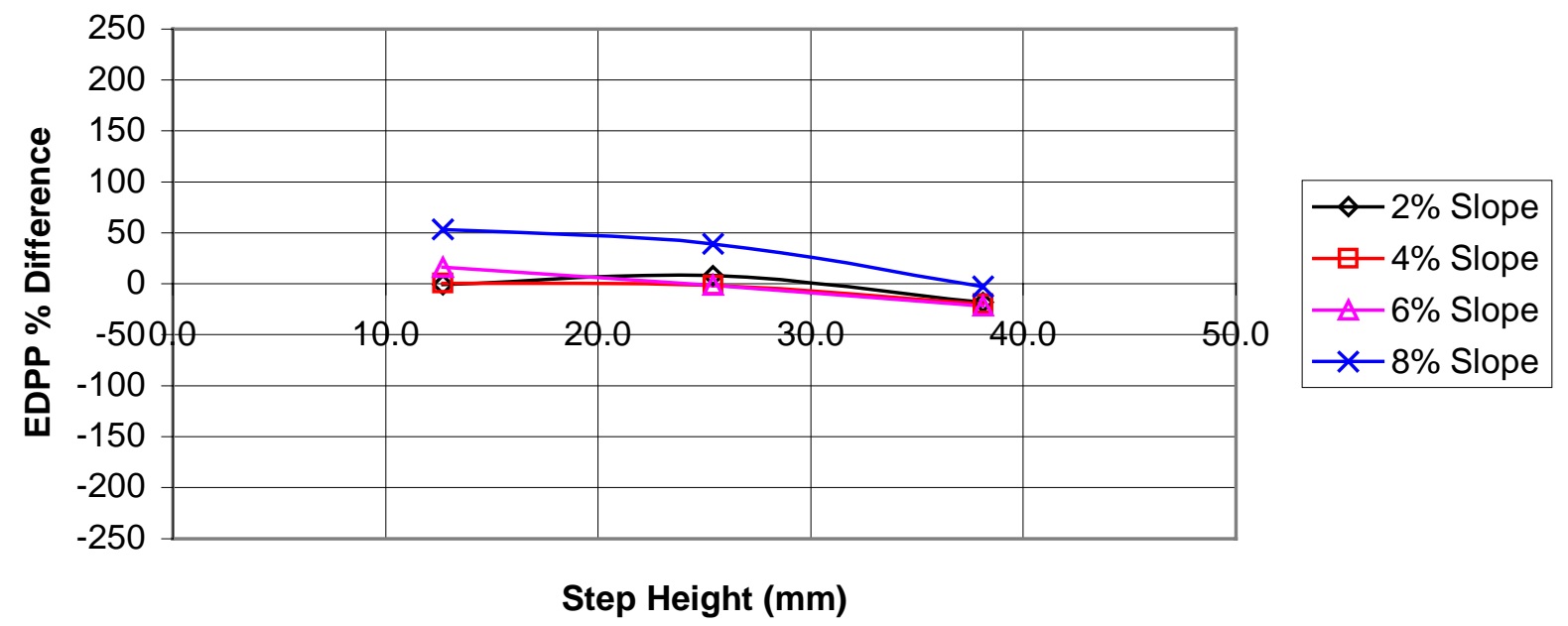

Figure 6.31 Riprap EDPP Percent Difference From Cast Acrylic at 100 gpm

\section{Riprap Energy Dissipation Performance Parameter \% Difference From Cast Acrylic at $125 \mathrm{gpm}$}

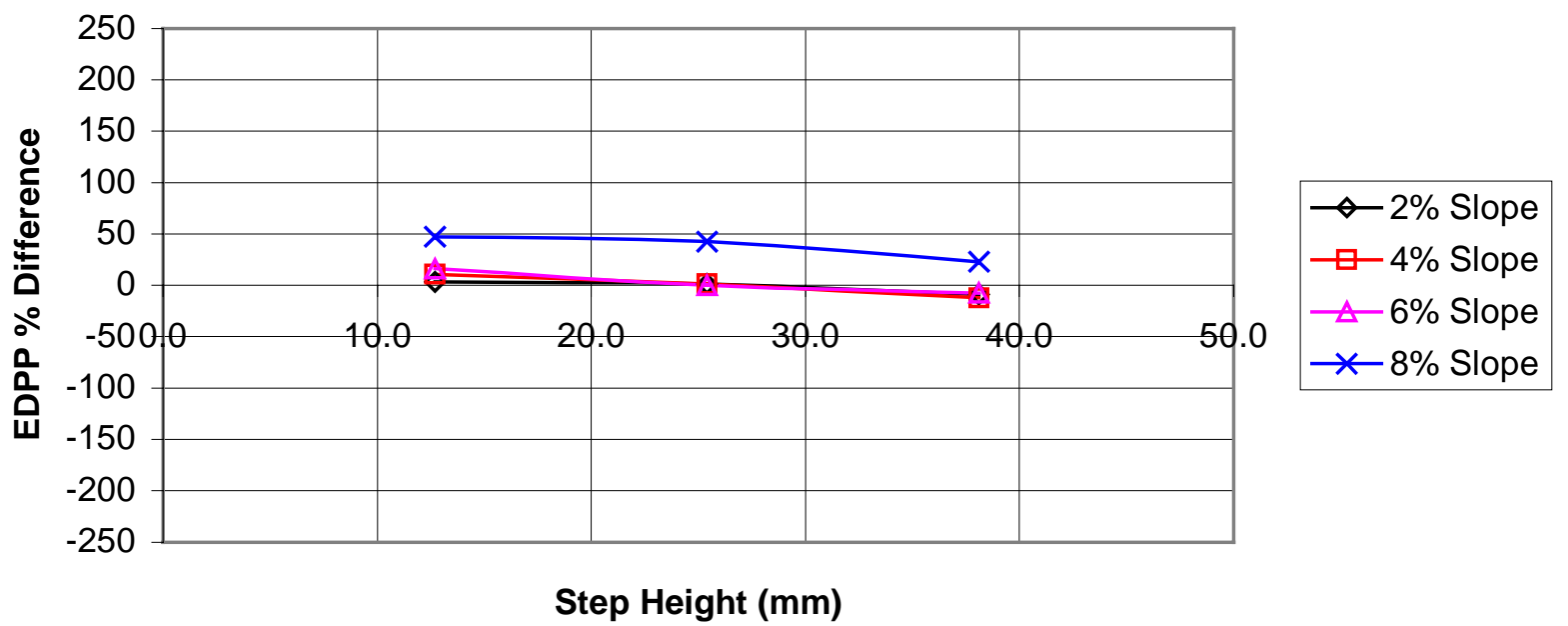

Figure 6.32 Riprap EDPP Percent Difference From Cast Acrylic at 125 gpm 


\section{Riprap Energy Dissipation Performance Parameter \% Difference From Cast Acrylic at $150 \mathrm{gpm}$}

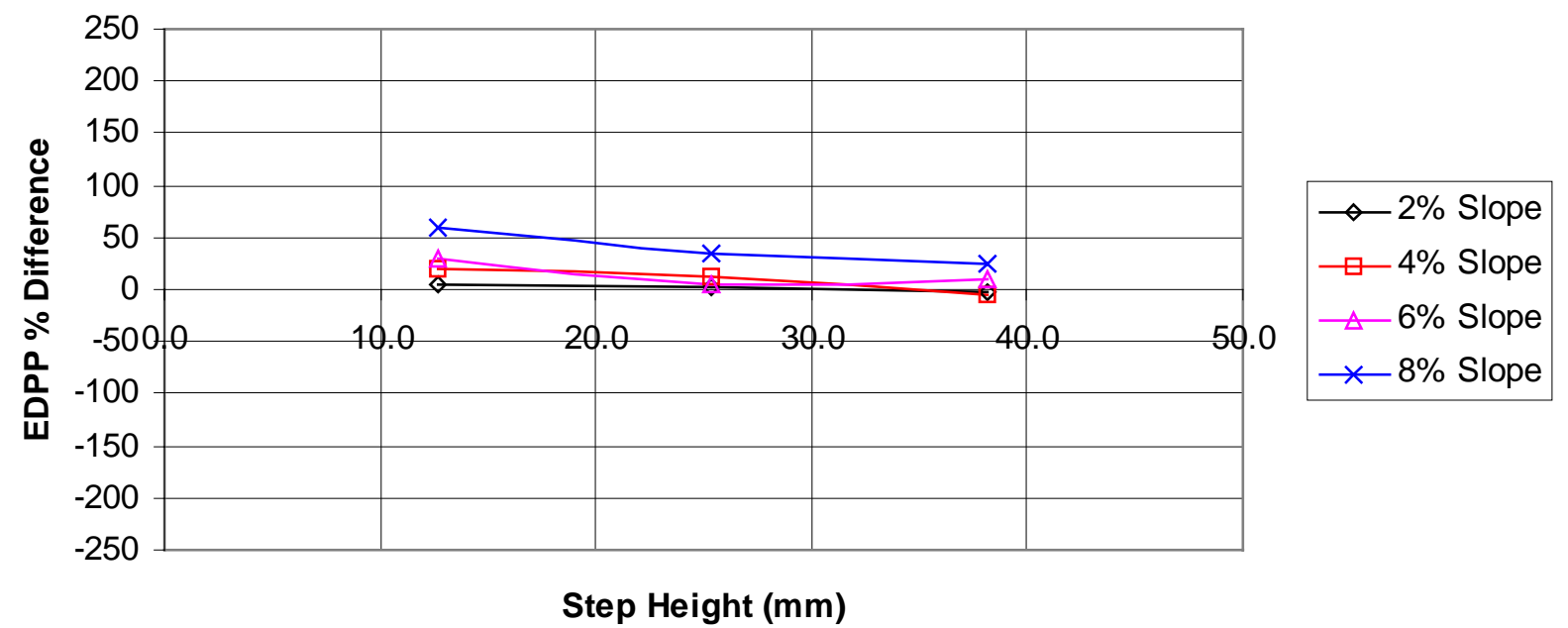

Figure 6.33 Riprap EDPP Percent Difference From Cast Acrylic at 150 gpm

In Figures 6.24 through 6.28, several EDPP culvert equivalent slope lines intersected. The intersection of these lines indicated a change of the more efficient energy dissipating step, either cast acrylic or riprap, becoming the least efficient or vice versa. The $8 \%$ culvert slope EDPP lines intersected at every flowrate except for the flowrate of $150 \mathrm{gpm}$. The 2\%, 4\% and 6\% culvert slope EDPP lines intersected at all flowrates. The intersection point for the $2 \%, 4 \%, 6 \%$, and $8 \%$ culvert slope EDPP lines occurred at increasingly higher steps as the flowrate increased. Once a flowrate of $150 \mathrm{gpm}$ was obtained, all culvert slope EDPP lines intersected at a step height except for the $8 \%$ culvert slope EDPP. At the flowrate of $150 \mathrm{gpm}$, the riprap steps were more efficient energy dissipators than the cast acrylic steps at all three step heights. As the flowrate increased, riprap steps became increasingly more efficient than the standard cast acrylic steps at attenuating energy for a larger range of step heights. Overall, the smallest culvert slope promoted the highest energy dissipation efficiency whereas the largest culvert slope promoted the lowest efficiency.

For Figures 6.29 through 6.33, positive y-axis values indicated riprap steps were more efficient than the standard cast acrylic steps whereas negative values indicated riprap steps were less efficient. A greater positive EDPP percent difference value indicated a greater energy attenuating efficiency and a more negative EDPP percent difference value indicated a lesser energy attenuating efficiency. At the lowest flowrate, $50 \mathrm{gpm}$, the greatest range 
of percent difference between the step heights was observed with the lowest step height being the most efficient at attenuating energy and the highest step height being the least efficient at attenuating energy. This trend gradually changed as the flowrate increased. Once the flowrate of $150 \mathrm{gpm}$ was obtained, the percent difference between the step heights remained relatively constant. 


\section{Chapter 7}

\section{Conclusions and Recommendations}

Based on the results presented in Sections 6.1 through 6.5, the riprap step is an effective method of energy attenuation. The riprap step forces a hydraulic jump to take place resulting in energy dissipation. The greatest efficiency for energy dissipation was observed with riprap step heights less than $25 \%$ of the culvert diameter at small culvert slopes. As the culvert slope and step height increased past the $25 \%$ culvert diameter, energy dissipation efficiency of the riprap step decreased. Construction of a full scale prototype model in the field is recommended with the following dimensions $(\mathrm{D}=$ culvert diameter $)$ :

- $\quad 0.235 \mathrm{D}$ riprap $\mathrm{D}_{90}$

- Wingwall and apron configuration as described in the Introduction

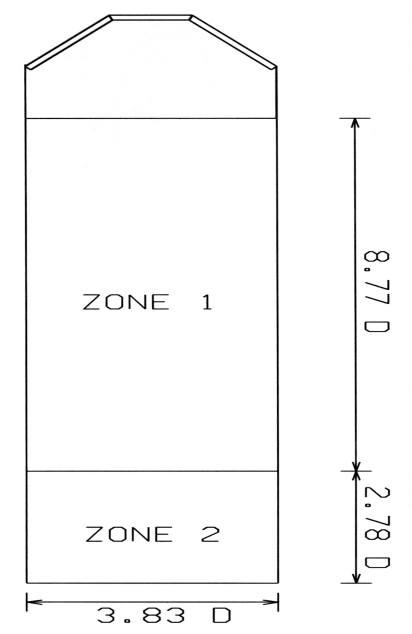

Figure 7.1 Prototype Model Design - Plan View

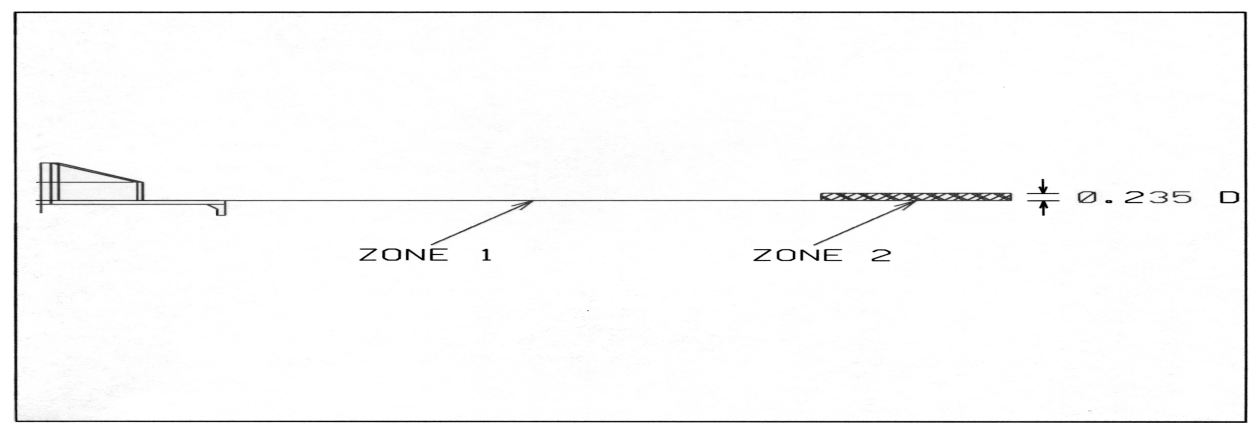

Figure 7.2 Prototype Model Design - Profile View 
Since this research was a preliminary investigation of energy dissipation at culvert outlets using a riprap step, further research is needed to provide a better understanding of riprap steps. A large portion of the time available for this project was used to develop the testing flume. Significant additional time was required to determine the most effective approach to obtaining an effective riprap step design. Further investigation of the riprap step could include:

- Further analysis of error associated with the testing flume

- Larger range of culvert slopes

- Larger range of step heights tested

- Larger range of material gradations tested

- Greater accuracy measuring velocities and depths (Laser Doppler Anemometer)

- Longer testing channel to allow for better establishment of uniform flow

- Construction of non-rigid downstream bed to examine scour characteristics

- Test riprap step geometry, and other geometries, for sedimentation characteristics

- Examination of a full scale prototype in the field 


\section{REFERENCES}

Abdel-Karim, Tadros, and Benak. "Structural Response of Full-scale Concrete Box Culvert." Journal of Structural Engineering 119 (1993): 3238-54.

Abrahams, et al. "Overland Flow on Desert Hillslopes.” Journal of Hydraulic Engineering 88 (1986): $343-63$.

Abt, et al. Development of Riprap Design Criteria by Riprap Testing in Flumes: Phase I. Colorado State University. May 1987.

Abt, et al. Development of Riprap Design Criteria by Riprap Testing in Flumes: Phase II - Follow-up Investigations. Colorado State University. August 1988.

Abt, Steven R., et al. "Evaluation of the ARS Low Drop Grade Control Structure." Proc. of the 1990 National Conference: Journal of Hydraulic Engineering 1 (1990): 342-7.

Abt, S. R., et al. "Gradation and Layer Thickness Effects on Riprap." Proc. of the 1987 National Conference on Hydraulic Engineering: Hydraulic Engineering Proceedings. Aug. 1987: 564-9.

Abt, Steven R., et al. "Resistance to Flow Over Riprap in Steep Channels." Water Resources Bulletin 24 (1988): 1193-200.

Abt, et al. "Riprap Design Criteria for the ARS Low Drop Structure." Hydraulic Engineering 1991 National Conference, 1991.

Abt, S., et al. "Riprap Criteria for the ARS Low Drop Structure." Proc. of the 1994 Conference: Hydraulic Engineering '94. 1994: 73-8.

Abt, Steven R., et al. "Sandstone Materials Used as Riprap.” 1 (1994): 467-71.

Abt, Hamilton, and Watson. "Riprap Sizing for Modified ARS-type Basins." Journal of Hydraulic Engineering 120 (1994): 260-7.

Abt, Steven, and Terry Johnson. "Riprap Design for Overtopping Flow.” Journal of Hydraulic Engineering 117 (1991): 959-72.

Abt, Steven R., James F. Ruff, and Rodney Wittler. "Estimating Flow Through Riprap.” Journal of Hydraulic Engineering 117 (1991): 670-5.

Abt, Thompson, and Lewis. "Enhancement of the Culvert Outlet Scour Estimation Equations." Transportation Research Record. 1996: 178-85.

Abt, and Watson. "RipRap Sizing for ARS-type Drop Stilling Basins.” Journal of Hydraulic Engineering 119 (1993): 864-9.

“Additional Guidance for Riprap Channel Protection.” ETL 1110-2-120. Army Corps of Engineers. 1971.

Afify, Assem M., and Gilberto E. Urroz. "Plunge-Pool Scour by Inclined Jets." Proc. of the 1994 Conference: Hydraulic Engineering '94 2 (1994): 1040-4.

Aguirre, and Moore. "Radial Flow Energy Dissipator for Large Culverts." Texas University, Texas State Department of Highways.

Aguierre-Pe, Julian, Ramon Fuentes, and Maria L. Olivero. "Flow Resistance of Riprap.” Journal of Hydraulic Engineering 118 (1992): 952-4. 
Ahmed, A. F. "Model Study of Side Slope Riprap.” Proc. of the International Symposium: Sediment Transport Modeling. Aug. 1989: 233-41.

Ahrens, John P., and Martha S. Heimbaugh. "Dynamic Stability of Dumped Riprap." Proc. of $6^{\text {th }}$ Symposium on Coastal and Ocean Management: Coastal Zone '89 4 Jul. 1989: 3377-89.

Ahrens, J.P., and Martha S. Heimbaugh. "Irregular Wave Runup on Riprap Revetments." Journal of Waterway, Port, Coastal and Ocean Engineering 114 (1988): 524-30.

Al-Azba, A., and T. Strelkoff. "Correct Form of Hall Technique for Border Irrigation Advance.” Journal of Irrigation and Drainage Engineering 120 (1994): 292-307.

Ali, H. S. Mohamed. "Effect of Roughened-Bed Stilling Basin on Length Rectangular Hydraulic Jump." Journal of Hydraulic Engineering 117 (1991): 83-93.

Alred-Coonrod. "Safety Grates in Supercritical Channels." Journal of Irrigation \& Drainage 120 (1994): 218-24.

Alonso, Klaus, and Wylie. “Turbulent Characteristics of Drag-Reducing Flows.” Journal of Hydraulic Research 14 (1976): 103-13.

Amano, Goel, and Chai. "Turbulence energy and Diffusion Transport of $3{ }^{\text {rd }}$ Moments in a Separating and Reattaching Flow.” 1900.

Anderson. "Preservation of Landscape Features." Highway Research Board Special Reports. 1973: 95-7.

Anderson, Alvin G., Amreek S. Paintal, and John T. Davenport. "Tentative Design Procedure for Riprap-Lined Channels." Highway Research Board. 1970.

Annandale, George W., and Hendrik A. D. Kirsten. "On the Erodibility of Rock and Other Earth Materials." Proc. of the 1994 Conference: Hydraulic Engineering '94 1 (1994) 68-72.

Annandale, George W., and David L. Parkhill. "Stream Bank Erodibility Index Method.” Water Resources Engineering 2 (1995): 973-8.

Annandale, George W. and David L. Parkhill. "Stream Bank Erosion: Application of the Erodibility Index Method.” Water Resources Engineering 2 (1995): 1570-4.

“Army Opens Riprap Test Channel.” Civil Engineering - ASCE. Nov. 1987: 21-2.

Atayee, A. Tamim, et al. "The Study of Riprap as Scour Protection for Bridge Abutments." Journal of Hydraulic Engineering 1 (1993): 973-8.

Ayala, Luis and Francisco Grandon. "Effect of Pier Geometry on Scour in Graded Gravels.” Journal of Hydraulic Engineering 1 (1994) 73-7.

Bagarello, Ferro, and Provenzano. "Experiment Study on Flow Resistance Law for Small Diameter Plastic Pipes." Journal of Irrigation \& Drainage 121 (1995): 313-6.

Bakry, Mohamed F., Timothy K. Gates, and Ahmed F. Khattab. "Field-Increased Hydraulic Resistance Characteristics in Vegetation Infested Canals." Journal of Irrigation and Drainage Engineering 118 (1992): 256-74.

Ball, Tullis, and Stripling. "Predicting Cavitation in Sudden Enlargements." ASCE Journal of the Hydraulics 101 (1975): 857. 
Ballinger, and Drake. Culvert Repair Practices Manual. Smith Associates, Federal Highway Administration, 1995.

Bardet. "Bounding Surface Plasticity Model for Sands." Journal of Mechanical Engineering 112 (1986): 19.

Barefoot. "Structures on Plymouth's St. Budeaux By-Pass.” Concrete 22 (1988): 32-3.

Barnes Jr., H.H. "Roughness Characteristics of Natural Channels.” Water Supply Paper Number 1849. U.S. Government Printing Office, 1967.

Beaton, et al. "Committee on Surface Drainage of Highways - Research Needs." Highway Research Circular. 1972: 14.

Belfadhel, M.B., G. Lefebvre, and Karol Rohan. "Comparison and Evaluation of Different Riprap Stability Formulas Using Field Performance.” Journal of Waterway, Port, Coastal and Ocean Engineering 122 (1996): 8-15.

Bellin, and Fiorotto. "Direct Dynamic Force Measurement on Slabs in Spillways Stilling Basins." Journal of Hydraulic Engineering 121 (1995): 686-93.

Berrill, and Davis. "Energy Dissipation and Seismic Liquefaction of Sands: Revised Model." $\underline{\text { Soil and }}$ Foundations 25 (1985): 106-18.

Bhowmik. "Stilling Basins for Low Froude Numbers." ASCE Journal of the Hydraulics 101 (1975): 901-15.

Biedenharn, David S., Charles D. Little, Jr., and Colin R. Thorne. "Effects of Low Drop Grade Control Structure on Bed and Bank Stability.” Journal of Hydraulic Engineering 1 (1990) 826-31.

Blackford. "The Hydraulic Jump in Radially Spreading Flow: A New Method and New Experimental Data." American Journal of Physics 64 (1996): 164-9.

Blaisdell. "The SAF Stilling Basin: A Structure to Dissipate the Destructive Energy in High Velocity Flow From Spillways.” Agriculture Department. 1959.

Blaisdell, and Anderson. "Pipe Plunge Pool Energy Dissipators.” Journal of Hydraulic Engineering 117 (1991): 303-23.

Blakeley. "Design of Bridges Incorporating Mechanical Energy Dissipating Devices.” Seismic Design of Bridges. 1979: 71-145.

Blancato, and Finger. "Offshore Mooring Island for Supertankers." ASCE Journal of Waterways and Harbors Division. 1962.

Blodget, J.C., and C.E. McConaughy. "Rock Riprap Design for Protection of Stream Channels Near Highway Structures.” Water-Resources Investigation Report 86-4127 (1986): 93-5.

Bloodgood, and Dell. "Manning's Coefficient Calculated from Test Data." Journal of Water Pollution Control Federation 33 (1961): 176.

Bohan, J. P. "Erosion and Riprap Requirements at Culvert and Storm Drain Outlets." Report H-70-2. Army Engineer Waterways Experiment Station. 1970.

Bone, Michael J. and James H. Olsen, Jr. "Rio Moquino Stream Stability and Erosion Protection." '91 National Conference Journal of Hydraulic Engineering. 1991: 406-10. 
Brandes, Roa, and Masch. "End Sills and the Force Hydraulic Jump in Circular Culverts Operating at Low Discharge Factors.” Texas University, Center for Highway Research. 1969.

Brater, Ernest F., and Horace Williams King. Handbook of Hydraulics for the Solution of Hydraulic Engineering Problems. $6^{\text {th }}$ Ed. New York: McGraw-Hill Book Company, 1976.

“1984 Bridge Design and Research Record.” RRU Bulletin. 1984.

"Bright Idea: Drain Low Land with a Culvert.” American Fruit Grower. Nov. 1995: 16.

Bryan. "Flood Control Project a Unique Solution for City." American City \& County 110 (1995): 58+.

Burgi. "Hydraulic Design of Vertical Stilling Wells.” ASCE Journal of the Hydraulics 101 (1975): 801-16.

"Buried Culvert Stands up as Short-Span Bridge.” Civil Engineering. Feb. 1993: 21-2.

Burnham, Michael W. and Darryl W. Davis. "Effects of Data Errors on Computed Steady-Flow Profiles." Journal of Hydraulic Engineering 116 (1990): 914-29.

“California Ski Resort to Make Snow From Treated Wastewater.” ENR. Feb. 1993: 24.

Cameron, et al. "Geotechnical Aspects of Rock Erosion in Emergency Spillway Channels." Waterways Experiment Station. 1988.

Campbell. "Culvert Rehabilitation at the Kennedy Space Center.” Public Works 126 (1995): 52-3.

Campbell, F. B. “Hydraulic Design of Rock Riprap.” Misc. Paper 2-777. U. S. Army Engineer Waterways Experiment Station. Feb 1966.

Chanson, Hubert. "Broad-Crested Weir.” Journal of Irrigation and Drainage Engineering 121 (1995): 222-6.

Chanson, H. "Model Study of a Roller Compacted Concrete Stepped Spillway.” Journal of Hydraulic Engineering 123 (1997): 931-6.

Chaudhry, M. H. Open-Channel Flow New Jersey: Prentice Hall, 1993.

Chein, Yee-Meng. "Mechanics of Riprap at Bridge Piers.” Journal of Hydraulic Engineering 121 (1995): $635-43$.

Chen, C.L. "Flow Resistance in Broad Shallow Channels." Journal of Hydraulic Engineering 102 (1976): $307-22$.

Chen, Cheng-lung. "Momentum and Energy Coefficients Based on Power-Law Velocity Profile." Journal of Hydraulic Engineering 118 (1992): 1571-84.

Cheong, and Xue. "Turbulence Model for Water Flow Over 2D Bed Forms." Journal of Hydraulic Engineering 123 (1997): 402-9.

Chiew, Yee-Meng. "Mechanics of Riprap Failure at Bridge Piers.” Journal of Hydraulic Engineering 121 (1995) 635-43.

Chow, Ven Te. Open-Channel Hydraulics. New York: McGraw-Hill Book Company, 1959. 
Christensen, B. A. "Dimensionally Homogeneous Mannings' Formula.” Journal of Hydraulic Engineering 119 (1993): 1442-5.

Chu, Yen-his and Gilbert K. Nersesian. "Scour Hole Development and Stabilization at Shinnecock and Moriches Inlets, New York." Proceedings of a Specialty Conference on the Planning, Design, Construction, and Performance of Coastal Engineering Coastal Engineering Practice '92-ASCE. March 1992: 571-82.

“Classification System for Varied Flow in Prismatic Channels.” Soil Conservation Service. Feb 1971.

Coastal Engineering '92. Proc. of a Specialty Conference on the Planning, Design, Construction, and Performance of Coastal Engineering Projects. American Society of Civil Engineers, 1992.

Coastal Zone '89. Proc. of the $6^{\text {th }}$ Symposium on Coastal and Ocean Management, 1989.

Codell, Richard, et al. "Estimation of Flow Through and Over Armored Slope." Journal of Hydraulic Engineering 116 (1990): 1252-69.

“Compensation for Manning Equation Error.” Public Works. Dec. 1991: 67-8.

“Concrete Bridge Design Review ‘Purely Precautionary'.” New Zealand Engineering. 1991: 11-4.

“Concrete Pipe Rehabilitates Culverts.” Public Works. July 1993: 78.

Copeland, R. P. "Bank Protection Techniques Using Spur Dikes.” Paper Number HL-83-1. Waterways Experiment Station. 1983.

Corry, et al. "Hydraulic Design of Energy Dissipators for Culverts and Channels." Federal Highway Administration. 1975.

Cox, R. G. "Velocity Forces on Submerged Rocks." Misc. Paper 2-265. U. S. Army Engineer Waterways Experiment Station. Apr 1958.

“Culvert Inventory Allows GIS Asset Management.” Civil Engineering. Sept. 1995: 24+.

“Culvert Rehabilitation at the Kennedy Space Center.” Public Works. March 1995: 52-3.

"Dam Inspection Begins in Underwater Tunnel." Civil Engineering News. 1992: 26.

Dasika. "New Approach to Design of Culverts.” Journal of Irrigation \& Drainage 121 (1995): 261-4.

Day. "Preliminary Observations of Turbulent Flow at Culvert Inlets." Journal of Hydraulic Engineering 123 (1997): 116-24.

Demirbilek. "Energy Dissipation in Sloshing Waves in a Rolling Rectangular Tank.” 1900.

"Demonstration Project \#31. Hydraulic Design of Energy Dissipators for Culverts and Channels.” Federal Highway Administration. 1900.

“Design of Riprap Revetment.” Hydraulic Engineering Circular. Sept. 1986: 153-6.

"Design of Quarry-Stone Cover Layers for Rubble Mound Breakwater.” Research Report \#22. Waterways Experiment Station. July 1958.

"Determining Rehabilitation Sewer Flow Capacity.” Journal of Irrigation and Drainage Engineering 122 (1996): 258-61. 
Dillingham. "Motion Studies of a Vessel with Water on Deck." Society of Navel Architects and Marine Engineers. 1980: 54.

Dively. "Corrosion of Culverts." Materials Performance 31 (1992): 31.

Dodge, R. A., et al. "Preventing Stilling Basin Abrasion.” Proc. of the 1991 National Conference: Hydraulic Engineering. 1991: 154-9.

Doehring, Fredrick, and Steven Abt. "Drop Height Influence on Outlet Scour.” Journal of Hydraulic Engineering 120 (1994): 1470-6.

Dong-Junrui, and Yongxiang. "An Experimental Study of the Turbulent Flow in the Stilling Basin with Dentated Sills." Acta Mechanica Sinica 21 (1989): 530-8

Dorton, et al. "Bridge Design and Research Seminar.” RRU Bulletin. 1984.

Douglas, et al. "14 $4^{\text {th }}$ Symposium on Rock Mechanics." Proc $14^{\text {th }}$ Symposium on Rock. 1973: 121-245.

Dowling, Steven, and Brian Mar. "Culvert Composite Sampler: A Cost Effective Storm Water Monitoring Device." Journal of Water Resources Planning and Management 122 (1996): 280-6.

Dunne, and Dietrich. "Experimental Study of Horton Overland Flow on Tropical Hillslopes. Hydraulic Characteristics and Hillslope Hydrographs." Geomorphology. Supplemental Band 35, 60-80.

Durr, and Davidge. "Design of Linear Plate Culverts for Underground Mining Environment." CIM Bulletin 88 (1995): 219-21.

The Effects of Stress and Environmental Factors on the Damping Response of a Cyclically Stressed Sand Clay. Proc. Symposium Earth and Earth Structures Under Earthquakes and Dynamic Loads, 1973.

Elser, and Schuster. "Pomme de Terre Dam of Earth Rockfill." ASCE Journal of Soil Mechanics 89 (1963): 89.

Emmit. "The Hydraulics of Overland Flow on Hillslopes." U.S. Geological Survey Prof. Paper 662-A. U.S. Government Printing Office, 1970.

Engman, E.T. "Roughness Coefficients for Routing Surface Runoff." Journal of Irrigation and Drainage Engineering 112 (1986): 39-53.

“Erosion Along Highway Right-of-Ways.” Federal Highway Administration. 1975: 2.

Esfandiari, M., and B.L. Maheshwari. "Suitability of selected Flow Equations and Variation of Manning's $n$ in Furrow Irrigation." Journal of Irrigation and Drainage Engineering 124 (1998): 89-95.

“Extensive Safety Fix Slated.” ENR. Sept. 1992: 32.

Ferguson, and Deak. "Role of Urban Storm-Flow Volume in Local Drainage Problems." Journal of Water Resource Planning 120 (1994): 523-30.

Ferro, Vito. “Applying Hypothesis of Self-Similarity for Flow-Resistance." Journal of Irrigation \& Drainage 123 (1997): 175-9.

"Final Report to Congress, The Streambank Erosion Control Evaluation and Demonstration Act of 1974." Section 32, Public Law. 93-251. 
Flammer, et al. "Closed Conduit to Open Channel Stilling Basin." ASCE Journal of Irrigation and Drainage Engineering. 1970.

Fletcher, B. P. and J. L. Grace, Jr. "Practical Guidance for Estimating and Controlling Erosion at Culvert Outlets." Miscellaneous Paper H-72-5 Waterways Experiment Station. May 1972.

A Floating Breakwater. Proc $11^{\text {th }}$ Conference on Coastal Engineering. 1968.

Fluid Amplifiers Ed. Joseph M. Kirshner 1966: 118-24.

Forbes, and Schwartz. "Supercritical Flow Past Blunt Bodies in Shallow Water." Zeitschrift fur Angewandt Mathematik und Physik 32 (1981): 314-28.

Forster, John W. and Raymond A. Skrinde. "Control of the Hydraulic Jump By Sills.” Paper \#2415 Transactions of the American Society of Civil Engineers 115 (1950): 973-1022.

Fotherby, Lisa M. "The Influence of Protective Material on Local Scour Dimensions.” Proc. of the 1993 Conference: Hydraulic Engineering '93 2 (1993) 1379-84.

Fotherby, Lisa M., and James F. Ruff. "Riprap and Concrete Armor to prevent Pier Scour.” Compact Disk. North American Water and Environment Congress, ASCE. 1996.

Fourteenth Symposium on Rock Mechanics. Proc from the Fourteenth Symposium on Rock Mechanics. 1973.

French, Richard H. Open Channel Hydraulics. New York: McGraw-Hill Book Company, 1985.

Froehlich, David C. "Riprap Particle Stability by Moment Analysis." Managing Water: Coping With Scarcity and Abundance. The $27^{\text {th }}$ Congress of the International Association for Hydraulic Research: Water For a Changing Global Community. 1997: 172-7.

Froehlich, David C. "Short-Duration Rainfall Intensity Equations for Drainage.” Journal of Irrigation \& Drainage Engineering 119 (1993): 814-28.

Froehlich, David C. "Width and Depth-Constrained Best Trapezoidal Section.” Journal of Irrigation and Drainage Engineering 120 (1994): 828-35.

Froehlich, David C., and Craig A. Benson. "Sizing Dumped Rock Riprap." Journal of Hydraulic Engineering 122 (1996): 389-96.

Froehlich, David C., and Craig A. Benson. "Sizing Loose Dumped Rock Riprap: A Probability-Based Approach." Proc. of the First International Conference: Water Resources Engineering 2 (1995): 1385-9.

"From King of the Road to 'Six Feet Under'.” Civil Engineering. Sept 1994: 22.

Fuller. "Concrete Blocks Gain Acceptance as Erosion-Control Systems." Geotechnical Fabrics Report 10 (1992): 24-37.

Gaines, Roger A. "Channel Rectification for Castor River, Missouri: A Case Study." Proc. of the First International Conference: Water Resources Engineering 1 (1995): 717-20.

George. "Bald Eagle Creek and Little Juniata River Channel Improvement Project: Hydraulic Model Investigation." Waterways Experiment Station 7612-7903 (1980): 92.

Glavin. "Coho in the Culvert." Canadian Geographic 117 (1997): 46-53. 
“Giant Culvert Quickly Placed.” ENR. July 1997: 18.

Gilley, John D., et al. "Roughness Coefficients for Selected Residue Materials.” Journal of Irrigation and Drainage Engineering 117 (1991): 503-14.

Goddard, James B. "Performance Review of Corrugated Polyethylene Cross Drain.” Public Works 127 (1996): 47.

Godfrey. "Fiber Reinforced Concrete.” ASCE Civil Engineering 52 (1982): 44-50.

Golding, Bernard L., and J.S. Montes. "Normal-Depth Equations for Irrigation Canals.” Journal of Irrigation and Drainage 122 (1996): 66-70.

Goldman, Jackson, and Bursztynsky. Erosion and Sediment Control Handbook 14 (1986): 439.

Grace, and Fletcher. "Practical Guidance for Design of Lined Channel Expansions at Culvert Outlets." Waterways Experiments Station. 1974: 90.

Grace, J. L., C. C. Calhoun, and D. N. Brown. "Drainage and Erosion Control Facilities, Field Performance Investigation.” Misc. Paper H-73-6. U. S. Army Engineer Waterways Experiment Station. June 1973.

Grace, and Pickering. "Evaluation of Three Energy Dissipators for Storm Drain Outlets." Highway Research Record. 1971.

Gray, Donald D. First Course in Fluid Mechanics for Civil Engineers. Highlands Ranch, CO: Water Resources Publications, LLC, 2000.

Griffiths, George A. "Flow Resistance in Coarse Gravel Bed Rivers." Journal of the Hydraulics Division 107 (1981): 899-918.

Gunal, Mustafa, and Rangaswami Narayanan. "Hydraulic Jump In Sloping Channels.” Journal of Hydraulic Engineering 122 (1996): 436-42.

Hager, Willi H. “Impact Hydraulic Jump.” Journal of Hydraulic Engineering 120 (1994): 633-7.

Hager, Willi H., and Markus Schwalt. "Broad-Crested Weir." Journal of irrigation and Drainage Engineering 120 (1994): 13-26.

Hager, Willi H., Stefano Pagliara, and Tatiana P. Provorova. "Incipient Jump Conditions for Flows Over a Vertical Sill." Journal of Hydraulic Engineering 124 (1998): 446-9.

Hamilton, Douglas. "Hydraulic Assessment for Riparian Restoration Projects." Water Forum '92 $\underline{\text { Journal of }}$ Hydraulic Engineering. 1992: 624-9.

Hart, W.E., B.P. Thoreson, and S.A. Musil. "Flow in Trapezoidal Channels." Journal of Irrigation and Drainage Engineering 118 (1992): 971-6.

Henderson, F.M. Open Channel Flow. New York: The Macmillian Company, 1966.

Henson, Clayton, and Tommy Wong. "Short-Duration Rainfall Intensity Equations for Drainage Design." Journal of Irrigation and Drainage Engineering 121 (1995): 219-21.

Hey, Richard D. "Flow Resistance in Gravel-Bed Rivers." Journal of the Hydraulics Division 105 (1979): 365-79. 
High - Performance Concrete In the U.S. Army Corps of Engineers. Proc International Workshop on High Performance Development Agency, 1994.

“Highway Drainage Restored Without Impeding Traffic.” Public Works. Aug. 1994: 46-7.

Holly, and Merkley. "Unique Patterns in Modeling Irrigation Channels." Journal of Irrigation \& Drainage 119 (1993): 656-62.

“Honeycombs Beef Up Pipe.” ENR 236 (1996): 38.

Horrocks, and McMullian. "Sediment and Debris Removal Inlet Structure for Canal Pipelines." Journal of Irrigation \& Drainage 120 (1994): 607-16.

Hotchkiss, and McCallum. "Peak Discharge for Small Agricultural Watersheds." Journal of Irrigation \& Drainage 121 (1995): 36-48.

"Hydraulic Design of Energy Dissipators for Culverts and Channels." Hydraulic Engineering Circular Number 14. U.S. Department of Transportation: Federal Highway Administration. Sep. 1983.

“Hydraulic Design of Flood Control Channels.” EM 1110-2-1601. Army Corps of Engineer. June 1994.

Hydraulic Engineering. Proc. of the 1987 National Conference. Hydraulics Division of the American Society of Civil Engineers, 1987.

Hydraulic Engineering. Proc. of the 1988 National Conference. Hydraulics Division of the American Society of Civil Engineers, 1988.

Hydraulic Engineering. Proc. of the 1989 National Conference. Hydraulics Division of the American Society of Civil Engineers, 1989.

Hydraulic Engineering. Proc. of the 1990 National Conference. Hydraulics Division of the American Society of Civil Engineers, 1990.

Hydraulic Engineering. Proc. of the 1991 National Conference. Hydraulics Division of the American Society of Civil Engineers, 1991.

Hydraulic Engineering: Saving a Threatened Resource - In Search of Solutions. Proc. of the Hydraulic Engineering Sessions at Water Forum '92. American Society of Civil Engineers, 1992.

Hydraulic Engineering '93. Proc. of the 1993 Conference. Hydraulics Division of the American Society of Civil Engineers, 1993.

Hydraulic Engineering '94. Proc. of the 1994 Conference. Hydraulics Division of the American Society of Civil Engineers, 1994.

Hydraulics of Energy Dissipators. Videocassette. FHWA-DOT, 1987.

"Innovative Breakwaters Protect Highway.” Civil Engineering - ASCE. Dec. 1987: 14.

Isbash, S. V. "Construction of Dams by Dumping Rock in Flowing Water.” U. S. Army Engineer District. 1935.

Jarrett, Robert D. "Hydraulics of High-Gradient Stream.” Journal of Hydraulic Engineering 110 (1984): 1519-39. 
Jiang, and Saiidi. "Response and Design of R/C One-way Pier Hinges in Strong Direction.” Journal of Structural Engineering 121 (1995): 1236-44.

Jin, Yee-Chung, Peter M. Steffler, and Faye E. Hicks. "Roughness Effects on Flow and Shear Stress Near Outside Bank of Curved Channel.” Journal of Hydraulic Engineering 116 (1990): 563-77.

Johns, Derek D., Steven Abt, and Chester Watson. "Riprap Sizing for ARS-type Low-Drop Stilling Basins.” Journal of Hydraulic Engineering 119 (1993): 864-9.

Johnson. “Temporary Soil Erosion Control.” Highway Focus 4 (1972): 21-43.

Johnson, Peggy A. "Uncertainty of Hydraulic Parameters.” Journal of Hydraulic Engineering 122 (1996): 112-4.

Jones. "Comment on the Closure that Addresses the Paper Entitled: Jury Verdict: Frequency versus RiskBased Culvert Design.” Journal of Water Resources Planning and Management 121 (1995): 400.

Jones, J. Sterling, David Bertoldi, and Stuart Stein. “Alternative Scour Countermeasures.” Water Resources Engineering 2 (1995): 1552-7.

Jones, Chaing, and Younkin. "Second Annual Report: Use of Large Roughness Elements for Hydraulic Energy Dissipation.” Virginia Polytechnical Institute. 1965.

Kadlec, Robert H. "Overland flow in Wetlands: Vegetation Resistance.” Journal of Hydraulic Engineering 116 (1990): 691-706.

Kang, and Nishiyama. "Analysis and Design of Microirrigation Laterals." Journal of Irrigation \& Drainage 122 (1996): 75-82.

Kang, and Nishiyama. "Design of Microirrigation Submain Units." Journal of Irrigation \& Drainage 122 (1996): 83-9.

Karim, Fazel. "Bed Configuration and Hydraulic Resistance in Alluvial-Channel Flows.” Journal of Hydraulic Engineering 121 (1995): 15-25.

Karney, and McInnis. "Efficient Calculations of Transient Flow in Simple Pipe Networks." Journal of Hydraulic Engineering 118 (1992): 1014-30.

Keim, S. Russell. "The Contra Costa Energy Dissipator." Proceedings of the American Society of Civil Engineers. Journal of the Hydraulics Division 1962: 109-22.

Kerr, Jeffery. “Catchy Culverts.” Civil Engineering 67 (1997): 59-61.

Khan, Abdul A., and Peter M. Steffler. "Physically Based Hydraulic Jump Model for Depth-Averaged Computations." Journal of Hydraulic Engineering 122 (1996): 540-8.

Khatsuria. "Dispersive-Flow Energy Dissipator.” Journal of Hydraulic Engineering 122 (1996): 361.

Kilgore, Roger T., and G. Kenneth Young. "Riprap Incipient Motion and Shields' Parameter." Proc. of the 1993 Conference: Journal of Hydraulic Engineering '93 2 (1993): 1552-7.

Kimura, I., and T. Hosoda. "Fundamental Properties of Flows in Open Channels with Dead Zone." Journal of Hydraulic Engineering 123 (1997): 98-107.

King. “Mechanical Energy Dissipators for Seismic Structures.” Auckland University, New Zealand. 1980: 196. 
Kirkham, Vander Ploeg, and Horton. "Potential Theory for Duel-Depth Subsurface Drainage of Ponded Land." Water Resource Research 33 (1997): 1643-54.

Klumpp, Cassie C., and Drew C. Baird. "Recent Criteria For Design of Groins." Proc. of the Hydraulic Engineering Session at Water Forum '92: Saving A Threatened Resource: In Search of Solutions: Journal of Hydraulic Engineering. (1992) 828-33.

Kobayashi, Nobubisa, and Jeffery H. Greenwald. "Waterline Oscillation and Riprap Movement.” Journal of Waterway, Port, Coast and Ocean Engineering 114 (1988): 281-96.

Kobelt, Paul. “New Hampshire DOT Rehabilitates Culvert.” Public Works 126 (1995) : 64.

Kohler, and Hager. "Mobile Flume for Pipe Flow.” Journal of Irrigation \& Drainage Engineering 123 (1997): 19-23.

Koloseus, and Ahmad. “Circular Hydraulic Jump.” ASCE Journal of Hydraulics Division. 1969.

Kouwen, N., and T.E. Unny. "Flexible Roughness in Open Channels." Journal of Hydraulic Engineering 99 (1973): 713-28.

Kowobari, Rice, and Garton. "Effect of Roughness Elements on Hydraulic Resistance for Overland Flow." Transactions of the ASAE 15 (1972): 979-84.

Kozin. "Hydraulic Jump in Prismatic Channel with a Trapezoidal Cross Section.” Fluid Mechanics Research 21 (1992): 80-4.

Krane, Anderson, and Villalon. "An Investigation of the Hydraulic Performance of Culvert Grates." University of South Florida, Florida Department of Transportation. 1990.

Kwai. "Seismic Behavior of Bridges on Isolated Bearings." Research Report. 1986.

Lagasse, P. F., E. V. Richardson, and L. W. Zevenbergen. "Design of Guide Banks for Bridge Abutment Protection." Compact Disc North American Water and Environment Congress-ASCE. 1996.

Lane-Serff, Beal, and Hadfield. "Gravity Current Flow Over Obstacles.” Journal of Fluid Mechanics 292 (1995): 39-53.

“Large Culverts Assist Highway Intersection.” Civil Engineering. Sept. 1997: 12-3.

Laursen, Emmett M., and Fazel Karim. "Bed Configuration and Hydraulic Resistance in Alluvial-Channel Flows." Journal of Irrigation and Drainage Engineering 122 (1996): 287.

Lea, Bill. "Pipe Dream.” Field and Stream.

Lefebrve, Guy, et al. "Field Performance and Analysis of Steep Riprap.” Journal of Geotechnical Engineering 118 (1992): 1431-48.

Leps, Thomas M. "Flow Through Rockfill." Embankment-Dam Engineering. Ed. Ronald C. Hirschfeld and Steve J. Poulos. John Wiley \& Sons. 1973: 87-107.

Liu, and McDonald. “Abrasion Erosion Resistance of Fiber Reinforce Concrete." Waterways Experiment Station. 1981: 31.

Liu, Yoon, and Dalrymple. "Wave Reflection from Energy Dissipation Region.” Journal of Waterway, Port, Coastal and Ocean Engineering 112 (1986): 632-44. 
Long. "Some Properties of Turbulence in a Stratified Shearing Flow.” Johns Hopkins University. 1972.

"Low Volume Rural Roads.” Washington D.C.: Transportation Research Board, National Research Council. 1986: 56.

Lutton, R. J., B. J. Houston, and J. B. Warriner "Evaluation of Quality \& Performance of Stone or Riprap as Armor." Technical Report GL-81-8. Geotechnical and Technical Laboratories. 1981.

Macdonald. "Energy Dissipators for Large Culverts.” ASCE Journal of the Hydraulics. 1969.

Macdonald. "Model Studies of Energy Dissipators for Large Culverts." CA Department of Public Works, Bureau of Public Roads. 1967.

Madsen, and White. "Breakwaters Reflection and Transmissive Characteristics of Porous Rubble-Mound." MIT, Department of CE. 1976: 141.

Managing Water: Coping with Scarcity and Abundance. Proc. of Theme A. The $27^{\text {th }}$ Congress of the International Assn for Hydraulic Research. 1997.

Markle, D. G., and D. D. Davidson. "Summary of Placed-Stone Stability Tests: Tillamook, Oregon." USAE Waterways Experiment Station. Apr 1979.

Marsal, Raul J. "Mechanical Properties of Rockfill.” Embankment-Dam Engineering. Ed. Ronald C. Hirschfeld and Steve J. Poulos. John Wiley \& Sons. 1973: 109-200.

Mayes, et al. "Enhancing the Seismic Performance of Toll Road Bridges." Transportation Research Board. 1991: $127-38$.

Maynord, Stephen T. "Flow Impingement Velocities, Snake River, Wyoming." Water Forum '92 Hydraulic Engineering. 1992: 139-44.

Maynard, Stephen T. "Flow Resistance of Riprap.” Journal of Hydraulic Engineering 117 (1991): 687-96.

Maynard, Stephen T. "Practical Riprap Design.” Technical Report H-78-7. U. S. Army Engineer Waterways Experiment Station. 1978.

Maynord, Stepthen T. "Riprap Stability Results from Large Test Channel." Hydraulic Engineering. Proc. of the 1990 National Conference. 1 (1990) 257-62.

Maynord, Stephen T. “Sizing Dumped Rock Riprap.” Journal of Hydraulic Engineering 124 (1998): 652.

Maynard, Stephen T. "Stable Riprap Size for Open Channel Flows.” Technical Report HL-88-4. U. S. Army Engineer Waterways Experiment Station. March 1988.

Maynord, Stephen T. "Toe Scour Protection Methods." Proc. of the 1994 Conference: Hydraulic Engineering '94 2 (1994): 1035-1039.

Maynord, Stephen T., and N. R. Oswalt. "Toe Scour Protection in Open Channels." Proc. of the 1988 National Conference: Journal of Hydraulic Engineering. 1988: 138-42.

Maynard, Stephen T., James Ruff, and Steven Abt. "Riprap Design.” Journal of Hydraulic Engineering 115 (1989): 937-49.

McDonald. "Maintenance and Preservation of Concrete Structures; Report 2, Repair of Erosion-Damaged Structures.” Technical Report C 78-4. Waterways Experiment Station. 1980. 
McDonald. "Properties of Silica-fume Concrete. Final Report." Waterways Experiment Station. 1991: 48.

McDonald, Giles N. "Riprap and Armor Stone." Arctic Coastal Processes and Slope Protection Design. Technical Council on Cold Regions Engineering Monograph, ASCE. 1988: 190-207.

Melville, B. W., C. S. Lauchlan, and S. E. Coleman. "Pier Riprap Protection." Managing Water: Coping With Scarcity \& Abundance. 1997: 166-71.

Merritt, Frederick S., ed. Standard Handbook for Civil Engineers. New York: McGraw-Hill Book Company, 1968.

Meshgin, and Moore. "Design Aspects and Performance Characteristics of Radial Flow Energy Dissipators.” Texas University, Center for Highway Research. 1970.

Microstation 95'. Version 2, Release 1. Bentley Systems, Inc. 1996.

Milhous, Robert T., Russell A. Dodge, and Perry L. Johnson. "Bed Material and Numerical Modeling in a Gravel/Cobble Bed Stream.” Journal of Hydraulic Engineering 2 (1994) 1055-9.

Mirza, and Varennes. "Durability Properties of Overlays for Erosion-Damaged Concrete." American Concrete Institute 1 (1991): 279-94.

Miura, and Murata, Yesufuku. "Stress-Strain Characteristics of Sand in a Particle-Crushing Region." Soil \& Foundations 24 (1984): 77-89.

Miura, and Yamanouchi. "Adhesion Bonds in Sand at High Pressure." ASCE Journal of Geotechnical Engineering 104 (1978): 1523-5.

Model Drainage Manual 1991. American Association of State Highway and Transportation Officials, 1991.

Mohamed Ali. "Effect of Roughened-Bed Stilling Basin on Length of Rectangular Hydraulic Pump." Journal of Hydraulic Engineering 117 (1991): 83-93.

Mohapatra, P.K., and Murty Bhallamud. "Bed-Level Variation in Channel Expansions with Movable Beds.” Journal of Irrigation and Drainage Engineering 120 (1994): 1114-21.

Montas. "New Approach to Design of Culverts." Journal of Irrigation \& Drainage Engineering 123 (1997): 71-2.

Moore, Ian. “3-D Analysis of Flexible Circular Culverts.” Journal of Geotechnical Engineering 120 (1994): 1829-44.

Moore, and Meshgin. "Adaptation of the Radial Flow Energy Dissipator for the Use with Circular or Box Culverts." Texas University, Center for Highway Research. 1970.

Morris. "Design of Roughness for Energy Dissipation in Highway Drainage Chutes." Highway Research Record. 1969.

Morris. "Hydraulics of Energy Dissipation in Steep, Rough Channels." Virginia Polytechnical Institute, Virginia Department of Highways. 1967.

Murakami. "Solution for Wave-induced Oscillations in Harbors Considering Energy Dissipation." Coastal Engineering in Japan 19 (1976). 
Nalluri, Chandra, and Wojcicah Dabrowski. "Need for New Standards to Prevent Deposition in Wastewater Sewers." Journal of Environmental Engineering 120 (1994): 1032-43.

Naot, Dan, Iehisa Nezu, and Hiroji Nakagawa. "Calculation of Compound-Open-Channel Flow.” 119 (1993): 1418-26.

Nemchinov, and Popov. "Interaction of a Plane Hydraulic-Jump Wave with an Abruptly Changing Bottom Relief in Low Water." Journal of Engineering Physics and Thermophysics 65 (1993): 856-60.

“Ohio DOT Adds Large PE Pipe to State Specs.” Public Works. March 1996: 59.

Ohtsu, Yamanaka, and Awazu. "Drag on Vertical Sill of Forced Jump." Journal of the Research Institute of Science and Technology, Nhion University 70 (1990): 1-17.

Ohtsu, Yasuda, and Hashiba. "Incipient Jump Conditions for Flows Over a Vertical Sill.” Journal of Hydraulic Engineering 122 (1996): 465-9.

Oregon Department of Transportation. "Keyed Riprap." Department of Transportation, Projects Division. 1976.

Oswalt, Noel R., and Stephen T. Maynord. "Section 32 Program; Streambank Erosion Control Evaluation and Demonstration Work Unit 3-Hydraulic Research.” Research Report 3. U. S. Army Engineer Waterways Experiment Station. Apr 1978.

Park, and Blakeley. "Seismic Design of Bridges.” National Roads Board, New Zealand. 1979: 145.

Patel, Desai, and Rana. "Properties and Applications of Steel Polypropylene and Polyester Fiber Reinforced Concrete." Fiber Reinforced Cements and Concretes: Recent Developments. 1989: 306-15.

A Perforated Mobile Breakwater for Fixed and Floating Applications. Proc $10^{\text {th }}$ Conference on Coastal Engineering, 1966.

Peterka, A. J. "Hydraulic Design of Stilling Basins and Energy Dissipators." Department of the Interior, Bureau of Reclamation. 1958 (also appeared as the $7^{\text {th }}$ printing in 1984).

Pettit. "Experimental High Energy Culverts Utilizing Concrete Rings on Concrete Pipe." Concrete Pipe News 27 (1975): 43-9.

Pettre, and Andre. "Surface-Pressure Through Loewe's Phenomena and Katabatic Flow Jumps: Study of Two Cases in Adelie Land, Antartica." Journal of the Atmospheric Sciences 48 (1991): 557-71.

Peyras, Royet, and Degoutte. "Flow and Energy Dissipation Over Stepped Gabion Weirs." Journal of Hydraulic Engineering 118 (1992): 707-17.

Pflaum, John M. "Successful Implementation of Grouted Boulder Grade Control Structures on Drainageways in the Denver Metropolitan Area." Compact Disk. North American Water and Environmental Congress. 1996.

Phelps. “Shallow Laminar Flows Over Rough Granular Surfaces.” Journal of Hydraulic Engineering 101 (1975): 367-84.

Pillai, Goel, and Dubey. "Hydraulic Jump Type Stilling Basin for Low Froude Number." Journal of Hydraulic Engineering 115 (1989): 989-94.

"Polyethylene Pipe Provides Landscape Relief." Civil Engineering. July 1997: 81. 
Porogrino, D.H. Rev. of "Energy Dissipators and Hydraulic Jumps," by Willi H.Hager. Journal of Fluid Mechanics. Feb. 1993: 689-90.

"Practical Guidance for Estimating and Controlling Erosion at Culvert Outlets." Misc. Paper H-72-5. U. S. Army Engineer Waterways Experiment Station. May 1972.

Price, and Masch. "Digital Computers in Circular Culvert Design." ASCE Journal of Transportation 98 (1972): 547-62.

Rae, Peter J. "Hydraulic Design of Spillway Plunge Pool Linings." Proc. of the 1994 Conference: Hydraulic Engineering '94 1 (1994): 396-400.

Rahman, Faghri, and Hankey. "Computation of Turbulent Flow in a Liquid Involving a Hydraulic Jump." Transactions of the ASME. Journal of Fluid Engineering 113 (1991): 411-8.

Rahmeyer, William. "The Effect of Aeration on Scour." Proc. of the 1990 National Conference: Hydraulic Engineering 1 (1990) 531-6.

Rajaratnam, Johnston, and Barber. "Energy Dissipation by Jet Diffusion in Stormwater Drop Shafts." Canadian Journal of Civil Engineering 20 (1993): 374-409.

Ramette, M. "Riprap Protection of River and Canal Banks." U. S. Army Engineer Waterways Experiment Station Translation No. 63-7.

Rand. "Sill-Controlled Flow Transitions and Extent of Erosion." ASCE Journal of the Hydraulics. 1970.

Rauch, Sargand, and Haze. "Behavior of Deeply Corrugated Steel Plate in Culvert." Journal of Geotechnical Engineering 120 (1994): 1651-55.

Rauch, Sargand, and Haze. "Performance of Deep Corrugated Steel Box-type Culvert." Journal of Geotechnical Engineering 119 (1993): 433-52.

Read. “On Line and Level Under Manchester International Airport.” Surveyor 164 (1984): 8-11.

“Report on Stabilization of Riprap Gradation.” Report CELMV-ED-W. U. S. Army Corps of Engineers. March 1989.

“Research Needs: Surface Drainage.” Highway Research Circular. 1970.

Rhodes, David G. "Gradually Varied Flow Solutions in Newton-Raphson Form." Journal of Irrigation and Drainage Engineering 124 (1998): 233-5.

Rhone. "Baffled Apron as Spillway Energy Dissipator." ASCE Journal of the Hydraulics 103 (1977): 1391-401.

Rice, Charles Edward. "Open Channel Junctions with Supercritical Flow.” U.S. Department of Agriculture. Jan 1985.

Rice, and Kadavy. "Protection Against Scour at SAF Stilling Basin.” Journal of Hydraulic Engineering 119 (1993): 133-9.

Rice, and Kadavy. "Model Study of a Roller Compacted Concrete Stepped Spillway." Journal of Hydraulic Engineering 122 (1996): 292-7. 
Rice, and Kadavy. "Riprap Design for SAF Stilling Basin." Transactions of the ASAE 35 (1992): 1817-25.

Rice, Charles E., and Kem C. Kadavy. "Scour Protection at the Straight Drop Spillway." Proc. of 1989 National Conference on Hydraulic Engineering: Hydraulic Engineering. 1989: 7-12.

Rice, C. E., K. C. Kadavy, and K. M. Robinson. "Roughness of Loose Rock Riprap on Steep Slopes.” Journal of Hydraulic Engineering 124 (1998): 179-85.

Rice, Charles E., Kerry M. Robinson, and Kem C. Kadavy. "Rock Riprap for Grade Control." Compact Disk. North American Water and Environmental Congress. 1996.

Richey, Morden, and Hartz. "Attenuation of Random Deep Water Waves By a Porous Walled Breakwater." Washington University, Department of Civil Engineering. 1974.

Roberson, J. A., J. J. Cassidy, and M. H. Chaudhry. Hydraulic Engineering John Wiley and Sons: New York, 1995.

Roberts. "Best Management Practices for Erosion and Sediment Control: Final Report." Federal Highway Administration 8810-9506 (1995): 187.

Robins. “City Fast-Tracs Culvert Replacement.” Journal of Hydraulic Engineering 128 (1997): 32.

Robinson, Kerry M., Charles E. Rice, and Kem C. Kadavy. "Stability of Rock Chutes." Proc. of the First International Conference: Water Resources Engineering 2 (1995) 1476-80.

Ruff, and Abt. "Evaluating Scour at Culvert Outlets." Transportation Research Record. 1980: 37-40.

Ruff, J. F., et al. "Scour at Culvert Outlets in Mixed Bed Materials." U.S. Department of Transportation: Federal Highway Administration. Report FHWA/RD-82/022. 1982.

Sarat. "Resistance to Flow in rough Supercritical Sheet Flow." Earth Surface Process and Land Forms 5 (1980): 103-22.

Sarikelle, S. and A. L. Simon. "Field and Laboratory Evaluation of Energy Dissipators for Culvert and Storm-Drain Outlets." Akron University, Department of Civil Engineering. 1974.

Sarikelle, and Simon. Field and Laboratory Evaluation of Energy Dissipators for Culvert and Storm Outlets Volumes 1 and 2. Akron University and the Ohio Department of Transportation, 1980.

Sarikelle, and Simon. “Modular Energy Dissipators.” Transportation Research News. 1982: 6-7.

Scaloppi, and Allen. "Hydraulics of Irrigation Laterals: Comparative Analysis." Journal of Irrigation \& Drainage 119 (1993): 91-115.

Schindler. "Fabrication and Installation of an A588 Canal Stilling Basin.” Welding Journal 71 (1992): 63-5.

Schmidt, O.J. "Measurement of Manning's Coefficient.” Sewage and Industrial Wastes 31 (1995): 995.

Sediment Transport Modeling. Proc. of the International Symposium, 1989.

Shafai-Bajestan, M., and M. L. Albertson. "Design of Riprap Stilling Basin For Overhanging Pipe.” Proc. of the 1993 Conference: Hydraulic Engineering '93 1 (1993) 861-8. 
Shafai-Bajestan, and M. L. Albertson. "Riprap Criteria Below Pipe Outlet.” Journal of Hydraulic Engineering 119 (1993): 181-200.

Shaikh, Aladdin. "Scour in Non-Cohesive Beds at Culvert Outlets." Proc. of the 1990 Conference: Journal of Hydraulic Engineering 1 (1990) 269-74.

Shen, and Wang. "Analysis of Commonly Used Riprap Design Guides Based on Extended Shields Diagrams." Transportation Research Record 2 (1984): 217-21.

Sherard, James L., Lorn Dunnigan, and James Talbot. "Basic Properties of Sand and Gravel Filters." Journal of Geotechnical Engineering 110 (1984): 684-700.

Shields, Jr., F. D., S. S. Knight, and C. M. Cooper. "Streambank Protection and Habitat Restoration.” Water Resources 1 (1995) 721-5.

Shields, Jr., F. D., Anne MacDonald, and H. H. Pahl III. "Vegetation on Riprap Revetment—Definition and Study Approach." Proc. of $16^{\text {th }}$ Annual Conference: Water Resources Planning and Management. 1989: 669-72.

Shou. “Dispersive Flow Energy Dissipator.” Journal of Hydraulic Engineering 120 (1996): 1401-8.

Sikso, and Johnson. "Pressure Cell Observations - Garrison Dam Project." ASCE Journal of Soil Mechanics 90 (1964): 157-79.

Silva-Araya, and Chaudry. "Computation of Energy Dissipation in Transient Flow." Journal of Hydraulic Engineering 123 (1997): 108-15.

Simon, and Sarikelle. "Internal Energy Dissipators for Culverts. Final Report." Akron University, Department of Civil Engineering: Ohio Department of Transportation: Federal Highway Administration. 1984: 84.

Simon, Sarikelle, and Korom. "Internal Energy Dissipators for Culverts on Steep Slopes with Inlet Control." Transportation Research Record. 1987: 25-31.

Simons, Watts, and Stevens. "Flood Protection at Culvert Outlets." Colorado State University, Wyoming Department of Transportation. 1970.

Smith, and Hallmark. "New Developments for Erosion Control at Culvert Outlets." Highway Research Board Bulletin. 1961.

Smoak. "Cold Weather Polymer Concrete Repair to Palisades Dam, Idaho." Polymers in Concrete. 1989: 27-33.

"Soil-Structure Interaction of Subsurface Conduits." Washington D.C.: Transportation Research Board, National Research Council. 1983.

Some Examples of Simple Drainage and Erosion Control Works in Earth Roads. Proc of the Fifth International Congress Association of Engineering Geology, 1986.

Son, Kwang-Ik, and Gilberto E. Urroz. "Local Scour Potential for Large Bed Material with Shallow Tailwater Depth.” Proc. of the 1994 Conference: Hydraulic Engineering '94 2 (1994): 1146-50.

Stevens, M. A., and D. B. Simons. "Stability Analysis for Coarse Granular Material on Slopes." River Mechanics. Ed. H. W. Shen. Colorado: Water Resources Publication, 1971. Chapter 17.

"Stilling Basins Shared with Ultra-High Strength Concrete." American Waterworks Association 76 (1984): 93. 
“Stone Stability Velocity versus Stone Diameter.” Sheet 712-1. Waterways Experiment Station. 1970.

Stonestreet, Scott E., Ronald R. Copeland, and Darla C. McVan. "Bed Load Roughness in Supercritical Flow." Journal of Hydraulic Engineering 2 (1994) 747-51.

"Streambank Protection Guidelines: For Landowners and Local Governments." Waterways Experiment Station. October 1983: 37-42.

Strelkoff. "One-Dimensional Equations of Open-Channel Flow.” ASCE Journal of Hydraulics Division 1969.

“Surveying the Performance of HDPE Pipe in Colder Climates.” Public Works. Apr. 1997: 46.

Swamee, Prabhata K. "Normal-Depth Equations for Irrigation Canals.” Journal of Irrigation and Drainage Engineering 120 (1994): 942-8.

Swamee, Prabhata K. "Optimal Irrigation Canal Sections.” Journal of Irrigation and Drainage Engineering 121 (1995): 467-9.

Symposium on Durability of Culverts and Stormdrains. Proc. from the Symposium on Durability of Culverts and Stormdrains, 1984.

Tate, Jr., Charles H. "Loose Riprap Grade Control Structure Design.” Proc. of the 1991 National Conference: Journal of Hydraulic Engineering 1991: 810-5.

Taylor, John R. An Introduction to Error Analysis - The Study of Uncertainties in Physical Measurements University Science Books, 1982.

“Tentative Procedures on Laboratory Tests for Use in Evaluating Stone Protection for Slopes.” North Pacific Division Laboratory. Mar 1982.

Thomas, David. "From Bauxite to Box Culvert.” ASTM Standardization News 23 (1995): 30-3.

Thompson, James. “Numerical Modeling of Irregular Hydraulic Jumps.” Hydraulic Engineering 1(1990) 749-54.

Thorson, Shirole, and Karim. "Design Criteria for Controlled Scour and Energy Dissipation at Culvert Outlets Using Rock and Sill.” Highway Research Record. 1971.

Tominaga, Akihiro, and Iehisa Nezu. “Turbulent Structure in Compound Open-Channel Flows.” 117 (1991): 21 41.

Trait, Thomas J. "Furrow Flow Velocity on Hydraulic Roughness." Journal of Irrigation and Hydraulic Engineering 118 (1992): 981-7.

"Traffic-Safe and Hydraulically Efficient Drainage Practice.” Hrb Nchrp Synthesis of Highway Practice. 1969

“Transition from Hydraulic Jump to Open Channel Flow.” Journal of Hydraulic Engineering. Sept. 1996: 526-8.

Tsihrintzis. "Effects of Sediment on Drainage - Culvert Serviceability." Journal of Performance of Construction 9 (1995): 172-83.

Turkington. "Seismic Design of Bridges on Lead-Rubber Bearings.” Research Report. 1986. 
"Underwater Concrete Placement for Stilling Basin Reconstruction.” Concrete International. Sept. 1992: 73.

U.S. Army Engineer Waterways Experiment Station. Streambank Protection Guidelines. Oct. 1983: 37-42.

United States. Dept. of the Army Corps of Engineers. Hydraulic Design of Flood Control Channels. Washington: July 1970.

United States. Dept. of Transportation, Federal Highway Administration. "Design of Riprap Revetment." Hydraulic Engineering Circular No. 11. Mar. 1989.

United States. Dept. of Transportation, Federal Highway Administration. "Design of Roadside Channels With Flexible Linings." Hydraulic Engineering Circular No. 15. Apr. 1988.

United States. Dept. of Transportation, Federal Highway Administration. "Hydraulic Design of Energy Dissipators for Culverts and Channels." Hydraulic Engineering Circular No. 14. Sept. 1983.

United States. Dept. of Transportation, Federal Highway Administration. "Hydraulic Design of Highway Culverts.” Hydraulic Design Series No. 5. Sep. 1985.

Van Bentum, Smout, and Xu. "Use of Pipelines to Improve Surface Irrigation in Hebei Province China." Journal of Irrigation \& Drainage 121 (1995): 405-10.

"Velocity Forces on Submerged Rocks." Misc. Paper No. 2-265. U. S. Army Engineer Waterways Experiment Station. Apr 1958.

Wahls, Harvey E. "Shallow Foundations for Highway Structures." Washington D.C.: Transportation Research Board, National Research Council. 1983.

“Water Project Flows to Restore Everglades.” ENR, May 1993: 20.

Water Resources. Proc. of the First International Conference: Water Resources Engineering Division of the American Society of Civil Engineers, 1995.

Watts, and Simons. "Hydraulics of Rigid Boundary Basins.” Highway Research Record, 1971.

Watts, Simons, and Stevens. "Analysis of Rigid Outfall Basins with High Tailwater.” Highway Research Record, 1971.

Wear, and Moore. "Culvert Outlet Energy Dissipators Incorporating Radial Flow and a Transverse Sill." Texas University, Center for Highway Research, 1968.

Wiggert, Erfle, and Morris. "Roughness Elements as Energy Dissipators of Free-Surface Flow in Circular Pipes.” Highway Research Record, 1971.

Wilkinson, and Wood. “A Rapidly Varied Flow Phenomenon in a Two-Layer Flow.” Journal of Fluid Mechanics 47 (1971): 241-56

Williams, David T., and Peter Passarelli. "Equivalencing Rock Riprap and Gabions for Stream Channel Protection. Water Resources Engineering 2 (1995): 1575-79.

Wittler, R. J., and S. R. Abt. "The Influence of Uniformity on Riprap Stability.” Proc. of the 1990 National Conference: Hydraulic Engineering 1 (1990) 251-6.

Wittler, Rodney Jay, and Steven R. Abt. "Riprap Design by Modified Safety Factor Method.” Proc. of the National Conference: Hydraulic Engineering. 1988. 143-8. 
Wong, Tommy S.W. "Time of Concentration and Peak Discharge for Planes in Series." Journal of Irrigation and Drainage Engineering 122 (1996): 256-8.

Woo, and Brater. "Laminar Flow in Rough Rectangular Channels.” Journal of GeoPhys Research 66 (1961): 4207-17.

Wood, and Antonia. "Measurement in a Turbulant Boundary Layer Over a D-type Surface Roughness." ASME Journal of Applied Mech 42 (1975): 591-659.

Wörman, Anders. "Riprap Protection Without Filter Layers.” Journal of Hydraulic Engineering 115 (1989): 1615-30.

Wright, John D. "Problems In Using the Manning Equation to Measure Sewer Flow.” Water Environment and Technology 3 (1991): 78-87.

Wu, S., and N. Rajartnam. "Transition from Hydraulic Jump to Open Channel Flow.” Journal of Hydraulic Engineering 122 (1996): 526-8.

Yang, Song Long. “Dispersive-Flow Energy Dissipators.” Journal of Hydraulic Engineering 120 (1994): 1401-8.

Yen, Ben Chie. "Dimensionally Homogeneous Manning's Formula.” Journal of Hydraulic Engineering 118 (1992):1326-32.

Yoon, Tai-Hoon, and Sung Bum Yoon. "Design Riprap to Protect Scour Around Circular Piers." The $27^{\text {th }}$ Congress of the International Association for Hydraulic Research: Water For a Changing Global Community. Managing Water: Coping With Scarcity and Abundance. 1997: 178-83.

Yourno, Joseph. "Pull-Through Pipe Installation Restores Culverts.” Water Environment \& Technology 5 (1993): 14.

Zissis, and Papadakis. "Drainage Pipe Performance Determined Using a Non-Darcy Finite Element Model." Agricultural Water Management 27 (1995): 259-65. 


\section{VITA}

Belinda M. Weikle was born in Union, West Virginia in 1972, but spent her entire childhood in Lewisburg, WV. She graduated from Greenbrier East High School in 1990 and entered college one year later.

Beginning at Bluefield State College, she majored in General Engineering and then transferred to West Virginia Institute of Technology into the Civil Engineering program where she received her Bachelors of Science in Civil Engineering in 1997. While at WVIT, she concentrated in the areas of fluid mechanics and water/wastewater.

Directly following undergraduate school she began graduate school at West Virginia University. Her graduate studies were in Hydrotechnical Engineering, concentrating on fluid mechanics and hydraulics. 